\title{
Detecção e Localização de Faltas em Sistemas Elétricos de Distribuição Usando Abordagem Inteligente Baseada em Análise Espectral de Sinais
}

Tese apresentada à Escola de Engenharia de São Carlos da Universidade de São Paulo, sendo parte dos requisitos para obtenção do título de Doutor em Ciências, Programa de Engenharia Elétrica, Área de Concentração em Sistemas Elétricos de Potência.

Orientador: Prof. Dr. Ivan Nunes da Silva

São Carlos 



\section{Detecção e Localização de Faltas em Sistemas Elétricos de Distribuição Usando Abordagem Inteligente Baseada em Análise Espectral de Sinais}

Tese apresentada à Escola de Engenharia de São Carlos da Universidade de São Paulo, sendo parte dos requisitos para obtenção do título de Doutor em Ciências, Programa de Engenharia Elétrica, Área de Concentração em Sistemas Elétricos de Potência.

Orientador: Prof. Dr. Ivan Nunes da Silva

\section{São Carlos}




\section{AUTORIZO A REPRODUÇÃO E DIVULGAÇÃO TOTAL OU PARCIAL DESTE TRABALHO, POR QUALQUER MEIO CONVENCIONAL OU ELETRÔNICO, PARA FINS DE ESTUDO E PESQUISA, DESDE QUE CITADA A FONTE.}

Ficha catalográfica preparada pela Seção de Tratamento da Informação do Serviço de Biblioteca - EESC/USP

Zamboni, Lucca.

Deteç̧ão e Localização de Faltas em Sistemas Elétricos de Distribuição Usando Abordagem Inteligente Baseada em Análise Espectral de Sinais. / Lucca Zamboni; orientador Ivan Nunes da Silva. São Carlos, 2013.

Tese - Doutorado (Programa de Pós-Graduação em Engenharia Elétrica e Área de Concentração em Sistemas Elétricos de Potência)-- Escola de Engenharia de São Carlos da Universidade de São Paulo, 2013.

1. Sistemas elétricos de potência. 2. Detecção de Faltas. 3. Sistemas Inteligentes. 4. Analise de Sinais. I. Título. 


\section{FOLHA DE JULGAMENTO}

Candidato: Engenheiro LUCCA ZAMBONI.

Título da tese: "Detecção e localização de faltas em sistemas elétricos de distribuição usando abordagem inteligente baseada em análise espectral de sinais".

Data da defesa: 21/10/2013

\section{Comissão Julgadora:}

Prof. Associado Ivan Nunes da Silva (Orientador)

(Escola de Engenharia de São Carlos/EESC)

Prof. Dr. Rogério Andrade Flauzino

(Escola de Engenharia de São Carlos/EESC)

Prof. Associado José Aquiles Baesso Grimoni

(Escola Politécnica/USP)

Prof. Dr. José Alfredo Covolan Ulson

(Universidade Estadual Paulista "Júlio de Mesquita Filho"/UNESP- Bauru)

Prof. Dr. Carlos Leônidas da Silva Souza Sobrinho

(Universidade Federal do Pará/UFPA)

\section{Resultado:}
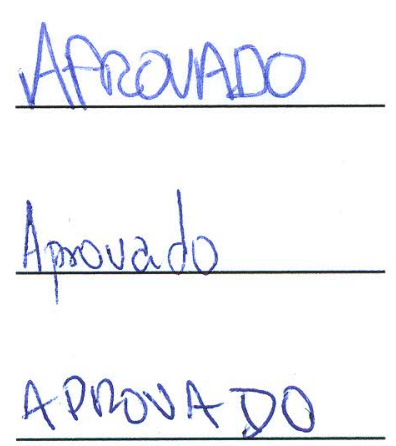
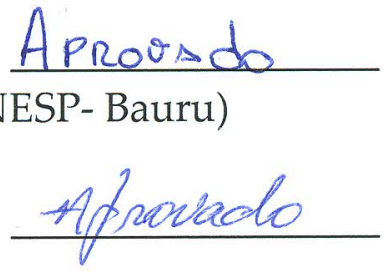

Coordenador do Programa de Pós-Graduação em Engenharia Elétrica e Presidente da Comissão de Pós-Graduação:

Prof. Titular Denis Vinicius Coury 

"A crítica elevada é mais criadora que a própria criação e o principal fim do crítico é ver as coisas como na realidade elas não o são."

Oscar Wilde (1854-1900) 



\section{Agradecimentos}

Ao Sábio Professor Dr. Ivan Nunes da Silva, minha sincera gratidão, pela paciência e competência insigne como orientador.

A todos os Professores e Servidores da Universidade São Paulo, em especial aos Professores do Programa de Pós-Graduação em Engenharia Elétrica, pelo incentivo e motivação à execução deste trabalho.

A toda equipe participante do projeto de P\&D com destaque aos Professores Rogério, Danilo e Alfredo, sempre nos surpreendendo com novidades e conhecimento.

Aos amigos e colaboradores da EDP, pelo interesse, curiosidade e ajuda, especialmente ao novo Mestre Nerivaldo dos Reis Santos.

À querida Jéssica, companheira em todos os momentos, pelo apoio e compreensão sempre oferecidos, e a Anita minha recém chegada filha.

Ao amigo Daniel Paiva, pelo encorajamento e pontapé inicial nesta empreitada e ao Marcelo, pela sala de estudos com a vista mais inspiradora de todos os tempos.

À minha querida Mãe (in memoriam) e ao meu Pai, que sempre me deram apoio e me ensinaram a vontade de sempre querer aprender e fazer mais.

Aos amigos, companheiros de trabalho, colegas e parentes, que de uma forma ou de outra, contribuíram com comentários, sugestões e críticas, sempre me descontraindo nas horas vagas.

Ao Programa de Pesquisa \& Desenvolvimento Tecnológico em Energia Elétrica, regulado pela Agência Nacional de Energia Elétrica - ANEEL. 



\section{Resumo}

ZAMBONI, L. (2013). Detecção e Localização de Faltas em Sistemas Elétricos de Distribuição Usando Abordagem Inteligente Baseada em Análise Espectral de Sinais. Tese (Doutorado) - Escola de Engenharia de São Carlos, Universidade de São Paulo, 2013.

O objetivo deste trabalho é estudar a identificação, classificação, localização e setorização de faltas em redes de distribuição radiais, verificar a maneira de aplicar e integrar diversas ferramentas numéricas convencionais, assim como ferramentas de sistemas inteligentes, visando identificar a ocorrência de uma falta, classificar as fases envolvidas com a mesma, e aplicar as diversas ferramentas existentes a fim de localizar em tempo real o eventual local onde houve a ocorrência da falta, permitindo que a mesma possa ser setorizada dentro do sistema da concessionária e informada ao centro de operações, usando uma nova abordagem inteligente baseada em análise espectral de sinais.

Palavras chave: Sistemas elétricos de potência, Detecção de Faltas, Sistemas Inteligentes, Analise de Sinais. 



\begin{abstract}
ZAMBONI, L. (2013). Fault Detection and Location in Power Distribution Systems Using Intelligent Approach Based in Spectral Signal Analysis. Thesis (PhD) - São Carlos School of Engineering, University of São Paulo, 2013.
\end{abstract}

The aim of this work is study the identification, classification, location and sectorization of a fault in distribution radial networks, check how to implement and integrate various conventional numerical tools, as well as intelligent systems based tools, to identify the occurrence of a fault, classify the phases involved with it, and apply the various tools available to locate the place where a fault was occurred in real time, enabling it to be sectorized into the utility system and informed to operational center using a new intelligent approach based on spectral signals analysis.

Keywords: Electrical Power Systems, Fault Detection, Intelligent Systems, Signal Analysis. 



\section{Lista de Siglas e Abreviaturas}

ANEEL Agência Nacional de Energia Elétrica

ANFIS Adaptive Neural Fuzzy Inference Systems

ATP Alternative Transients Program

CC Corrente contínua

COD Centro de Operação da Distribuição

DEC Duração Equivalente de Interrupção por Unidade Consumidora

DIC Duração de Interrupção Individual por Unidade Consumidora ou por Ponto de Conexão

DLF $\quad$ Faltas fase-fase

DMIC Duração Máxima de Interrupção Contínua por Unidade Consumidora

EMTP Electromagnetic Transients Program

EPRI Electric Power Research Institute

FEC Frequência Equivalente de Interrupção por Unidade Consumidora

FIC Frequência de Interrupção Individual por Unidade Consumidora

FFF Faltas trifásicas

FFP Faltas fase-terra paralela

FFS Faltas fase-terra série

FFT Faltas fase-fase- terra

FFT Fast Fourier Transform

PRODIST Procedimentos de Distribuição de Energia Elétrica no Sistema Elétrico Nacional 
SCADA Supervisory Control and Data Acquisition

TACS Transient Analysis Control System

TC's Transformadores de Corrente

TP's Transformadores de Potencial 


\section{Lista de Figuras}

Figura 1.1 - DEC de uma concessionária de distribuição..................................8

Figura 1.2 - Causas do DEC de uma concessionária de distribuição.....................8

Figura 1.3 - FEC de uma concessionária de distribuição. ................................9

Figura 1.4 - Causas do FEC de uma concessionária de distribuição. .....................9

Figura 1.5 - Multas por indicador de qualidade do serviço de uma concessionária..10

Figura 2.1 - Configuração da janela de dados. 29

Figura 2.2 - Formas de onda de corrente e tensão para uma falta fase terra com ocorrência de arco elétrico.

Figura 2.3 - Diagrama de blocos do método de diagnóstico de faltas baseado em características estatísticas das correntes de falta. 32

Figura 2.4 - Skewness para uma forma de onda de corrente faltosa e para uma forma_de corrente normal. 35

Figura 2.5 - Kurtosis para uma forma de onda de corrente faltosa e para uma forma de corrente normal. 35

Figura 2.6 - Estrutura do sistema de diagnóstico de falta proposto. 39

Figura 2.7 - Exemplo de base de regras do sistema fuzzy. 39

Figura 2.8 - Procedimentos para estimação de faltas para o sistema de inferência fuzzy.

Figura 2.9 - Fluxograma do algoritmo de localização de falta proposto. 42

Figura 2.10 - Classificação de perturbações no domínio wavelet. 44

Figura 2.11 - llustração de um sinal composto por diversas perturbações e sua representação no domínio wavelet. 45

Figura 2.12 - Diagrama de blocos do esquema de detecção proposto. 47 
Figura 2.13 - Diagrama de blocos representando o filtro adaptativo....................... 47

Figura 2.14 - Diagrama de blocos de modelo da falta de alta impedância............... 50

Figura 2.15 - Diagrama esquemático do sistema de localização de faltas por meio de

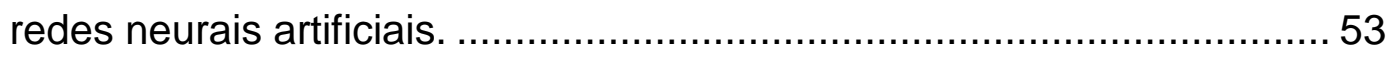

Figura 2.16 - Distância de falta em função dos autovalores. ................................. 54

Figura 2.17 - Modelo computacional para automatização do tratamento de faltas em sistemas de distribuição 56

Figura 3.1 - Modelo reduzido representativo da Topologia 1, a qual possui somente o alimentador principal. 61

Figura 3.2 - Modelo reduzido representativo da Topologia 2, a qual possui tanto o alimentador principal como um ramo lateral. 61

Figura 3.3 - Forma de onda obtida quando da ocorrência de uma falta na Topologia 1 62

Figura 3.4 - Forma de onda obtida quando da ocorrência de uma falta na Topologia 2. 62

Figura 3.5 - Métodos convencionais de busca da região faltosa. ........................... 70

Figura 3.6 - Modelo de uma falta de alta-impedância.......................................... 72

Figura 3.7 - Sistema de distribuição com geração distribuída................................. 73

Figura 3.8 - Circuito de exemplo para localização de faltas.................................... 75

Figura 4.1 - Representação esquemática do sistema de identificação e localização de faltas. 81

Figura 4.2 - Diagrama esquemático do sistema identificador de faltas. 83

Figura 4.3 - Diagrama esquemático para o sistema de identificação da tipologia da falta. 83 
Figura 4.4 - Diagrama esquemático para discriminação das fases participantes para faltas do tipo DLF e FFT. 84

Figura 4.5 - Diagrama esquemático para discriminação das fases participantes para faltas do tipo FFP e FFS. .84

Figura 4.6 - Processo de segmentação da oscilografia. 87

Figura 4.7 - Representação do alimentador JCE1312 ...................................90

Figura 4.8 - Representação do alimentador e suas derivações...........................91

Tabela 4.1: Equações da Impedância Aparente Z = V/I ..................................92

Figura 4.9 - Diagrama unifilar do sistema. 93

Figura 4.10 - Método da impedância aparente AN mede corretamente a reatância até a falta para uma linha radial. 94

Figura 4.11 - Sobrealcance da impedância aparente AN com RF e fluxo de potência exportado $\left(\delta=30^{\circ}\right)$ 95

Figura 4.12 - O Desempenho do critério de impedância aparente depende de RF e de $\delta$. 96

Figura 4.13 - Sistema elétrico no instante pré-falta. 97

Figura 4.14 - Sistema elétrico no instante de ocorrência de uma falta. 98

Figura 4.15 - Sistema elétrico equivalente no instante de ocorrência de uma falta..99

Figura 4.16 - Rede de sequencia para uma falta fase-terra. 102

Figura 4.17 - Modelo simplificado do alimentador de distribuição. 106

Figura 4.18 - Modelo completo do alimentador de distribuição. 109

Figura 4.19 - Impedância Z1 para o INP1306. 111

Figura 4.20 - Impedância Z0 para o INP1306.

Figura 4.21 - Impedâncias harmônicas - MCl1305. 112

Figura 4.22 - Exemplo de localização de faltas com múltiplas frequências. 113 
Figura 4.23 - Detecção da alteração da potência ativa e reativa para uma oscilografia de falta. 114

Figura 4.24 - Arquitetura do sistema de localização de faltas. 115

Figura 4.25 - Mapa de evolução da Reatância - INP1306 116

Figura 4.26 - Mapa de evolução da Resistência - INP1306. 116

Figura 4.27 - Mapa de evolução da Reatância - MCl1305.

Figura 4.28 - Mapa de evolução da Resistência - MCl1305.

Figura 4.29 - Exemplo de arquivo ".CFG" gerado pelo sistema instalado na SE... 120

Figura 4.30 -. Exemplo de arquivo ".DAT" gerado pelo sistema instalado no alimentador $\mathrm{MCl} 1305$ 120

Figura 4.31 - Conteúdo do arquivo ".ZIP” gerado pelo sistema instalado na SE. .. 122 Figura 4.32 - Exemplo de arquivo ".GZ" gerado pelo sistema instalado no alimentador MCl1305 122

Figura 4.33 - Banco de dados de faltas. 124

Figura 4.34 - Rede virtual entre a ETD piloto e COD. 125

Figura 5.6 - Cruzamento (fase 1). 128

Figura 5.7 - Cruzamento (fase 2). 128

Figura 5.8 - Oscilografia JCE1312-71 completa. 130

Figura 5.9 - Detalhe da oscilografia JCE1312-71. 131

Figura 5.10 - Detalhe da oscilografia JCE1312-72. 131

Figura 5.11 - Detalhe da oscilografia JCE1312-73. 132

Figura 5.12 - Detalhe da oscilografia JCE1312-74. 132 


\section{Lista de Tabelas}

Tabela 3.1 - Resultados obtidos com a aplicação do método proposto sobre faltas geradas no modelo reduzido de alimentador (Topologia 2). 63

Tabela 3.2 - Resultados obtidos com a aplicação do método proposto sobre dados reais de faltas. 64

Tabela 3.3 - Resultados obtidos para faltas fase-terra geradas no início do alimentador. 66

Tabela 3.4 - Resultados obtidos para diversos tipos de faltas ocorridas em um sistema de distribuição real.

Tabela 4.1: Equações da Impedância Aparente Z = V/I .92

Tabela 4.2 - Banco de Dados (armazenamento das informações de faltas) ....124

Tabela 5.1 - Cruzamento de oscilografias para JCE1312. 134

Tabela 5.2 - Cruzamento de oscilografias para BIR1305. 135

Tabela 5.3 - Cruzamento de oscilografias para MCl1305. 136

Tabela 5.4 - Cruzamento de informações oscilográficas - JCE1312. 138

Tabela 5.5 - Cruzamento de informações oscilográficas - INP1306. 139

Tabela 5.6 - Cruzamento de informações oscilográficas - BIR1305. 139

Tabela 5.7 - Cruzamento de informações oscilográficas - MCl1305. 140 



\section{Sumário}

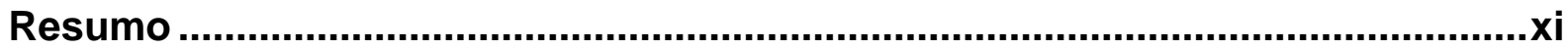

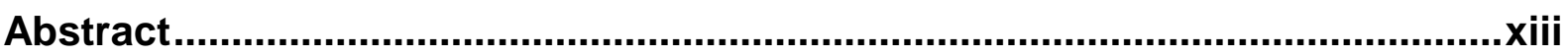

Lista de Siglas e Abreviaturas ….........................................................................

Lista de Figuras..................................................................................................

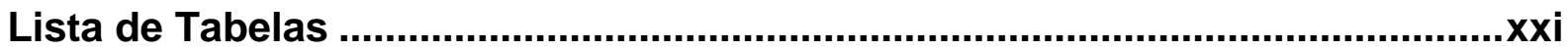

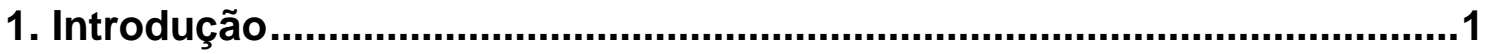

1.1 Motivação e relevância do trabalho......................................................

1.2 Identificação de faltas vs. qualidade do serviço ......................................

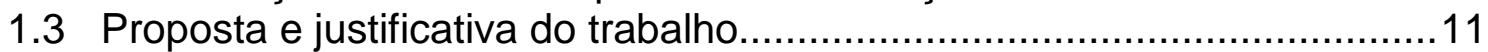

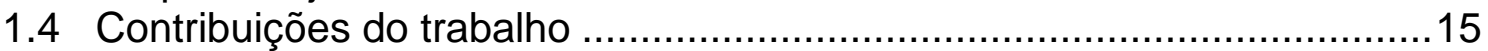

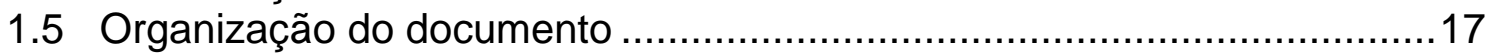

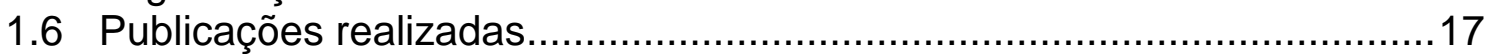

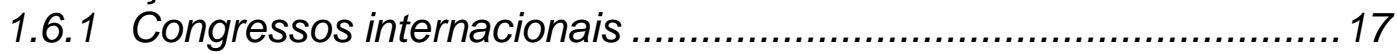

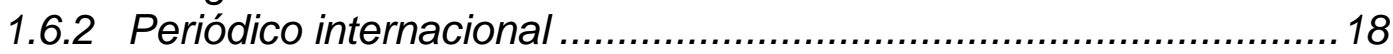

1.6.3 Capítulo de livro internacional ............................................... 19

2. Estado da Arte Referente às Principais Metodologias Empregadas na Detecção de Faltas em Sistemas de Distribuição ........................................21

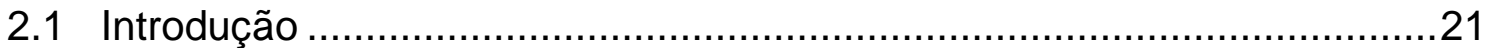

2.2 Detecção de faltas de alta impedância em alimentadores de sistema de distribuição utilizando redes neurais artificiais ....................................27

2.3 Técnicas de identificação de faltas de alta impedância utilizando redes

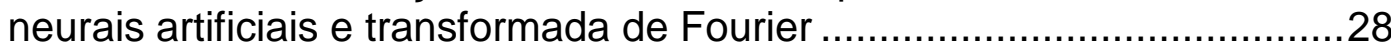

2.4 Abordagem neural utilizando características estatísticas das correntes de falta 30

2.5 Modelagem fuzzy aplicada na identificação de faltas de alta impedância com característica passiva ................................................................36

2.6 Método para diagnóstico de faltas em subestações de distribuição utilizando sistemas fuzzy e redes de causa e efeito.

2.7 Técnicas de localização de faltas baseadas em sinais de alta frequência e transformada wavelet .................................................................... 41

2.8 Classificação e medição dos níveis de perturbação em sistema de potência por meio de wavelet...........................................................43

2.9 Detecção de distúrbios em sistemas de distribuição utilizando wavelet....46

2.10 Modelagem de faltas de alta impedância baseada na teoria de arcos elétricos 49

2.11 Localização de faltas por meio de redes neurais artificiais e da transformada de Clarke-Concórdia ..................................................51

2.12 Tratamento automatizado de faltas em linhas de distribuição....................54

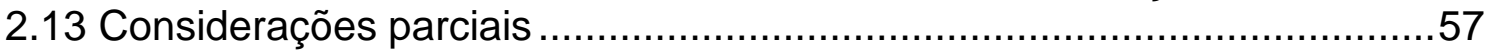


3. Propostas Modernas para Detecção de Faltas em Sistemas de

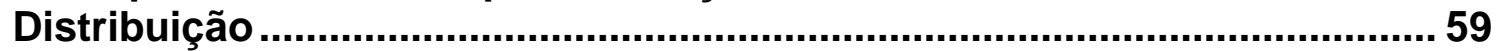

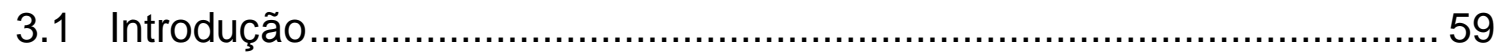

3.2 Propostas convencionais para a detecção de faltas.............................. 59 3.2.1 Localização de faltas em sistemas de distribuição utilizando análise multiresolução de transformadas wavelets............................................6 60 3.2.2 Metodologia de localização de faltas baseada na arquitetura do alimentador e medidas tomadas na subestação...................................... 65

3.3 Propostas inteligentes para a detecção de faltas ................................... 67 3.3.1 Estratégia para localização de faltas monofásicas em sistemas de distribuição utilizando sistemas fuzzy, wavelets e FFT........................... 68 3.3.2 Localização de faltas de alta-impedância em alimentadores de distribuição com geração distribuída ................................................. 71 3.3.3 Localização de faltas utilizando informações qualitativas da rede. 74 3.3.4 Localização de faltas utilizando sistemas inteligentes híbridos...... 76

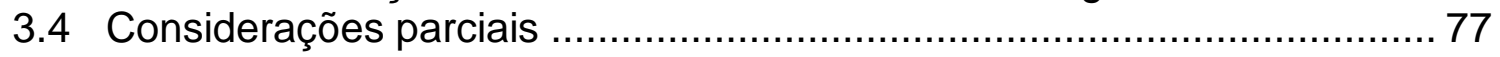

4. Aspectos da Metodologia Desenvolvida .............................................. 79

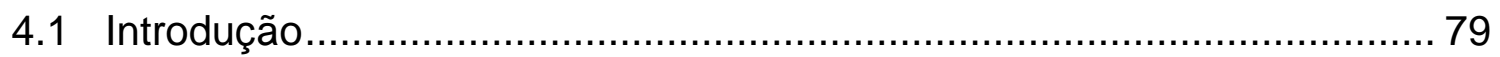

4.2 Aspectos do sistema automatizado para identificação e localização de faltas 80

4.3 Sistema de aquisição de dados elétricos.

4.3.1 Automatização das etapas de identificação e localização de faltas85

4.4 Sistema para modelagem de alimentadores para fins de identificação e localização de faltas

4.5 Aspectos de método inovador para propósitos de localização de faltas... 92

4.6 Mapas de impedâncias para discriminar seção faltosa ………………... 115

4.7 Conversão de arquivos COMTRADE para auxiliar processos de localização de faltas pelo Centro de Operação da Distribuição............... 118

4.8 Implementação de sistema de comunicação em tempo real ................... 123

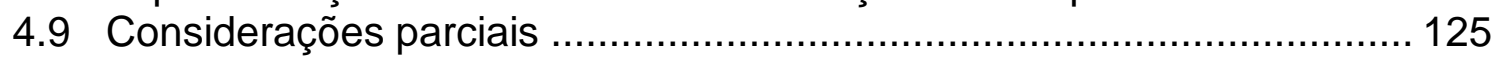

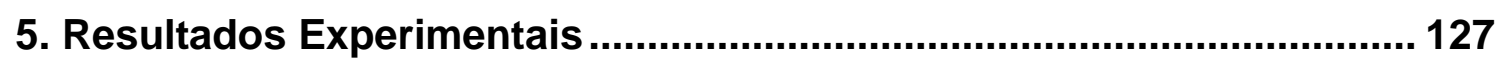

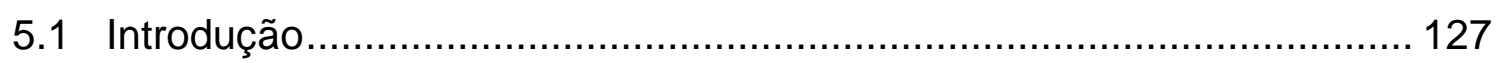

5.2 Análise comparativa entre registros oscilográficos e eventos ................ 128

5.3 Análise de oscilografias referentes às faltas dos alimentadores piloto ... 134

6. Considerações Finais e Continuidade do Trabalho............................... 141

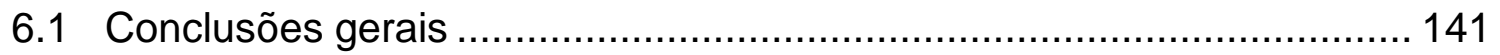

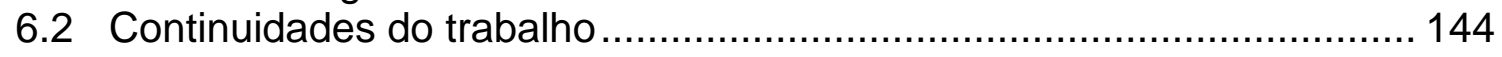

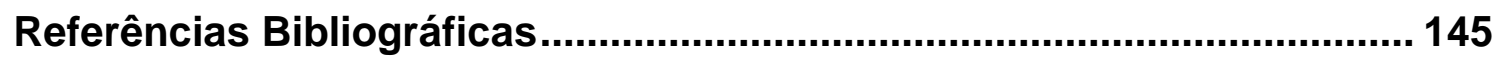

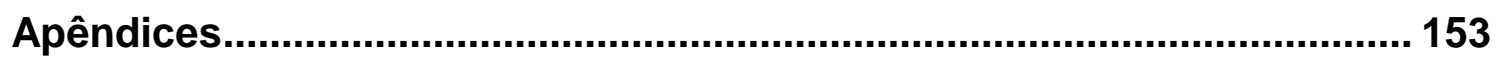

Apêndice A - Código da função para Identificação dos segmentos de falta ... 153 Apêndice B - Código função para determinação da fase participante da falta 154 Apêndice $C$ - Código da função para análise de reatância e resistência de falta

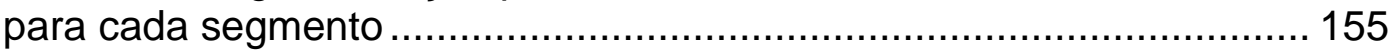

Apêndice D - Código de conversão dos arquivos ".DAQ" para COMTRADE . 156 Apêndice E - Sistema de Oscilografia ........................................................ 158 


\section{Introdução}

\subsection{Motivação e relevância do trabalho}

A detecção, a classificação e a localização de faltas em sistemas de energia elétrica constituíram-se, ao longo dos anos, em metas almejadas por diversos setores do sistema elétrico de potência, tais como os setores de transmissão e distribuição de energia elétrica. Assim, em função da declarada demanda por sistemas automáticos capazes de detectarem, classificarem e localizarem faltas em sistemas de energia elétrica, observa-se junto à literatura correlata proposições de trabalhos que fazem uso das mais distintas ferramentas, nas mais variadas conjunções, com o intuito de contribuírem à concretização das bases envolvidas com o trinômio detecção-classificação-localização de faltas.

Alguns autores, por exemplo, propuseram o emprego de algoritmos computacionais baseados na análise da hexa-decomposição dos fasores de tensão e de corrente do sistema elétrico sob falta com o objetivo de determinar sua localização, ou seja, determinar o quão distante da fonte a falta ocorreu (Chunju et al., 2005). Essa metodologia inicialmente foi proposta para elaboração de algoritmos específicos para proteção de sistemas de energia elétrica (Yaozhong, 1996). No entanto, conforme apresentado nas discussões (Chunju et al., 2005), a grande limitação da abordagem proposta é a necessidade de se efetuar medição em pelo 
menos dois pontos do sistema, ou seja, essa metodologia torna-se mais adequada à localização de faltas em sistemas de transmissão de energia elétrica do que em sistemas de distribuição.

Contornando o inconveniente da obrigação de se efetuar medições das tensões e correntes trifásicas em pelo menos dois pontos do sistema de energia elétrica, delineia-se uma proposição para a identificação de faltas empregando-se apenas um conjunto de medições (Mahmood et al., 2004).

Assim, de posse desse conjunto e de suas correspondentes decomposições em componentes simétricas, a abordagem proposta estrutura a matriz de impedância do sistema e, por meio de sua dinâmica temporal, sugere-se que o trecho sob falta possa ser determinado. A fim de validar a abordagem proposta, estudos de caso são então conduzidos e os resultados providos pela metodologia são comparados com aqueles que de fato denotam a realidade das faltas simuladas. Porém, apesar da correta identificação das faltas em grande parte dos casos, os autores pontuam que a eficiência da técnica está condicionada à precisão das impedâncias da linha de distribuição. Dessa forma, as simples e constantes variações de carga, umidade e de temperatura ambiente, por exemplo, seriam capazes de comprometer a eficiência da abordagem desenvolvida. Constata-se assim, que essas metodologias, tais como a destacada por Mahmood et al. (2004), carecem de robustez frente à dinâmica não-linear de um sistema elétrico de potência o que pode gerar falsos alarmes ou inoperância sob certas condições.

Uma forma de contornar as limitações de técnicas determinísticas, como aquela destacada em Mahmood et al. (2004), é incorporar ao sistema proposto redundâncias de informações. Tendo como base essa constatação, a qual é herdada de outros ramos do conhecimento, outros autores apresentaram um 
trabalho (Choi et al., 2004), onde procuraram não apenas se valer de impedâncias calculadas a partir da topologia física da rede, mas também de seus valores obtidos por meio das medidas de tensão e de corrente constantemente oscilografados na subestação de origem do alimentador sob monitoramento. No referido trabalho, resultados de simulações computacionais são destacados e a qualidade das respostas são superiores àqueles obtidos por técnicas convencionais. Porém, limitações quanto à localização de faltas em sistemas de distribuição de energia elétrica com correntes desbalanceadas são pontuadas, podendo o erro de estimação ser de até $25 \%$.

Contornando as limitações das técnicas convencionais, os sistemas inteligentes surgem como uma nova proposta à tratabilidade de problemas cujas soluções são intrinsecamente complexas. Esse é o caso da detecção, classificação e localização de faltas de sistemas de distribuição de energia elétrica onde, em virtude do número e da não-linearidade das variáveis envolvidas, a precisão, a robustez e a eficácia de um sistema dedicado a essas finalidades podem ser profundamente afetadas quando constituído unicamente por ferramentas ditas convencionais.

Um exemplo dessa nova tendência é o trabalho de Luo et al. (2004), em que técnicas correlatas aos espaços esparsos e algoritmos genéticos são combinadas de maneira a constituir um sistema capaz de localizar faltas em sistemas de energia elétrica. Assim, o referido trabalho buscou contornar a problemática do mau condicionamento das matrizes de admitância do sistema por meio de técnicas convencionais, sendo que o problema da localização de faltas é realizado por meio dos algoritmos genéticos, os quais possuem eficiência comprovada quando da busca por soluções ótimas. 
Outro exemplo de convergência de técnicas convencionais e de sistemas inteligentes é o trabalho de Youssef (2004), cujo objetivo de seu desenvolvimento foi a classificação de faltas em sistemas de energia elétrica por meio de análise multinível fornecida pela decomposição wavelet das formas de onda de tensão e de corrente. Esse tipo de ferramenta reconhecidamente fornece informações sobre distúrbios em sistemas elétricos de potência e possui ampla aplicabilidade no contexto da qualidade de energia, uma vez que permite uma análise no domínio do tempo e da freqüência simultaneamente. No entanto, a análise dos resultados oriundos de tal ferramenta para processamento de sinais não se procede de forma natural e é necessária grande experiência para que as conclusões alcançadas sejam factíveis aos fatos reais.

Por outro lado, os sistemas de inferência fuzzy possuem a meta de emularem a forma aproximada do raciocínio humano. Desta forma, Youssef (2004) apresenta em outro trabalho, como se pode implementar, por meio das ferramentas de processamento de sinais empregados e por intermédio dos sistemas fuzzy, um sistema para classificação de faltas em sistemas de distribuição de energia elétrica com habilidades para distinguir as faltas reais frente às situações de manobras programadas no sistema, como por exemplo, a energização de transformadores.

Além dos algoritmos genéticos e dos sistemas de inferência fuzzy, outra ferramenta advinda da inteligência computacional são as redes neurais artificiais. Como exemplo da aplicação das redes neurais no contexto da localização de faltas em sistemas de distribuição destaca-se o trabalho de Martins et al. (2005), onde os autores conduzem sua pesquisa empregando decomposições vetoriais das formas de onda de tensão e de corrente e redes neurais artificiais para a determinação do local de ocorrência da falta no referido sistema. 
No entanto, mesmo diante do emprego de sistemas inteligentes, os resultados comprobatórios podem não possuir todos os requisitos almejados, ou ainda, tais resultados são dignos de melhorias. Tendo tais aspectos como premissa, é cada vez mais comum o desenvolvimento de sistemas para a detecção, classificação e localização de faltas que fazem uso não de apenas um sistema especialista, mas sim de vários desses sistemas dispostos de maneira ordenada. Esse é o caso de uma abordagem que emprega redes neurais artificiais dispostas em paralelo, cada qual sendo responsável por indicar qual fora o tipo e localização da falta (Mahanty e Gupta, 2004).

Mais recentemente, uma pesquisa desenvolvida pela Universidade do Texas (Depew et al., 2006) e fomentada em parte pelo Electric Power Research Institute (EPRI) utiliza um sistema especialista de reconhecimento de padrões dos níveis harmônicos para detectarem faltas de alta impedância, o qual usa uma taxa de amostragem de 64 amostras/ciclo nas entradas de corrente alternada visando fornecer um padrão espectral usado nas análises das assinaturas.

Assim, observa-se que esses tipos de abordagens, empregando técnicas inteligentes e técnicas convencionais para tratamento de faltas, são bem promissoras e que já vêm proporcionando resultados bem expressivos. Tais estratégias são denominadas híbridas, pois combinam uma ou mais ferramentas inteligentes a outras com reconhecidas características de tratamento de sinais. Este é o caso também da abordagem apresentada em Moshtagh e Aggarwal (2004), onde o avançado processamento de sinais proporcionado pela transformada wavelet é empregado para se extrair características dos sinais de tensão e corrente e, em seguida, são apresentados a um sistema fuzzy para a inferência do local da falta. 
Paralelamente, conforme historicamente relatado em Zaborzsky (1980), a integração e a comunicação de sistemas voltados à operação de um sistema elétrico de potência é uma tônica mundial desde meados dos anos 70 . É certo, porém, que nesses mais de 30 anos de evolução dos sistemas de controle e monitoramento muitos conceitos foram criados, bem como novas alternativas para redução de custos com tais sistemas foram implementadas (Tomsovic, 2005).

Acompanhando as tendências de um moderno sistema de supervisão e controle da distribuição, almeja-se disponibilizar aqui um sistema integrado que auxilie os operadores do sistema de distribuição a tomarem decisões mais acertadas, contribuindo assim para o aumento dos índices de desempenho e, consequentemente, aumento do nível de satisfação de seus clientes.

\subsection{Identificação de faltas vs. qualidade do serviço}

Os Procedimentos de Distribuição - PRODIST (ANEEL, 2011) estabelece em seu Módulo 8 os procedimentos relativos à qualidade da energia elétrica - QEE, abordando a qualidade do produto e a qualidade do serviço prestado.

As distribuidoras são avaliadas em diversos aspectos no fornecimento de energia elétrica. Entre eles, está a qualidade do serviço e do produto oferecidos aos consumidores.

A qualidade dos serviços prestados compreende a avaliação das interrupções no fornecimento de energia elétrica. A qualidade do produto caracteriza os fenômenos, estabelece os parâmetros e valores de referência relativos à conformidade de tensão em regime permanente e às perturbações na forma de onda de tensão.

Destacam-se no aspecto da qualidade do serviço os indicadores de continuidade coletivos, DEC e FEC, e os indicadores de continuidade individuais 
DIC, FIC e DMIC, De acordo com o Módulo 8 do PRODIST, são aqueles indicadores que aferem a qualidade de fornecimento de energia elétrica de determinada distribuidora, considerando os aspectos da "frequência de interrupções" e "duração das interrupções". A duração e frequência das interrupções estão diretamente ligadas aos processos de identificação e localização e eliminação de faltas.

Os indicadores coletivos e individuais são respectivamente determinados e aferidos por conjunto de unidades consumidoras da área de concessão (DEC e FEC) e por unidade consumidora (DIC, FIC e DMIC), conforme descrito a seguir.

DEC (Duração Equivalente de Interrupção por Unidade Consumidora): indica o número de horas que, em média, as unidades consumidoras de determinado conjunto ficaram sem energia elétrica durante um determinado período: mensal, trimestral ou anual;

FEC (Frequência Equivalente de Interrupção por Unidade Consumidora): indica quantas vezes, em média, as unidades consumidoras de determinado conjunto sofreram interrupção;

DIC (Duração de Interrupção Individual por Unidade Consumidora): quantidade de horas que o consumidor ficou sem energia elétrica;

FIC (Frequência de Interrupção Individual por Unidade Consumidora): quantidade de interrupções que o consumidor experimentou no período de apuração (mensal, trimestral ou anual);

DMIC (Duração Máxima de Interrupção Contínua por Unidade Consumidora): indica o número de horas da maior interrupção experimentada pelo consumidor no período de apuração. 
Na Figura 1.1, pode-se observar a evolução do DEC anual móvel de uma empresa de distribuição de energia elétrica do Brasil e sua comparação com períodos de referencia anteriores.

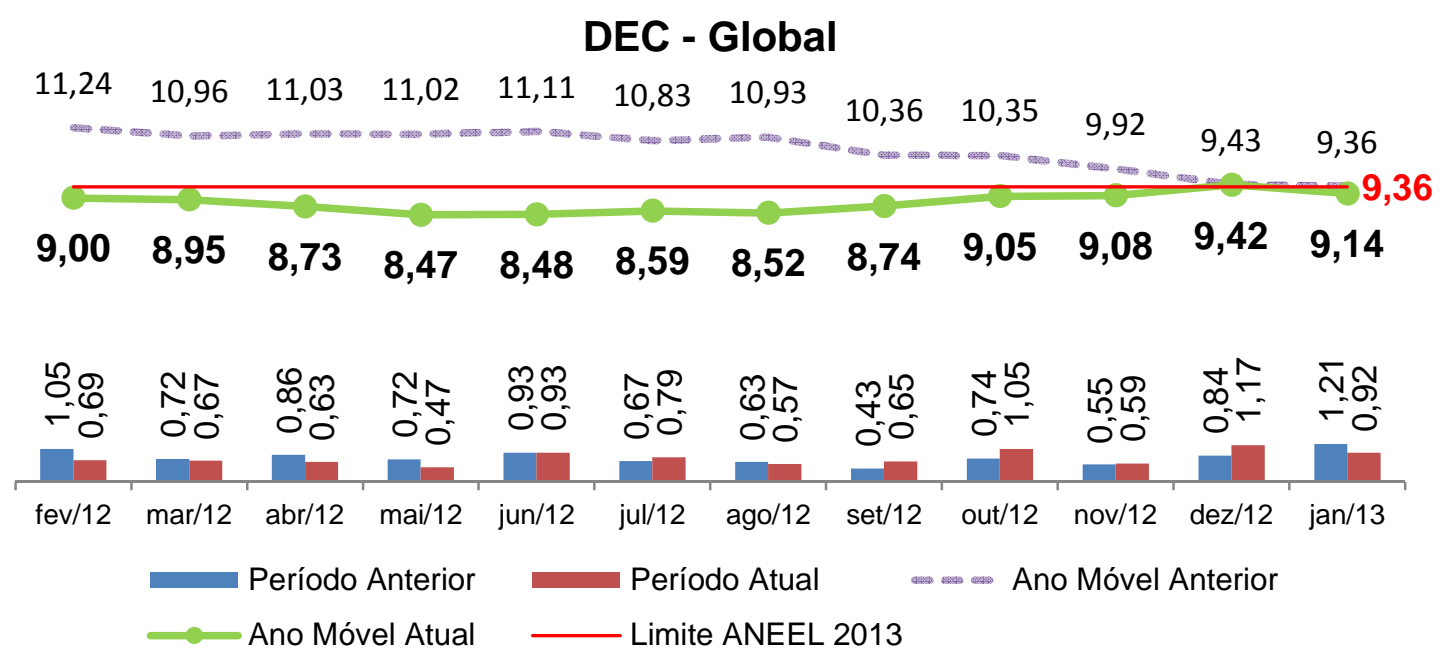

Figura 1.1 - DEC de uma concessionária de distribuição.

Na Figura 1.2 podem-se observar as principais causas da duração da interrupção identificadas nesse período. Nota-se uma participação expressiva da vegetação e deterioração de equipamentos.

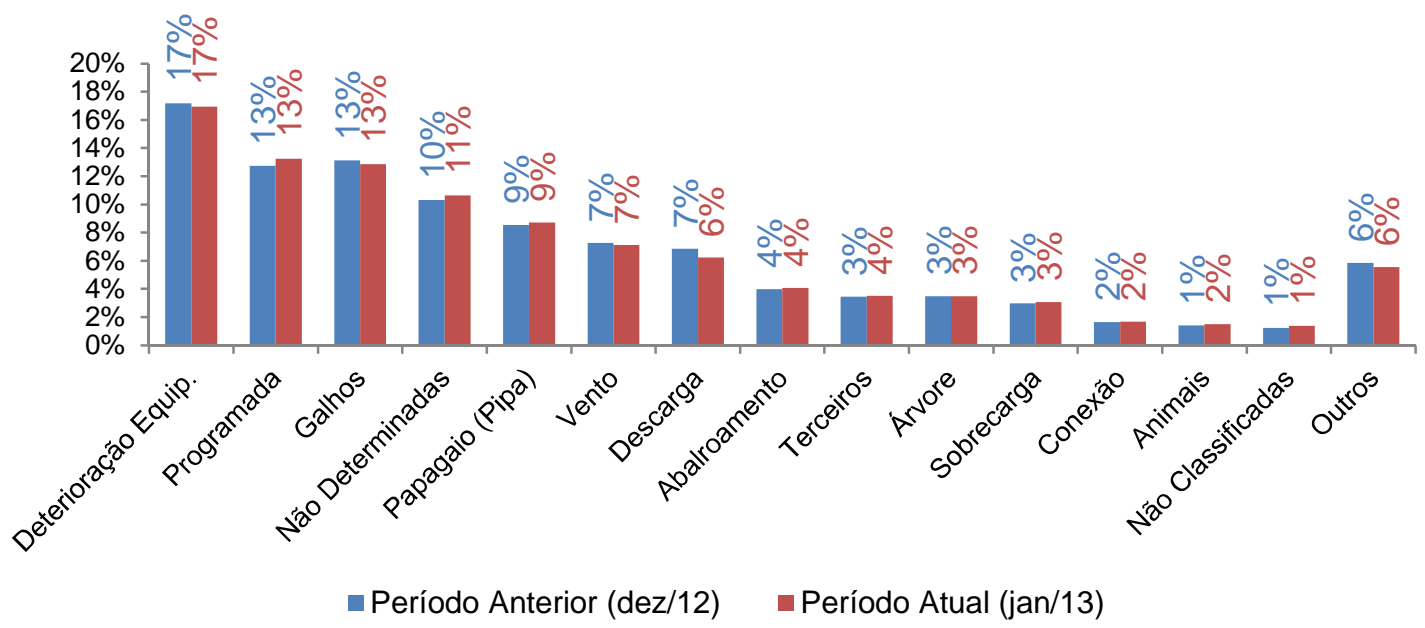

Figura 1.2 - Causas do DEC de uma concessionária de distribuição.

De forma análoga, pode-se verificar nas Figuras 1.3 e 1.4, para a mesma empresa e período de apuração, os dados da frequencia de interrupções (FEC) e suas principais causas. 
FEC - Global

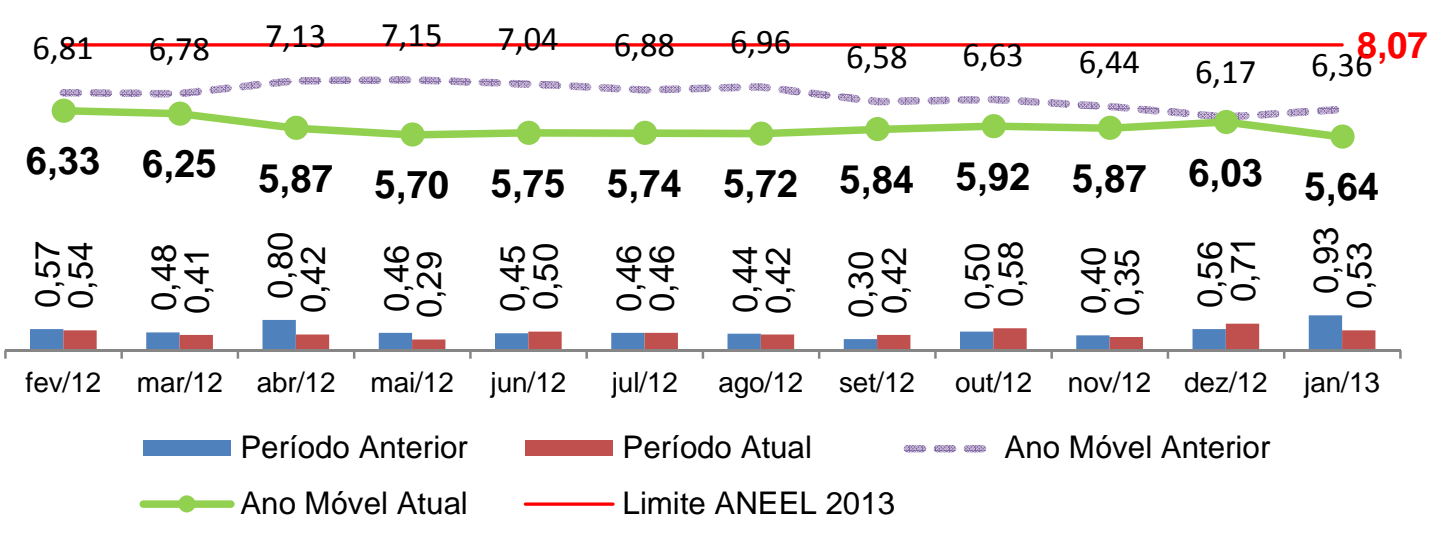

Figura 1.3 - FEC de uma concessionária de distribuição.

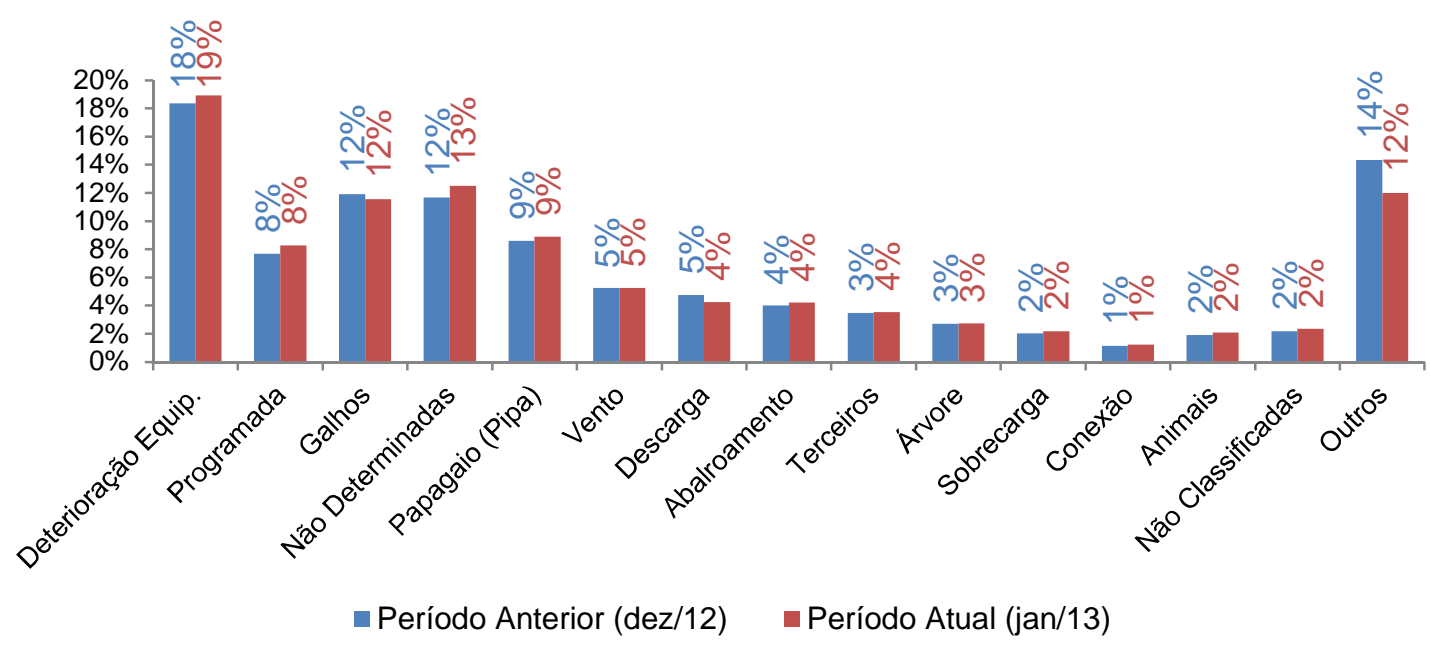

Figura 1.4 - Causas do FEC de uma concessionária de distribuição.

Nota-se que apesar da frequência possuir certa margem em relação ao limite estabelecido pelo regulador, a duração ficou muito próxima desse limite. Essa análise permite verificar que apesar do número de interrupções estarem dentro das expectativas para a região, o tempo de restabelecimento do sistema ficou próximo do limite regulatório, o que pode ser beneficiado com uma rápida e correta identificação e localização de faltas. 
Todos os anos são estabelecidos pelo Órgão Regulador limites para a qualidade do serviço prestado em dois aspectos (frequência e duração das interrupções) e, havendo violação dos indicadores individuais (DIC, FIC e DMIC), a distribuidora deve realizar compensação ao consumidor afetado, na forma de crédito na fatura, em até dois meses após o período de apuração. $O$ consumidor não precisa realizar qualquer solicitação, pois o cálculo e o crédito devem ser realizados automaticamente pela distribuidora.

A Figura 1.5 registra as penalidades de uma concessionária no ano de 2012 pelo não cumprimento da qualidade do serviço. Pode-se notar que o maior custo de compensações pagas aos consumidores é relativo a transgressões na duração da interrupção.

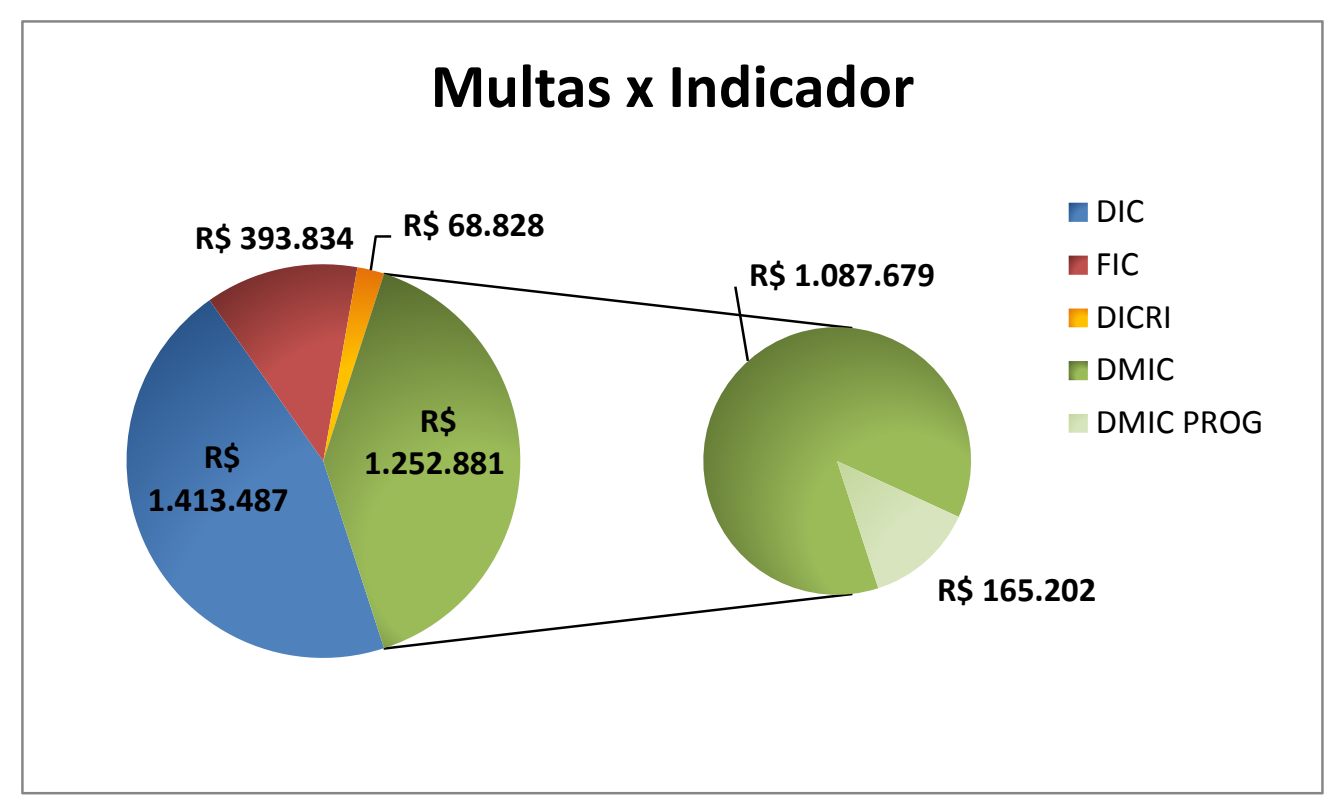

Figura 1.5 - Multas por indicador de qualidade do serviço de uma concessionária.

Sistemas eficientes para identificação e localização de faltas começam a tomar grande importância nas empresas de distribuição à medida que contribuem efetivamente na redução de eventos de maior impacto financeiro e, também, na redução de custos da interrupção do fornecimento. 
Assim, sistemas inteligentes de baixo custo e de alto valor agregado podem rapidamente se converterem em retornos financeiros.

\subsection{Proposta e justificativa do trabalho}

As justificativas referentes ao desenvolvimento desta tese de doutorado são pautadas em investigações técnico-científicas e fatos que inspiram a importância e relevância do tema, os quais são delineados nos parágrafos a seguir.

Atualmente tem sido verificada junto ao setor elétrico brasileiro uma constante busca pela melhoria dos serviços prestados pelas companhias de distribuição de energia elétrica aos seus clientes. Sobretudo, essa busca pelo acréscimo na qualidade procura reduzir as durações e frequências das interrupções do fornecimento de energia elétrica a níveis considerados adequados pela comunidade técnica internacional e pelos órgãos reguladores do setor de energia elétrica. Esta preocupação cresce proporcionalmente ao nível de industrialização da nação, pois eventuais paradas não programadas do sistema acarretam prejuízos econômicos a todos os setores dependentes deste sistema. De maneira ampla, pode-se caracterizar todo este empenho tendo como objetivo geral a melhoria da robustez dos sistemas de distribuição de energia elétrica.

Dentro desse contexto, destaca-se o desenvolvimento sempre crescente de técnicas e metodologias para identificação e localização de faltas em alimentadores responsáveis pela distribuição de energia elétrica. O aporte conferido a este desenvolvimento fundamenta-se na constatação de que grande parte das interrupções não programadas no fornecimento de energia elétrica pelo sistema de distribuição provém da ocorrência de faltas ao longo da extensão dos alimentadores. Desta forma, técnicas modernas e eficientes para detecção e localização de faltas 
têm sido desenvolvidas para auxiliar na tomada de decisão dos Centros de Operação do sistema de distribuição.

Como benefício direto da aplicação de tais técnicas pode-se constatar o aumento da eficiência das equipes de manutenção quando da extinção de faltas no sistema de distribuição, pois tais equipes serão despachadas para o local bem provável da ocorrência da falta, minimizando, portanto, o tempo de restabelecimento do serviço.

Paralelamente, as investigações que levem a esquemas eficientes que permitam a identificação e localização de faltas de maneira rápida e confiável são assuntos de suma importância para as concessionárias de distribuição de energia elétrica, tendo em vista que os resultados decorrentes podem implicar em incrementos substantivos dos índices de qualidade e confiabilidade dos serviços oferecidos aos seus clientes. A adoção de tais práticas que levem então a incrementar esses índices tem sido também incentivada pelos agentes da atual legislação que rege o setor elétrico brasileiro, os quais tem constantemente acompanhado a qualidade dos serviços fornecidos pelas concessionárias de distribuição por meio da avaliação mensal dos índices de qualidade individual e coletivo DIC e DEC.

Diante deste quadro, um efetivo projeto de esquemas que levem à identificação e localização de faltas de forma eficiente deve levar em consideração dois aspectos fundamentais. O primeiro aspecto refere-se à definição de técnicas e metodologias efetivas que objetivam discriminar as características dos diversos tipos de faltas que podem incidir no sistema de distribuição. Já o segundo aspecto a ser tratado tem como foco principal o desenvolvimento de ferramentas que serão 
responsáveis pela automatização em tempo-real de todo processo de tomada de decisão por parte do Centro de Operação da Distribuição (COD).

O primeiro aspecto mencionado anteriormente já tem sido tratado de forma exaustiva e abrangente em diversos trabalhos, dentre as quais se destacam dissertações de mestrado, teses de doutorado, pesquisas de pós-doutorado e a produção de vários artigos técnico-científicos, os quais têm como resultados um conjunto de diversos sistemas especialistas dedicados à identificação e localização de faltas no sistema de distribuição.

Mais especificamente, projetaram-se, em primeira instância, diversos sistemas especialistas eficientes que identificam se a perturbação (distúrbio) observada nos alimentadores deveu-se ou não a uma falta ocorrida no mesmo. Após a identificação real da falta, os sistemas especialistas estimam o trecho (relativo à subestação) em que ocorreu o defeito no respectivo alimentador. Os sistemas que já foram desenvolvidos utilizam ferramentas inteligentes (redes neurais artificiais e sistemas de inferência fuzzy) integrados com diversas outras ferramentas matemáticas e computacionais que têm sido também utilizadas neste tipo de problema.

As compilações dos resultados obtidos a partir de ensaios experimentais demonstram que as tecnologias desenvolvidas fornecem respostas bem precisas, identificando de forma eficiente diversas situações de faltas ocorridas no alimentador.

Os resultados finais foram plenamente satisfatórios, sendo os mesmos testados e validados tanto através de dados advindos de simulações como também aqueles obtidos de oscilografias de faltas realizadas em subestações reais. 
Assim, outro aspecto motivador que justifica a factibilidade do desenvolvimento da presente tese é que a mesma está pautada em resultados sólidos que já têm sido alcançados, permitindo então partir para a segunda fase (segundo aspecto) para que se obtenham esquemas eficientes de localização e identificação de faltas em sistemas de distribuição, ou seja, a automatização de todos os processos envolvidos nesses esquemas, permitindo a tomada eficiente de decisão por parte do Centro de Operação da Distribuição.

Desta forma, este trabalho almeja, ao longo de todas as suas etapas metodológicas, levantar os principais aspectos relacionados com a implementação eficiente de novos processos envolvidos com a localização e identificação de faltas frente às ocorrências das mesmas, cujos resultados podem trazer uma elevada agregação de valores aos procedimentos utilizados por uma concessionária no que tange à temática de identificação e localização de faltas em seu sistema de distribuição.

Por meio da constituição de um banco de dados de ocorrências de faltas, tornar-se-á também viável a elaboração de estratégias que visam à melhoria e ampliação da rede de distribuição. Dessa forma, procura-se por meio desse trabalho a sistematização de metodologias que auxiliem não apenas a operação do sistema, mas também a área de engenharia e de manutenção da concessionária como um todo.

Em suma, o objetivo final do trabalho consiste em disponibilizar uma nova ferramenta que visa identificar, quase que instantaneamente, a ocorrência de faltas e de distúrbios transitórios no sistema primário de distribuição, bem como determinar a respectiva origem e sua provável localização usando abordagens inteligentes baseadas em análise espectral de sinais. 


\subsection{Contribuições do trabalho}

O principal aspecto inovador do trabalho está no desenvolvimento e na concepção de todos os processos envolvidos com a automatização dos esquemas de identificação e localização de faltas em alimentadores do sistema de distribuição de uma concessionária, analisando de forma integrada os diversos aspectos técnicos e operacionais envolvidos com os mesmos, os quais serão responsáveis pela extração de características de diversos padrões de faltas, principalmente as faltas de alta impedância, podendo efetivamente contribuir para minimização dos impactos das faltas sobre o sistema de distribuição.

As ferramentas disponíveis hoje em dia são normalmente aplicadas de maneira isolada usando apenas uma ou duas técnicas de identificação e localização de faltas, sendo que as mesmas são bem limitadas a determinadas situações de faltas.

Diferentemente, outro fator de inovação do trabalho proposto é que a metodologia formulada utilizará de ferramentas inteligentes e convencionais, que serão integradas e sintonizadas entre si por um sistema especialista, visando reunir as potencialidades individuais de cada uma delas num único sistema. Assim, a tecnologia proposta possui um grau de robustez e eficiência bem superiores às demais técnicas.

Outro fator de inovação também associado ao trabalho é que o mesmo executará a identificação e localização de faltas utilizando informações registradas somente nas subestações, fato este que difere o sistema proposto de outras ferramentas as quais requerem também a medição de sinais ao longo dos alimentadores. 
Portanto, as características diferenciais do sistema de automatização a ser proposto neste trabalho estão pautadas em sua abrangência de agregação tecnológica e na sua análise integrada de diversos fatores e características que estão associados com os processos que possibilitam a identificação e localização de faltas de maneira eficiente e robusta.

Em suma, o quê se propõe é a confecção e a agregação de todo o ferramental necessário para que essas técnicas comprovadamente eficazes sejam viabilizadas do ponto de vista técnico e de operacionalização por parte do Centro de Operação de uma concessionária de distribuição de energia elétrica.

Assim, o quê se busca é o domínio de toda tecnologia envolvida com os processos de identificação e localização de faltas, levando-se em consideração desde as fases iniciais de aquisição e tratamento de sinais, passando pelas diversas metodologias desenvolvidas para a correta extração de características dos padrões de faltas e indo até a fase final, a qual possibilitará a disponibilização de todos os subsídios necessários para auxiliar a correta tomada de decisão por parte do Centro de Operação da Distribuição.

Portanto, pretende-se neste trabalho estudar a Identificação, Classificação, Localização e Setorização de Faltas, verificar maneiras de aplicar e integrar diversas ferramentas de sistemas inteligentes, assim como ferramentas numéricas convencionais, visando detectar em tempo-real a ocorrência de uma falta e classificar as fases envolvidas com a mesma, e aplicar as diversas ferramentas existentes a fim de localizar em tempo-real o eventual local onde houve a ocorrência da falta, permitindo então que a mesma possa ser setorizada dentro do sistema da concessionária usando uma nova abordagem inteligente baseada na análise espectral de sinais. 


\subsection{Organização do documento}

Este documento será organizado em 5 capítulos conforme se segue.

A motivação, relevância, justificativas e contribuições do trabalho foram registradas neste Capítulo 1.

No Capítulo 2 será apresentado o estado da arte referente às principais metodologias clássicas empregadas na detecção de faltas em sistemas de distribuição.

No Capítulo 3 serão apresentadas propostas modernas, tanto convencionais como inteligentes, para detecção de faltas em sistemas de distribuição.

No Capítulo 4 serão apresentados os aspectos da metodologia desenvolvida para o sistema automatizado para identificação e localização de faltas e do método inovador para propósitos de localização de faltas.

No Capítulo 5 serão apresentados alguns resultados experimentais

No Capítulo 6 serão feitas as considerações finais a respeito deste trabalho, assim como se apresentarão também as propostas de continuidade desse trabalho.

\subsection{Publicações realizadas}

Ao longo da execução deste trabalho, foram realizadas algumas contribuições técnico-científicas em congressos internacionais, periódico internacional e capítulo de livro que evidenciam a originalidade desta pesquisa, conforme citado a seguir:

\subsubsection{Congressos internacionais}

1. Lucca Zamboni, Nerivaldo dos Reis Santos, Leandro Nascimento Soares, Ivan Nunes da Silva, Danilo H. Spatti, Rogério A. Flauzino. "Expert System Solution for Fault Detection Purposes in Power Distribution Systems", World 
Congress in Computer Science, Computer Engineering, and Applied Computing at the International conference on Artificial Intelligence (ICAl'13), 2013.

2. Nerivaldo dos Reis Santos, Lucca Zamboni, Leandro Nascimento Soares, Ivan Nunes da Silva, Danilo H. Spatti. "Identificação e Localização de Faltas em Sistemas de Distribuição Utilizando Sistemas Especialistas Híbridos", 9th Latin_american Congress: Eletricity Generation and Transmission, 2011.

3. Lucca Zamboni, Ivan Nunes da Silva, Leandro Nascimento Soares, Danilo H. Spatti, "Automated Integration of Intelligent Architectures for Purposes of Fault Detection in Distribution Systems", XVIII IEEE International Congress of Electronic, Electrical and Systems Engineering, 2011.

4. Lucca Zamboni, Ivan Nunes da Silva, Leandro Nascimento Soares, Ricardo Augusto Souza Fernandes. "Integração Automatizada de Arquiteturas Inteligentes para Propósitos de Detecção de Faltas em Sistemas de Distribuição", IEEE/IAS - IX International Conference of Industry Applications, 2010.

\subsubsection{Periódico internacional}

1. Lucca Zamboni, Ivan Nunes da Silva, Leandro Nascimento Soares, Ricardo Augusto Souza Fernandes. "Fault Detection in Power Distribution Systems Using Automated Integration of Computational Intelligence Tools". IEEE Latin America Transactions, vol. 9, pp. 522-527, 2011. 


\subsubsection{Capítulo de livro internacional}

1. Ivan N. da Silva, Nerivaldo R. Santos, Lucca Zamboni, Leandro N. Soares, José A. C. Ulson, Rogério A. Flauzino, Danilo H. Spatti, Ricardo A. S. Fernandes, Marcos M. Otsuji and Edison A. Goes. "Intelligent Expert System for Protection Optimization Purposes in Electric Power Distribution Systems", Intelligent Systems, ISBN 979-953-307-593-7, pp. 277-296, 2012. 



\section{Estado da Arte Referente às Principais Metodologias Empregadas na Detecção de Faltas em Sistemas de Distribuição}

\subsection{Introdução}

A manutenção da continuidade no fornecimento de energia elétrica pelas concessionárias distribuidoras de energia elétrica, de suma importância para todos os setores da sociedade, pode ser fragilizada devido às faltas causadas por uma variedade de situações, tais como condições climáticas, contatos de árvores, falhas de equipamentos, acidentes, etc. Se houverem informações sobre a falta, mais rápido é o processo de manutenção e, consequentemente, mais rápido é o restabelecimento da energia elétrica (Cho e Há, 1998).

O progresso dos sistemas elétricos de potência está intimamente ligado com o progresso de sua proteção. A localização rápida e precisa de uma falta é imprescindível para uma operação segura e econômica em um sistema elétrico de potência (Zahra et al., 2000).

As interrupções a que os consumidores são submetidos se enquadram dentro da área de qualidade da energia elétrica no tema denominado qualidade do serviço, que pode ser traduzida pelos índices que contabilizam o tempo e a frequência em que o consumidor fica sem energia elétrica (Dugan et al.,2003). 
Além disso, existem índices que avaliam a continuidade no fornecimento de energia como o DEC (Duração Equivalente de Interrupção por Unidade Consumidora) e FEC (Frequência Equivalente de Interrupção por Unidade Consumidora), conforme descrito pelo PRODIST - Módulo 8 da ANEEL (ANEEL, 2009).

A identificação, localização e classificação, as quais podem ser coletivamente chamadas de processos de detecção de faltas, constituíram-se ao longo dos anos em metas almejadas por diversos segmentos do sistema elétrico de potência, tais como o setor de transmissão e o segmento de distribuição de energia elétrica, destacando-se três linhas de pesquisa: i) estudo das formas de onda fundamentais de corrente e tensão, principalmente por medições de impedâncias; ii) estudo de ondas viajantes e componentes de alta frequência; iii) aplicação de sistemas inteligentes (Tang, 2000).

Assim, em função da declarada demanda por sistemas automáticos capazes de identificarem, classificarem e localizarem faltas em sistemas de energia elétrica, diversas proposições de trabalhos que fazem uso das mais distintas ferramentas são observados junto à literatura correlata, nas mais variadas conjunções, com o intuito de contribuírem à concretização das bases envolvidas com o trinômio identificaçãoclassificação-localização de faltas.

A introdução da comunicação entre os dispositivos e também dos relés numéricos, uma tônica desde meados dos anos 70, permitiu melhorar a resposta do sistema frente a uma falta, como pode ser observado em Cong et al. (2005), onde os autores adotaram uma postura totalmente automatizada para o tratamento de uma falta. Esta linha de pesquisa fornece subsídios ao debate a partir do momento em que há ainda uma grande dificuldade em se adaptar os sistemas automáticos de tratamento de faltas às condições peculiares de cada circuito de distribuição. 
Diversas pesquisas têm sido realizadas objetivando o desenvolvimento de esquemas de automatização eficientes de processos envolvidos com a detecção de faltas em sistemas de distribuição. A utilização recente de técnicas de sistemas inteligentes visando tratar tanto o problema de identificação de faltas como a classificação e localização das mesmas têm sido uma tônica nos processos investigativos desses problemas. Os resultados já advindos da aplicação dessas técnicas têm proporcionado a confecção de sistemas de detecção eficientes e robustos.

Complementarmente, as pesquisas envolvendo a proposição de sistemas automatizados para os processos envolvidos com a detecção de faltas, baseados em sistemas inteligentes, têm despertado a atenção da comunidade científica que lida com o assunto. Como por exemplo, pesquisas desenvolvidas nos Estados Unidos mostram a utilização desses sistemas para detectarem faltas de alta impedância (Butler e Momoh, 2000). Os sistemas desenvolvidos foram bastante satisfatórios, obtendo taxas de acerto superiores a $90 \%$. Estudos semelhantes a esses foram também realizados na Coréia (Ko, 1998).

Ainda, em pesquisas realizadas na "Pacific Gas \& Electrical Company" da Califórnia (Liu e Zhong, 1996), esquemas que utilizam os sinais referentes à ocorrência de uma falta, os quais foram integrados com resultados obtidos de simulação de situações de falta, foi desenvolvido com bastante sucesso. Os resultados finais alcançados pelos sistemas inteligentes obtiveram resultados melhores que aqueles previamente fornecidos por técnicas convencionais, cujos modelos foram desenvolvidos utilizando apenas dados registrados por dispositivos de proteção. Outro método semelhante a este é proposto em Jarventausta et al. (1994). 
Um dos requisitos para a operação econômica e confiável de um sistema de potência é a determinação exata e em tempo hábil do ponto onde uma falta ocorreu. A localização destas faltas nos sistemas de distribuição de energia elétrica, em geral, é realizada pelo cruzamento das informações fornecidas pelos clientes com a experiência acumulada pelos profissionais da área técnica, os quais são responsáveis pelo despacho das equipes de manutenção aos lugares onde provavelmente a falta ocorreu. Se a estimação inicial estiver incorreta, então novos lugares candidatos deverão ser investigados pelas equipes responsáveis até que o local da falha seja identificado e os procedimentos de reparo possam ser efetuados.

Atualmente, a competição incremental ocasionada pela regulamentação do setor de energia elétrica aliada à necessidade crescente em fornecer melhores serviços aos clientes, tem contribuído para que as companhias de distribuição de energia elétrica investiguem novos métodos de localização de faltas que sejam mais rápidos e confiáveis que as abordagens convencionais. Outro aspecto motivador que vem impulsionando o desenvolvimento de novas abordagens para identificação e localização de faltas é a possibilidade de otimização dos recursos técnico-financeiros das companhias, bem como a melhoria dos indicadores de eficiência energética do sistema de distribuição.

De uma maneira ampla, as faltas observadas junto aos sistemas de distribuição de energia elétrica podem ser classificadas em faltas de alta impedância e em faltas de baixa impedância.

As faltas de baixa impedância passíveis de ocorrência nos sistemas elétricos de distribuição são as faltas fase-fase e as faltas trifásicas. Estes tipos de faltas se caracterizam por provocarem a ocorrência de correntes com magnitudes suficientemente altas para sensibilizar os dispositivos de proteção instalados ao longo 
do alimentador ou junto à subestação. Além destes dois tipos de faltas, as faltas faseterra de baixa impedância, num sistema de distribuição estrela aterrada podem também ser identificadas pelos dispositivos de proteção do sistema de distribuição. Assim, as abordagens referenciadas na bibliografia correlata, relacionadas às faltas de baixa impedância, procuram, mediante a oscilografia do sistema e do estado dos equipamentos seccionalizadores, localizar dentro do segmento faltoso o local de ocorrência da falta para que as medidas corretivas cabíveis sejam providenciadas.

No entanto, dados estatísticos indicam uma maior probabilidade de ocorrência de faltas de alta impedância junto aos sistemas de distribuição de energia elétrica. As faltas de alta impedância se caracterizam por apresentarem magnitudes de corrente de falta menores que a corrente de carga (trabalho) do alimentador. Assim, os sistemas de proteção convencionais são ineficazes na identificação e consequente atuação junto ao sistema de distribuição frente à ocorrência deste tipo de falta. Como uma consequência direta destas limitações, tem-se que cabos rompidos, encostados no solo, por exemplo, podem permanecer energizados por um logo período. Esta situação ilustrativa pode representar um sério risco, pois pode provocar acidentes envolvendo pessoas e animais ou ainda desencadear incêndios resultando em danos ao meio ambiente, bem como prejuízos de ordem econômica.

Desta forma, as faltas de alta impedância podem ser definidas como um evento anormal sobre um alimentador de distribuição primário que não pode ser facilmente detectado por dispositivos de proteção modernos. A maioria das faltas de alta impedância envolve níveis de corrente muito menores que aqueles necessários à sensibilização dos dispositivos de proteção de corrente. Essas faltas frequentemente exibem arcos voltaicos quando nenhum retorno sólido para a corrente é disponível, resultando em correntes de falta com componentes de alta frequência observáveis. 
Como decorrência direta destas faltas, este mesmo comportamento pode resultar de outros eventos, tais como o chaveamento de capacitores e mudanças de tap de transformadores.

Basicamente, existem dois tipos de faltas de alta impedância, quais sejam elas as faltas ativas e as faltas passivas. Uma falta ativa é caracterizada pela presença de arco elétrico junto ao local de ocorrência da falta. A maioria das técnicas propostas na literatura para detectar faltas ativas utiliza inferências que empregam os valores de módulo e ângulo das frequências harmônicas e não harmônicas geradas pela corrente de arco elétrico.

Uma falta de alta impedância passiva é caracterizada pela ausência do arco elétrico. Este tipo de falta pode representar um risco maior visto que o condutor não fornece qualquer indicação visual de uma condição de perigo. Além disso, as faltas passivas são mais difíceis de serem detectadas, pois as informações contidas no espectro harmônico da corrente da falta não são tão evidentes quanto aquelas contidas no espectro harmônico das correntes de falta ativas. Uma visão ampla sobre os principais aspectos relacionados às faltas de alta impedância passiva é apresentada no trabalho de Jota e Jota (2004).

Nas seções seguintes serão apresentadas, em mais detalhes, algumas das principais abordagens para identificação e localização de faltas em sistemas de distribuição de energia elétrica por meio de técnicas atuais. Dentre estas técnicas, destaque especial será conferido às Redes Neurais Artificiais, aos sistemas de inferência fuzzy e às abordagens baseadas na Transformada Wavelet devido aos promissores resultados apresentados por essas abordagens e relatados junto à bibliografia correlata. 


\subsection{Detecção de faltas de alta impedância em alimentadores de sistema de distribuição utilizando redes neurais artificiais}

A metodologia proposta aqui foi formulada por Ebron et al. (1990), sendo constituída de três etapas principais, as quais são utilizadas para o processo de detecção de faltas em sistemas de distribuição. A primeira etapa consiste em se coletar e processar um conjunto de sinais referentes às correntes de linha do alimentador. A segunda etapa é responsável por empregar este conjunto de medidas para treinar a abordagem neural de maneira que a mesma seja capaz de identificar situações de ocorrência de falta ou condições de operação normal do sistema. Finalmente, a terceira etapa é dedicada aos procedimentos envolvidos com a validação da abordagem neural com dados que não pertenceram ao conjunto de treinamento, de forma a comprovar a eficiência da abordagem frente a novas situações.

Tanto os dados de treinamento como os dados de validação da abordagem neural foram gerados utilizando para tal propósito o programa de simulações de transientes eletromagnéticos EMTP. Diversas simulações foram executadas envolvendo diferentes situações de transitórios, tais como simulações de acionamento de motores e de energização de capacitores. Quatro tipos de casos foram gerados que podem ser listados da seguinte forma:

$>$ Casos de chaveamento normal de cargas;

> Casos de carga normal com chaveamento de capacitores;

> Casos de falta de alta impedância com chaveamento de cargas;

> Casos de falta de alta impedância com chaveamento de carga e de capacitor.

As amostras de corrente empregada no treinamento da rede foram inicialmente separadas dentro de conjuntos de um único ciclo cada. Para cada conjunto, 20 
parâmetros foram computados para representar a condição do alimentador perante o ciclo de operação. Dentre estes parâmetros, podem-se listar os seguintes:

$>$ O valor de pico da corrente transitória nas três fases;

> O valor da corrente antes e imediatamente após a ocorrência do maior transitório;

$>$ O número de transitórios caindo abaixo de $75 \%$ do valor máximo;

$>$ A magnitude da corrente de sequencia positiva;

> O nível de desequilíbrio entre as fases;

$>$ As componentes harmônicas de primeira, terceira e quinta ordem da corrente de neutro.

Vários desses parâmetros, tais como a corrente de sequencia positiva, são somente empregados para propósitos de referência, pois desta maneira, permite-se que a rede neural possa fazer comparações entre os níveis de corrente transitória e outros parâmetros a fim de que a mesma possa extrair ponderações relativas às perturbações.

\subsection{Técnicas de identificação de faltas de alta impedância}

\section{utilizando redes neurais artificiais e transformada de Fourier}

Conforme mencionado anteriormente, as faltas de alta impedância são geralmente difíceis ou impossíveis de serem detectadas com dispositivos de proteção de sobrecorrente (relés, elos fusíveis e religadores), pois a corrente de falta pode não possuir magnitude suficientemente alta para ativá-los, dificultando assim a discriminação entre as correntes de carga e correntes de falta de alta impedância principalmente nos sistemas de distribuição multi-aterrados. 
O método proposto em Ko et al. (1998) para detecção de faltas de alta impedância consistiu também em utilizar Redes Neurais Artificiais do tipo perceptron para identificar a ocorrência ou não de faltas. A metodologia opera dividindo inicialmente um ciclo da forma de onda de corrente e tensão dentro de quatro janelas iguais, sendo duas localizadas em posições contendo os valores mais altos de tensão, e as outras duas estando localizadas junto aos valores mais baixos de tensão. Uma ilustração deste procedimento é apresentada na Figura 2.1.

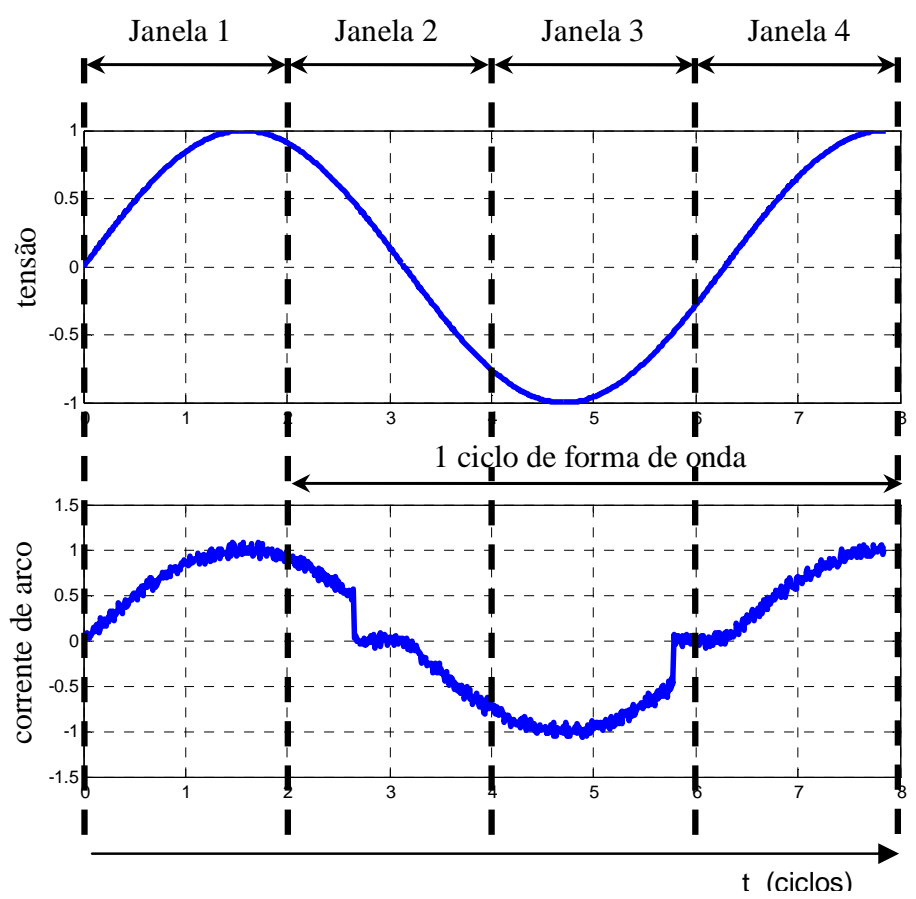

Figura 2.1 - Configuração da janela de dados. Adaptado de Ko et al., 1998.

Para detectar as componentes de alta impedância da corrente de falta, aplicase a transformada rápida de Fourier (Fast Fourier Transform - FFT) nos sinais de corrente em cada uma das quatro janelas. Em seguida, as harmônicas fornecidas pela FFT são utilizadas como variáveis de entradas de uma rede neural do tipo perceptron. Baseado nas informações de entrada, a saída da rede fornece como resultado o valor +1 quando há ocorrência da falta de alta impedância, fornecendo o valor -1 quando o sistema opera em condições normais. 
A rede perceptron utilizada neste método é composta de três camadas neurais, tendo oito neurônios na primeira camada, dezesseis neurônios na segunda camada e um neurônio na camada de saída. As entradas da rede são as magnitudes das sete primeiras harmônicas do espectro de frequência, as quais são fornecidas pela aplicação da FFT. O tempo de amostragem dos dados do sinal ficou em $260 \mu$ s (64 pontos por ciclo) ou 3840 amostras por segundo.

\subsection{Abordagem neural utilizando características estatísticas das correntes de falta}

Um fato observável em faltas que exibem uma baixa corrente é que as mesmas normalmente apresentam grandes magnitudes nos sinais de tensão de fase. Entretanto, há uma alteração destacável no formato de onda da corrente na fase faltosa (Butler et al., 1997). Para condições de faltas sem a presença de arco, a amplitude e/ou fase da corrente na fase faltante implica em alterações determinísticas, enquanto que nas condições de falta com presença de arco, distorções aleatórias em intervalos intermitentes podem ser observadas na fase ou na amplitude da corrente da fase faltante. Na presença de um distúrbio devido à ocorrência de falta, as formas de onda das correntes de fase e de neutro apresentam-se distorcidas. Assim, a forma de onda de uma corrente faltosa $i_{p}$ pode ser representada pela corrente $i_{p}^{\prime}$ definida em (2.1) em adição ao distúrbio provocado pela falta, ou seja:

$$
i_{p}^{\prime}(t)=i_{p}(t)+n(t)
$$

onde $n(t)$ representa um processo aleatório. No entanto, nas abordagens convencionalmente empregadas, tanto academicamente como tecnicamente, não contemplam os distúrbios gerados na forma de onda de tensão. A fim de garantir uma maior confiabilidade das estimativas realizadas, a distorção na forma de onda de 
tensão será considerada ao longo da apresentação da metodologia proposta por Butler et

al.

(1997).

A

Figura 2.2 apresenta formas de onda de tensão e de corrente para um sistema elétrico sob falta fase-terra de alta impedância com presença de arco elétrico.
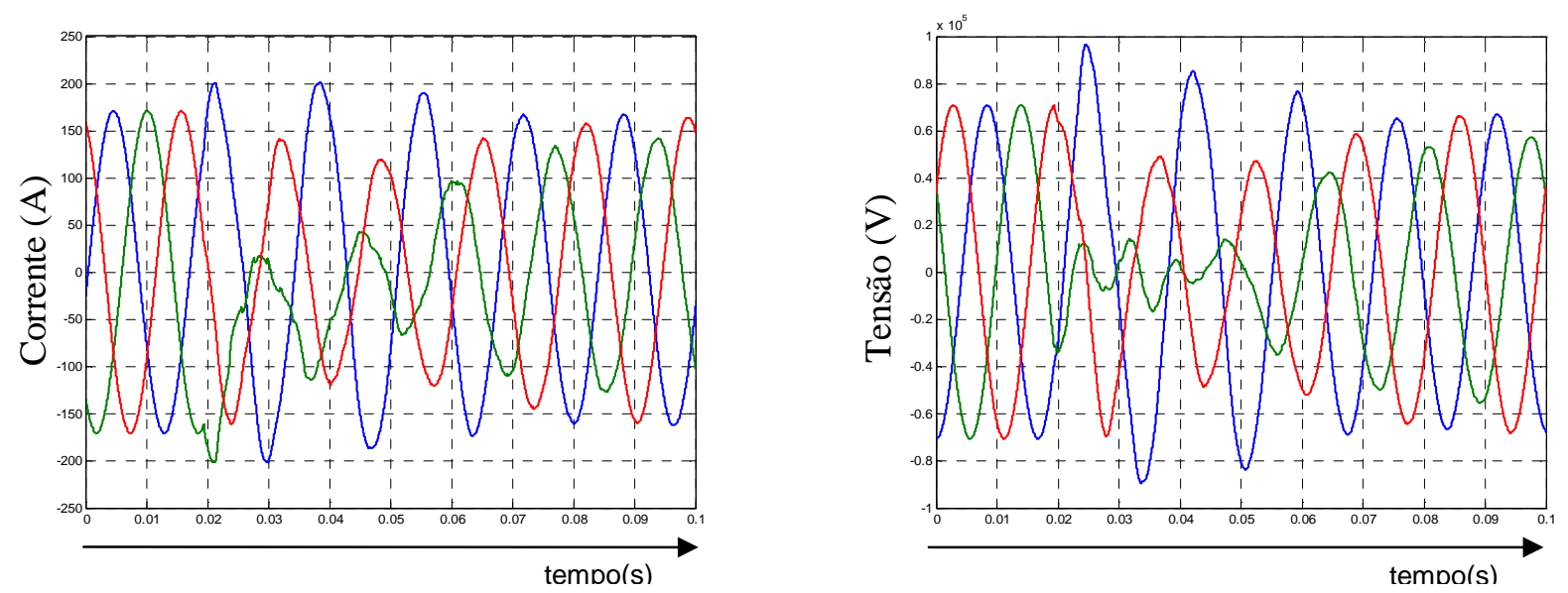

Figura 2.2 - Formas de onda de corrente e tensão para uma falta fase terra com ocorrência de arco elétrico. Adaptado de Butler et al. 1997.

Pode-se observar por intermédio dos gráficos da

Figura 2.2 a constante alteração de formato de onda a cada ciclo tanto para as formas de onda de tensão como para as formas de onda de corrente. A assimetria de formato das formas de onda no domínio do tempo torna complexa a tarefa de extração de características que permitam ajustar corretamente o sistema de identificação de faltas. No entanto, quando a análise espectral de frequência é realizada sob os dados disponíveis, periodicidades ocultas ou pequenos picos de energia em determinadas frequências podem ser observados. Assim, o levantamento destas peculiaridades do domínio da frequência pode contribuir positivamente para a detecção de eventuais falhas junto ao sistema de distribuição de energia elétrica.

O método de diagnóstico de falta utilizado nesta abordagem consiste em aplicar a capacidade de reconhecimento de padrões oferecido pelas Redes Neurais Artificiais com o objetivo de detectar faltas de baixa e alta impedância, na presença de 
arco, em sistemas aterrados ou não aterrados, que são normalmente não detectadas por dispositivos de proteção de sobrecorrente em virtude da baixa magnitude das mesmas.

De forma geral, pode-se caracterizar esta abordagem por meio de duas etapas principais. A primeira etapa é responsável por realizar um pré-processamento de sinais e a segunda etapa é constituída por um sistema de diagnóstico baseado em clusterização supervisionado. As entradas do sistema de diagnóstico de faltas são as três correntes de fase medidas em cada alimentador. O alimentador da subestação monitora as tensões e correntes fornecidas pelos dispositivos de proteção do sistema. O pré-processador computa as características estatísticas vindas das correntes de fase passando as mesmas para o classificador neural de padrões. A Figura 2.3 ilustra o diagrama de blocos deste método de diagnóstico de faltas.

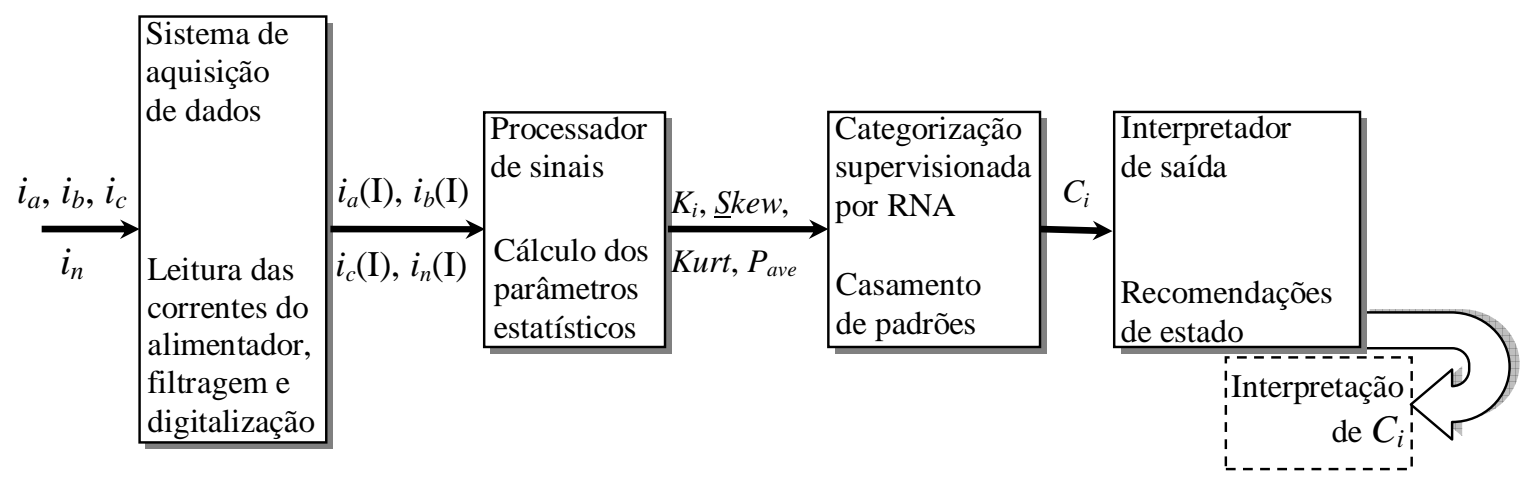

Figura 2.3 - Diagrama de blocos do método de diagnóstico de faltas baseado em características estatísticas das correntes de falta. Adaptado de Butler e Momoh, 1993.

As características pertinentes à forma de onda são fundamentais para se determinar o tipo de metodologia a ser empregada na análise em frequência das formas de onda oscilografadas. Uma vez que os dados obtidos estão comprometidos por um ruído branco, o emprego da transformada de Fourier torna-se inadequada (Butler e Momoh, 1993). Desta maneira, o emprego de técnicas de processamento 
estatístico se configura mais adequado aos propósitos do problema de identificação de faltas em sistemas de distribuição de energia elétrica.

Dentre as diversas metodologias disponíveis para se realizar a análise espectral estatística destaca-se a abordagem onde o conceito de análise espectral pela máxima entropia é formulado (Ulrych e Bishop, 1975). Aplicando-se este conceito à análise espectral verifica-se que tal procedimento pode ser representado como sendo um processo gaussiano estacionário, ou seja:

$$
H=\frac{1}{4 f_{n}} \int_{-f_{n}}^{f_{n}} \log [S(f)] d f
$$

onde $f_{n}$ é a frequência de Nyquist. Reescrevendo a expressão (2.2) em termos da autocorrelação do sistema, tem-se:

$$
H=\frac{1}{4 f_{n}} \int_{-f_{n}}^{f_{n}} \log \left[\sum_{-\infty}^{+\infty} \phi(k) \exp (-j 2 \pi f k \Delta t)\right] d f
$$

Maximizando (2.3) com relação aos termos $\phi(k)$ desconhecidos e respeitando as restrições impostas por $S(f)$, onde se deve observar a consistência das autocorrelações $\phi(0) \ldots \phi(M-1)$, tem-se a função densidade espectral. Para um processo linear $x$ a função densidade espectral estimada pode ser representada da seguinte forma:

$$
\hat{S}_{x}(t)=\frac{P_{m}}{2 B\left[1+\sum_{m=1}^{M} a_{m} \exp (-j 2 \pi m f \Delta t)\right]^{2}}
$$

onde $P_{m}$ é a potência normalizada do filtro de ordem $m$ e, $B$ é a largura de banda do processo estocástico $x$.

Um dos principais limitantes da aplicação da função densidade espectral conforme apresentado em (2.4) reside na estimação da ordem do filtro de estimação de 
erro. No entanto, o critério de estimação do erro final, a qual incorpora o erro quadrático de estimação, mostra-se efetivo na determinação da ordem ótima para o filtro (Akaike,1968). O erro final de predição pode ser calculado da seguinte forma:

$$
\operatorname{EFP}(M)=\frac{N+M+1}{N-M-1} P_{m}
$$

onde Né o número de pontos da forma de onda amostrada.

Por meio do processamento espectral estatístico das formas de onda, as principais características extraídas pelo pré-processador de sinais e empregadas nesta metodologia são as seguintes:

$>$ Matrizes de coeficientes de reflexão;

$>$ Coeficientes de skewness;

$>$ Coeficientes de kurtosis;

$>$ Coeficientes de potência média.

Cada um dos parâmetros estatísticos empregados nesta abordagem representa quantitativamente características inerentes às formas de onda de corrente e tensão. Os coeficientes de skewness fornecem informações estatísticas de terceira ordem e podem ser interpretados como sendo uma medida da assimetria em torno do valor médio das formas de onda das tensões e correntes faltosas, enquanto que os coeficientes de kurtosis indicam o quão próximo ou o quão distante a função densidade probabilidade está de uma distribuição gaussiana. Os coeficientes de reflexão são um indicativo da repetibilidade das formas de onda, enquanto que os coeficientes de potência média fornecem à abordagem um patamar referencial para a correta categorização dos eventos.

Para ilustrar como alguns destes parâmetros variam para uma forma de onda de corrente faltosa são apresentados na Figura 2.4 e Figura 2.5 os valores de 
skewness e de kurtosis para uma corrente de falta e para uma corrente normal ao longo de 14 ciclos.

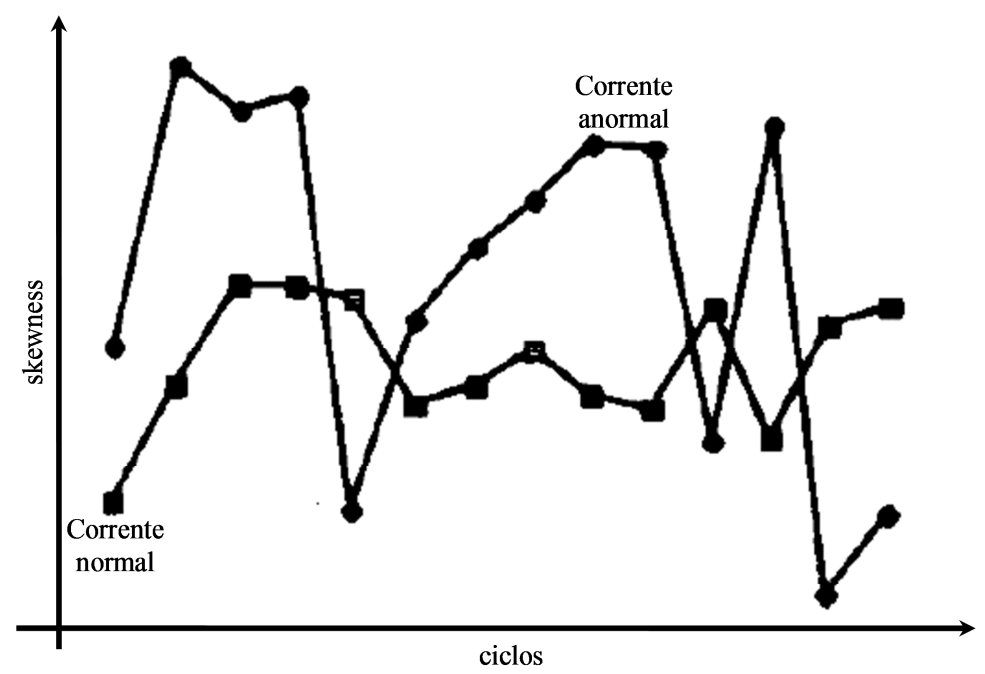

Figura 2.4 - Skewness para uma forma de onda de corrente faltosa (anormal) e para uma forma de corrente normal. Adaptado de Akaike, 1968.

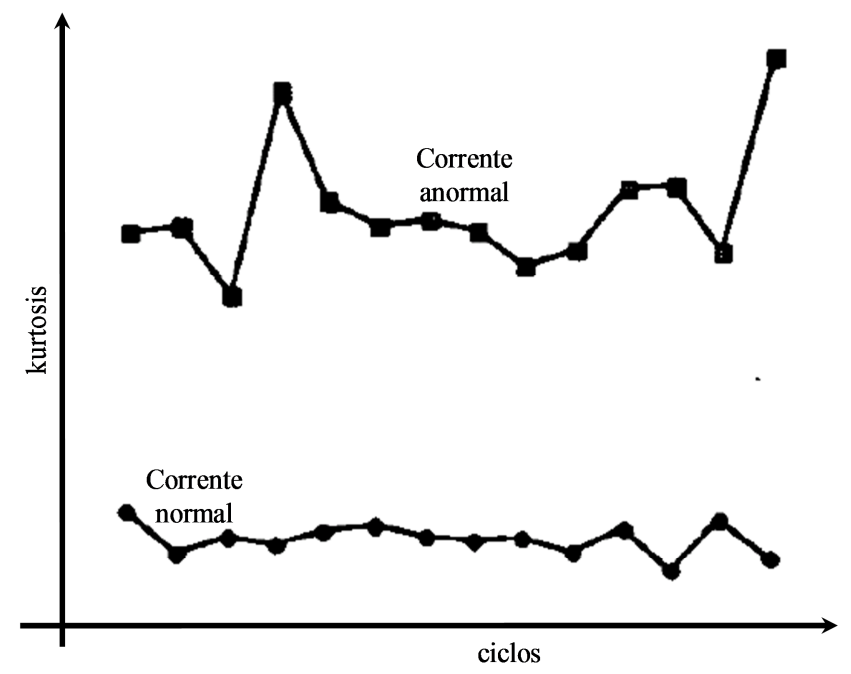

Figura 2.5 - Kurtosis para uma forma de onda de corrente faltosa (anormal) e para uma forma de corrente normal. Adaptado de Akaike, 1968.

Os resultados fornecidos pela rede neural indicam se um determinado padrão de sinal se deve a uma falta ou não. Se o sinal é detectado como falta, a rede neural adicionalmente classifica o tipo de falta e identifica a fase faltante. 


\subsection{Modelagem fuzzy aplicada na identificação de faltas de alta}

\section{impedância com característica passiva}

Poucas soluções são apresentadas na literatura correlata com o objetivo de identificar as faltas de alta impedância passiva. Verifica-se, ainda, que a maioria das abordagens referenciadas é baseada na análise do desbalanço de fases dos alimentadores do sistema de distribuição. No entanto, em virtude dos sistemas de distribuição normalmente apresentarem um alto nível de correntes desbalanceadas, verifica-se inúmeras limitações destas metodologias quanto da correta identificação de faltas. Um dos principais fatores que contribuem para o desbalanço natural dos sistemas de distribuição é a grande quantidade de cargas monofásicas (fase-terra e fase-fase) instaladas ao longo da extensão dos alimentadores do sistema.

Para contornar esses problemas, o método abordado por Jota e Jota (1998) consiste no emprego de um sistema fuzzy supervisório que periodicamente monitora as correntes e tensões dos alimentadores do sistema de distribuição. A partir dos valores de tensão e corrente observados, o sistema fuzzy, por meio de comparações e operadores específicos, realiza inferências que fornecem como resultado a indicação de uma ocorrência ou não de falta no sistema.

No entanto, para que o sistema fuzzy opere de maneira a fornecer níveis confiáveis de resposta é necessário que exista um volume adequado de conhecimento acerca do sistema de distribuição a fim de que as comparações e inferências ocorram dentro de universos de discurso com dados normalmente distribuídos. A base de dados responsável por armazenar este montante de informações pode ser construída por diferentes técnicas. Dentre as técnicas mais usuais, duas merecem destaque especial. Uma dessas técnicas consiste na simulação computacional dos possíveis eventos do alimentador. Por meio de simulações exaustivas uma grande quantidade de 
informações pode ser computada e, como consequência direta, uma consistente base de dados é construída.

A segunda metodologia usualmente empregada é baseada na aplicação de formas de onda impulsivas no início dos alimentadores e observar as respostas originadas por este procedimento. As ondas impulsivas, que são injetadas no alimentador, viajam ao longo da linha, trazendo informações sobre o status real do alimentador. Após a realização de cada medição, o sinal de resposta é précondicionado, convertido para o domínio da frequência e então armazenado junto à base de regras correspondente. As componentes complexas dos sinais préprocessados são então calculadas por intermédio da transformada rápida de Fourier.

Na metodologia apresentada nesta seção a base de dados foi constituída por meio da aplicação de formas de onda impulsivas no início dos alimentadores. No entanto, a adoção desta metodologia deve respeitar importantes requisitos como, por exemplo, levar em consideração todas as possíveis configurações operacionais do alimentador. Para tanto, a equipe responsável pelo planejamento, operação e manutenção do sistema deve fornecer informações relevantes sobre as diversas configurações operacionais possíveis do alimentador.

Com relação à operação do sistema, primeiramente, os sinais das respostas impulsivas são comparados com aqueles conhecidos e armazenados junto à base de regras. Na sequencia, o sistema busca por evidências de ocorrências de faltas de alta impedância, considerando para tanto o grau de discrepância entre os sinais medidos e as respostas armazenadas na referida base de dados. Como resposta, o sistema fuzzy é responsável por fornecer indicadores de supervisão dos estados do sistema de distribuição. 
Análises de respostas típicas têm mostrado que a utilização de 20 frequências características é suficiente para discriminar satisfatoriamente os sinais medidos. As respostas dos sinais impulsivos (5000 amostras) são descompostas em duas janelas $W_{1}$ e $W_{2}$. Para cada janela, componentes reais e imaginárias das 20 frequências têm sido calculadas, perfazendo assim um total de 80 componentes que serão as entradas do sistema fuzzy.

\subsection{Método para diagnóstico de faltas em subestações de distribuição utilizando sistemas fuzzy e redes de causa e efeito}

A estrutura para o diagnóstico de falta proposto por Chen et al. (2000) é compreendida por uma rede de causa e efeito, uma base de regras, uma base de dados fuzzy, um mecanismo de inferência e um processador de dados em tempo real. Um diagrama esquemático do sistema proposto é mostrado na Figura 2.6.

Nesta metodologia, a rede causa e efeito representa a casualidade entre faltas e ações de relés e disjuntores. Para os diversos tipos de faltas, considerando todas as seções possíveis, especificam-se os fluxogramas que representam as sequencias de causa e efeito. 


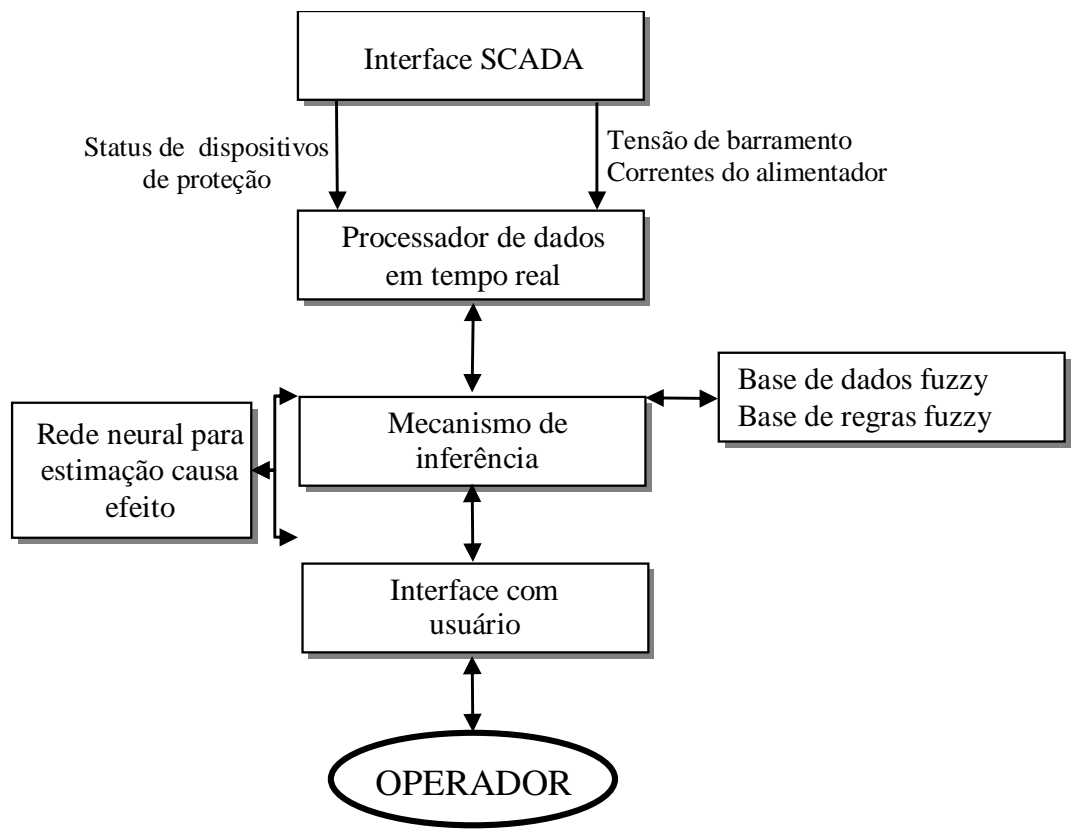

Figura 2.6 - Estrutura do sistema de diagnóstico de falta proposto. Adaptado de Chen et al., 2000.

A outra tarefa do método proposto é classificar os tipos de faltas, levando em consideração as correntes e tensões no alimentador, através da utilização de um sistema fuzzy. A base de regras fuzzy é formada por regras que são extraídas a partir de características de todos os tipos de faltas. A definição dessas regras requer um conhecimento detalhado do comportamento dos sinais de corrente e tensão que são gerados durante uma situação de falta. As regras fuzzy desta abordagem são baseadas na premissa de quando uma falta ocorre, as correntes normalmente aumentam em magnitude e as tensões diminuem. $O$ formato das regras do sistema fuzzy possui o padrão apresentado na Figura 2.7.

$$
\begin{aligned}
& \text { Se }\left(\mathrm{I}_{\mathrm{A}}=\text { Alta e } \mathrm{I}_{\mathrm{B}}=\text { Normal e } \mathrm{I}_{\mathrm{C}}=\text { Normal e } \mathrm{I}_{\mathrm{N}}=\text { Alta }\right) \text { e }\left(\mathrm{V}_{\mathrm{A}}=\text { Baixa e } \mathrm{V}_{\mathrm{B}}=\text { Normal e } \mathrm{V}_{\mathrm{C}}=\text { Normal }\right) \\
& \text { Então (Tipo de Falta })=\text { Fase }(\mathrm{A}) \_ \text {Terra } \\
& \operatorname{Se}\left(\mathrm{I}_{\mathrm{A}}=\text { Alta e } \mathrm{I}_{\mathrm{B}}=\text { Normal e } \mathrm{I}_{\mathrm{C}}=\text { Alta e } \mathrm{I}_{\mathrm{N}}=\text { Alta }\right) \text { e }\left(\mathrm{V}_{\mathrm{A}}=\text { Baixa e } \mathrm{V}_{\mathrm{B}}=\text { Normal e } \mathrm{V}_{\mathrm{C}}=\text { Baixa }\right) \\
& \text { Então (Tipo de Falta })=\text { Fase }(\mathrm{A}) \_F a s e(C) \_ \text {Terra } \\
& \text { (...) }
\end{aligned}
$$

Figura 2.7 - Exemplo de base de regras do sistema fuzzy. Adaptado de Chen et al., 2000. 
O processo de identificação da falta pelo sistema fuzzy consiste de quatro estágios que podem ser representados esquematicamente conforme apresentado na Figura 2.8.

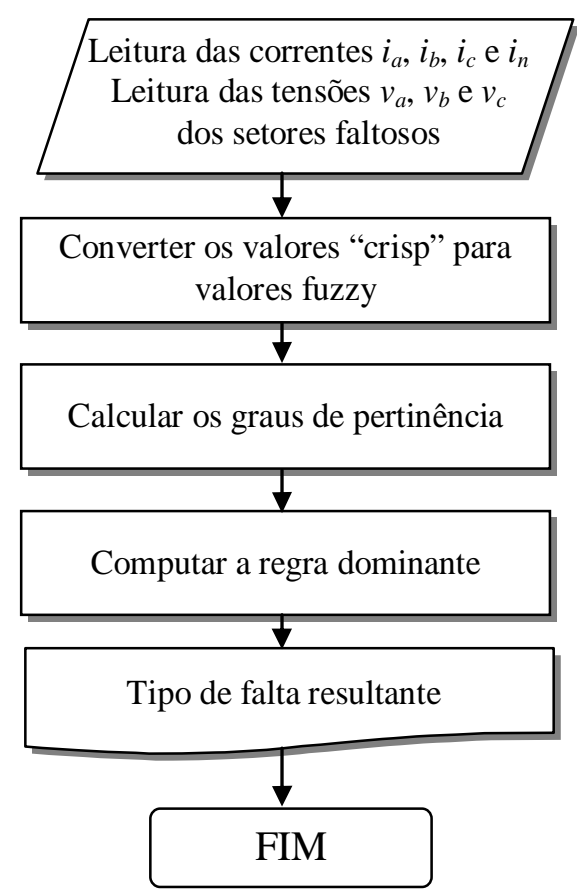

Figura 2.8 - Procedimentos para estimação de faltas para o sistema de inferência fuzzy. Adaptado de Chen et al., 2000.

Conforme apresentado na Figura 2.8, o primeiro passo deste processo é a obtenção das correntes e tensões do alimentador. O segundo passo consiste em converter esses valores para os respectivos termos linguísticos que são especificados através de funções de pertinência. Em seguida, esses termos linguísticos serão empregados na avaliação das regras fuzzy. Finalmente, através da aplicação dos procedimentos de inferência, torna-se possível a obtenção dos resultados que permitam identificar o tipo de falta. 


\subsection{Técnicas de localização de faltas baseadas em sinais de alta frequência e transformada wavelet}

Uma técnica proposta por Magnago e Abur (1999) para localização de faltas em alimentadores de distribuição radial é formulada sob as informações fornecidas pelos equipamentos de medição instalados na subestação, levando-se também em consideração detalhes de configuração do alimentador.

O método proposto, opera identificando o trecho da falta com base nas informações das ondas trafegantes fornecidas pelas componentes de alta frequência, as quais estão intrínsecas nos transitórios dos sinais de faltas coletados pelos instrumentos de medição. Em seguida, é calculado, baseado nas intensidades dos sinais de frequência, o local exato da falta ao longo do trecho identificado no passo anterior.

Para tanto, os sinais transitórios das correntes trifásicas são inicialmente decompostos em suas componentes modais. Em seguida, os sinais modais são decompostos em suas componentes wavelets, sendo obtidos então os correspondentes coeficientes wavelets. Esses coeficientes são usados para extrair padrões relevantes dos sinais, os quais são subsequentemente utilizados para identificar o ramo ou trecho onde a falta está localizada. Finalmente, a distância da falta a partir da subestação principal é calculada utilizando informações baseadas nas potências dos sinais.

A fim de ilustrar esta metodologia, a Figura 2.9 apresenta o diagrama de blocos funcionais da abordagem descrita nesta seção. 


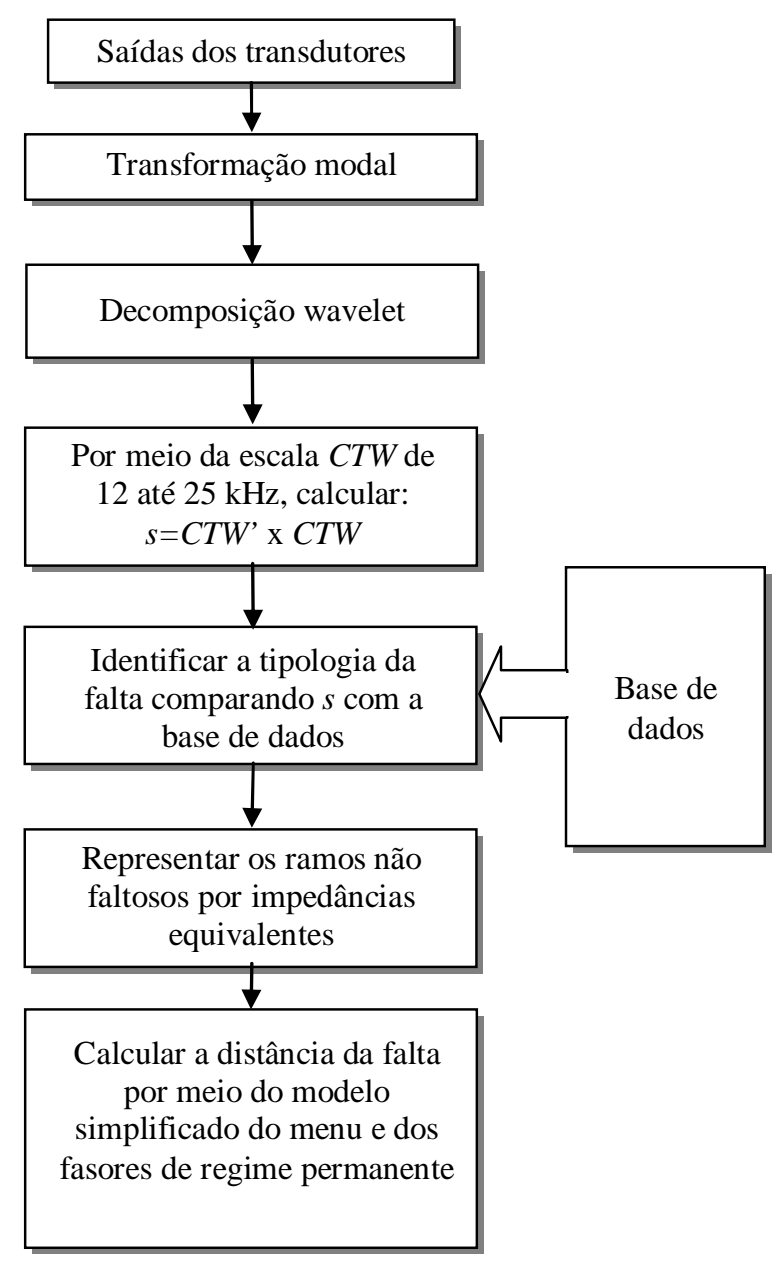

Figura 2.9 - Fluxograma do algoritmo de localização de falta proposto. Adaptado de Magnago e Abur, 1999.

Em suma, o procedimento de localização de faltas pode ser descrito da seguinte forma:

- As tensões e correntes de fase são transformadas para o domínio modal.

- Os sinais modais são decompostos visando obter os Coeficientes da Transformada Wavelet (CTW).

- O trecho e a distância à falta é estimado utilizando informações fornecidas pelos coeficientes da Transformada Wavelets.

Um dos aspectos observados neste método está relacionado à ocorrência de faltas fase-terra. Se a falta é produzida quando a tensão da fase faltante é pequena, 
isto é, o ângulo de incidência é pequeno, os sinais transitórios produzidos pelas ondas trafegantes também serão pequenos. Entretanto, mesmo para os ângulos de incidência pequenos, os coeficientes da Transformada Wavelet identificam o trecho sob falta, pois se pôde observar que este processo opera sob um mapeamento linear.

\subsection{Classificação e medição dos níveis de perturbação em sistema de potência por meio de wavelet}

O método proposto na abordagem apresentada em Gaouda et al. (2002) consiste em utilizar a técnica de wavelets para detectar, classificar e medir as perturbações que incidem nos sistemas de distribuição.

Um sinal $f_{s}(t)$ de duração finita com uma distorção aditiva $s_{d}(t)$ pode ser representado matematicamente por:

$$
f_{s}(t)=f_{p}(t)+s_{d}(t)
$$

onde $f_{p}(t)$ é o sinal puro que está compondo $f_{s}(t)$ e $s_{d}(t)$ representa o sinal de distúrbio inserido ao sinal original.

Aplicando análise multi-resolução é possível decompor o sinal $f_{s}(t)$ em diferentes níveis de resolução e apresentá-lo na forma de uma expansão por série utilizando uma combinação de funções escalas $\varphi_{k}(t)$ e funções wavelets $\psi_{k}(t)$. Formalmente, pode-se representar esta decomposição na sua forma canônica pela seguinte equação:

$$
f_{s}(t)=\sum_{k} c_{0}(k) \cdot \varphi(t-k)+\sum_{k} \sum_{j=0}^{k-1} d_{j}(k) \cdot 2^{\frac{j}{2}} \cdot \psi\left(2^{j} t-k\right)
$$

onde $j$ representa o número total de níveis de resolução, $c_{j}(k)$ são os coeficientes da função escala e $d_{j}(k)$ são os coeficientes da função wavelets. Os coeficientes de escala $c_{j}(k)$ são obtidos a partir do sinal. Se a taxa de amostragem do sinal $f_{s}(t)$ estiver acima 
da taxa de amostragem determinada pelo Teorema de Nyquist, então os mesmos são boas aproximações para os coeficientes de escala para uma determinada escala. Isto significa que nenhum coeficiente de escala será necessário.

Assim, quaisquer alterações no sinal $f_{s}(t)$ podem ser detectadas e localizadas no tempo devido às mudanças nas magnitudes desses coeficientes. De acordo com o teorema de Parseval, a energia de $f_{s}(t)$ poderá ser particionada em diferentes caminhos dependendo do tipo de evento associado à distorção. Portanto, o mapeamento dos dados da distorção $s_{d}(t)$ dentro de um domínio wavelet é o primeiro passo para executar o processo de classificação dos sinais. Em seguida a distribuição da energia de distorção $E_{d}$ em diferentes níveis de resolução é computada para gerar um conjunto de características não variantes no que diz respeito à mudança de posição (translação) com baixa dimensionalidade.

A Figura 2.10 apresenta a diferença na distribuição de energia $\Delta E_{d}$ em diferentes níveis de resolução para 25 sinais distorcidos por diferentes perturbações.

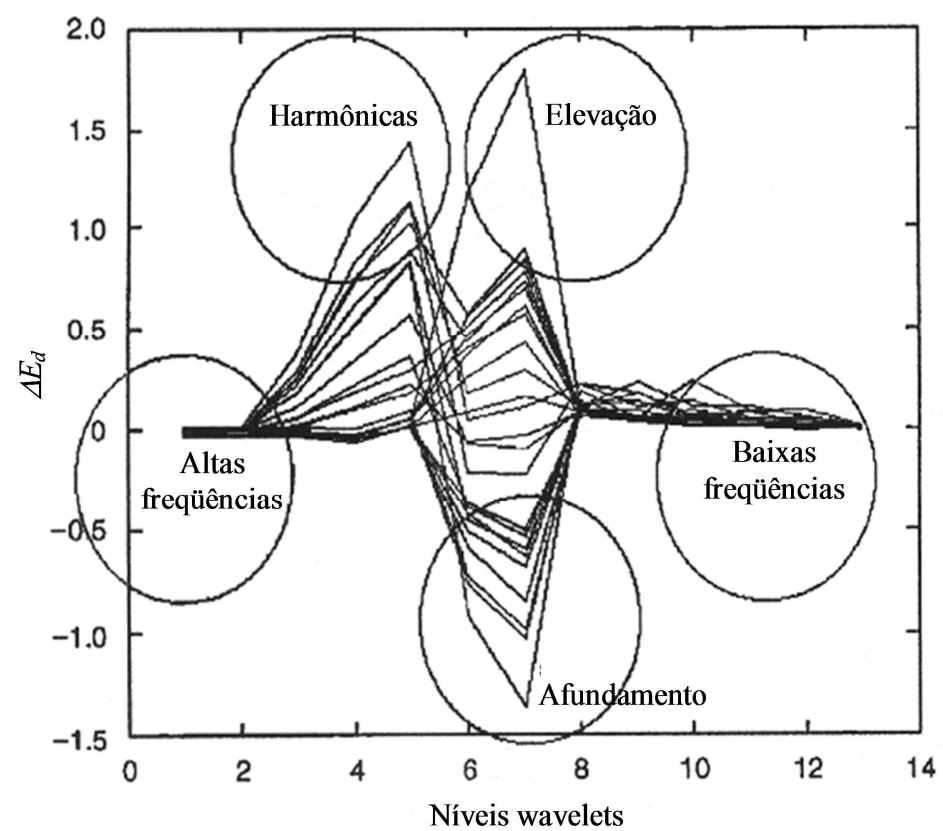

Figura 2.10 - Classificação de perturbações no domínio wavelet. Adaptado de Gaouda et al., 2002. 
Podem-se observar por intermédio do gráfico da Figura 2.10 que as características de perturbações envolvendo harmônicas no sistema são melhores identificadas no nível 5, enquanto que afundamento e elevação de tensão são melhores reconhecidos no nível de resolução 7.

A Figura 2.11 ilustra em detalhes um sinal $f_{s}(t)$ constituído de diversas perturbações, ilustrando a decomposição do sinal no primeiro nível $D_{1}$, bem como $\Delta E_{d}$ nos diferentes níveis de resolução.
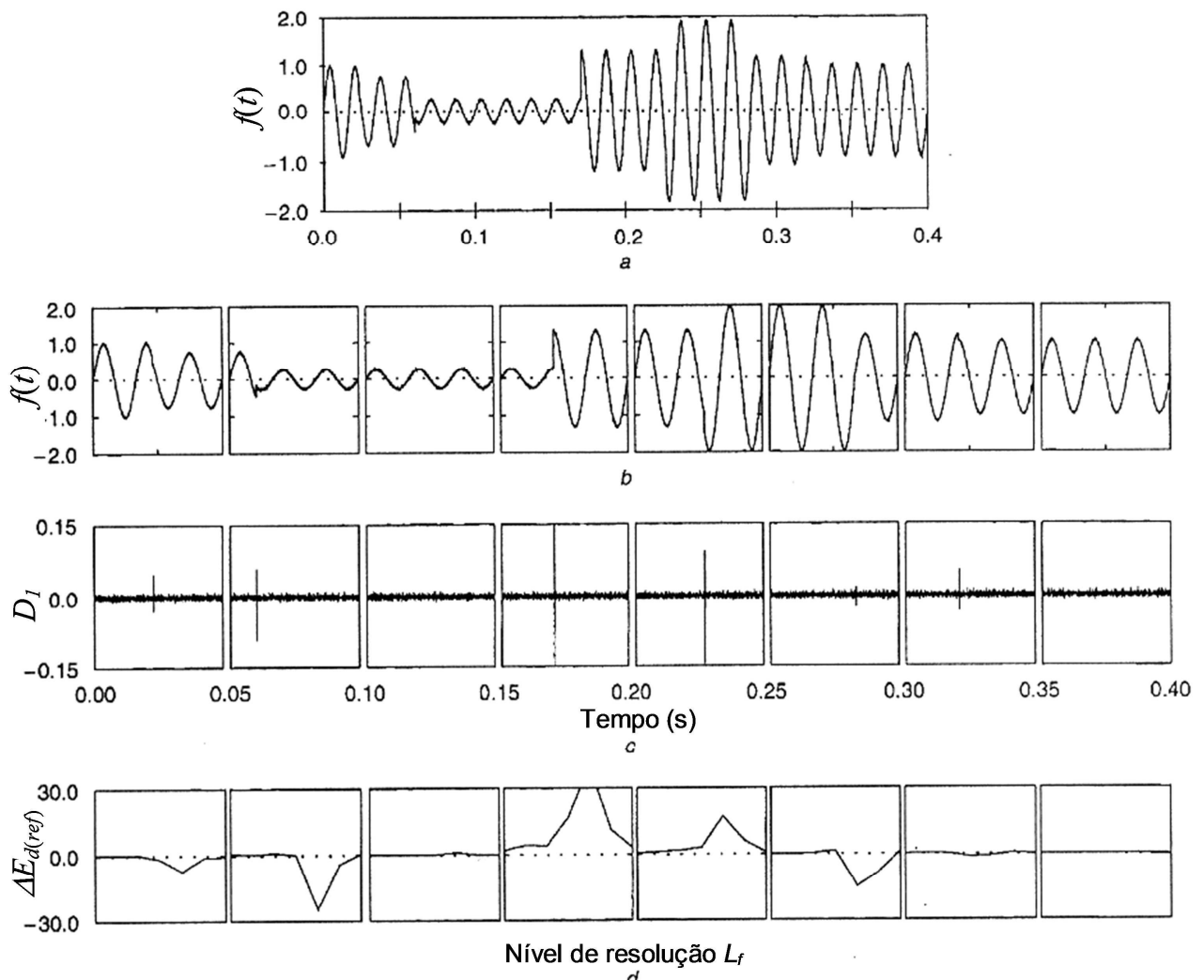

Figura 2.11 - Ilustração de um sinal composto por diversas perturbações e sua representação no domínio wavelet. Adaptado de Gaouda et al., 2002.

Portanto, a partir da utilização desta técnica, diversas distorções nos sinais de medição podem ser detectadas através da utilização dos coeficientes wavelets em diferentes níveis de resolução. A energia associada à distorção em diferentes níveis de resolução é empregada como um vetor discriminante que pode classificar diferentes perturbações. 


\subsection{Detecção de distúrbios em sistemas de distribuição utilizando}

\section{wavelet}

Existem eventos no sistema de distribuição que geram transitórios que são ocasionados pela energização das próprias cargas instaladas no sistema, como por exemplo, a energização de capacitores e o acionamento de máquinas de elevada potência. Nesses casos, mesmo que os distúrbios de tensão ultrapassem momentaneamente os limites normais que foram pré-estabelecidos para as cargas, nenhuma medida operacional é necessária, pois as oscilações são originadas pelas próprias particularidades do sistema.

Contrariamente, no caso de distúrbios de tensão provocados por eventos associados aos diversos tipos de faltas, há então a necessidade de realizar ações operacionais que levem à isolação da mesma. Portanto, a investigação de técnicas que permitam a classificação rápida desses eventos torna-se de suma importância para o incremento da qualidade e confiabilidade do sistema.

O objetivo do método proposto por Karimi et al. (2000) consiste na aplicação de transformadas wavelets para a detecção de distúrbios de tensão em sistemas de distribuição, bem como a identificação do tipo de evento transitório que resultou a respectiva perturbação.

O diagrama de blocos apresentando o esquema de detecção e classificação de distúrbios é ilustrado na Figura 2.12. Esta metodologia é composta por quatro blocos principais, sendo eles a geração do sinal de erro, a análise do sinal de erro usando wavelets, a extração de características e o suporte à decisão. 


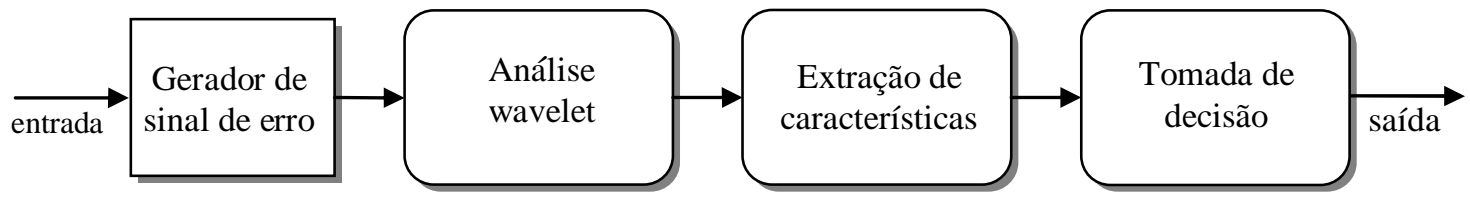

Figura 2.12 - Diagrama de blocos do esquema de detecção proposto.

Adaptado de Karimi et al., 2000.

O bloco dedicado à geração do sinal de erro extrai as distorções superpostas nas tensões medidas, gerando um sinal de erro por intermédio de um filtro adaptativo conforme apresentado na Figura 2.13.

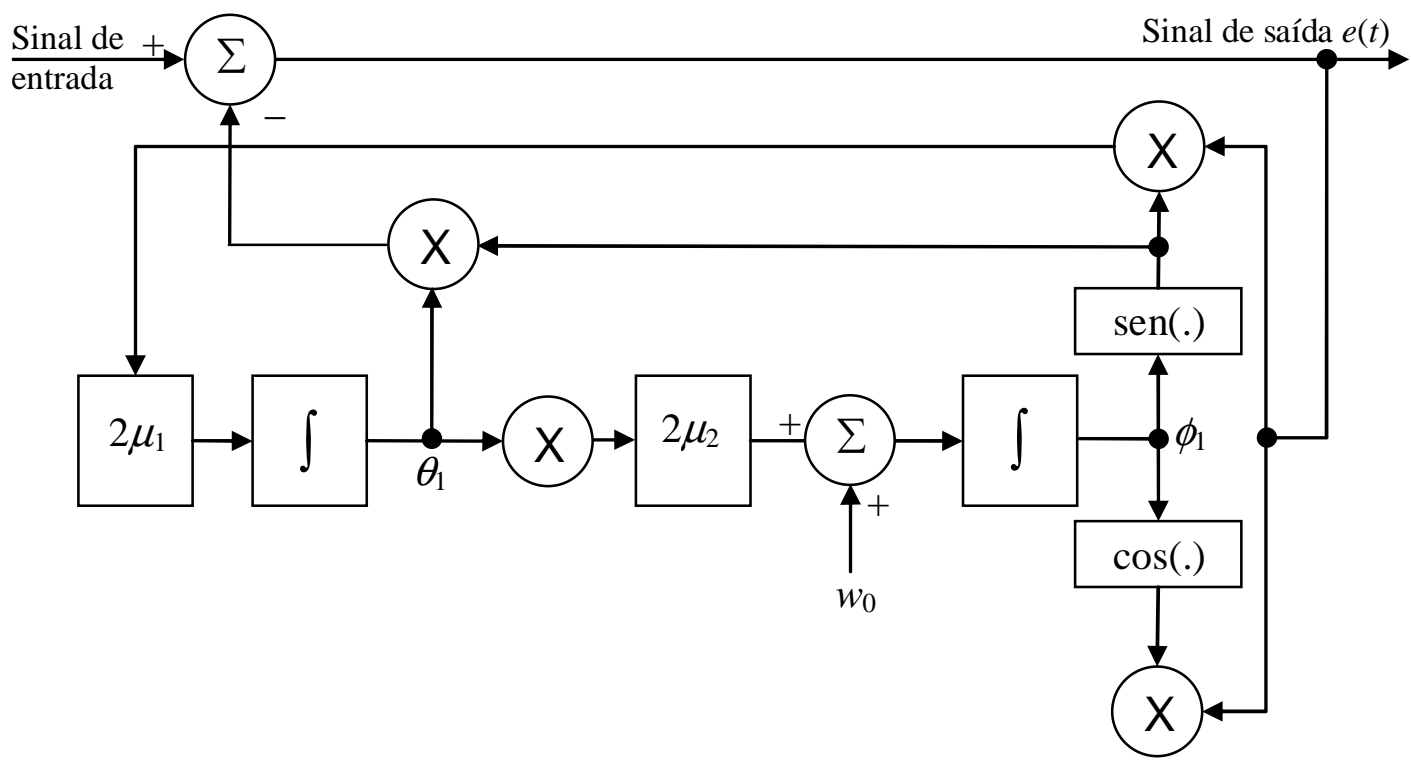

Figura 2.13 - Diagrama de blocos representando o filtro adaptativo.

Adaptado de Karimi et al., 2000.

O filtro rastreia a amplitude $\left(\theta_{1}\right)$ e o ângulo $\left(\phi_{1}\right)$ da componente fundamental do sinal de entrada, sendo o comportamento dinâmico do filtro é descrito por:

$$
\left\{\begin{array}{l}
\dot{\theta}_{1}=-2 \mu_{1} \cdot \sin \left(\phi_{1}\right) \cdot e(t) \\
\dot{\phi}_{1}=-2 \mu_{2} \cdot \theta_{1} \cdot \cos \left(\phi_{1}\right) \cdot e(t)+w_{0}
\end{array}\right.
$$


O sinal de erro e(t) é obtido subtraindo a componente fundamental do sinal de entrada. Esta é a principal vantagem de usar este filtro no algoritmo.

O bloco responsável pela análise por wavelets transforma o sinal de erro em diferentes escalas no domínio da frequência. A Transformada Wavelet fornece informações sobre o conteúdo das frequências de um sinal da mesma forma com que faz a transformada de Fourier. Entretanto, diferentemente da transformada de Fourier, a Transformada Wavelet é capaz de focar componentes de alta frequência em curtos intervalos de tempo, bem como componentes de baixa frequência presentes em longos intervalos. Portanto, torna-se uma ferramenta adequada para análise de transitórios de alta frequência na presença de componentes de baixa frequência.

O objetivo do bloco de extração de características é identificar assinaturas específicas dos diversos tipos de perturbações atuando no sistema. A Transformada Wavelet decompõe o sinal de erro dentro de diferentes escalas de frequência. Cada escala representa o sinal de erro na banda correspondente. O conteúdo de energia dos sinais da escala relativo aos sinais de erro se altera dependendo do tipo de perturbação. Portanto, a amplitude relativa dos sinais da escala com relação ao sinal de erro é selecionada como características discriminantes.

Finalmente, a função do bloco de apoio à decisão é discriminar tipos de distúrbios tão precisamente quanto possível. Uma função probabilidade é definida para as características, e a decisão é realizada utilizando o critério de máxima verossimilhança. Este critério é baseado na maximização da função probabilidade das características. 


\subsection{Modelagem de faltas de alta impedância baseada na teoria de arcos elétricos}

A simulação de chaveamentos de bancos de capacitores em programas como Electromagnetic Transients Program - EMTP e MatLab/SimPowerSystems são bem próximos da realidade e os resultados fornecidos tem um alto grau de precisão quando o sistema é modelado de forma adequada.

No entanto, a modelagem dos fenômenos que simulam o comportamento de faltas de alta impedância é complexa, pois, em função da presença do arco elétrico cuja natureza é bastante complexa e diversa, acarreta em um esforço extra durante a fase de confecção do sistema equivalente.

Desta forma, a investigação de um modelo geral que represente de forma realista a falta de alta impedância é de suma importância para a pesquisa de métodos de detecção de falta de alta impedância, bem como para o projeto de equipamentos de proteção.

Alguns modelos de falta de alta impedância utilizam para propósitos de simulação a inclusão de uma resistência ou modelo de impedância não linear na rede no ponto de falta. O método proposto por Chan et al. (1998) é baseado na teoria de arco voltaico, onde um modelo realista englobando impedância não linear, fonte de tensão variante no tempo, cujos chaveamentos são controlados por um TACS (Transient Analysis Control System) que é empregado com a finalidade de trazer às simulações um maior grau de fidelidade. A Figura 2.14 ilustra o diagrama esquemático do circuito elétrico dedicado à modelagem física do arco elétrico. As chaves 1 e 2 são chaves convencionais com controle temporal que isolam o alimentador da carga conectando-o ao caminho da falta. A chave 3 é uma chave controlada por um TACS que simula a reignição e extinção do arco. 


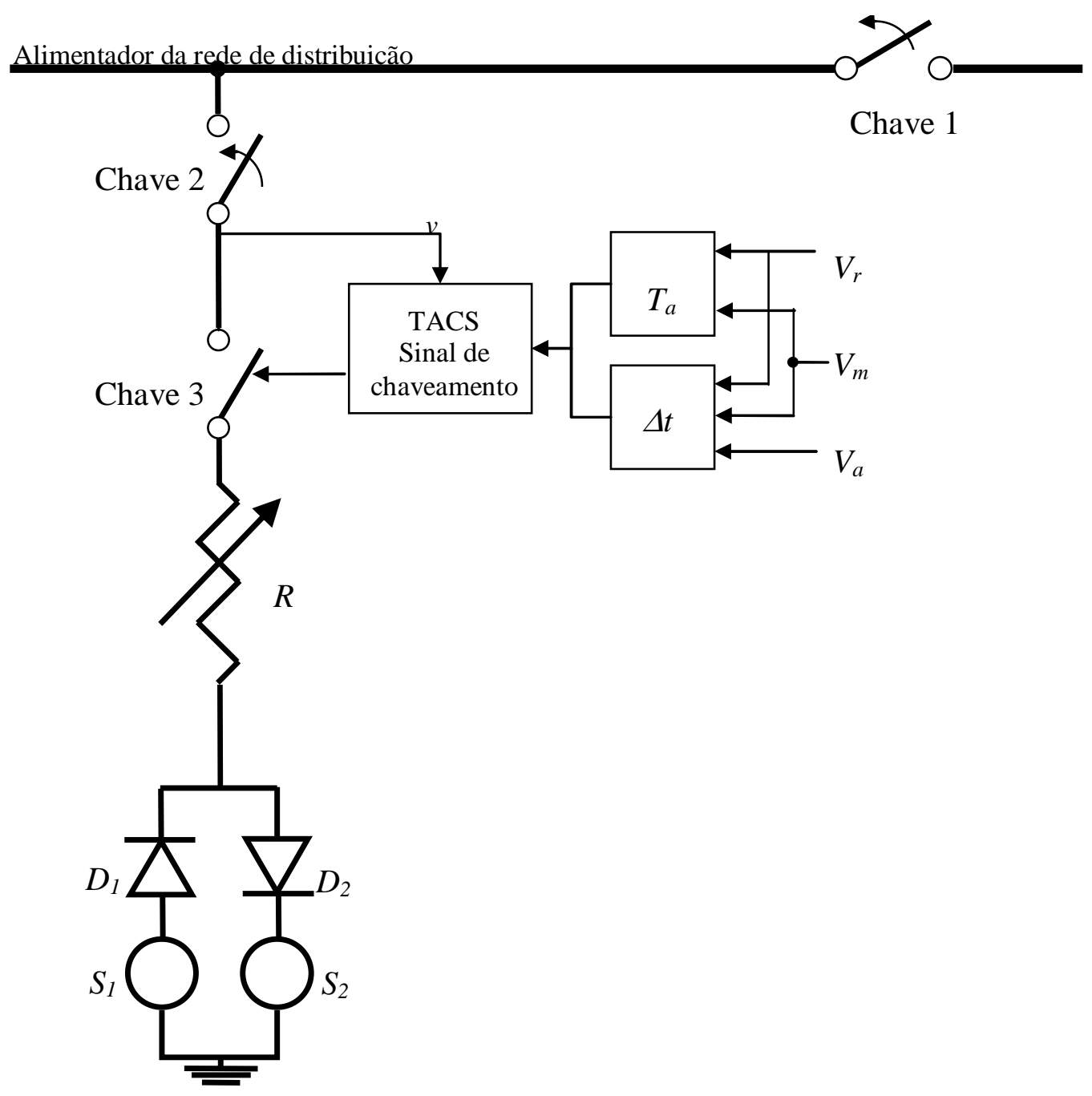

Figura 2.14 - Diagrama de blocos de modelo da falta de alta impedância. Adaptado de Chan et al., 1998.

Sua operação depende da comparação de tempo entre os parâmetros de simulação $T_{a}$ e $\Delta t$. O parâmetro $T_{a}$ é o tempo para a reignição do arco a partir do momento que a tensão aplicada passa por zero e $\Delta t$ é o tempo de condução do arco em meio ciclo, sendo esses parâmetros dados por:

$$
\begin{gathered}
T_{a}=\frac{1}{w} \sin ^{-1} \frac{V_{r}}{V_{m}} \\
\Delta t=\frac{\pi \cdot V_{r}+2 \sqrt{V_{m}^{2}+V_{r}^{2}}}{w \cdot\left(V_{a}+V_{r}\right)}
\end{gathered}
$$


onde $V_{r}$ é a tensão de reignição do arco, $V_{m}$ é o valor de pico da tensão aplicada e $V_{a}$ é a tensão de arco, sendo que a tensão aplicada é assumida como:

$$
v=V_{m} \cdot \sin (w t)
$$

A resistência não linear $R$ controla a magnitude da corrente de falta e é conectada à parte de condução do arco que consiste de dois diodos $D_{1}$ e $D_{2}$ e duas fontes de tensão $S_{1}$ e $S_{2}$. Essas fontes possuem formato de onda tipo dente de serra com linearidade crescente e decrescente, as quais podem representar a característica dinâmica $v-i$ do arco melhor que fontes DC e ajustar a diferença de fase entre a tensão aplicada e a corrente de falta.

\subsection{Localização de faltas por meio de redes neurais artificiais e da transformada de Clarke-Concórdia}

A localização de faltas em sistemas de distribuição de energia elétrica diretamente aterrados pode ser realizada de maneira semelhante à localização de faltas em sistemas de distribuição com alta impedância de aterramento. No entanto, devido às peculiaridades das formas de onda de tensão e corrente, novas técnicas de pré-processamento de sinais devem ser incorporadas.

Dentre as técnicas de pré-processamento usualmente empregadas nos diversos trabalhos verificados junto à bibliografia correlata, destaca-se o emprego da análise fasorial dos sinais em conjunto com Redes Neurais Artificiais (Martins et al., 2002).

No entanto, devido à complexidade do processo de localização de faltas, observa-se a necessidade de se incorporar novas técnicas de processamento às técnicas convencionais. Nesta seção, será apresentada a metodologia de localização de faltas em sistemas de distribuição de energia elétrica diretamente aterrados 
empregando a transformada de Clarke-Concórdia em conjunto com abordagens que empregam a teoria dos autovalores.

A principal vantagem observada quando da aplicação desta técnica reside no fato de que a mesma é imune às interferências harmônicas e de sinais ruidosos uma vez que a localização das faltas é realizada com base na comparação de padrões por meio de uma rede neural artificial do tipo perceptron multicamada.

A Transformada de Clarke constitui-se em uma metodologia para desacoplamento paramétrico para sistemas trifásicos. As duas componentes estacionárias de corrente são denotadas por $\alpha$ e $\beta$. A terceira variável originada desta transformação é conhecida por componente de sequencia zero. A fim de se desenvolver uma metodologia destinada à operação em tempo real de sinais, torna-se conveniente uma alteração da transformada original de Clarke. Dentre as possíveis alterações existentes, destaca-se a Transformada de Clarke-Concórdia (Faria, 2000). O desenvolvimento teórico desta modificação é realizado supondo-se que a componente $\alpha$ da transformada original está sobreposta à corrente da primeira fase do sistema trifásico. Desta maneira, verifica-se que a componente $\beta$ estará atrasada em relação à $\alpha$ de $\pi / 2$ radianos. A matriz de transformação proposta pode então ser definida da seguinte forma:

$$
\boldsymbol{T}_{c}=\sqrt{\frac{2}{3}}\left[\begin{array}{ccc}
1 & -\frac{1}{2} & -\frac{1}{2} \\
0 & \frac{\sqrt{3}}{2} & -\frac{\sqrt{3}}{2} \\
\frac{1}{\sqrt{2}} & \frac{1}{\sqrt{2}} & \frac{1}{\sqrt{2}}
\end{array}\right]
$$

Desta maneira, é possível caracterizar cada um dos estágios de falta por meio da análise das componentes de corrente $i_{\alpha}, i_{\beta}$ e $i_{0}$. Essas componentes de corrente podem ser obtidas por meio da seguinte expressão: 


$$
\left[\begin{array}{l}
i_{\alpha} \\
i_{\beta} \\
i_{0}
\end{array}\right]=\mathbf{T}_{\mathbf{c}}\left[\begin{array}{l}
i_{1} \\
i_{2} \\
i_{3}
\end{array}\right]
$$

onde $i_{1}, i_{2}$ e $i_{3}$ são respectivamente as correntes de cada uma das fases do sistema de distribuição.

Com a finalidade de se extrair as principais características das componentes $i_{\alpha}$, $i_{\beta}$ e $i_{0}$ é conveniente a análise dos autovetores e autovalores da matriz de correlação de dados.

A arquitetura neural proposta nesta seção para localização de faltas possui como entradas os autovalores da matriz de correlação, bem como o tipo de falta identificado durante a fase de pré-processamento dos sinais. O diagrama esquemático da estrutura neural sugerida é apresentado na Figura 2.15.

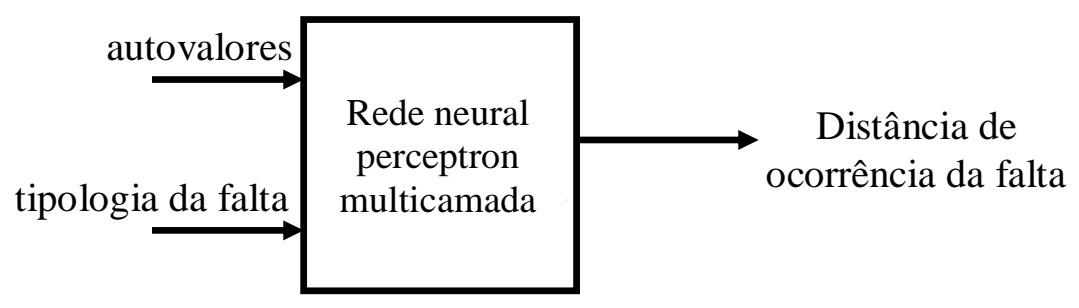

Figura 2.15 - Diagrama esquemático do sistema de localização de faltas por meio de redes neurais artificiais. Adaptado de Faria., 2000.

Para ilustrar a variação da distância de falta em função dos autovalores para diferentes tipos de falta, a Figura 2.16 apresenta o gráfico da distância em função dos autovalores. 


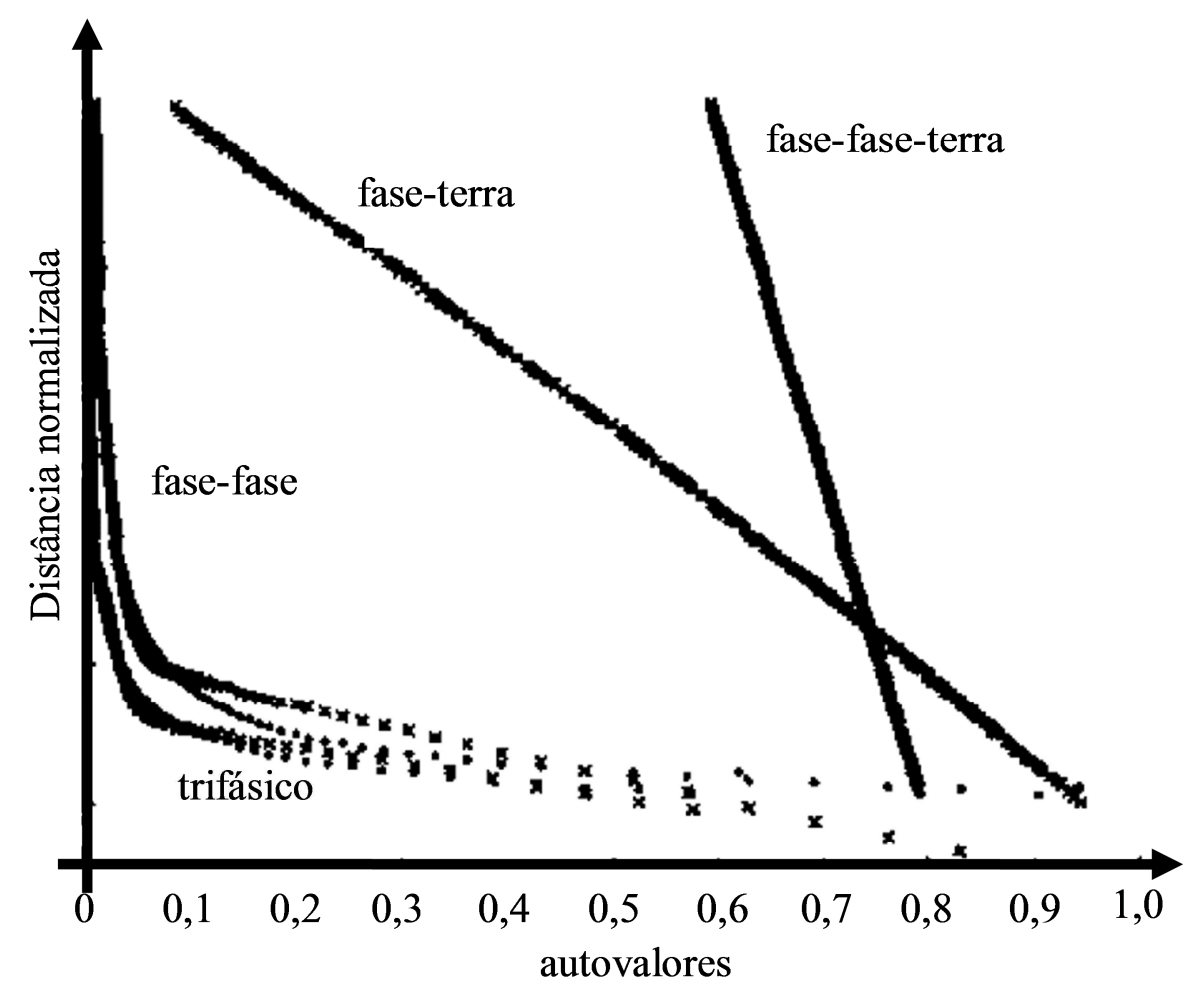

Figura 2.16 - Distância de falta em função dos autovalores. Adaptado de Faria., 2000.

\subsection{Tratamento automatizado de faltas em linhas de distribuição}

Nesta seção é apresentada uma nova estratégia de gerenciamento de faltas em sistemas de distribuição, usando informações vindas dos diversos dispositivos instalados no circuito, realizando-se assim uma coordenação entre os mesmos.

O método tradicional para o tratamento de uma falta em uma linha de distribuição é por tentativa e erro, onde as seções dos alimentadores são energizadas uma a uma até que nenhum sinal de falta seja identificado pelos relés. Através de disjuntores e chaves seccionadoras, consegue-se este tipo de operação que na maioria das vezes ocorre de forma manual. Nestas situações a localização rápida e precisa da falta diminui o tempo em que o sistema fica desenergizado.

Com a introdução de relés numéricos e também da comunicação entre os dispositivos, tornou-se possível melhorar a resposta do sistema frente a uma falta. No entanto, há uma forte discussão entre os pesquisadores no sentido de que o comando 
final na proteção dos sistemas de distribuição deve ficar a cargo de um operador especialista ou totalmente automatizado. Tal ceticismo por parte das metodologias totalmente automatizadas se deve à grande dificuldade em se adaptar os diversos sistemas de controle às peculiaridades de cada circuito de distribuição.

O modelo de tratamento de faltas investigado por Lehtonen et al. (2000) adota uma postura totalmente automatizada para localização de faltas, isolamento dos setores faltosos e restauração do fornecimento de energia. Para tal, o modelo computacional trabalha integrado ao sistema SCADA e também com os dispositivos de automatização de um sistema de distribuição georeferenciado.

O tratamento das faltas neste modelo se inicia pela etapa de localização da mesma, que é realizada por meio de três técnicas distintas. Após a ocorrência de uma falta, valores de correntes medidos são confrontados com valores armazenados para estimar o ponto em que a mesma ocorreu. Em seguida, tais informações são confrontadas com os sinais enviados pelos Indicadores de Faltas instalados ao longo do alimentador e que possuem capacidade de comunicação. Visando refinar a resposta, utiliza-se das informações estatísticas sobre a ocorrência de faltas nos trechos identificados pelo software de localização e pelos Indicadores de Faltas.

Os setores faltosos são automaticamente isolados por meio de chaves acionadas por controle remoto. Os setores não afetados pela falta são então energizados. Durante o processo de restabelecimento são efetuados cálculos para se determinar a capacidade real de fornecimento do sistema após a falta, bem como os limites térmicos das linhas com base no carregamento do circuito. A integração do modelo com o sistema SCADA pode ser observada na Figura 2.17. 


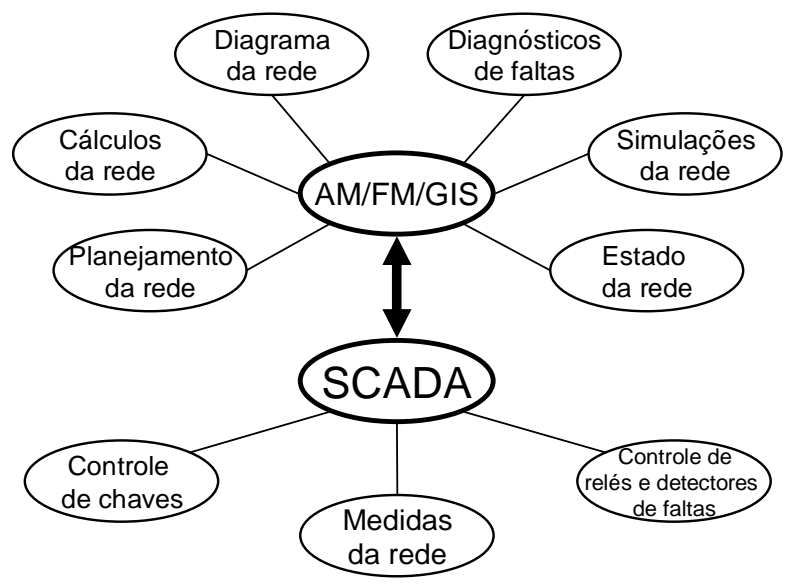

Figura 2.17 - Modelo computacional para automatização do tratamento de faltas em sistemas de distribuição. Adaptado de Lehtonen et al., 2000.

O sistema AM/FM/GIS (Automated Mapping, Facilities Management and Geographic Information System) é responsável por realizar diversas tarefas no processo de automatização, indo desde a estimação do estado atual da rede até os cálculos envolvendo os diagnósticos das faltas. Este sistema tem comunicação bidirecional com o SCADA, que recolhe informações vindas dos dispositivos, tais como chaves, disjuntores, medidas diversas da rede e o controle sobre os dispositivos que detectam as faltas.

Neste modelo automatizado até mesmo o fato de parte da rede possuir indicadores de falta, e parte não possuir, é levado em consideração, modelando-se matematicamente as zonas de atuação. O principal benefício para a automatização da isolação de uma falta é a diminuição de custo ao consumidor. Além de reduzir o número de seguidas interrupções em consequência da localização errônea de uma falta.

Outra aplicação envolvendo a integração do sistema SCADA para automação do tratamento de faltas pode ser contemplada em Tannlund e Bjorkman (2000). Nesta aplicação é descrito um sistema de distribuição de energia automatizado que adota, dentre outros parâmetros, a utilização de Indicadores de Faltas instalados em determinados ramos do sistema para tomada de decisão. 
Nesta mesma linha de pesquisa é possível se encontrar trabalhos que utilizam sistemas computacionais para automatização de procedimentos envolvendo localização de faltas fundamentados em computadores pessoais (Choi et al., 1999), como é o caso do KODAS (Sistema Automático de Distribuição da Coréia) (Cho E Há, 1998).

\subsection{Considerações parciais}

Abordando a pesquisa bibliográfica realizada em bases técnico-científicas em busca de trabalhos que contemplem metodologias de detecção de faltas em sistemas de distribuição, constata-se aqui o empenho de pesquisadores de vários países em se solucionar o problema.

De fato, o problema é complexo e apresenta inúmeros desafios, principalmente quanto à generalidade da ferramenta a ser desenvolvida, frente às mais variadas situações de carga e faltas inerentes aos sistemas de distribuição. Sua complexidade também se reflete nos poucos trabalhos relevantes que são encontrados, em que houve realmente a implementação prática em sistemas de distribuição reais. 



\section{Propostas Modernas para Detecção de Faltas em Sistemas de Distribuição}

\subsection{Introdução}

Ao longo do Capítulo 2 foram apresentadas diversas abordagens já consideradas clássicas, propostas em literatura técnico-científica, para agregar confiabilidade no processo de detecção de faltas. Apesar de se observar um grande número de aplicações, vindas de diversos países, destaca-se um número limitado de trabalhos que realmente são promissores e passíveis de agregação de valores para o objetivo final desta tese.

A seguir será apresentada uma coleção de trabalhos científicos mais contemporâneos que propõem metodologias para a identificação e localização de faltas, sendo que as mesmas foram divididas em "Propostas Convencionais" e "Propostas Inteligentes".

\subsection{Propostas convencionais para a detecção de faltas}

As técnicas convencionais para a detecção de faltas em sistemas de distribuição têm contribuído de maneira interessante, especialmente na etapa de pré-processamento dos dados e correlações feitas com informações sobre a arquitetura dos alimentadores e medições tomadas da rede. 


\subsubsection{Localização de faltas em sistemas de distribuição utilizando análise multiresolução de transformadas wavelets}

Analisando-se a literatura correlata às técnicas de localização de faltas em sistemas de distribuição de energia elétrica, verifica-se que grande parte destas faz uso das Transformadas Wavelet durante a etapa de pré-processamento dos dados, com o intuito de extrair (do sinal original) características que possam ser empregadas durante o processo de localização da falta. Desta forma, cabe comentar que em um dos trabalhos mais promissores e recentes da área (Borghetti et al., 2010), os autores realizam uma decomposição Multiresolução Wavelet (tempofrequência) sobre os sinais transitórios que estão associados com as ondas viajantes provenientes da falta.

A análise no domínio do tempo e da frequência através de decomposição Wavelet foi empregada para melhorar a precisão de identificação das frequências associadas com os padrões de localização de faltas utilizados nas análises no domínio da frequência apenas.

Durante a etapa de testes do método, os autores desenvolveram uma configuração laboratorial de forma a simular um modelo reduzido de um alimentador monofásico. Neste ensaio, foram empregados cabos do tipo blindado, um gerador de função (representando a fonte de alimentação), um osciloscópio para adquirir e armazenar as medidas, além de uma placa de entrada/saída de alta velocidade (gera a falta no sistema). Entretanto, duas topologias distintas foram configuradas para que os testes fossem devidamente realizados. Nas Figura 3.1 e Figura 3.2, podem-se visualizar ambas as topologias, as quais foram desenvolvidas mantendose um fator de escala 1:50. 


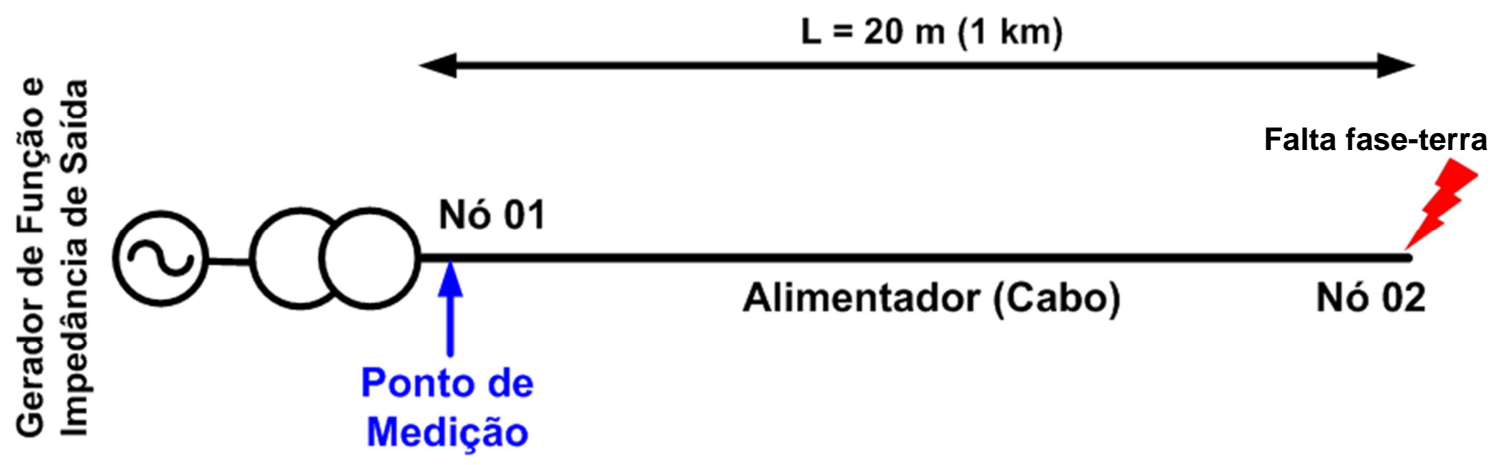

Figura 3.1 - Modelo reduzido representativo da Topologia 1, a qual possui somente 0 alimentador principal.

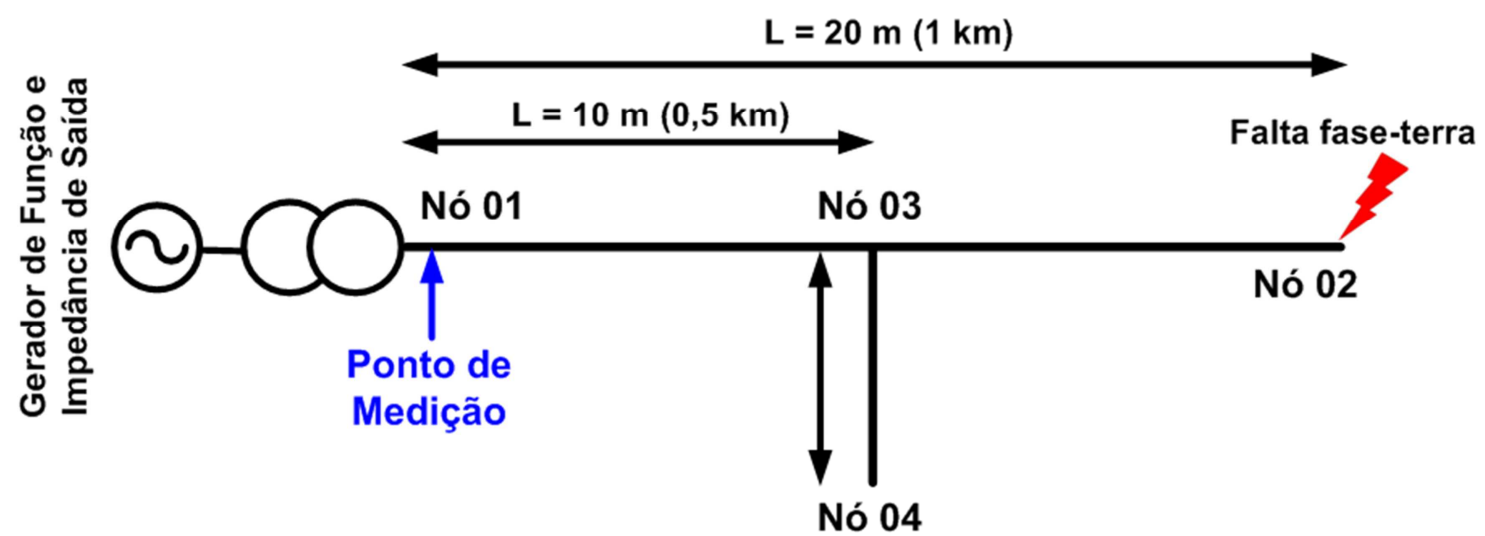

Figura 3.2 - Modelo reduzido representativo da Topologia 2, a qual possui tanto o alimentador principal como um ramo lateral.

Após configurar as topologias de rede previamente apresentadas, as faltas foram geradas e obtidas as formas de onda por meio do osciloscópio alocado no "ponto de medição" destacado nas Figura 3.1 e Figura 3.2. Destas medições, puderam-se observar as formas de onda apresentadas respectivamente pela Figura 3.3 e Figura 3.4 . 


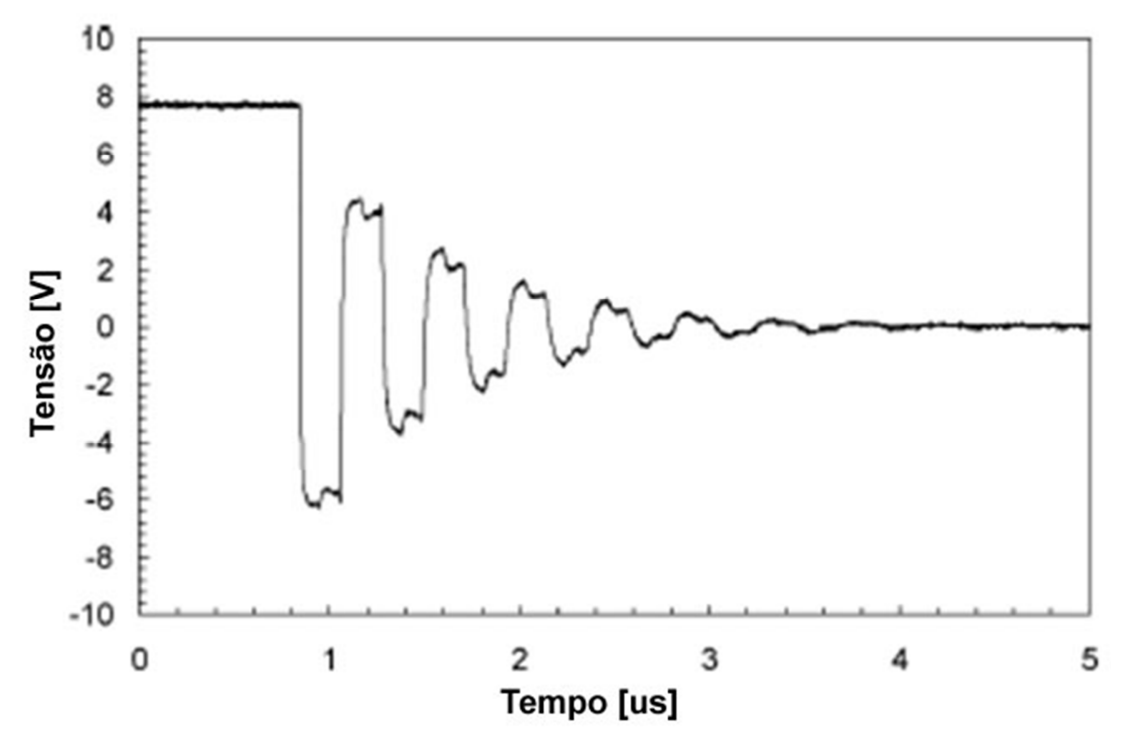

Figura 3.3 - Forma de onda obtida quando da ocorrência de uma falta na Topologia 1.

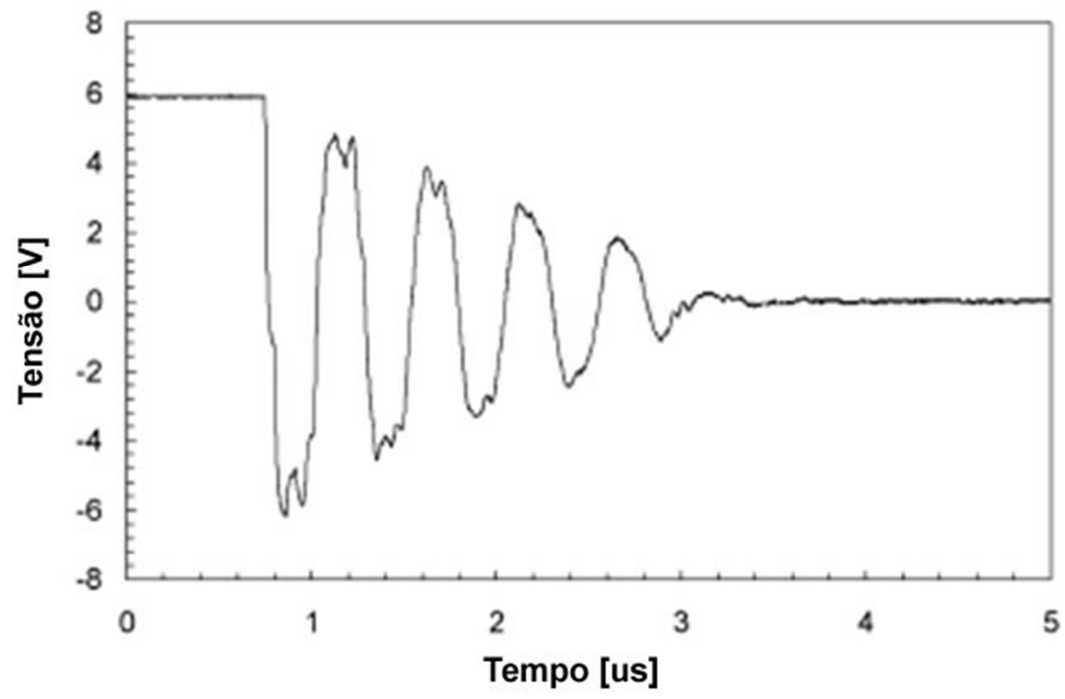

Figura 3.4 - Forma de onda obtida quando da ocorrência de uma falta na Topologia 2.

Cabe comentar que depois de realizados os primeiros testes, verificou-se a integridade da simulação em termos do sinal medido após a falta. Assim, toda a metodologia proposta foi aplicada para verificar a eficácia de tal método. Somente após todos estes testes, a metodologia proposta foi aplicada a dados reais de faltas ocorridas em sistemas de distribuição de energia elétrica. 
O método proposto neste trabalho foi dividido em duas etapas, sendo que na primeira se realiza a estimação inicial das frequências das ondas viajantes por meio de:

$$
f_{p}=\frac{V}{n_{p} L_{p}}
$$

sendo que $V$ é a velocidade de propagação da onda viajante; $n_{p}$ é o número de vezes que a onda viajante se propaga pelo trecho $p$; e $L_{p}$ é o comprimento do trecho p.

A partir desta estimativa inicial das frequências, inicializa-se a segunda etapa, onde a finalidade é melhorar a estimação inicial mediante o uso da Transformada Wavelet. Por meio desta etapa, além de melhorar a estimação das frequências, também se obtém uma faixa de frequências que delimita a frequência obtida durante a correção da estimativa inicial. Portanto, pode-se dizer que a frequência característica para determinada falta encontra-se dentro desta faixa de frequências.

Os resultados obtidos quando da aplicação desta metodologia sobre o modelo reduzido de alimentador foram considerados satisfatórios, pois, conforme mostrado na Tabela 3.1 , os valores das frequências das ondas viajantes obtidas pelo método proposto são bastante próximas às frequências reais das ondas viajantes geradas após a falta.

Tabela 3.1 - Resultados obtidos com a aplicação do método proposto sobre faltas geradas no modelo reduzido de alimentador (Topologia 2).

\begin{tabular}{|c|c|c|}
\hline Trecho & $\begin{array}{c}\text { Frequência obtida pelo } \\
\text { método (MHz) }\end{array}$ & $\begin{array}{c}\text { Frequência de } \\
\text { Referência (MHz) }\end{array}$ \\
\hline Nó 01-02 & 2,233 & 1,980 \\
\hline Nó 01-03 & 4,465 & 3,922 \\
\hline Nó 01-04 & 5,953 & 5,844 \\
\hline
\end{tabular}


Cabe comentar que, após a aplicação da estimação inicial de frequência, o erro encontrado com relação à frequência de referência era de 11,3\% e, após a aplicação da etapa 2 do método, a correção da frequência apresentou boa eficiência e pôde ser observada a queda do erro da estimação de frequência que atingiu 8,6\%.

Portanto, garantindo-se tal eficiência, o método foi aplicado a dados reais de um sistema de distribuição. Assim, observaram-se as seguintes respostas com relação às estimações de frequências (Tabela 3.2).

Tabela 3.2 - Resultados obtidos com a aplicação do método proposto sobre dados reais de faltas.

\begin{tabular}{|c|c|c|}
\hline Trecho & $\begin{array}{c}\text { Frequência obtida pelo } \\
\text { método (MHz) }\end{array}$ & $\begin{array}{c}\text { Frequência de } \\
\text { Referência (MHz) }\end{array}$ \\
\hline Nó 01-02 & 52,65 & 50,25 \\
\hline Nó 01-03 & 41,88 & 38,35 \\
\hline Nó 01-04 & 62,81 & 62,10 \\
\hline Nó 01-05 & 25,35 & 25,95 \\
\hline Nó 01-06 & 16,28 & 18,25 \\
\hline Nó 01-07 & 15,35 & 13,40 \\
\hline Nó 01-08 & 11,44 & \\
\hline
\end{tabular}

Conforme pode ser visualizado na Tabela 3.2, a estimação das frequências pode ser considerada satisfatória para dados reais e que, para os trechos entre os nós 01-07 e 01-08, observou-se uma mesma estimativa de frequências. Portanto, o método proposto identificou que a falta encontra-se localizada entre os nós 07 e 08. Desta forma, tal metodologia é considerada promissora para o propósito da localização de faltas em sistemas de distribuição de energia elétrica, a qual identifica de forma consistente o trecho de linha que sofreu a falta. Entretanto, a metodologia foi testada somente em um alimentador com dimensões bem reduzidas, a qual pode se tornar ineficiente para alimentadores maiores. 


\subsubsection{Metodologia de localização de faltas baseada na arquitetura do alimentador e medidas tomadas na subestação}

Além da metodologia supracitada, também podem ser encontrados atualmente na literatura correlata outros tipos de localizadores de faltas promissores. Desta forma, dois autores (Mirzai e Afzalian, 2010) desenvolveram um novo sistema de localização de falta para sistemas de distribuição radiais, o qual se baseia na arquitetura do alimentador e nas medidas de tensão e corrente realizada na subestação.

O algoritmo proposto determina a localização da falta levando-se em consideração a característica de variação do carregamento da rede, condição de desbalanceamento e a natureza assimétrica do alimentador. Neste trabalho, os autores mostram que a variação do carregamento da rede afeta significativamente a precisão do sistema de localização de falta. De forma a contornar tal problema, realiza-se a estimação do carregamento em tempo-real a fim de garantir uma minimização do erro entre a localização da falta calculada e a localização real da falta (valor de referência).

Com o intuito de mostrar a eficácia da metodologia proposta, os autores realizaram testes sobre dados reais de sistemas de distribuição radiais.

Conforme comentado previamente, a metodologia empregada necessita a priori dos valores de carregamento atual do sistema. Assim, a primeira etapa do método é a estimação do carregamento antes da ocorrência da falta. Portanto, este método deve ser implementado junto ao fluxo de carga do sistema de distribuição, onde são calculadas as variações de carregamento com base nos valores de préfalta e na configuração do alimentador. Desta forma, podem-se calcular também os 
valores das impedâncias do sistema durante a pré-falta e que será utilizada durante a etapa de localização da falta.

O carregamento da rede foi considerado como impedância constante e a variação deste carregamento foi calculada por meio da Lei de Kirchhoff das Tensões.

Após esta primeira etapa, deve-se executar então o algoritmo de localização de falta, o qual se baseia no cálculo do funcional (derivadas parciais). Por meio deste cálculo obtém-se o valor da distância entre a subestação e a falta. Entretanto, devido ao sistema de distribuição possuir diversos ramos (característica radial do alimentador), o algoritmo de localização de falta pode fornecer como resposta múltiplos ramos como pontos de ocorrência da falta. Com o intuito de sobrepor este problema, realiza-se uma análise da assimetria dos ramos laterais.

De forma a garantir o bom funcionamento e a validação da metodologia proposta, foram realizados testes iniciais sobre um sistema simulado por meio do software ATP (Alternative Transients Program). Os resultados obtidos para alguns destes testes são apresentados na Tabela 3.3, onde são mostrados apenas testes para faltas fase-terra. No entanto, os autores comentam que os resultados para os demais tipos de faltas são similares.

Tabela 3.3 - Resultados obtidos para faltas fase-terra geradas no início do alimentador.

\begin{tabular}{|c|c|c|}
\hline Caso & $\begin{array}{c}\text { Distância obtida pelo } \\
\text { método }(\mathbf{m})\end{array}$ & $\begin{array}{c}\text { Distância de } \\
\text { Referência }(\mathbf{m})\end{array}$ \\
\hline 01 & 4347,5 & 4342,0 \\
\hline 02 & 5324,6 & 5317,0 \\
\hline 03 & 5938,0 & 5929,0 \\
\hline 04 & 6577,8 & 6558,0 \\
\hline 05 & 7048,0 & 7029,0 \\
\hline 06 & 8480,2 & 8455,0 \\
\hline 07 & 8775,2 & 8750,0 \\
\hline 08 & 9534,3 & 9506,0 \\
\hline 09 & 10997,9 & 10969,0 \\
\hline 10 & 13098,5 & 13098,5 \\
\hline
\end{tabular}


Os resultados supracitados também foram analisados quanto à variação no carregamento do sistema e quanto ao aumento da distância. No caso da variação do carregamento, verificou-se que o erro somente torna-se maior do que $1 \%$ quando o carregamento varia em torno de $100 \%$ de seu valor nominal. Com relação à variação da distância, o erro somente atingiu 1\% após uma distância de $14 \mathrm{~km}$ entre a subestação e o ponto de falta.

Verificados os resultados da metodologia sobre o sistema de distribuição simulado, houve a necessidade de se realizar testes sobre dados reais de sistema de distribuição radiais. Estes resultados podem ser visualizados por meio da Tabela 3.4 .

Tabela 3.4 - Resultados obtidos para diversos tipos de faltas ocorridas em um sistema de distribuição real.

\begin{tabular}{|c|c|c|}
\hline Tipo de Falta & $\begin{array}{c}\text { Distância obtida pelo } \\
\text { método }(\mathbf{m})\end{array}$ & $\begin{array}{c}\text { Distância de } \\
\text { Referência }(\mathbf{m})\end{array}$ \\
\hline Fase-terra & 8003 & 8173 \\
\hline Fase-terra & 10708 & 11074 \\
\hline Fase-terra & 5109 & 5200 \\
\hline Fase-Fase-terra & 4735 & 4816 \\
\hline Fase-Fase & 4505 & 4580 \\
\hline Trifásica & 5973 & 6090 \\
\hline
\end{tabular}

Conforme mostrado pelos autores, os resultados obtidos com a metodologia proposta são satisfatórios. Entretanto, faz-se extremamente necessária a obtenção dos valores de carregamento no momento pré-falta para que se possa ser calculada a impedância do sistema no momento que precede a falta, o qual pode prejudicar o algoritmo de localização de falta caso apresente valores incoerentes.

\subsection{Propostas inteligentes para a detecção de faltas}

Em literatura científica a respeito da detecção de faltas constata-se uma utilização crescente de ferramentas pertencentes à classe de sistemas inteligentes. 
Isto porque determinados tipos de faltas, especialmente aquelas de alta-impedância, são de extrema dificuldade de mapeamento (Mora-Florez et al., 2003).

A seguir, serão apresentados alguns artigos que constituem contribuições pertinentes ao desenvolvimento deste trabalho, especialmente pela combinação de ferramentas de processamento de sinais com Redes Neurais Artificiais e sistemas fuzzy, sendo, aliás, tais associações uma tônica para a garantia de sucesso no processo de detecção de faltas.

\subsubsection{Estratégia para localização de faltas monofásicas em sistemas de distribuição utilizando sistemas fuzzy, wavelets e FFT}

O trabalho de Mora-Florez et al. (2008) contribui com um algoritmo de classificação estatística fundamentado em funções de probabilidades fuzzy para localizar faltas monofásicas em sistemas de distribuição, esse trabalho realiza uma combinação interessante de ferramentas para se garantir a localização de seções faltosas em um sistema de distribuição da Colômbia.

As maiores contribuições desta proposta advêm da percepção estatística dos autores com relação às variáveis elétricas passíveis de serem mensuradas do ponto de vista da subestação de distribuição, tomando leituras de correntes vindas de TC's (transformadores de corrente) e tensões vindas de TP's (transformadores de potencial).

Os autores combinaram uma variante de sistemas fuzzy para uso estatístico, transformadas Wavelet e Transformada Rápida de Fourier (FFT), aplicando tais ferramentas em um sistema automatizado de simulações envolvendo o Matlab e o ATP. Destaca-se também esta associação Matlab/ATP como uma interessante contribuição, pois permitem realizar simulações tão aderentes ao real 
comportamento de um alimentador quanto forem precisas as informações na base de dados de circuitos de distribuição.

A justificativa dos autores em se empregar uma ferramenta inteligente no processo de detecção de faltas se dá ao fato de que métodos convencionais estimam a distância do provável local da falta através da impedância calculada a partir do transitório de curto-circuito, e inicia-se então um procedimento de busca pela região faltosa.

Tal linha de raciocínio esbarra no fato de que múltiplas regiões do alimentador podem apresentar características similares de impedância, consequentemente, tem-se um problema de multi-estimação da região faltosa.

Para exemplificar a dificuldade da estimação da impedância para a localização de faltas, tem-se na Figura 3.5 uma representação de um circuito de distribuição relativamente pequeno, onde os dados de uma falta permitiram estimar uma impedância. Como resultado destes cálculos, tem-se quatro regiões candidatas ao local da falta, como destacado pelas setas em amarelo. 


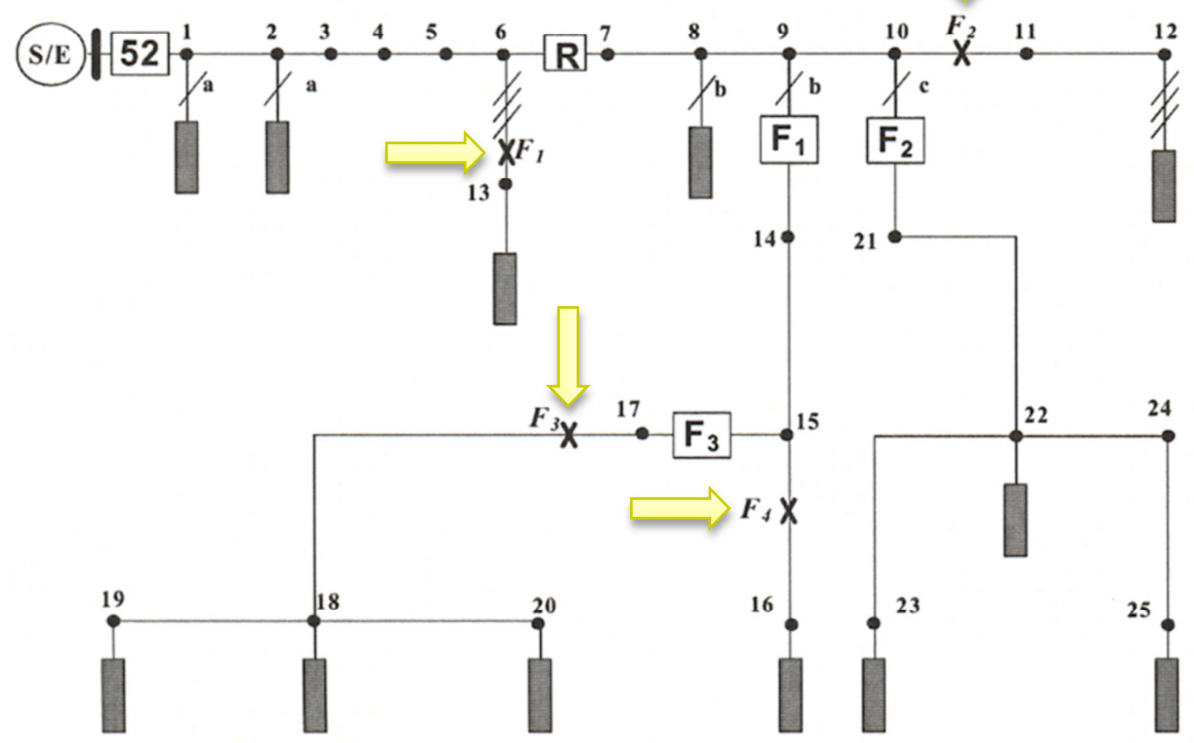

Figura 3.5 - Métodos convencionais de busca da região faltosa. Adaptado de Mora-Florez et al., 2008.

Mesmo reduzindo para quatro possíveis seções, é possível observar que se trata de um alimentador pequeno e com poucos ramais, sendo assim a estimação da impedância, uma metodologia ineficiente ao se pensar em alimentadores maiores.

Para então contornar as deficiências dos métodos convencionais de localização de faltas, os autores propuseram um sistema inteligente combinado com ferramentas de processamento de sinais, a fim de estimar a localização de faltas em linhas de distribuição. Utilizaram diversas variáveis e operações sobre elas, sendo as mesmas descritas a seguir:

$\Delta V$ - Variação da magnitude da tensão: esta variável está associada ao valor eficaz em regime permanente da tensão antes e durante a ocorrência de uma falta;

$\Delta \mathrm{l}$ - Variação da corrente: esta variável está associada ao valor eficaz em regime permanente da corrente antes e durante a ocorrência de uma falta; 
$\Delta S$ - Variação da potência aparente: esta variável está associada às variações de carga antes e durante as situações de falta. Mudanças na potência aparente em condições faltosas ajudam a delinear quais tipos de cargas foram afetadas, devido a mudanças no fator de potência;

> Xf - Reatância da falta: normalmente utiliza-se a impedância de falta como sendo resistiva, mas a reatância da falta fornece informações mais precisas e que se relacionam melhor com o local da falta;

F - Frequência do sinal de tensão transitório provocado pela falta: a frequência da tensão transitória durante a falta relaciona-se diretamente com os parâmetros capacitivos e indutivos do circuito remanescente, podendo ser associada à distância da falta.

Como resultado da escolha destas variáveis e da combinação de ferramentas, os autores obtiveram uma assertividade de $100 \%$ na identificação da fase envolvida na falta. Já a localização da região faltosa apresentou um erro de pouco menos de $4 \%$.

Obviamente, destaca-se a combinação de ferramentas inteligentes e convencionais como fatores preponderantes aos bons resultados obtidos para a resolução do problema proposto. Entretanto, os autores exploraram apenas um tipo de falta e, apesar de mencionarem uma metodologia automatizada de simulações, fora utilizado o circuito equivalente de um alimentador de distribuição de $25 \mathrm{kV}$.

\subsubsection{Localização de faltas de alta-impedância em alimentadores de distribuição com geração distribuída}

A presença de geração distribuída é uma preocupação que se encontra presente na maioria dos trabalhos que empregam sistemas inteligentes na 
identificação e localização de faltas em alimentadores de distribuição, pois os relés atuais produzem erros significativos de detecção de faltas de alta impedância em alimentadores com geração distribuída (Bretas et al., 2006).

Bretas et al. (2006) utilizam Redes Neurais Artificiais e particularidades das faltas de alta impedância para localizar as regiões faltosas, investigando-se a magnitude e fase da corrente de falta até a $5^{\underline{a}}$ harmônica.

Estudos apontam que é possível se modelar as faltas de alta-impedância como sendo duas fontes $\mathrm{CC}$ em série com diodos, conforme ilustrado na Figura 3.6. Durante o semiciclo positivo, a corrente flui através de $V_{P}$ e, durante a fase negativa, por meio de $V_{N}$. As harmônicas geradas pelas faltas são funções da diferença $V_{N}-V_{P}$ e da relação $X_{L} / R$.

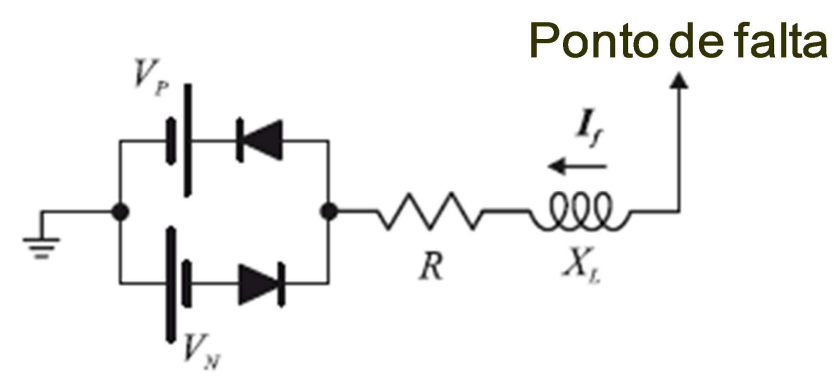

Figura 3.6 - Modelo de uma falta de alta-impedância. Adaptado de Bretas et al., 2006.

A metodologia proposta utiliza dados adquiridos em tempo real e processados de maneira que a falta possa ser detectada e localizada através da extração de características das tensões e correntes medidas na subestação.

O esquema é fundamentado no cálculo de componentes simétricas dos sinais harmônicos de corrente no ponto de conexão do relé. A metodologia combina a magnitude da $3^{a}$ harmônica, diferença angular entre a $3^{\text {a }}$ harmônica de corrente e a componente fundamental de tensão, computando-se a passagem por zero. Complementando as variáveis de entrada, tensões e correntes vindas do TP e TC da 
subestação são processadas para se estimar $2^{\underline{a}}$, $3^{\underline{a}}$ e $5^{\underline{a}}$ harmônicas. As componentes de $1^{1}$ a $2^{\underline{a}}, 3^{\underline{a}}$ e $5^{\underline{a}}$ harmônicas alimentam uma Rede Neural responsável por identificar e classificar faltas fase-fase e fase-terra. A saída da Rede Neural Artificial é a detecção e localização da falta.

O sistema de distribuição investigado encontra-se ilustrado na Figura 3.7.

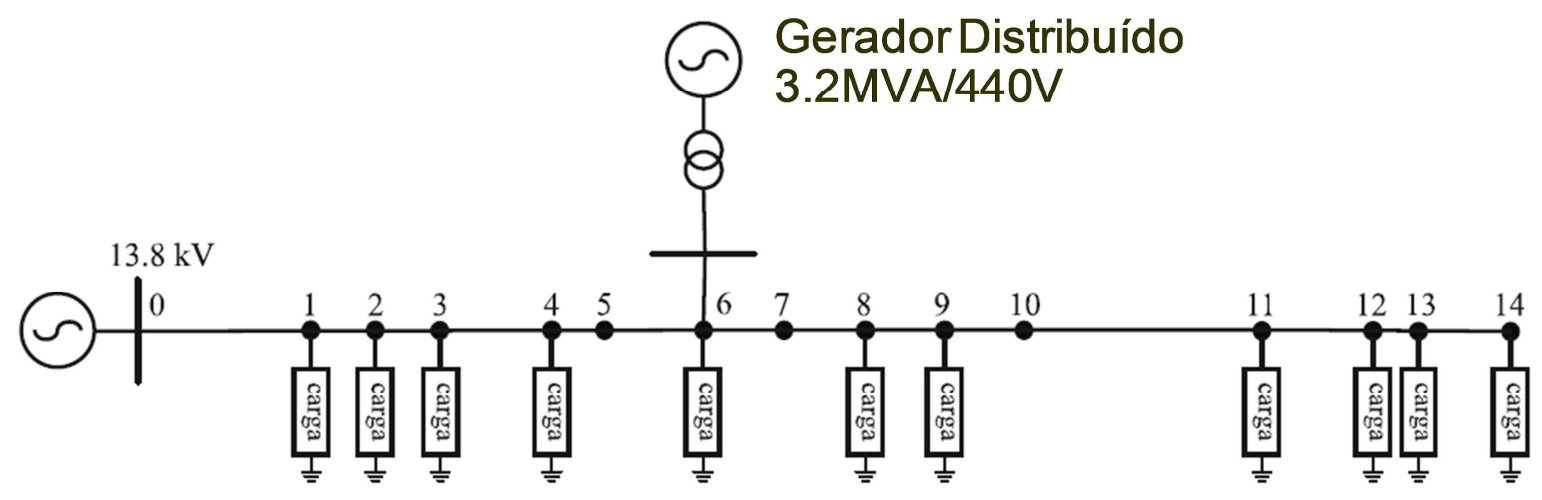

Figura 3.7 - Sistema de distribuição com geração distribuída. Adaptado de Bretas et al., 2006.

Na barra de número 6 do alimentador de estudo encontra-se conectado o gerador distribuído. É possível destacar que os procedimentos de simulações dos autores não conseguem reproduzir todos os detalhes do alimentador, sendo o mesmo representado através de circuito equivalente.

$\mathrm{Na}$ identificação de faltas de alta-impedância com geração distribuída, o método proposto apresentou $95 \%$ de acertos e o mesmo foi comparado com um convencional que apresentou $60 \%$ de acertos.

A localização da região faltosa apresentou um erro médio de $1 \%$ do comprimento total do alimentador, sendo a resposta da ferramenta a distância da falta até a subestação.

Os autores apresentam um estudo do impacto da geração distribuída para o processo de detecção de faltas, explorando diversos tipos de faltas e impedâncias e 
apesar de bons resultados, a ferramenta proposta localiza faltas apenas no tronco principal do alimentador.

O esquema proposto é capaz de obter estimações precisas do local de faltas de baixa impedância (lineares) e de alta-impedância (não-lineares). Esta última classe representa um tópico importante para os sistemas de distribuição de energia porque podem dificultar a detecção e localização por parte dos dispositivos de proteção comumente utilizados atualmente.

Os resultados deste trabalho mostram que a metodologia proposta é digna de futuras pesquisas visando aplicações em tempo real.

\subsubsection{Localização de faltas utilizando informações qualitativas da rede}

A proposta de se localizar faltas, observada em Marusic e GruhonjicFerhatbegovic (2006), consiste de uma metodologia bastante diferenciada em relação às demais encontradas em literatura. Isto porque foram explorados os aspectos qualitativos e não quantitativos da rede de distribuição. Sob esta ótica, é possível encontrar diversas informações envoltas de incertezas, sendo um ambiente propício para a aplicação de sistemas fuzzy no tratamento de tais informações.

Para compor todos os aspectos de desenvolvimento desta nova ferramenta de localização de faltas, os autores inspiraram-se no fato de que metodologias fundamentadas na estimação da impedância da falta para localização são ineficientes quando os alimentadores apresentam muitos ramais.

Assim, inicia-se a análise especialista para confecção dos sistemas fuzzy a partir da figura do operador, que coordena as equipes de inspeção. Nestes casos, o operador muitas vezes utiliza conhecimento especialista sobre o possível local da falta. 
De uma maneira mais geral, é possível afirmar que os autores combinam a estimação da impedância com sistemas fuzzy para inferir o local da falta. Na Figura 3.8 tem-se um exemplo de como funciona o processo de localização de faltas proposto pelos autores.

Neste exemplo, considerando-se uma falta trifásica, o indicador de faltas em RCD3 encontra-se atuado, além da religadora ter desconectado o circuito. A impedância calculada da falta foi de $4,2 \Omega$, sendo que os trechos de $F 1$ a F5 são os possíveis candidatos.

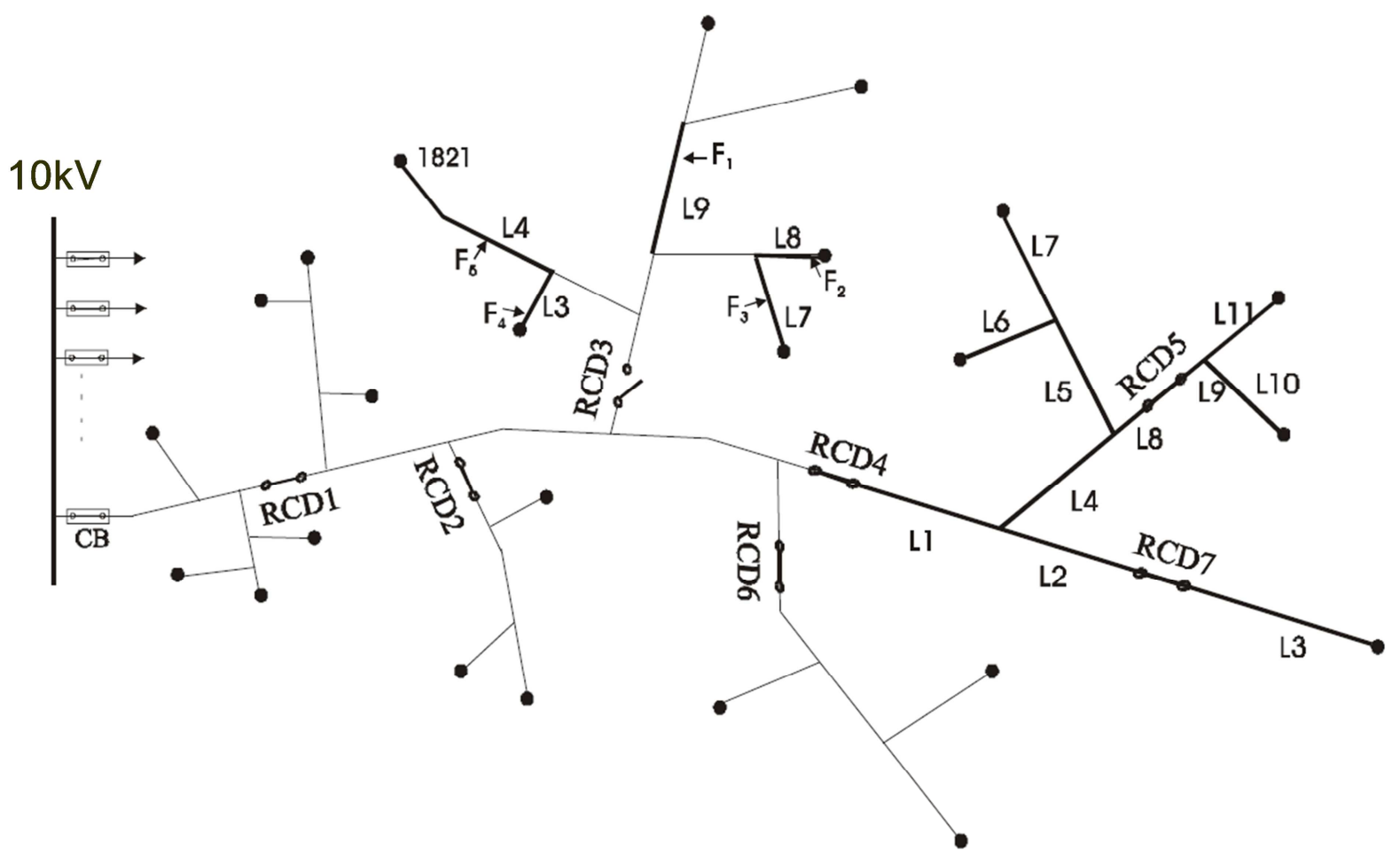

Figura 3.8 - Circuito de exemplo para localização de faltas. Adaptado de Marusic e Gruhonjic-Ferhatbegovic, 2006.

Após o processo de estimação da impedância, as variáveis linguísticas "Status das religadoras", "Sinalização de indicadores de faltas", "Qualidade da rede" e "Condições de terreno" são avaliadas pelo sistema fuzzy. Utilizam-se dados históricos de interrupções para ajustar as funções de pertinência referentes à 
“Qualidade da rede”. Para compor a variável "Condições de terreno" são necessárias informações climáticas e também geográficas.

Após o processo de inferência, tem-se a indicação do trecho L4 como sendo o local mais provável da falta. Este método permite localizar trechos sob falta com grande assertividade, estimando também dentro de cada trecho a distância provável do defeito.

Apesar destas qualidades, faz-se necessário para a implementação desta estratégia um elevado automatismo do alimentador, sendo estes traduzidos na forma de Religadoras e Indicadores de Faltas com comunicação, além de mudanças nas funções de pertinência que compõem as variáveis do sistema fuzzy a cada mudança da rede.

\subsubsection{Localização de faltas utilizando sistemas inteligentes híbridos}

Para exemplificar todas as imprecisões, incertezas e não linearidades envolvidas com o processo de identificação e localização de faltas pode-se aqui destacar o trabalho contido em Mora et al. (2006). Isto porque os autores empregaram a ferramenta $A N F I S$, que é um poderosíssimo sistema inteligente híbrido, do tipo incorporado, e que possui Redes Neurais Artificiais e sistemas fuzzy em sua composição.

Além da ferramenta inteligente híbrida, os autores também empregaram ferramentas de processamento de sinais, tais como a Transformada Wavelet, explorando-se as informações contidas nos sinais de corrente de falta.

A combinação com Transformadas Wavelet permite realizar análises no tempo e na frequência simultaneamente, localizando dentro do sinal no tempo, determinados grupos de frequências. Tal ferramenta permite identificar mudanças abruptas em amplitude e frequência do sinal de corrente em condições de falta. 
Para o processo de aprendizado do sistema ANFIS, dados reais de correntes de faltas são utilizados, sendo que a saída do sistema representa o trecho onde ocorreu a falta. As variáveis de entrada são processadas pela Wavelet, buscando-se determinar:

Relação entre: corrente de falta e o tempo de operação da proteção;

Variação entre: corrente na pré-falta e primeiro chaveamento;

> Variação entre: corrente na pré-falta e último chaveamento;

Vetores de tempo de operação da proteção: disjuntores, religadoras e fusíveis.

O sistema investigado consiste de um alimentador que foi dividido em 5 trechos, sendo simuladas faltas com resistências variando entre $0,5 \Omega$ e $40 \Omega$. Os autores utilizaram 930 amostras para o aprendizado do sistema ANFIS. A taxa global de acertos verificada pelos autores foi de $99,14 \%$.

Este trabalho apresenta importante contribuição ao constatar o grande relacionamento entre a variação da corrente após o último chaveamento e a préfalta, culminando em eficiência de localização.

Como foi destacado, o alimentador utilizado para a investigação era relativamente pequeno, sendo tal fato determinante para a aplicação desta ferramenta.

\subsection{Considerações parciais}

Destacaram-se aqui neste capítulo algumas das ferramentas inteligentes como sendo aquelas mais referenciadas nos artigos científicos, pois o seu grande potencial de aplicação já vem sendo empregado com algum sucesso em diversos outros setores relacionados aos sistemas elétricos de potência. 
Fica também evidente na pesquisa correlata que apenas a utilização de uma ferramenta inteligente não é capaz de suprir as necessidades de fenômenos faltosos nos sistemas de distribuição de energia elétrica brasileiro.

Apesar das soluções para identificar faltas de alta impedância apresentar um grande crescimento nos últimos anos, a maioria das metodologias encontradas em literatura foram apenas simuladas ou experimentadas com dados reais, não sendo implementadas na prática.

Ainda frente a este contexto, cabe-se também ressaltar que a representação dos alimentadores, por meio de circuitos equivalentes encontrada na maioria das abordagens pesquisadas, não é aplicável em alimentadores de grande porte. 


\section{Aspectos da Metodologia Desenvolvida}

\subsection{Introdução}

A combinação de ferramentas de processamento de sinais com ferramentas pertencentes à classe de Sistemas Inteligentes tem obtido sucesso no processo de detecção de faltas.

Um aspecto da metodologia desenvolvida é a utilização de estratégias híbridas, pois a combinação de uma ou mais ferramentas inteligentes integradas a outras com reconhecidas características de tratamento de sinais já vêm proporcionando resultados promissores aos processos envolvidos com a identificação, classificação e localização das faltas nos sistemas de distribuição.

A metodologia proposta utiliza de ferramentas inteligentes e numéricas, que são integradas e sintonizadas entre si por um sistema automatizado, visando reunir as potencialidades individuais de cada uma delas em um único sistema. Assim, a tecnologia proposta possui um maior grau de robustez e eficiência que a diferencia das demais. 


\subsection{Aspectos do sistema automatizado para identificação e}

\section{localização de faltas}

O desenvolvimento de todo o sistema automatizado pode ser dividido em diversos objetivos. Assim, por meio da Figura 4.1, tem-se a ilustração, de forma esquemática, da modularização do sistema de identificação e localização de faltas proposto.

Conforme se pode observar o sistema é composto pelo módulo de aquisição de dados, módulo de pré-processamento, módulo de identificação de transitórios, sistema de identificação das fases participantes da falta, sistema classificador de faltas e pelo sistema localizador de faltas. Resumidamente, esse sistema opera fazendo-se uso dos dados aquisitados do sistema de distribuição. Em princípio, esses dados são constituídos pelas três tensões de fase e pelas três correntes de linha. Considerando-se que o emprego de transformadores de corrente (TC) não é comum na medição da corrente de terra, essa grandeza é calculada tendo como resultado a corrente residual dos transformadores de corrente de fase.

O módulo de aquisição de dados tem por funcionalidade a adequação dos níveis de tensão e de corrente do sistema de distribuição de maneira que os mesmos possam ser digitalizados e aquisitados, mais detalhes do modulo de aquisição de dados estão caracterizados no Apêndice E.. Esses dados digitalizados são, por sua vez, processados e seus principais parâmetros são determinados por meio do módulo de pré-processamento. 


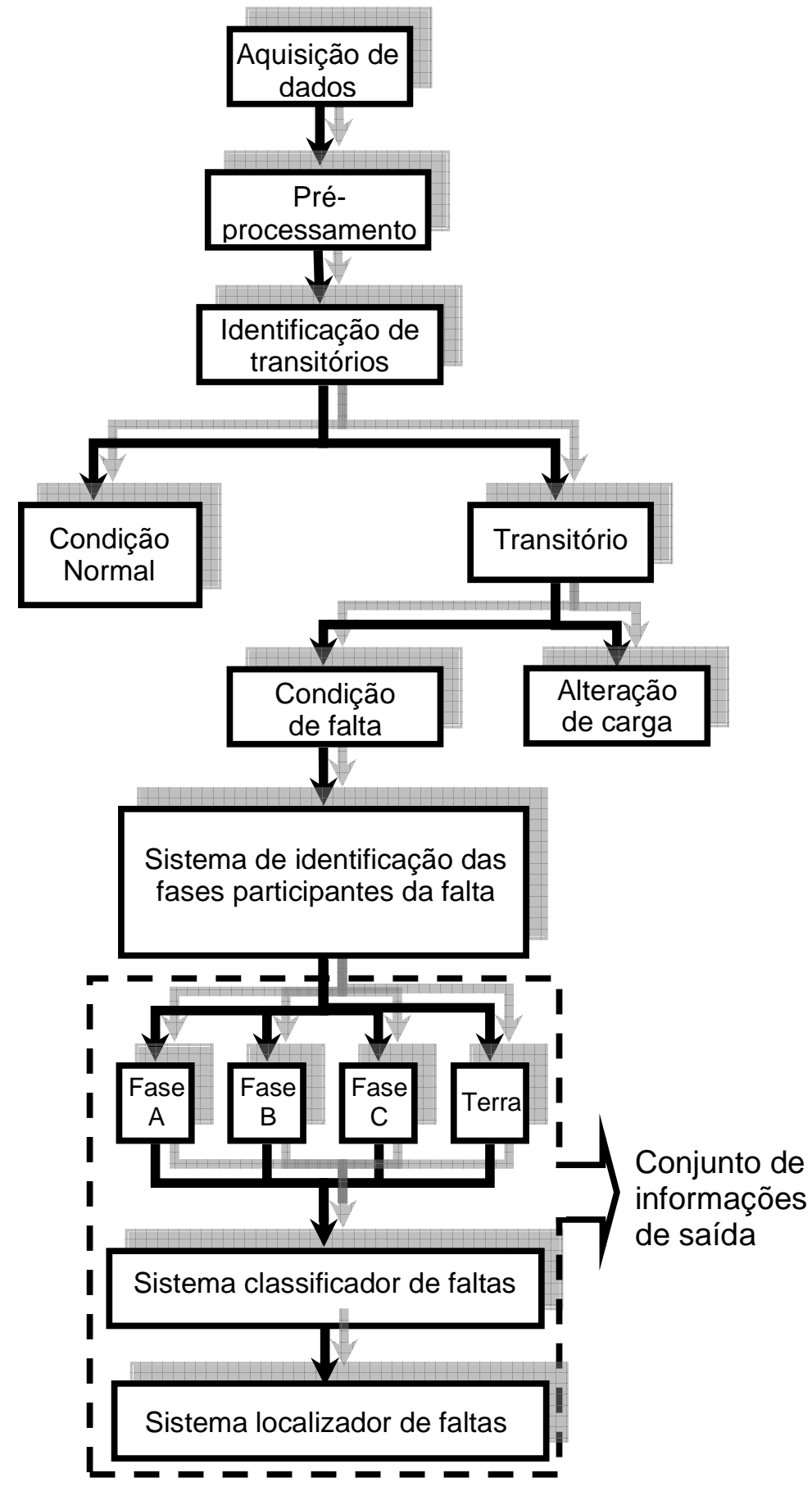

Figura 4.1 - Representação esquemática do sistema de identificação e localização de faltas.

Fazendo-se uso desses parâmetros, o módulo de identificação de transitórios detecta quando um distúrbio se inicia e, em virtude de sua identificação, classifica o mesmo como sendo advindo de alterações de carga no sistema de distribuição ou proveniente de uma condição de falta. A identificação de uma condição de falta, por sua vez, desencadeia a operação do sistema de identificação 
das fases participantes da falta. Por fim, tendo como dados as fases que participaram da falta, o sistema classificador de faltas informa qual o tipo de falta que tem sido identificado, ao passo que o sistema localizador de falta indica o local onde a mesma ocorreu.

A principal funcionalidade do módulo de pré-processamento é de agrupar ou compactar os dados de formas de onda a fim de que a quantidade excessiva de dados, advindos desses sinais, possa a ser representado por um menor número de parâmetros.

O módulo de identificação de transitórios permite identificar a existência de transitórios de corrente e tensão em sistemas de distribuição, independentemente de sua origem. Esse resultado dará seguimento ao processo de identificação das fases participantes e de sua respectiva classificação.

De forma mais específica, a representação esquemática mostrada na Figura 4.1 pode ser complementada pelo diagrama de blocos apresentado na Figura 4.2, em que se observam as etapas destinadas à identificação de faltas, discriminação de fases participantes e estimação da distância e da resistência de falta.

Por intermédio desse diagrama esquemático é possível observar que, diante da identificação da ocorrência de uma falta, tem-se a consequente determinação do tipo de falta identificada. A identificação do tipo de falta recebe grande importância, uma vez que essa característica determinará a forma pela qual os dados do distúrbio serão processados com o objetivo de se determinar as fases participantes da falta, assim como de se proceder com a estimação da distância de ocorrência e da resistência de falta. $O$ rótulo $F F F$ ou $3 F$ refere-se às faltas trifásicas, DLF às faltas fase-fase, FFT às faltas fase-fase- terra, FFP às faltas fase-terra paralela e FFS às faltas fase-terra série. 


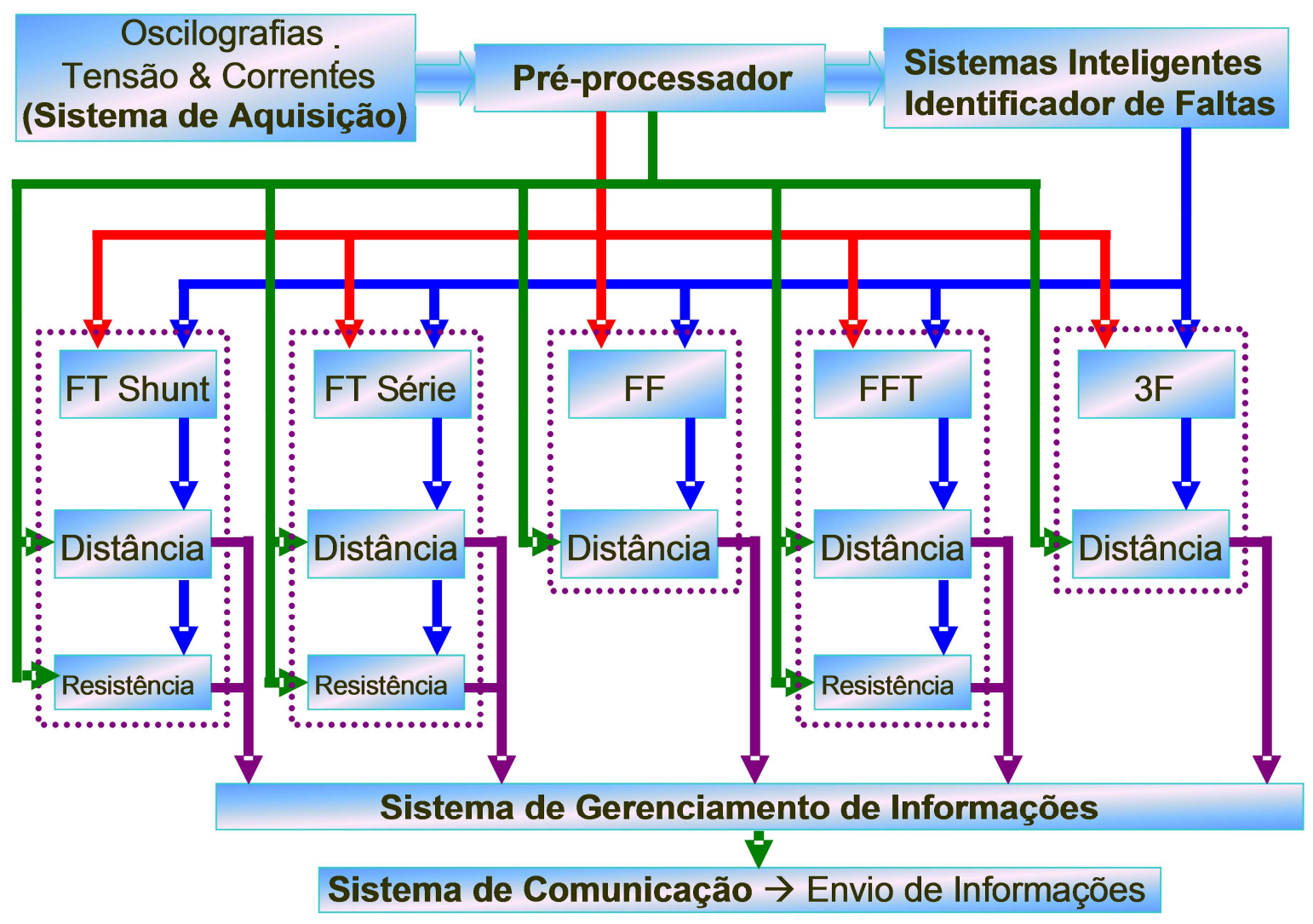

Figura 4.2 - Diagrama esquemático do sistema identificador de faltas.

A Figura 4.3 apresenta a arquitetura do sistema para determinação do tipo de falta identificada. A operação deste sistema atribui, para cada tipo de falta, um índice de probabilidade o qual, se próximo à unidade, indica uma forte tendência do distúrbio estar associado a esse tipo de falta.

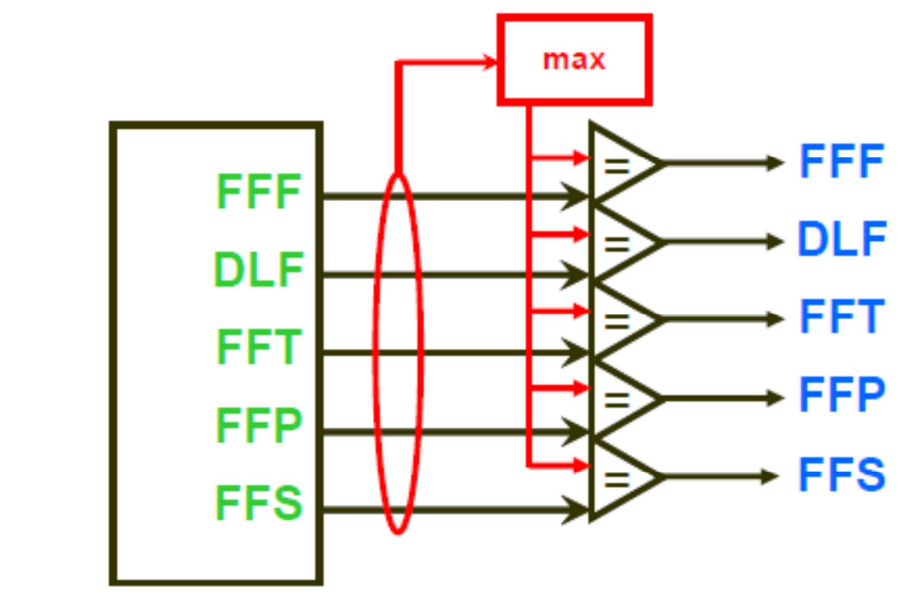

Classificação de faltas

Figura 4.3 - Diagrama esquemático para o sistema de identificação da tipologia da falta. Adaptado de Flauzino, 2007. 
Se, por outro lado, esse índice estiver próximo de ser nulo, o oposto se aplica. Assim, o módulo de classificação de falta informa o tipo de falta tendo como base o maior índice de probabilidade calculado.

Uma vez identificada o tipo de falta, tem-se a necessidade de se identificar as fases participantes da falta. Para as faltas do tipo DLF e FFT, o sistema da Figura 4.4 é empregado.

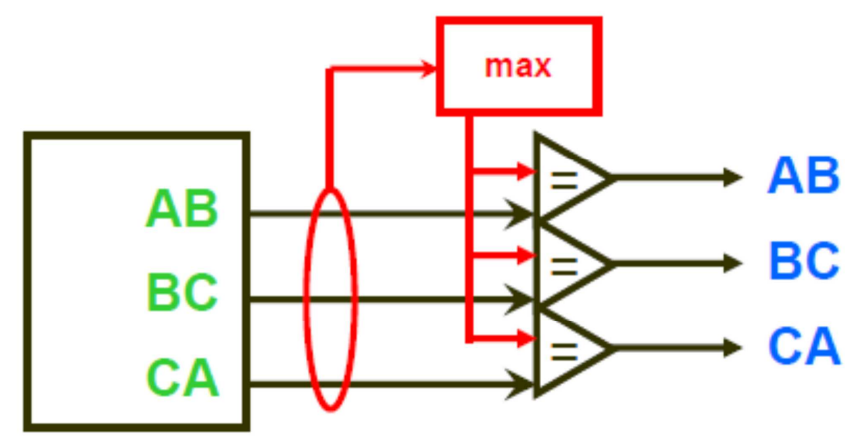

Discriminação de fases

Figura 4.4 - Diagrama esquemático para discriminação das fases participantes para faltas do tipo DLF e FFT. Adaptado de Flauzino, 2007.

Já para as faltas do tipo FFP e FFS, o diagrama representado na Figura 3.8 passa a ser então válido.

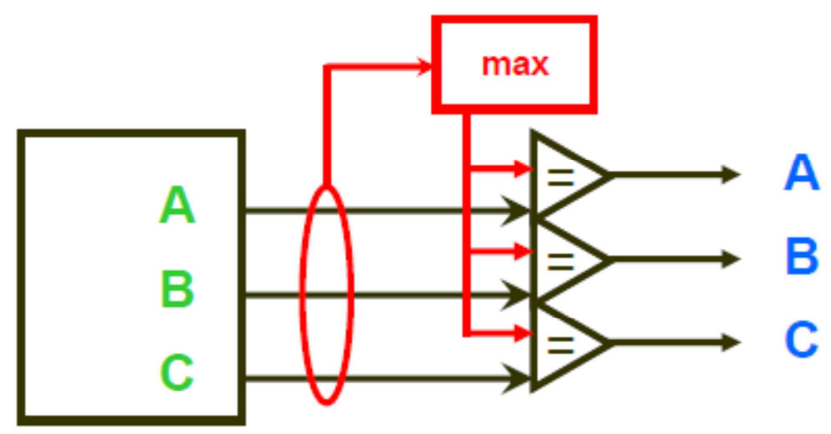

Discriminação de fases

Figura 4.5 - Diagrama esquemático para discriminação das fases participantes para faltas do tipo FFP e FFS. Adaptado de Flauzino, 2007.

Tanto a identificação do tipo de falta como o processo de discriminação das fases participantes da falta fizeram uso de dados advindos da técnica de decomposição em componentes ortogonais, conforme propostos em Flauzino e Silva 
(2007) e Flauzino (2007). O número de componentes empregadas em cada uma dessas tarefas fora igual a cinco. Além disso, recebendo como entradas tais componentes, tem-se redes neurais artificiais do tipo perceptron multicamadas, as quais foram treinadas por meio de conjuntos de amostras compostos, para cada tipo de falta, por um total de 18 mil situações de faltas simuladas computacionalmente.

\subsection{Sistema de aquisição de dados elétricos}

Com a finalidade de refinar os procedimentos de localização de faltas, os processos envolvidos foram automatizados na forma de funções independentes. Esta linha de trabalho permite um maior controle do fluxo de código à medida que também deixa modular os processos relacionados com as etapas de identificação e localização de faltas, proporcionando ao sistema uma arquitetura robusta com redundância de informações.

Assim, nas sessões que se seguem serão detalhados os desenvolvimentos que foram realizados neste processo de automatização da detecção de faltas.

\subsubsection{Automatização das etapas de identificação e localização de faltas}

O arquivo principal do Sistema de Aquisição de Dados Elétricos (SADE) funciona de maneira compartimentar, acionando-se outras funções. A estrutura deste arquivo funciona de forma contínua dentro de um laço, que se inicia com a aquisição de novas amostras de sinais elétricos, tal como descrito a seguir:

1. Aquisição de sinais de corrente e tensão mediante uma solicitação de trip, previamente ajustada para cada alimentador;

2. Identificação dos segmentos de faltas;

3. Cálculo dos fasores de tensão e corrente, e componentes simétricas;

4. Determinação da fase participante da falta; 
5. Análise de reatância e resistência de falta para cada segmento;

6. Criação do arquivo de saída.

Cada um dos itens de 2 a 6 é realizado por uma função específica, sendo que as maiores contribuições e avanços realizados foram nos itens de 2 a 5 .

\section{Identificacão dos segmentos de falta:}

Após a obtenção do registro de oscilografia, deve-se definir como os dados serão utilizados, ou seja, se todo o registro será processado de uma vez ou se a análise será feita em partes, mediante a segmentação do sinal. Esta escolha vai depender do tipo de distúrbio que se deseja analisar. Neste aspecto, de uma maneira simplificada, os distúrbios podem ser enquadrados em duas classes:

- Variações: São distúrbios em regime permanente, ou quase regime permanente, como por exemplo, a existência de conteúdo harmônico indesejável na rede elétrica.

- Eventos: São distúrbios bruscos, como interrupções, afundamentos de tensão, faltas, entre outros.

Apesar de serem definidos para estudos de qualidade de energia, estes termos também podem ser utilizados em outras aplicações. É na etapa de segmentação que os eventos (ou variações) são detectados e, caso necessário, o registro da oscilografia é dividido em partes conforme a necessidade da metodologia de análise utilizada.

Na Figura 4.6 tem-se um exemplo de registro, onde é armazenado um fasor (módulo e fase) para cada ciclo da frequência fundamental do sistema. O segmento de falta é representado pela região hachurada. 


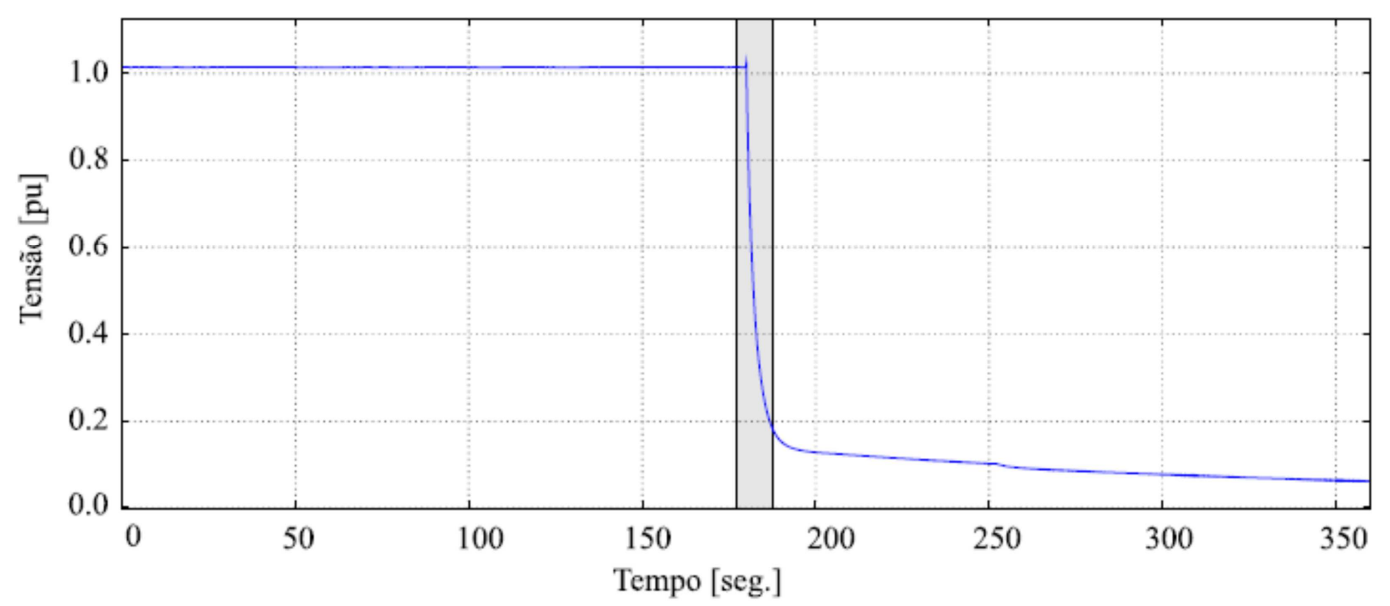

Figura 4.6 - Processo de segmentação da oscilografia.

$\mathrm{Na}$ ocorrência de um distúrbio real em redes de distribuição, diferente de ambientes simulados, as faltas transitórias e a dinâmica não linear dos sistemas de distribuição dificultam o ajuste de trip para as oscilografias de falta. Isso requisitou criar uma função no sistema de aquisição de dados para segmentar corretamente os dados de uma falta oscilografada nos diferentes alimentadores em estudo.

A correta segmentação das faltas é muito importante, pois determinará os dados que serão utilizados nos módulos de identificação e localização das faltas.

A função desenvolvida, denominada FindFaultsSegments, tem por objetivo determinar os segmentos de falta de uma oscilografia. Os segmentos de falta são definidos como aqueles que possuem uma corrente superior ao limiar inLimiar, com uma duração mínima de minCycles. Segmentos com uma distância igual ou inferior a minCycles são agrupados em um único segmento. Detalhes desta função podem ser conferidos no Apêndice A.

\section{Determinação da fase participante da falta:}

Feita a segmentação, a próxima etapa é a extração de características em cada segmento e determinação das fases participantes num determinado evento. A escolha das características vai depender do problema abordado e da metodologia de solução. As características mais utilizadas são as seguintes: 
- Valores médios ou eficazes das grandezas monitoradas (tensões e correntes) em cada segmento.

- Valores médios de grandezas calculadas, tais como potência elétrica ou componentes simétricas.

- Conteúdo harmônico dos dados, obtido por meio da transformada de Fourier.

- Coeficientes de detalhe obtidos com a análise multiresolução da transformada wavelet.

A extração de características tem a função de reduzir a quantidade de dados a serem utilizadas para avaliar, automaticamente ou não, uma ocorrência registrada em uma oscilografia.

Esta função, denominada FindFaultedPhase, tem por objetivo determinar a fase participante da falta. $O$ critério de definição é baseado na diferença angular entre os fasores das componentes de sequencia zero e negativa. Detalhes desta função podem ser conferidos em Flauzino e Silva (2007), Flauzino (2007) e no Apêndice B.

\section{Análise de reatância e resistência de falta:}

As atividades desenvolvidas nessa análise foram focadas na elaboração de uma nova técnica destinada aos propósitos de localização de faltas em sistemas de distribuição, a qual se apresenta com mais detalhes no decorrer das próximas seções. Desta forma, essa nova metodologia foi adicionada às técnicas inteligentes anteriormente desenvolvidas.

Esta função, denominada FaultLocation, tem por objetivo estimar o local provável de ocorrência das faltas, considerando-se aqui os segmentos de falta 
identificados. Detalhes desta função podem ser conferidos nas Seções seguintes e no Apêndice C.

\subsection{Sistema para modelagem de alimentadores para fins de identificação e localização de faltas}

Para os processos de identificação e localização de faltas é preciso que a modelagem dos alimentadores seja a mais fiel possível.

Visando tal objetivo, foram então empregadas metodologias de leitura e extração de informações dos alimentadores pilotos a partir das bases de dados das redes elétricas disponíveis na concessionária, as quais são capazes de realizar a modelagem completa do alimentador. Enfatiza-se que a fidelidade destas informações estão ainda diretamente relacionadas àquelas cadastradas nos seus mínimos detalhes.

Para ilustrar tal processo, na Figura 4.7 é possível visualizar a representação completa de um alimentador real, objeto de estudo. 


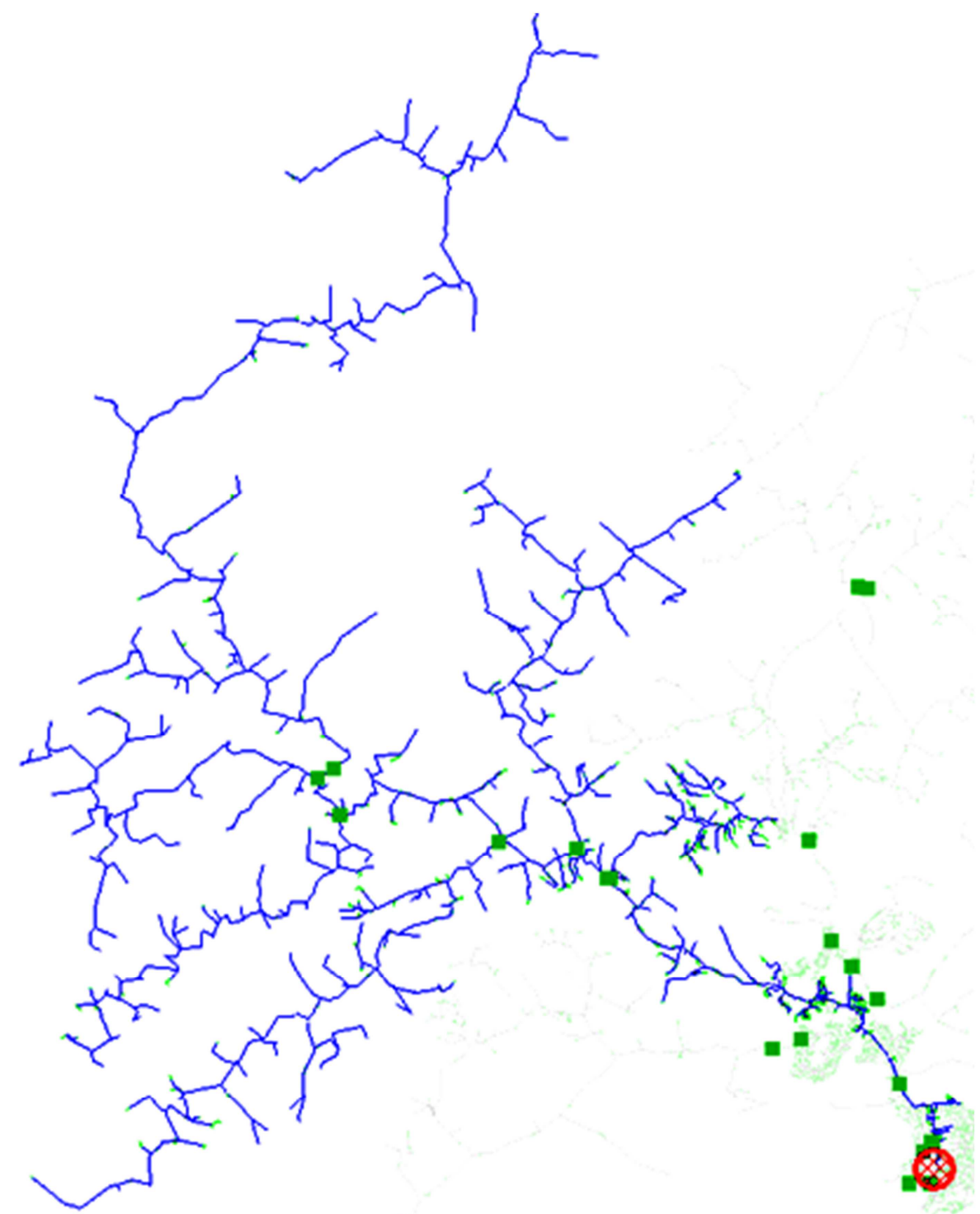

Figura 4.7 - Representação do alimentador JCE1312.

O sistema computacional desenvolvido para fins de modelagem de alimentadores opera da seguinte forma:

> Leitura do arquivo descritivo de cada ETD;

> Interpretação dos dados e seleção do alimentador;

> Identificação da distribuição das cargas no alimentador;

> Determinação do estado das chaves manobráveis;

$>$ Cálculo do tronco principal.

A leitura das informações nos arquivos bases de simulação tem por objetivos identificar os circuitos presentes na ETD correspondente, e também identificar os 
componentes descritos, tais como trechos primários, estações transformadores, bancos de capacitores, reguladores de tensão, chaves, etc. Como resultado, têm-se então todos os elementos constituintes do circuito de interesse para a modelagem.

Assim, em resumo, ter-se-á uma representação sumarizada do alimentador de maneira que em cada derivação se tenha a impedância equivalente do sistema elétrico à frente.

Na Figura 4.8 tem-se uma representação desse sistema elétrico com suas respectivas derivações.

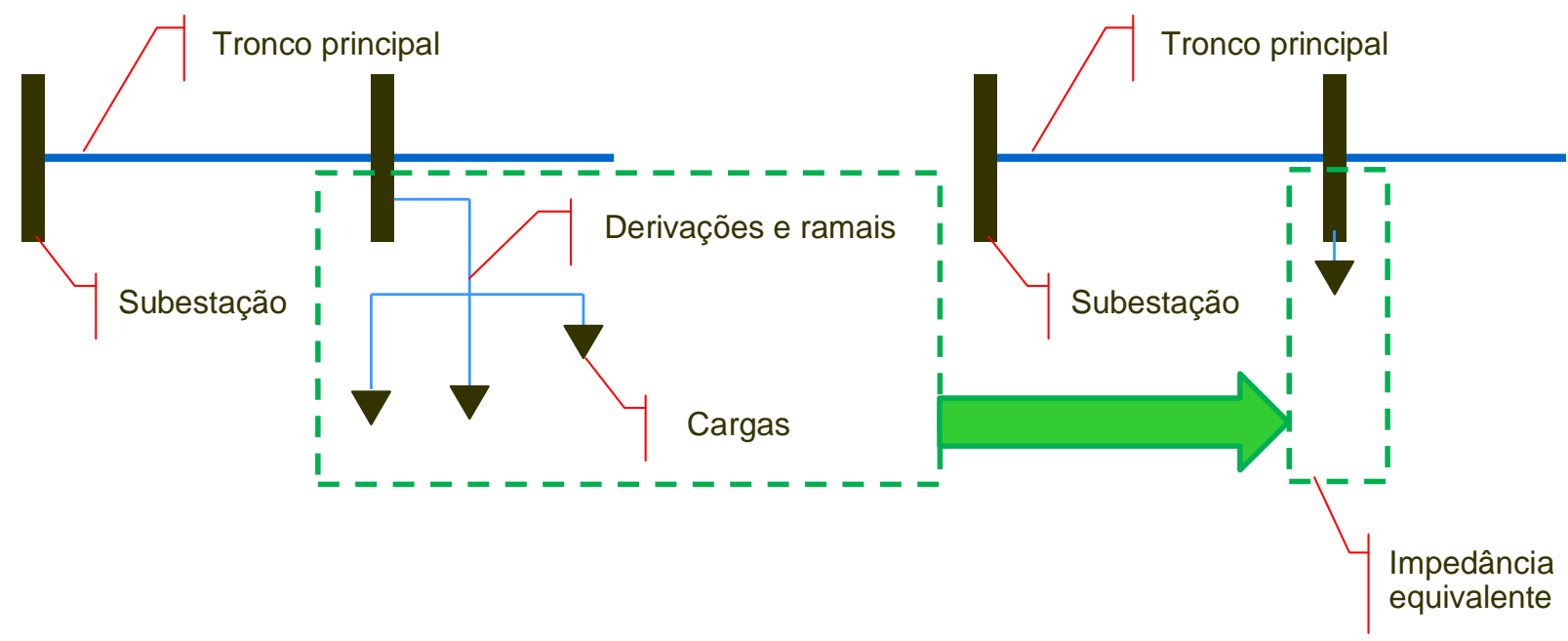

Figura 4.8 - Representação do alimentador e suas derivações.

O cálculo da impedância equivalente leva em consideração as seguintes informações do sistema elétrico:

$>$ Clientes;

> Iluminação pública;

$>$ Tipo de estrutura e bitola dos condutores elétricos do sistema de média tensão;

Condições de pré-falta oscilografadas pelos sistemas de aquisição de dados. 
O trecho de tronco principal entre duas barras subsequentes é representado pelo seu quadripolo equivalente.

Uma vez que o sistema de distribuição passa a ser representado pelo seu equivalente elétrico torna-se então possível a estimação do local de ocorrência da falta por meio de técnicas de cálculo de impedância similares às equações das impedâncias aparentes (Roberts et al., 1993) listadas na Tabela 4.1.

Tabela 4.1: Equações da Impedância Aparente Z = V/I

\begin{tabular}{|c|c|}
\hline "Loop" de Falta & Equações \\
\hline$A N$ & $V_{A} /\left[I_{A}+k_{0} . I_{R}\right]$ \\
\hline$B N$ & $V_{B} /\left[I_{B}+k_{0} . I_{R}\right]$ \\
\hline$C N$ & $V_{C} /\left[I_{C}+k_{0} . I_{R}\right]$ \\
\hline$A B$ & {$\left[V_{A}-V_{B}\right] /\left[I_{A}-I_{B}\right]$} \\
\hline$B C$ & {$\left[V_{B}-V_{C}\right] /\left[I_{B}-I_{C}\right]$} \\
\hline$C A$ & {$\left[V_{C}-V_{A}\right] /\left[I_{C}-I_{A}\right]$} \\
\hline
\end{tabular}

Nota:

$I_{R}=3 I_{0}=I_{A}+I_{B}+I_{C}$

$\mathrm{k}_{0}=\left(\mathrm{Z}_{\mathrm{OL}}-\mathrm{Z}_{1 \mathrm{~L}}\right) /\left(3 . \mathrm{Z}_{1 \mathrm{~L}}\right)$;

ZoL = impedância de sequencia zero da linha;

$Z_{1 L}=$ impedância de sequencia positiva da linha.

\subsection{Aspectos de método inovador para propósitos de localização de faltas}

Devido à variedade de tipos de falta possíveis num circuito trifásico, os relés de distância, que visam encontrar o provável local da ocorrência de uma falta, devem estar disponíveis para responder às tensões e correntes associadas a seis diferentes circuitos ("loops") de falta (AB, BC, CA, AN, BN e CN) (Roberts et al., 1993). 
Um enfoque para implementar relés de distância é calcular a impedância aparente $Z=V / I$, e então verificar se essa impedância localiza-se no interior de alguma forma geométrica, como um círculo ou um quadrilátero.

Embora relés tenham sido construídos a partir deste critério, seu desempenho varia sob várias condições práticas de fluxo de potência e resistência de falta.

O método $Z=V / I$ é atraente naquilo em que requer apenas um cálculo de impedância por "loop" de falta, conforme equações listadas na Tabela 4.1.

Analisando o desempenho do método para uma falta fase-neutro para um sistema equivalente ao apresentado na Figura 4.9, observa-se que para o sistema radial, $\angle \mathrm{I} F=\angle \mathrm{l}$ e o método $\mathrm{Z}=\mathrm{V} / \mathrm{I}$ mede acuradamente a reatância até a falta.

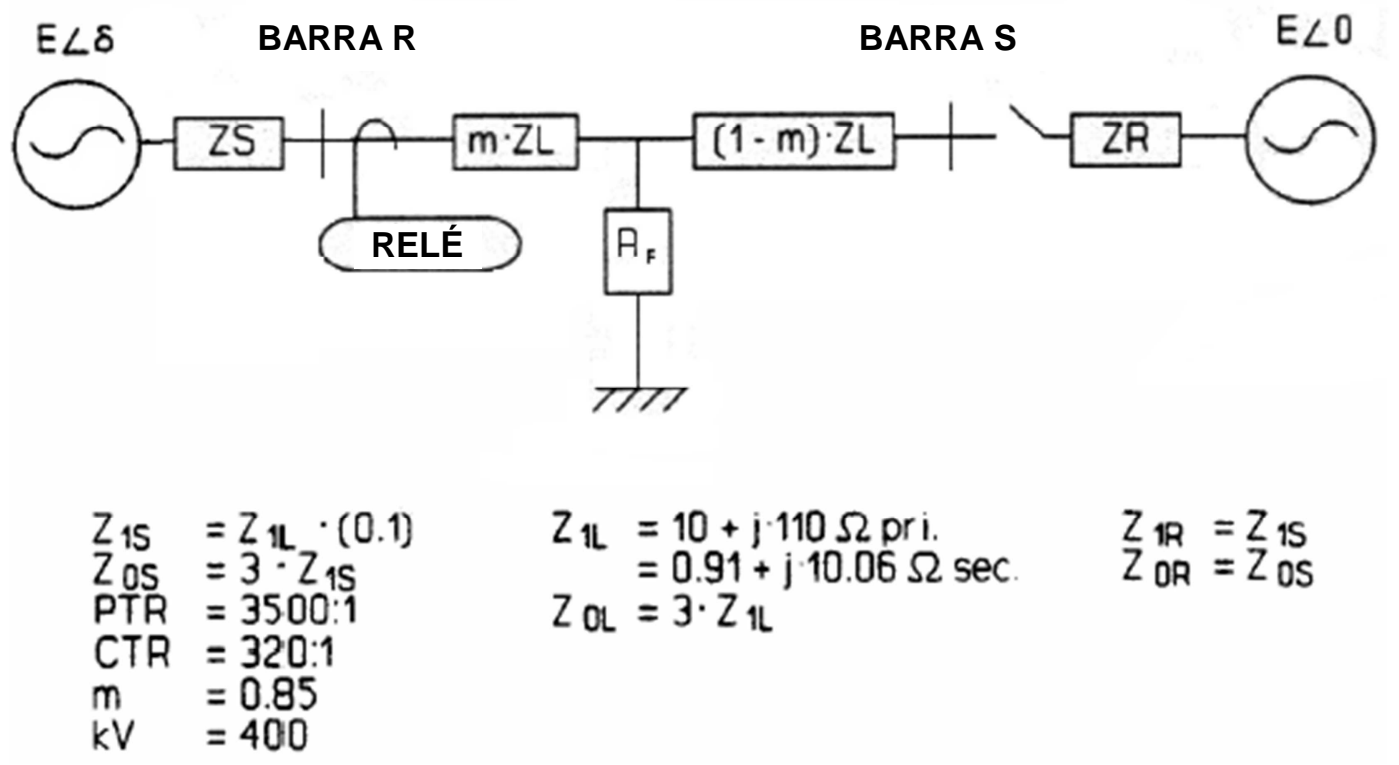

Figura 4.9 - Diagrama unifilar do sistema.

onde:

$\mathrm{V}$ = tensão da fase $\mathrm{A}$ medida na Barra $\mathrm{S}$;

$\mathrm{m}$ = distância em por-unidade da falta até a barra S; 
$Z_{1 L}=$ impedância de sequencia positiva da linha;

$\mathrm{I}_{\mathrm{A}}=$ corrente da fase A medida na Barra $\mathrm{S}$;

$k_{0}=\left(Z_{0\llcorner}-Z_{1 L}\right) /\left(3 . Z_{1\llcorner}\right)$, onde $Z_{0 L}=$ impedância de sequencia zero da linha;

$I_{R}=$ corrente residual medida na Barra $S$;

$\mathrm{R}_{\mathrm{F}}=$ resistência de falta;

$\mathrm{I}_{\mathrm{F}}=$ corrente total que flui em $\mathrm{R}_{\mathrm{F}}$;

A Figura 4.10 mostra as componentes resistiva e reativa da impedância medida por um relé para uma falta $\mathrm{AN}$ com $\mathrm{m}=0,85$ e com $\mathrm{R}_{\mathrm{F}}=4,6 \Omega$ secundários (ou $50 \Omega$ primários, dados $\mathrm{RTP} / \mathrm{RTC}=3500 / 320)$. Como $\mathrm{RF} .(\mathrm{IF} / \mathrm{l})$ é um número real, o $\operatorname{Im}(\mathrm{V} / \mathrm{I})=\mathrm{m} . \mathrm{X}_{1 L}$, qualquer que seja o valor de $\mathrm{R}_{\mathrm{F}}$.

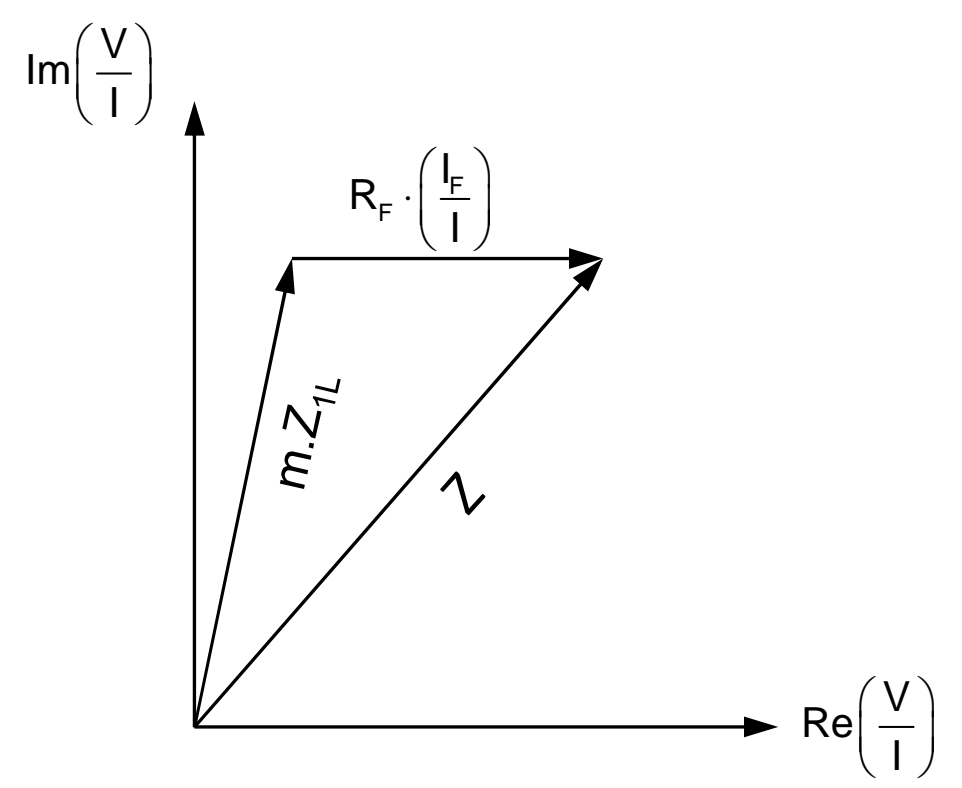

Figura 4.10 - Método da impedância aparente AN mede corretamente a reatância até a falta para uma linha radial.

Se analisarmos novamente o circuito da Figura 4.9, considerando agora a chave junto à Barra $\mathrm{R}$ fechada, e assumido fluxo de potência da Barra $\mathrm{S}$ para a Barra $R \operatorname{com} \delta=30^{\circ}$, pode-se então observar os efeitos do fluxo de potência e resistência de falta na medição da impedância aparente. 
A Figura 4.11(a) mostra que o relé da Barra S sobrealcança em função de $\operatorname{lm}(\mathrm{V} / \mathrm{I})$ medir uma reatância menor que a reatância da linha até a falta. Isto é porque IF e I não estão em fase, Figura 4.11(b), e RF aparece como uma impedância complexa.

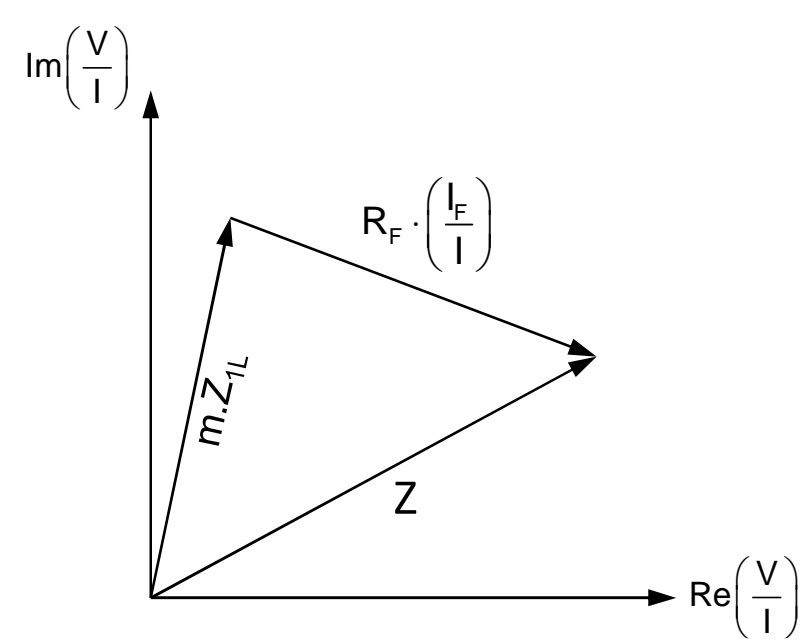

(a) Plano da impedância

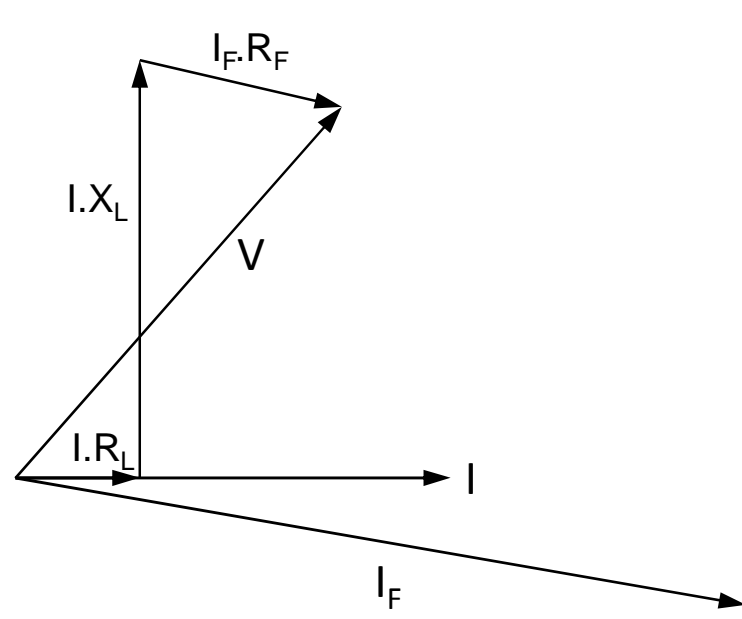

(b) Fasores de tensão e corrente

Figura 4.11 - Sobrealcance da impedância aparente AN com RFe fluxo de potência exportado $\left(\delta=30^{\circ}\right)$

Este sobrealcance torna-se mais pronunciado conforme $R_{F}$ e $\delta$ aumentam. A Figura 4.12 ilustra sub e sobrealcances do critério $Z=V / I$ para diferentes $R_{F}$ e condições de fluxo de potência. $O$ alcance do relé está ajustado em r.Z1L, onde $r=$ 0,85. O critério $Z=V / I$ subalcança para potência importada ( $I_{F}$ adiantada de $I$ ) e sobrealcança para potência exportada (IF atrasada de I). 


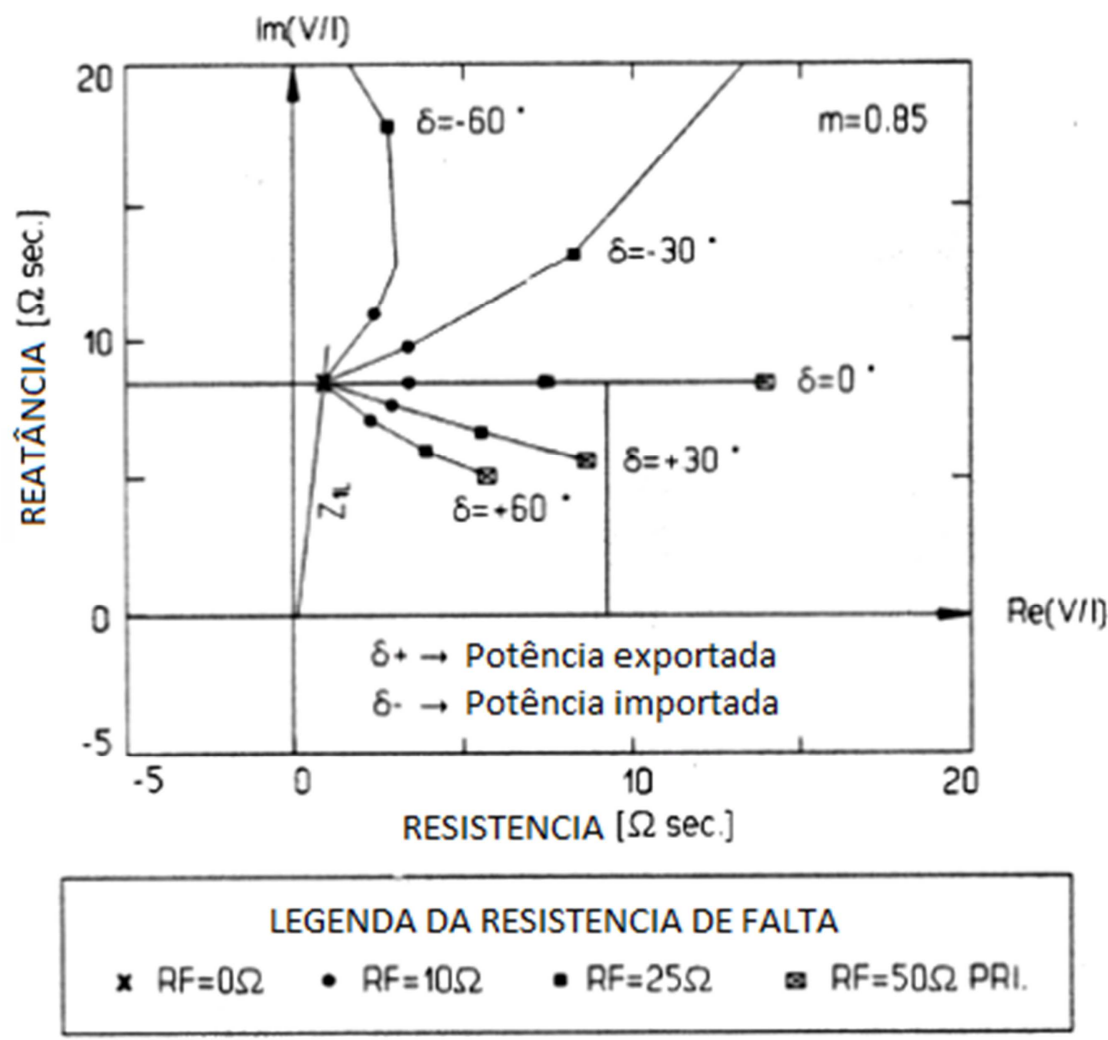

Figura 4.12 - O Desempenho do critério de impedância aparente depende de RFe de $\delta$.

Há meios melhores para se estimar a correta reatância até a falta, assim como a resistência de falta, sendo que estes métodos dependem da seleção adequada das grandezas de polarização (Roberts et al., 1993).

A Figura 4.11 mostra que a corrente da fase defeituosa não está sempre em fase com a corrente total de falta, IF. Portanto, a corrente de fase é uma opção fraca para ser o sinal de referência ou polarização. A corrente de sequencia negativa ou a corrente residual são opções melhores, pois não são afetadas por $\delta$ ou pela resistência de falta.

Métodos que puramente analisam a impedância acabam por se deparar com múltiplas seções faltosas para um mesmo universo de busca de valores. A metodologia empregada nesse trabalho para cálculo das impedâncias considera as implicações colocadas por Roberts et al. (1993). 
Os métodos para localização de faltas em sistemas de energia elétrica podem ser delineados de diferentes formas, sendo que aquelas que se baseiam em análises de circuitos elétricos constituem uma dessas. Dessa forma, nessa seção será delineada a formulação proposta por Takagi et al. (1981) tanto para sistemas monofásicos como sua generalização para sistemas trifásicos.

Para tanto, será considerado o sistema elétrico apresentado por meio da Figura 4.13, onde a linha de transmissão possui uma impedância série $z$ e uma condutância shunt $y$.

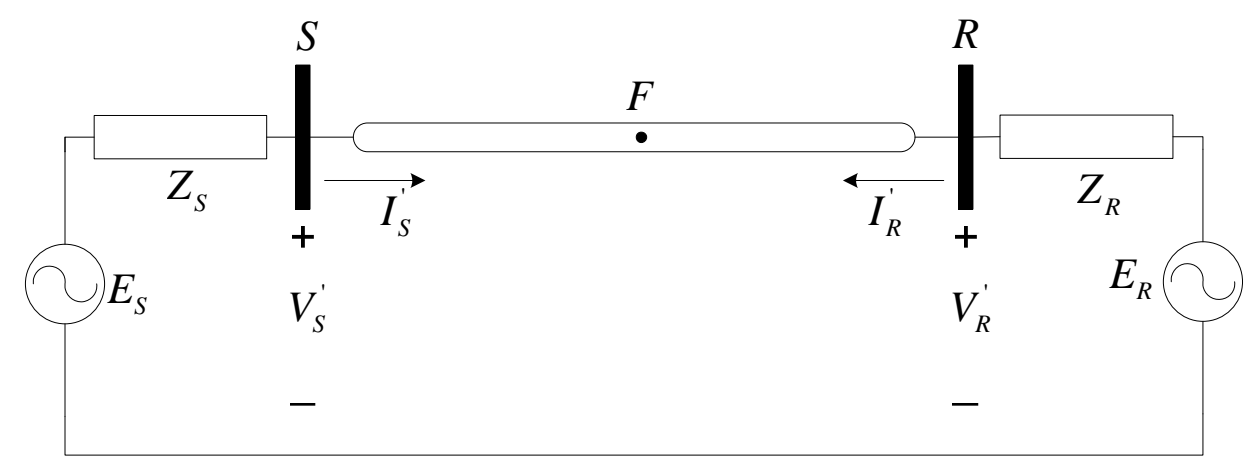

Figura 4.13 - Sistema elétrico no instante pré-falta.

No diagrama esquemático destacado por meio da Figura 4.13, tem-se que $V_{S}^{\prime}$ representa o fasor de tensão na barra $S$ antes da ocorrência da falta, bem como $V_{R}^{\prime}$ denota o fasor de tensão na barra $R$ nesse instante. A corrente medida na barra $S$ é representada pelo seu fasor $I_{S}^{\prime}$, enquanto que $I_{R}^{\prime}$ representa o fasor de corrente medido na barra $R$.

Com base no teorema da superposição de respostas para sistemas lineares, diante da ocorrência de uma falta, tal como a ilustrada por meio da Figura 4.14, o circuito pode ser representado pela condição puramente faltosa, resultando, por sua vez, no circuito ilustrado por meio da Figura 4.15. 
No circuito ilustrado por meio da Figura 4.14, tem-se que $I_{F}$ representa 0 fasor da corrente de falta e $R_{F}$ a respectiva resistência para essa falta. É notável que em função dessa ocorrência os fasores de tensão e de corrente observados nas barras $R$ e $S$ também se alteraram, sendo que, durante a condição de falta, nomearse-á os fasores de tensão por $V_{R}$ e por $V_{S}$, enquanto que os fasores de corrente serão denotados por $I_{R}$ e $I_{S}$, respectivamente.

Assim, sendo $V_{F}$ o fasor de tensão no ponto de ocorrência da falta, a qual ocorrera a uma distância $x$ da barra $S$, e $I_{F}$ a corrente de falta que circula por meio da resistência de falta $R_{F}$, tem-se: (Figura 4.15)

$$
V_{F}=R_{F} I_{F}=-R_{F}\left(I_{F S}^{\prime \prime}+I_{F R}^{\prime \prime}\right)
$$

onde $I_{F S}^{\prime \prime}$ é a parcela da corrente de falta que circula pela linha em direção à barra $S$, enquanto $I_{F R}^{\prime \prime}$ circula em direção à barra $R$.

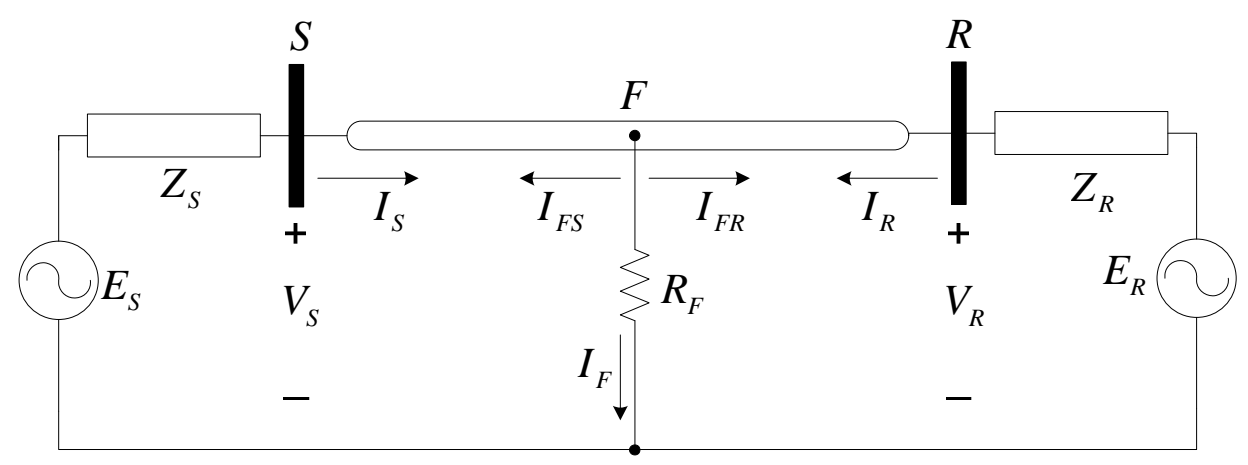

Figura 4.14 - Sistema elétrico no instante de ocorrência de uma falta.

Com base nesses dois fasores de corrente é possível definir a variável $K(x)$, a qual representa a razão entre os mesmos, ou seja:

$$
K(x)=\frac{I_{F R}^{\prime \prime}}{I_{F S}^{\prime \prime}}
$$

Dessa maneira, a expressão (4.1) pode ser escrita da seguinte forma:

$$
V_{F}=R_{F} I_{F}=-R_{F} I_{F S}^{\prime \prime}(1+K(x))
$$


Como os valores de $V_{F}$ e $I_{F S}^{\prime \prime}$ não são conhecidos, torna-se então conveniente representar a linha de transmissão por meio de um quadripolo e, assim, por meio da informação da barra $S$, determiná-los. Dessa forma, a seguinte representação é possível:

$$
\begin{aligned}
& V_{F}=A(x) V_{S}-B(x) I_{S} \\
& I_{F S}^{\prime \prime}=C(x) V_{S}^{\prime \prime}-D(x) I_{S}^{\prime \prime}
\end{aligned}
$$

onde os parâmetros do quadripolo da linha no trecho $S-F$ podem ser obtidos por meio das seguintes equações:

$$
\begin{aligned}
& A(x)=D(x)=\cosh (\gamma x) \\
& B(x)=Z_{c} \operatorname{senh}(\gamma x) \\
& C(x)=\frac{1}{Z_{c}} \operatorname{senh}(\gamma x)
\end{aligned}
$$

onde $\gamma=\sqrt{z y}$ é denominada por constante de propagação da linha e $Z_{c}=\sqrt{z / y}$ é sua respectiva impedância característica. Os fasores observados quando da condição faltosa podem ser obtidos diretamente por meio de medidas realizadas na barra $S$ durante os instantes de pré-falta e de pós-falta.

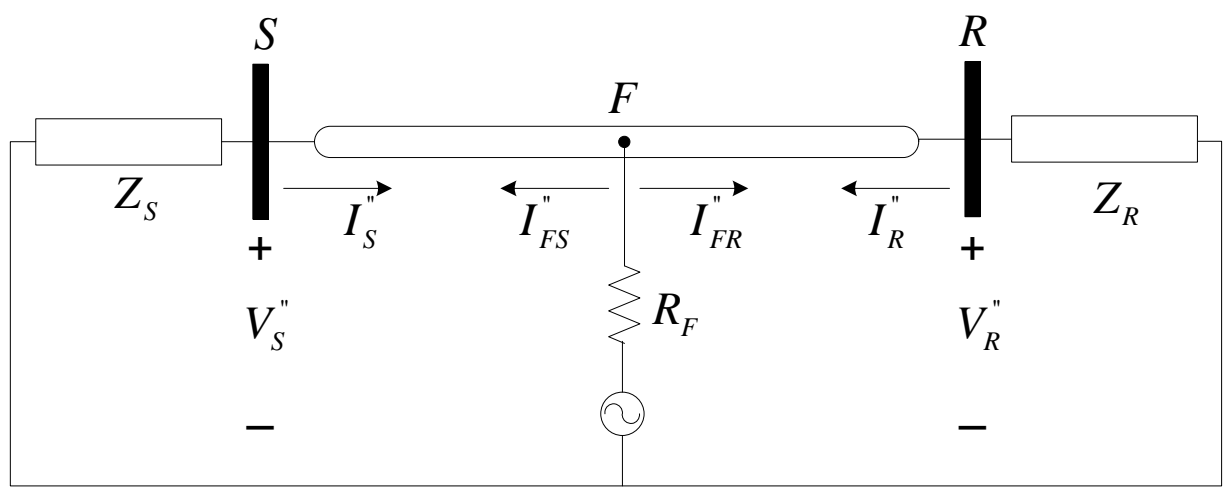

Figura 4.15 - Sistema elétrico equivalente no instante de ocorrência de uma falta.

Dessa maneira, as seguintes equivalências podem ser estabelecidas: 


$$
\begin{aligned}
& V_{S}^{\prime \prime}=V_{S}-V_{S}^{\prime} \\
& I_{S}^{\prime \prime}=I_{S}-I_{S}^{\prime}
\end{aligned}
$$

Como consequência direta do exposto em (4.4) e (4.5), tem-se a possibilidade de desenvolver a expressão (4.11) da seguinte forma:

$$
\begin{aligned}
& V_{F}=-R_{F} I_{F S}^{\prime \prime}(1+K(x)) \\
& A(x) V_{S}-B(x) I_{S}=-R_{F}\left(C(x) V_{S}^{\prime \prime}-D(x) I_{S}^{\prime \prime}\right)(1+K(x)) \\
& R_{F}(1+K(x))=-\frac{A(x) V_{S}-B(x) I_{S}}{C(x) V_{S}^{\prime \prime}-D(x) I_{S}^{\prime \prime}}
\end{aligned}
$$

Observando-se a equação (4.11) é possível a identificação que a distância $x$ de ocorrência da falta, a resistência de falta $R_{F}$ e o valor de $K(x)$ constituem suas incógnitas. Assim, a fim de se determinar a distância $x$ torna-se necessário algumas aproximações que sejam hábeis na desconsideração de $R_{F}$ e o valor de $K(x)$. A primeira dessas aproximações impõe que $R_{F}$ seja puramente resistiva, não possuindo, portanto, parcela imaginária. A segunda aproximação, pontuada por Takagi et al. (1981), estabelece que a relação $K(x)$ também é um valor real. Essa consideração é válida supondo-se uma linha de transmissão sem perdas, bem como tendo impedâncias equivalentes para as fontes como sendo puramente indutivas. Portanto, valendo-se de ambas considerações é possível inferir que $R_{F}(1+K(x))$ possui apenas componentes reais, ou seja:

$$
\operatorname{Im}\left(\frac{A(x) V_{S}-B(x) I_{S}}{C(x) V_{S}^{\prime \prime}-D(x) I_{S}^{\prime \prime}}\right)=0
$$

A expressão destacada em (4.12) possui um comportamento linear em função das funções $A(x), B(x), C(x)$ e $D(x)$, sendo imperativo para a obtenção de $x 0$ 
emprego de técnicas para solução de equações não-lineares. No entanto, é possível constatar que a referida distância entre a barra $S$ e o ponto de ocorrência da falta é estimada apenas com medidas locais na referida barra. Além disso, a estimativa de $x$ não dependerá da resistência de falta $R_{F}$.

método apresentado pode ser estendido para a localização de faltas em sistemas trifásicos, bem como ser particularizado para faltas fase-terra. Para que o desenvolvimento seja possível, torna-se conveniente a representação do sistema trifásico por meio de suas redes de sequencia, assim como se ilustra por meio da Figura 4.16.

Assim, empregando-se as equações de linha e efetuando-se os desenvolvimentos e considerações necessárias, a Expressão (4.13) é alcançada, a qual mediante sua solução numérica resulta na distância, em relação à barra $S$, da ocorrência da falta.

$$
\operatorname{Im}\left(\frac{V_{F}^{(0)}+V_{F}^{(1)}+V_{F}^{(2)}}{C(x)^{(1)} V_{S}^{\prime(1)}-D(x)^{(1)} I_{S}^{\prime \prime(1)}}\right)=0
$$

onde:

$$
\left\{\begin{array}{l}
V_{F}^{(0)}=A(x)^{(0)} V_{S}^{(0)}-B(x)^{(0)} I_{S}^{(0)} \\
V_{F}^{(1)}=A(x)^{(1)} V_{S}^{(1)}-B(x)^{(1)} I_{S}^{(1)} \\
V_{F}^{(2)}=A(x)^{(2)} V_{S}^{(2)}-B(x)^{(2)} I_{S}^{(2)}
\end{array}\right.
$$

O método apresentado em Takagi et al. (1981) fora posteriormente particularizado para linhas com comprimento inferior a $100 \mathrm{~km}$. As considerações necessárias à referida particularização são relatados em Takagi et al. (1982) e, tal como feito em Takagi et al. (1981), o método se fundamenta sobre o conjunto de equações que segue. 


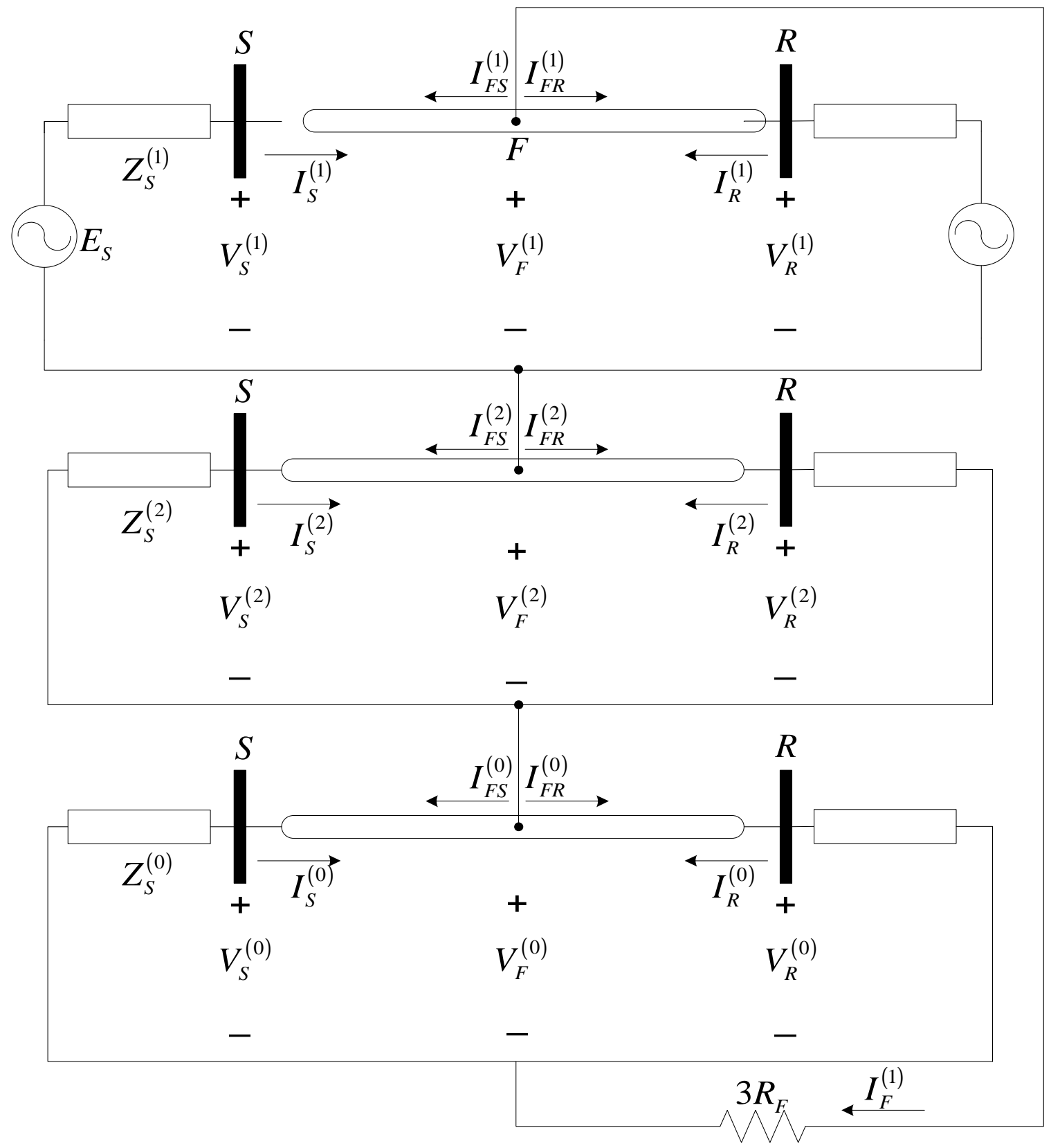

Figura 4.16 - Rede de sequencia para uma falta fase-terra.

$$
\begin{aligned}
& V_{F}=R_{F} I_{F}=-R_{F}\left(I_{F S}^{\prime \prime}+I_{F R}^{\prime \prime}\right) \\
& V_{F}=V_{S} \cosh (\gamma x)-I_{S} Z_{c} \operatorname{senh}(\gamma x) \\
& I_{F S}^{\prime \prime}=\frac{V_{S}^{\prime \prime}}{Z_{c}} \operatorname{senh}(\gamma x)-I_{S}^{\prime \prime} \cosh (\gamma x)
\end{aligned}
$$

Dessa forma, a corrente de falta $I_{F}$ fora expressa por meio do seguinte relacionamento: 


$$
I_{F}=I_{F S}^{\prime \prime} \dot{\zeta}
$$

onde $\dot{\zeta}=\zeta e^{j \theta}$ e $\theta=\arg \left(I_{F} / I_{F S}^{\prime \prime}\right)$ representa a diferença angular entre as correntes de falta provenientes da barra $S$ e da barra $R$. Segundo Takagi et al. (1982), o valor de $\theta$ esperado é próximo a zero. Dessa forma, substituindo (4.18), bem como (4.16), (4.17) e (4.18) na referida expressão e dividindo ambos os termos por $\cosh (\gamma x)$, tem-se:

$$
V_{S}-I_{S} Z_{c} \tanh (\gamma x)-R_{F}\left(\frac{V_{S}^{\prime \prime}}{Z_{c}} \tanh (\gamma x)-I_{S}^{\prime \prime}\right) \zeta e^{j \theta}=0
$$

Percebe-se que $\zeta$ e $R_{F}$ são números reais. Então, isolando-se o termo $\zeta R_{F}$ e tomando apenas a parte imaginária de ambos os lados da igualdade se pode eliminar estas duas incógnitas da formulação, chegando-se à seguinte expressão:

$$
\operatorname{Im}\left[\left(V_{S}-I_{S} Z_{c} \tanh (\gamma x)\right)\left(\frac{V_{S}^{\prime \prime}}{Z_{c}} \tanh (\gamma x)-I_{S}^{\prime \prime}\right)^{*} e^{j \theta}\right]=0
$$

Na equação acima, $\theta$ e $x$ são valores desconhecidos. Então, sabendo-se do valor de $\theta$, a distância da falta $x$ pode ser determinada. Conforme mencionado anteriormente, o ângulo $\theta$ representa a diferença angular entre as correntes de falta do terminal local e remoto. Segundo Takagi et al. (1982), o valor do ângulo $\theta$ é aproximadamente nulo. Então, substituindo $\theta$ por zero e usando as seguintes aproximações, que segundo Takagi et al. (1982) são válidas para linhas curtas,

$$
\begin{aligned}
& \tanh (\gamma x) \cong \gamma x \\
& \frac{V_{S}^{\prime \prime}}{Z_{c}} \tanh (\gamma x)<<I_{S}^{\prime \prime}
\end{aligned}
$$


chega-se a expressão seguinte que pode ser utilizada para determinar a distância da falta:

$$
x=\frac{\operatorname{Im}\left(V_{S} I_{S}^{\prime * *}\right)}{\operatorname{Im}\left(Z I_{S} I_{S}^{\prime *}\right)}
$$

onde $Z=\gamma Z_{c}$ é a impedância da linha por unidade de comprimento. Por meio das aproximações sugeridas em Takagi et al. (1982), a localização de faltas para sistemas trifásicos pode ser particularizada para as faltas fase-terra da seguinte maneira:

$$
x=\frac{\operatorname{Im}\left(I_{S}^{\prime *}\left(V_{S}^{(0)}+V_{S}^{(1)}+V_{S}^{(2)}\right)\right)}{\operatorname{Im}\left(I_{S}^{\prime \prime *}\left(Z^{(0)} I_{S}^{(0)}+Z^{(1)} I_{S}^{(1)}+Z^{(2)} I_{S}^{(2)}\right)\right)}
$$

De fato, os métodos de localização de faltas apresentados nessa seção foram desenvolvidos especificamente para sistemas de transmissão de energia. As linhas de transmissão são geralmente consideradas homogêneas ao longo de sua extensão, ou seja, é constituída de um único condutor sem cargas ou derivações em pontos intermediários. Por outro lado, nos sistemas de distribuição de energia, um mesmo alimentador pode ser constituído de segmentos com diferentes condutores, resultando em trechos com valores de impedância por unidade de comprimento distintos. Além disso, diversas cargas e ramificações podem estar conectadas ao longo do alimentador. Estas características fazem com que os métodos descritos anteriormente não possam ser utilizados diretamente nestes sistemas. Para se obter uma estimativa precisa da distância da falta em sistemas de distribuição de energia elétrica se faz necessário considerar as diversas cargas conectadas ao longo do alimentador, bem como eventuais ramificações laterais, ou seja, a modelagem do 
alimentador deve contemplar o máximo de informações possíveis a fim de garantir resultados próximos aos observados em sistemas de distribuição reais.

Complementando a citação dos adventos nessa linha, no trabalho de Lee et al. (2004) foi apresentado um algoritmo iterativo para localização de faltas em sistemas de distribuição de energia que leva em conta as características de tais sistemas. O algoritmo executa o cálculo da distância de falta para cada seção do alimentador, sendo as tensões e correntes em cada nó do circuito estimadas via análise de circuitos. Assim, pode-se pensar no algoritmo proposto como a aplicação do Takagi simplificado para cada trecho da linha de distribuição. Além do referido trabalho, Girgis et al. (1993), Zhu et al. (1997) e Das et al. (2000) já haviam publicado anteriormente metodologias semelhantes, também baseadas nas estimativas dos valores de corrente e tensão em cada nó do alimentador. O algoritmo de Lee et al. (2004) será detalhado a seguir, uma vez que representa uma das abordagens, baseadas em análises de circuitos elétricos, mais recentes reportadas na literatura correlata.

Para o desenvolvimento do método proposto por Lee et al. (2004) faz-se necessário, inicialmente, a consideração de uma falta fase-terra envolvendo a fase a de um alimentador de distribuição de energia conforme a Figura 4.17.

Assim, a tensão na barra $S$, representativa da barra da subestação de distribuição, pode ser calculada da seguinte maneira:

$$
V_{S a}=x\left(Z_{L a} I_{S a}\right)+I_{F} R_{F}
$$

A equação (4.25) pode então ser desenvolvida conforme se segue:

$$
\begin{aligned}
& I_{F} R_{F}=V_{S a}-x Z_{L a} I_{S a} \\
& I_{F}^{*} I_{F} R_{F}=I_{F}^{*}\left(V_{S a}-x Z_{L a} I_{S a}\right)
\end{aligned}
$$




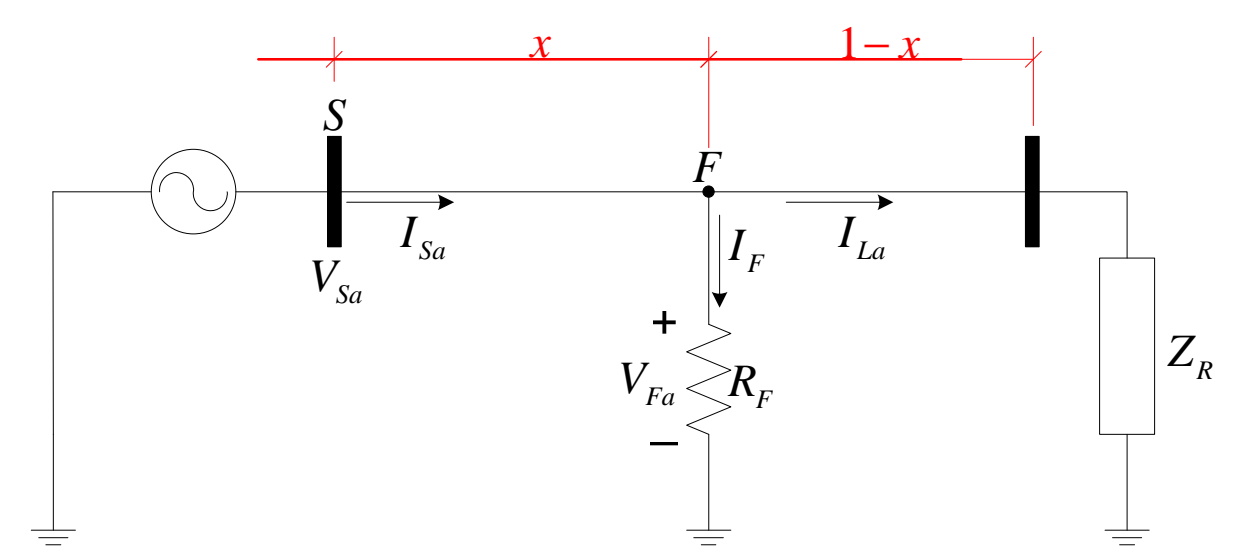

Figura 4.17 - Modelo simplificado do alimentador de distribuição.

Como $I_{F}^{*} I_{F} R_{F}$ resulta em um valor real, tem-se que a parcela imaginária de $I_{F}^{*}\left(V_{S a}-x Z_{L a} I_{S a}\right)$ será nula, tornando então possível a determinação da distância $x$, ou seja:

$$
x=\frac{\operatorname{Im}\left(V_{S a} I_{F}^{*}\right)}{\operatorname{Im}\left(Z_{L a} I_{S a} I_{F}^{*}\right)}
$$

onde:

$$
I_{F}=I_{S a}-I_{L a}
$$

Em função da existência de cargas intermediárias ao longo de um alimentador de distribuição e da elevada resistência da linha, as quedas de tensão provocadas pela falta podem se tornar significativas e com isso modificar a corrente consumida por cada carga do circuito, se estas forem modeladas como impedância ou potência constante. Assim, é equivocada a hipótese de que a corrente de carga durante a falta $\left(I_{L a}\right)$ pode ser assumida como sendo seu valor pré-falta $\left(I_{S a}\right)$. Pode-se observar que se esta aproximação for feita, a Equação (4.27) torna-se idêntica à Equação (4.23) determinada pelo método de Takagi para linha curtas.

Logo, $I_{\text {La }}$ é também uma incógnita na formulação. Lee et al. (2004) propuseram em seu trabalho uma técnica iterativa para estimar seu valor. Esse 
processo iterativo compõe o algoritmo de localização de faltas em sistemas de distribuição de energia elétrica, o qual é composto das seguintes etapas:

ETAPA 1: Assume-se $I_{L a}$ como sendo o valor da corrente de carga;

ETAPA 2: Calcula-se a corrente de falta $I_{F}$ utilizando (4.28);

ETAPA 3: Determina-se a primeira estimativa da localização da falta utilizando (4.27);

ETAPA 4: Calcula-se a tensão no ponto da falta utilizando (4.29);

$$
\left(\begin{array}{l}
V_{F a} \\
V_{F b} \\
V_{F c}
\end{array}\right)=\left(\begin{array}{l}
V_{S a} \\
V_{S b} \\
V_{S c}
\end{array}\right)-x\left(\begin{array}{l}
Z_{L a} I_{S a} \\
Z_{L b} I_{S b} \\
Z_{L c} I_{S a}
\end{array}\right)
$$

ETAPA 5: Utiliza-se a tensão de falta para obter um valor de $I_{L a}$ atualizado;

ETAPA 6: Volta-se à Etapa 2 com um novo valor de $I_{F}$ e o processo é repetido até que $x$ convirja.

Verifica-se, contudo, que conforme apresentado para a Etapa 4 do algoritmo proposto por Lee et al. (2004), faz-se necessário a estimação do valor da corrente de carga $I_{L a}$ durante a falta a partir do valor atualizado da tensão no ponto da falta. Se a carga é modelada como impedância constante e seu valor é conhecido, pode-se calcular $I_{L a}$ da seguinte forma:

$$
I_{L a}=Y_{L a} V_{F a}
$$

$\mathrm{Na}$ equação anterior, $Y_{L a}$ representa a matriz admitância da seção da linha após o ponto da falta e da carga, sendo que seu valor pode ser calculado da seguinte maneira:

$$
Y_{L a}=\left((1-x) Z_{L a}+Z_{R}\right)^{-1}
$$


Se a impedância da carga não for conhecida, pode-se estimar $I_{L a}$ a partir da equação (4.32).

$$
I_{L a}=\frac{I_{L a}^{\prime}}{V_{F a}^{\prime}} V_{F a}
$$

onde $V_{F a}^{\prime}$ é a tensão pré-falta da fase a no ponto da falta, dada por meio de (4.33); $I_{L a}^{\prime}$ é a corrente de carga pré-falta da fase a, tal como $V_{S a}^{\prime}$ é a tensão pré-falta da fase a medida na barra $S$. Nota-se que na equação (4.32), $Y_{L a}$ foi substituído por uma estimativa do seu valor com base em valores pré-falta medidos na subestação.

$$
V_{F a}^{\prime}=V_{S a}^{\prime}-x Z_{L a} I_{L a}^{\prime}
$$

Se a distância de falta obtida $x$ é maior do que a extensão da seção considerada significa que a falta não ocorreu nesta, mas sim em alguma das seções seguintes. Então, um novo processo de localização da falta deve ser executado para a próxima seção, utilizando os valores de corrente e tensão no seu nó inicial. No entanto, como as medições de corrente e tensão são realizadas apenas na subestação, faz-se necessário uma maneira de estimar estes valores em cada nó do alimentador. Assim, considerando o modelo completo de um alimentador radial exposto na Figura 4.18, a tensão no nó $k+1$ pode ser obtida por meio da Equação (4.34).

$$
V_{k+1}=V_{k}-Z_{k} I_{k}
$$

onde $V_{k}$ é a tensão na barra $k, Z_{k}$ é a impedância da $k$-ésima seção de linha e $I_{k}$ é o valor da corrente na k-ésima seção. Considerando as cargas como impedância constante, a $k$-ésima corrente de carga pode ser calculada por meio de (4.35).

$$
I_{L k}=Y_{L k} V_{k}
$$


onde $I_{L k}$ é a corrente consumida pela carga conectada na barra $k$ e $Y_{L k}$ é a admitância desta carga. Finalmente, pode-se calcular a corrente da k-ésima seção do alimentador utilizando a equação (4.36).

$$
I_{k}=I_{k-1}-I_{L k}
$$

Assim, o algoritmo de localização de faltas em sistemas de distribuição de energia elétrica proposto executa um processo de localização de faltas para cada seção do alimentador, utilizando as estimativas de $V_{k}$ e de $I_{k}$ descritas. Uma vez que $x$ converge para um valor de distância no intervalo da seção em análise, o algoritmo é finalizado, bastando somar a distância $x$ com o valor das distâncias das seções de linha anteriores para que a localização da falta seja determinada.

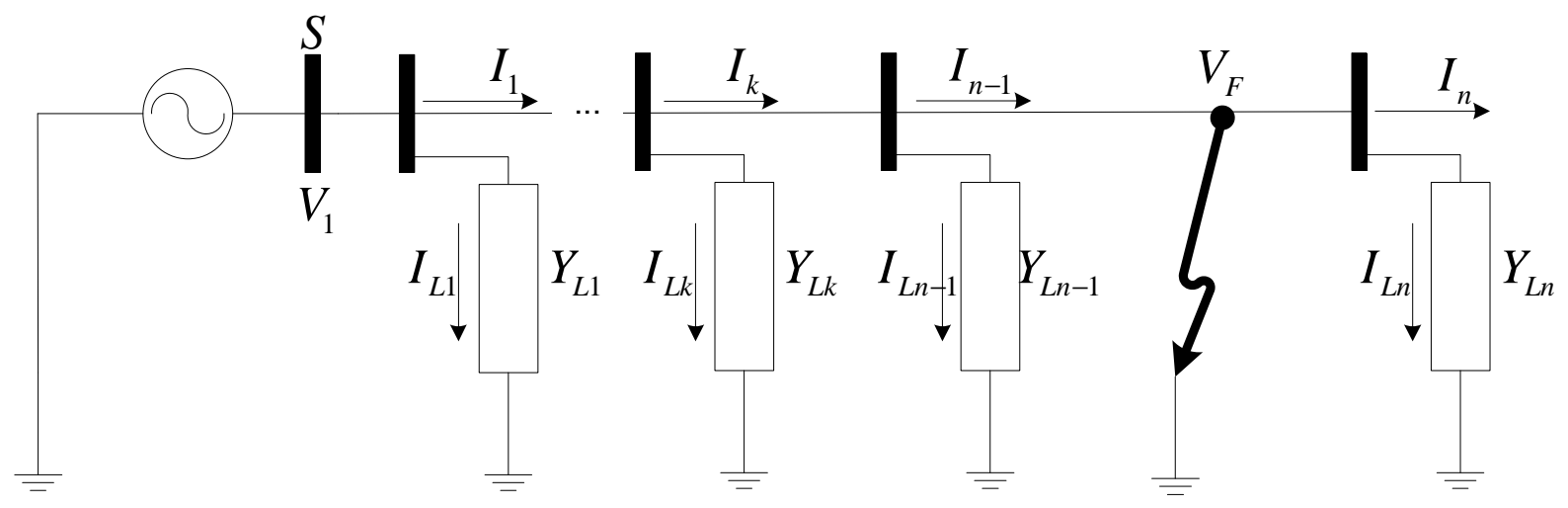

Figura 4.18 - Modelo completo do alimentador de distribuição.

Uma das características principais dos sistemas de distribuição de energia é a presença de ramificações laterais nos alimentadores. Nos métodos de localização de faltas descrito nessa seção, a presença de ramificações laterais pode fazer com que uma determinada falta seja localizada em diversos pontos diferentes do sistema. Ou seja, a mesma falta, aplicada em locais diferentes pode induzir valores de tensão e corrente iguais na subestação.

No trabalho de Lee et al. (2004) é também proposta uma metodologia para a identificação da lateral na qual ocorreu a falta. O método é baseado na observação 
dos padrões da corrente durante o tempo de isolamento da falta. Dadas as características dos diversos dispositivos de proteção presentes ao longo do alimentador (basicamente fusíveis e religadores) e suas localizações, é possível determinar, por meio da forma de onda da corrente na subestação, qual dispositivo atuou no isolamento da falta e com isso, determina-se a lateral. Além destas informações, o método utiliza a medida da quantidade de carga interrompida após a atuação da proteção, como indicativo da lateral envolvida na falta.

Assim, desenvolveu-se para utilização neste trabalho uma metodologia de análise que busca averiguar mapas de impedância e modificações das potências e sua evolução durante a falta.

Através da modelagem computacional dos circuitos, Figuras 4.19 à 4.21 , é possível traçar diferentes mapas de impedâncias dos circuitos modelado em diferentes frequências, o que traz para um mesmo circuito representações diferentes, permitindo observar seu comportamento em diferentes frequências.

A impedância observada para uma determinada falta vai depender do comportamento do circuito perante essa falta, contento todas distorções harmônicas dos sinais de tensão e corrente de falta.

Comparando o mapa da variação da impedância Z1 da Figura 4.19, com o mapa da variação da impedância Z0 da Figura 4.20 para o alimentador INP1306, podem-se observar representações diferentes para um mesmo circuito. 


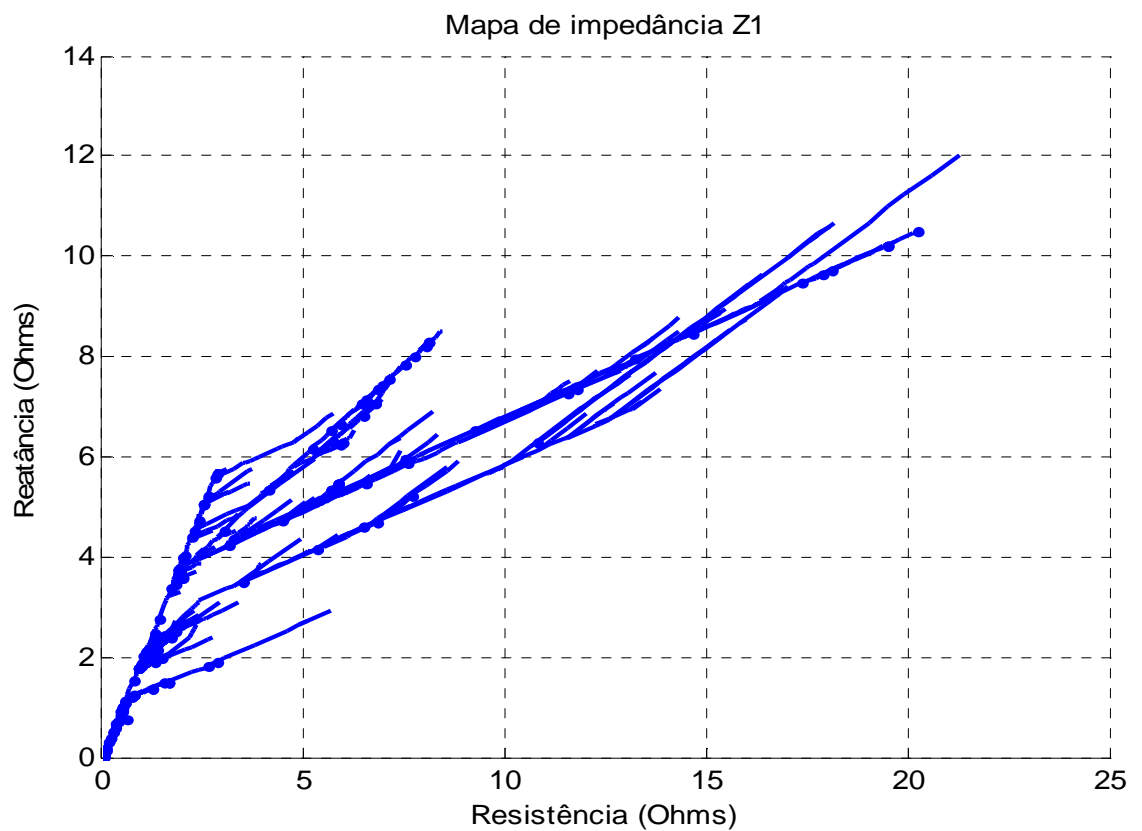

Figura 4.19 - Impedância Z1 para o INP1306.

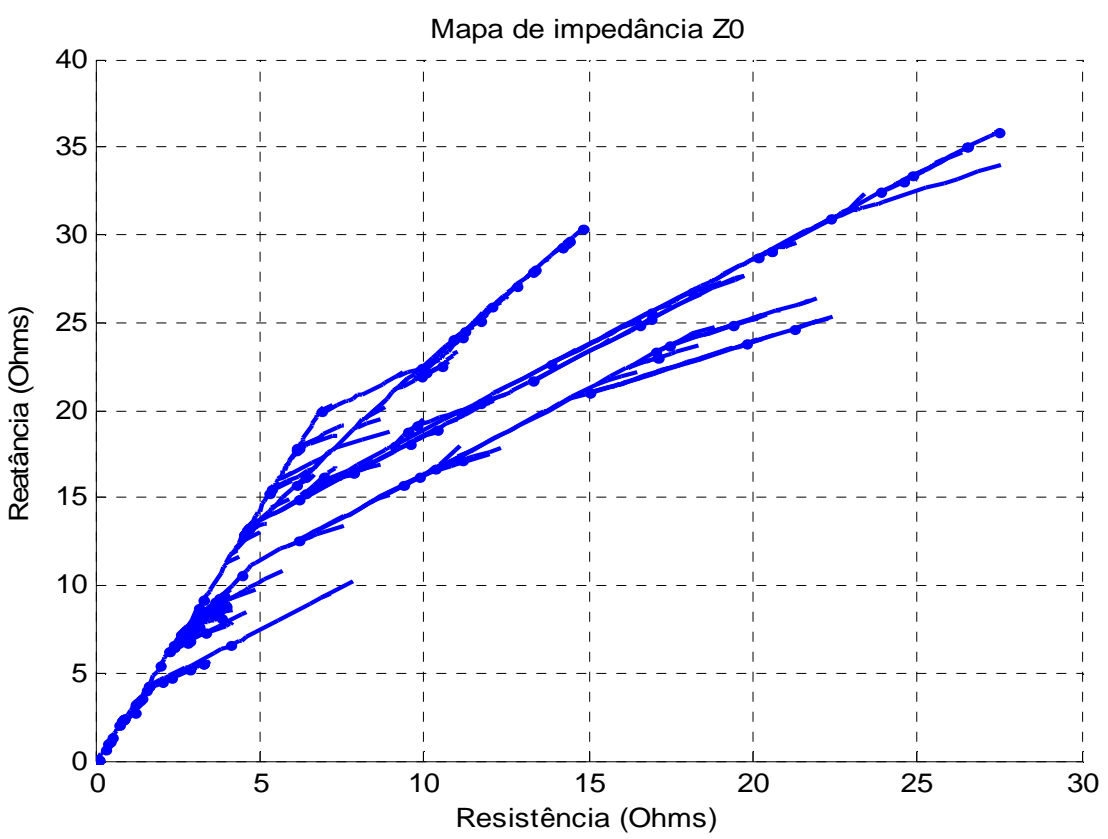

Figura 4.20 - Impedância Z0 para o INP1306.

Outra análise que também se configurou interessante foi à influência das componentes harmônicas da impedância fundamental. Quando da estimação da impedância da falta, uma característica elétrica de importante análise é a impedância fundamental estimada. 
Tais fenômenos podem ser conferidos na Figura 4.21, onde um estudo de caso fora realizado para o alimentador MCl1305.

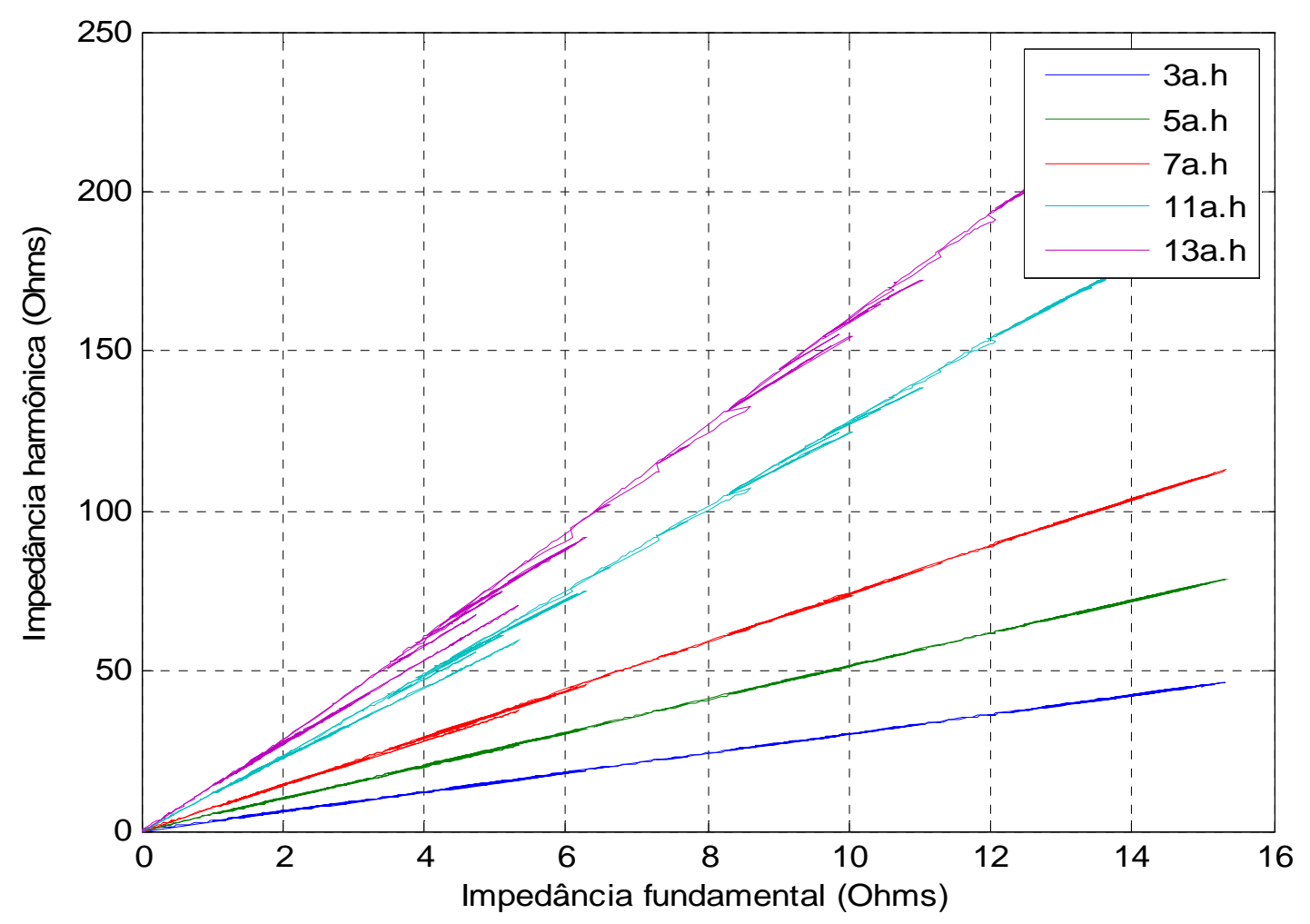

Figura 4.21 - Impedâncias harmônicas - MCl1305.

A figura acima mostra que a impedância harmônica também pode trazer varias representações para um mesmo circuito.

Desta maneira, elabora-se então o sistema de localização de faltas por múltiplas frequências, onde se permite obter também várias estimativas de local de falta, conforme ilustrado na Figura 4.22. 

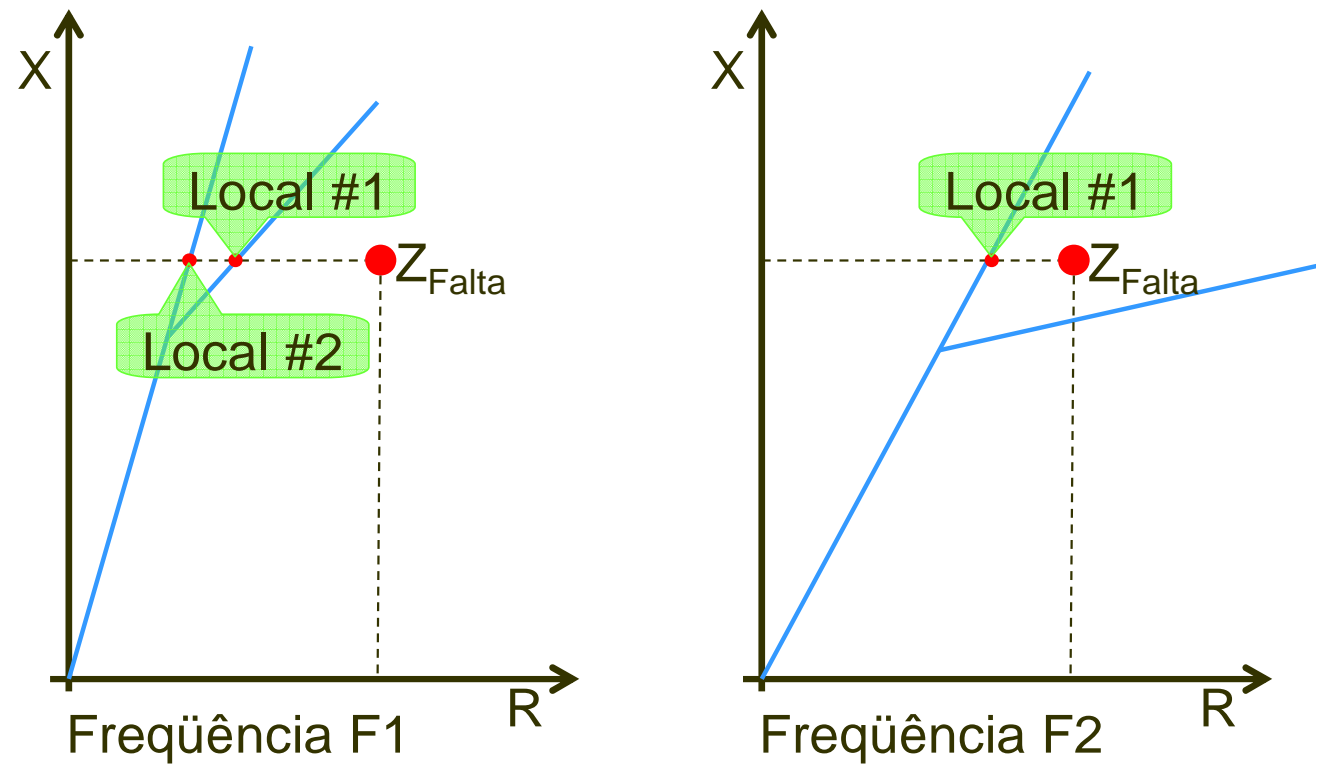

Figura 4.22 - Exemplo de localização de faltas com múltiplas frequências.

Da análise da figura anterior, observa-se que o ponto com os locais com a menor variância tende a ser aquele com maior probabilidade de ocorrência da falta. Assim, a variância será uma das métricas para se quantificar a probabilidade da falta ter acontecido em um determinado ponto.

Outro aperfeiçoamento realizado no sistema de identificação de faltas tem relação direta com as alterações de potência ativa e reativa durante a falta, as quais foram observadas por meio de diversas análises oscilográficas. Um exemplo de tais alterações pode ser conferido por meio da Figura 4.23. 


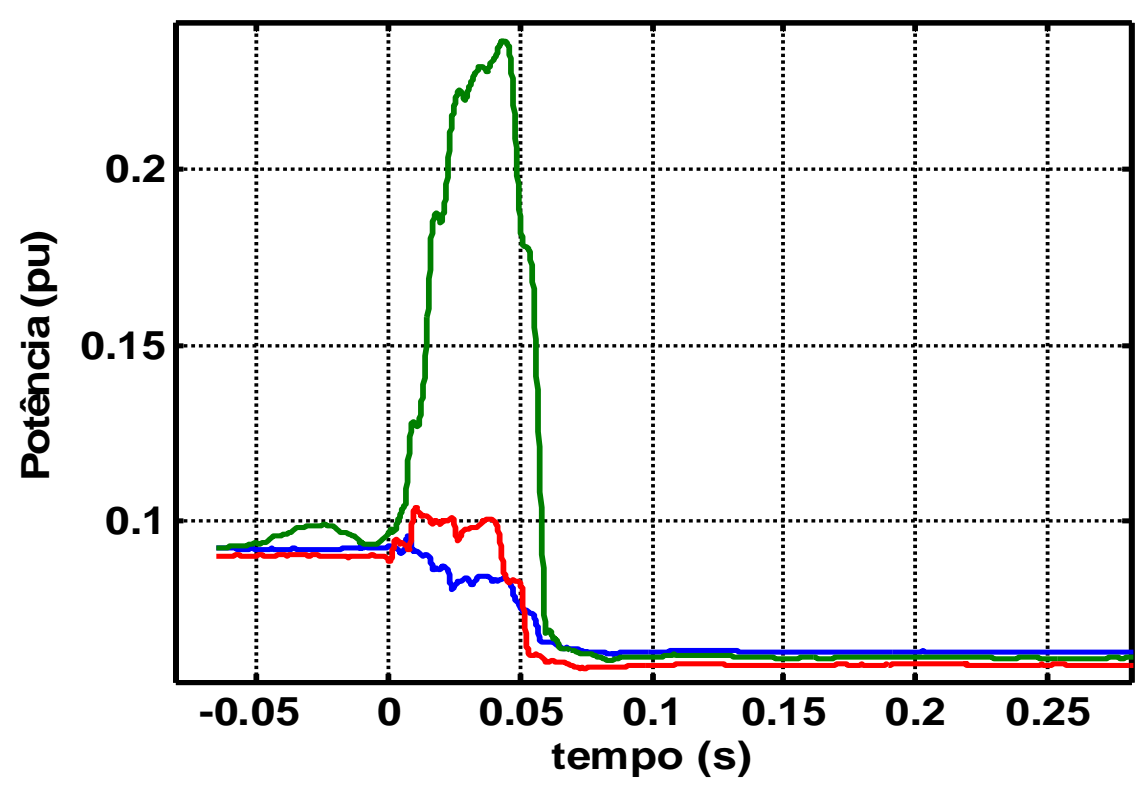

Figura 4.23 - Detecção da alteração da potência ativa e reativa para uma oscilografia de falta.

As variações de potência pré-falta e pós-falta permitem colher informações que ajudam no processo de classificação de locais prováveis de falta. Quando da modelagem dos circuitos para localização de faltas é possível inferir para cada um dos possíveis caminhos elétricos desse circuito sua distribuição de carga. Quando da ocorrência de uma falta às potências após o ponto de falta são afetadas. Essa distribuição de carga se comparada com essas alterações de potência pré e pós falta podem fornecer informações importantes para o propósito de setorização do local mais provável da ocorrência do defeito.

A Figura 4.24 sintetiza a arquitetura do sistema para localização de faltas desenvolvida. 


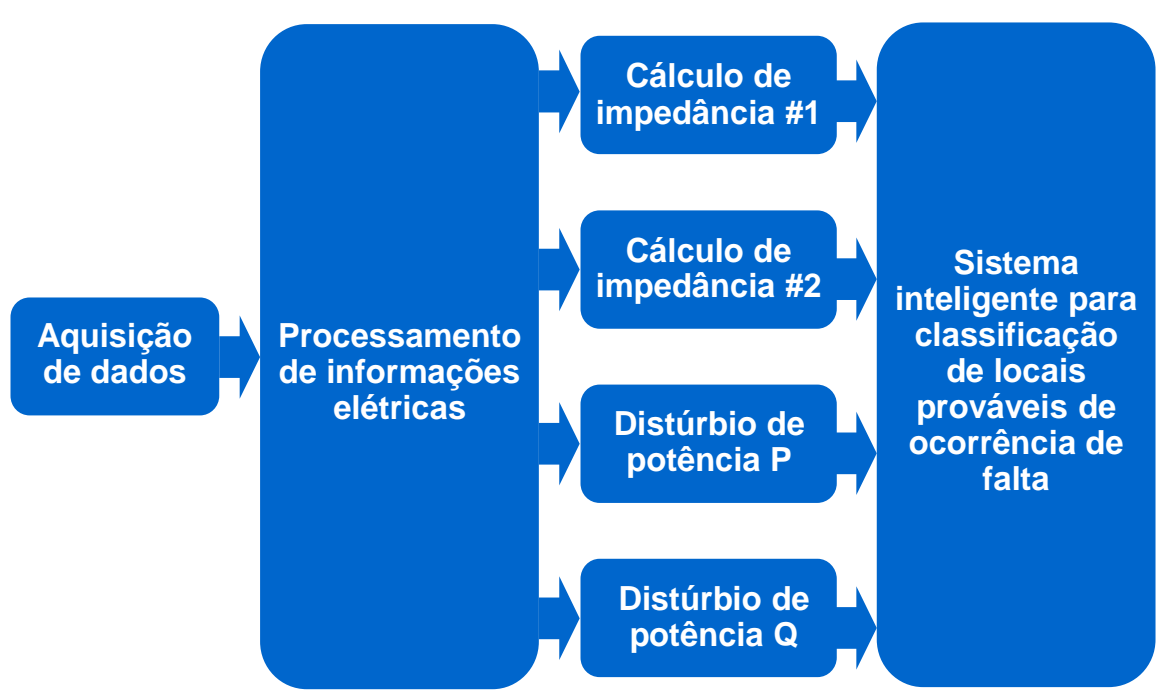

Figura 4.24 - Arquitetura do sistema de localização de faltas.

\subsection{Mapas de impedâncias para discriminar seção faltosa}

Um dos pontos mais importantes relacionados com a seleção da seção faltosa por qualquer mecanismo de localização relaciona-se com a escolha do trecho candidato que mais se assemelha com as características elétricas observadas durante a falta.

As análises consistem em investigar os mapas de resistência para R0 e R1, além dos mapas de reatância X0 e X1 em função da distância.

Nas quatro figuras 4.25 a 4.28 , a seguir, exemplificam-se os mapas de impedância para dois estudos de caso envolvendo os alimentadores pilotos INP1306 e MCl1305. 


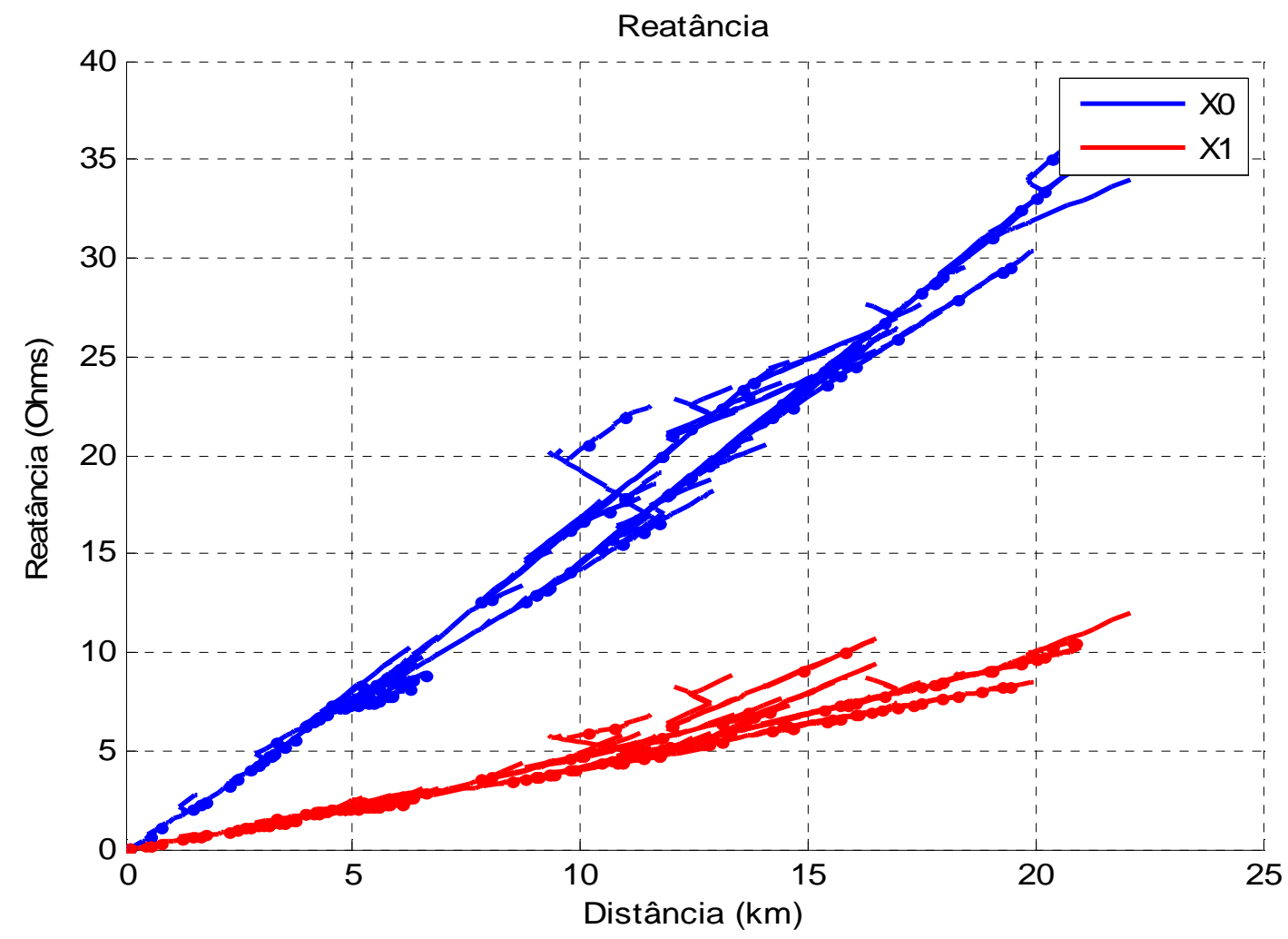

Figura 4.25 - Mapa de evolução da Reatância - INP1306.

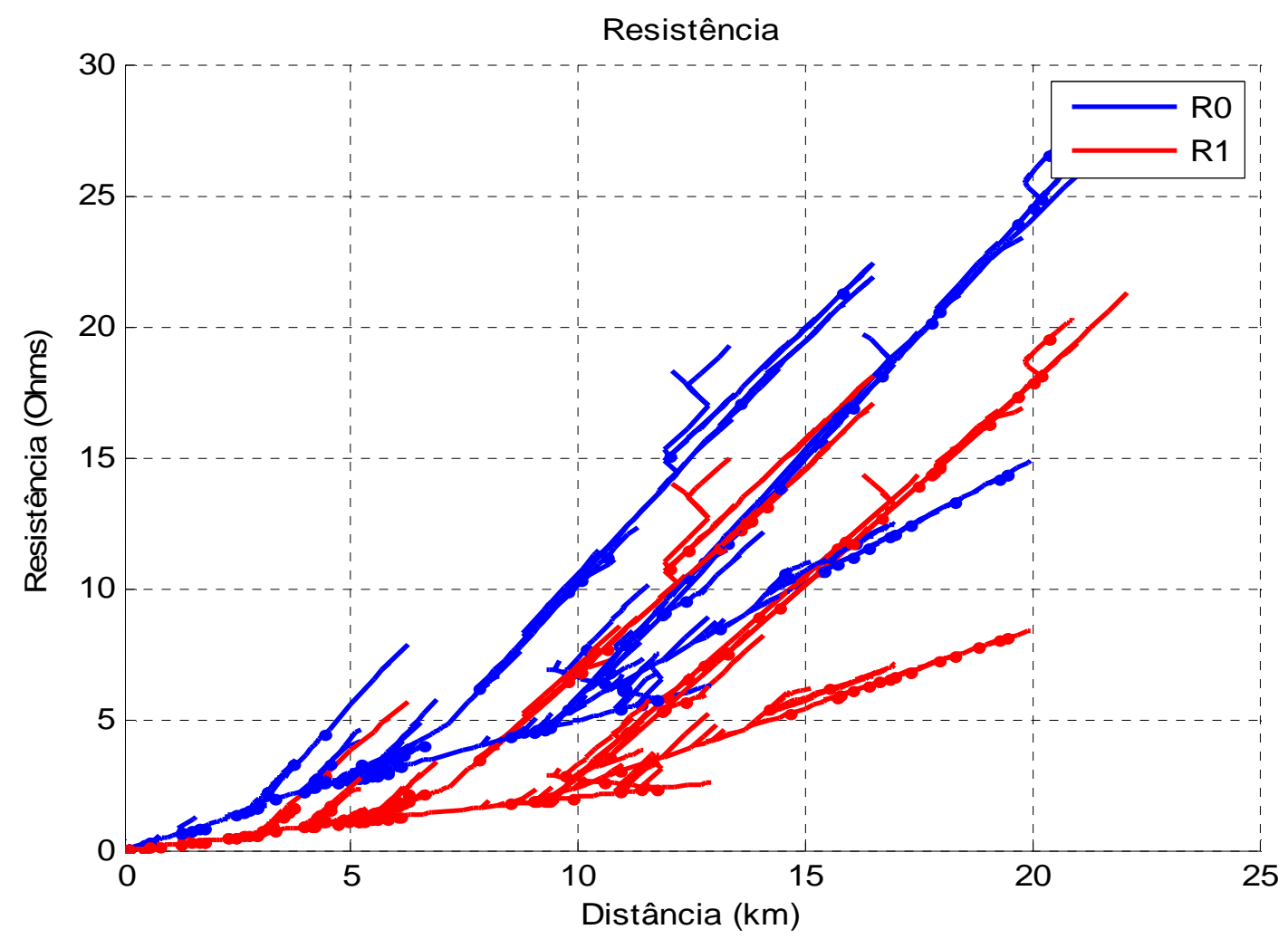

Figura 4.26 - Mapa de evolução da Resistência - INP1306. 


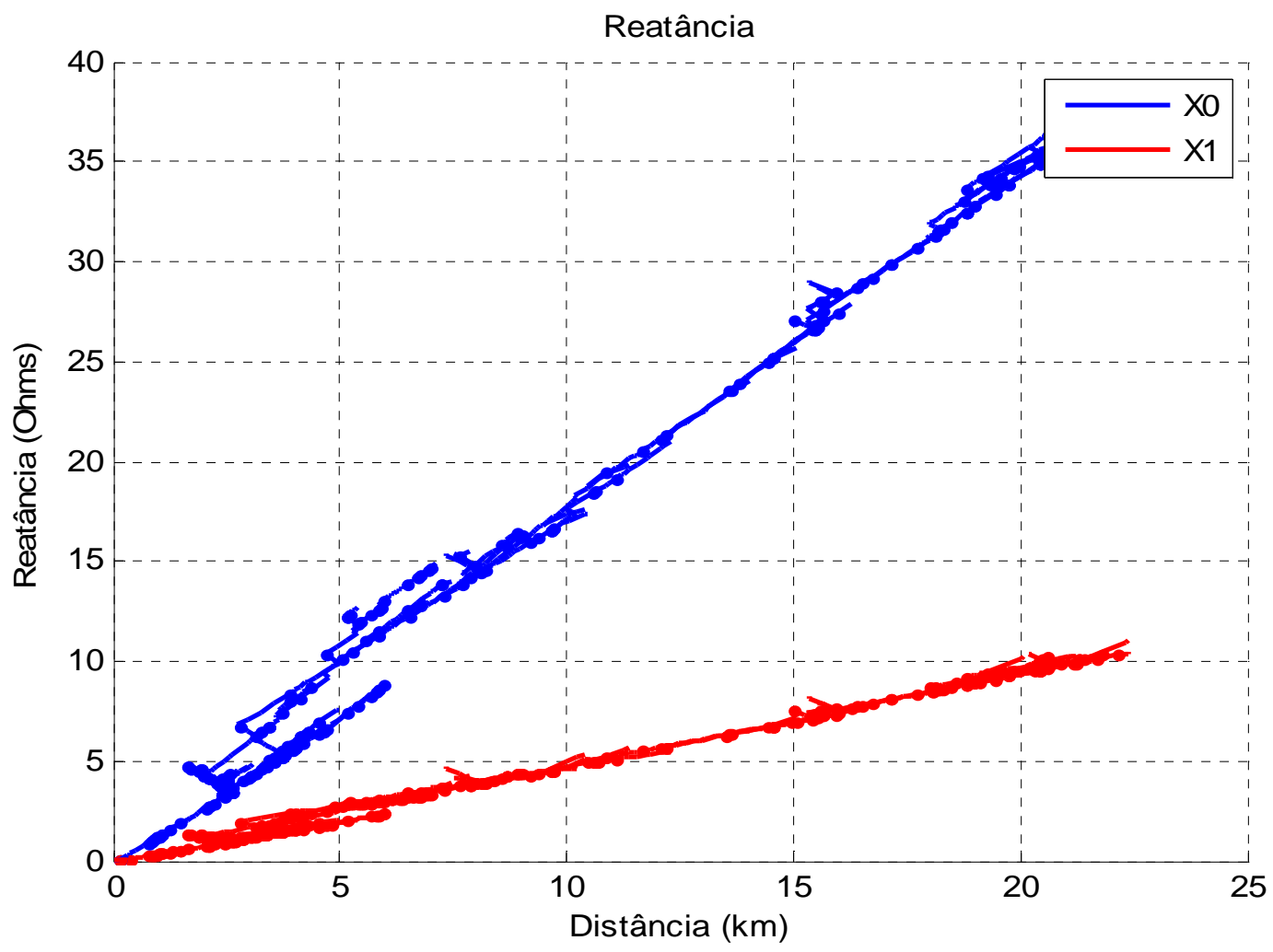

Figura 4.27 - Mapa de evolução da Reatância - MCl1305.

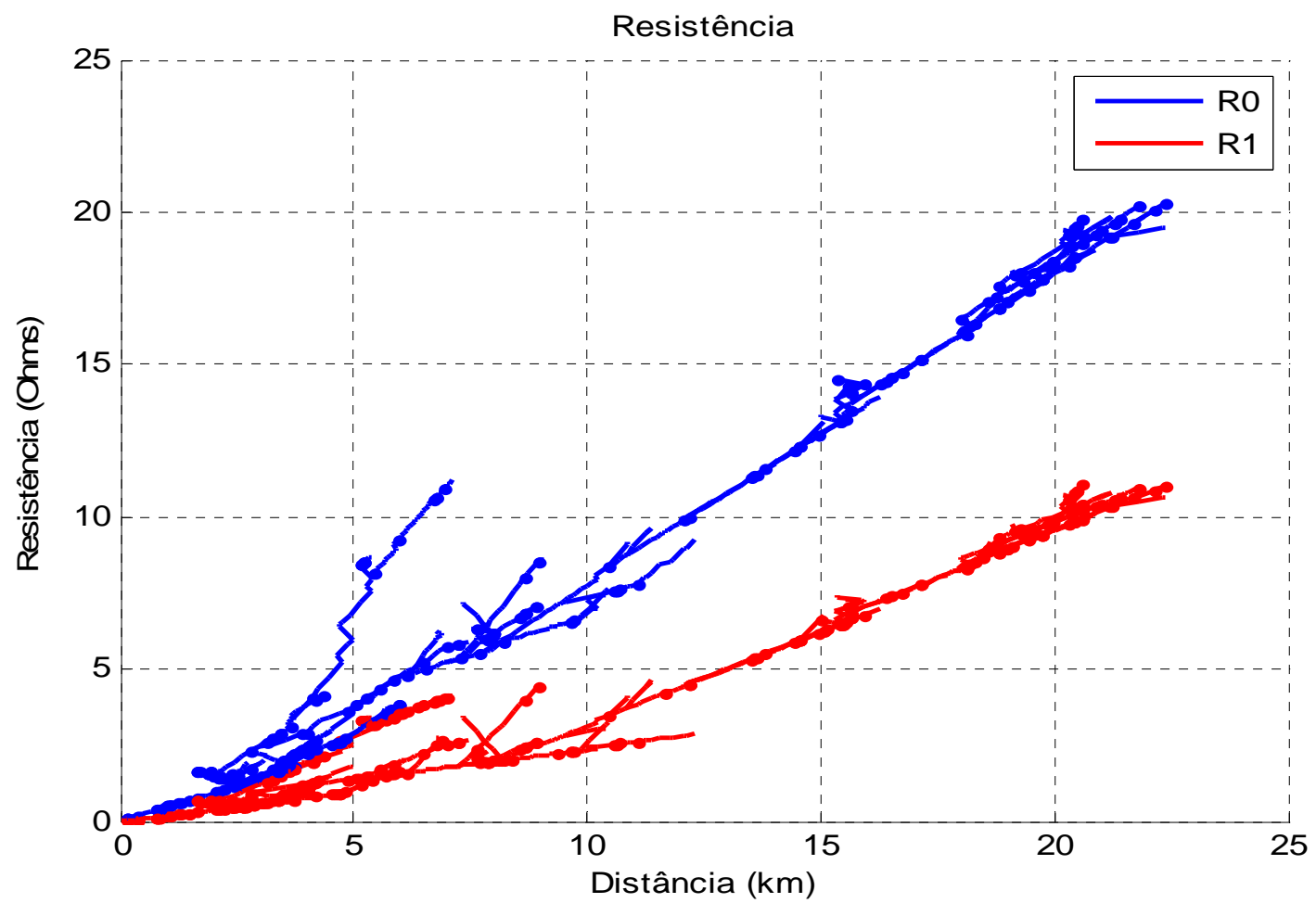

Figura 4.28 - Mapa de evolução da Resistência - MCl1305. 
Mapas como os apresentados nos exemplos acima permitem inferir a influência da distância $(\mathrm{em} \mathrm{km})$ para o processo de estimação da impedância da falta, fornecendo-se assim caminhos de solução que contornam o problema da multiestimação de seções faltosas.

\subsection{Conversão de arquivos COMTRADE para auxiliar processos de localização de faltas pelo Centro de Operação da Distribuição}

Com o aumento das aplicações de tecnologias digitais na medição, proteção e controle de sistemas elétricos de potência, tem-se criado uma grande quantidade de dados trafegados digitalmente. Os usuários desses dados se deparam com o problema de ter que lidar com diferentes formatos de arquivos usados pelos diversos sistemas de aquisição de dados existentes.

O formato COMTRADE (IEEE Standard Common Format for Transient Data Exchange for Power Systems) surgiu de modo a possibilitar a troca de informações a respeito de um determinado evento na rede. Nele é definido um padrão comum para a troca de dados digitais e mídias em sistemas elétricos de potência (IEEE C37.111, 1999).

Os arquivos definidos pelo COMTRADE devem estar a princípio em formato ASCII e são formados por um conjunto de arquivos. São definidos, para cada evento, três tipos de arquivos: cabeçalho, configuração e dados. Os arquivos são na forma "xxxxxxxx.yyy" onde "xxxxxxxx" é usado para identificar o evento e ".yyy" é usado para identificar o tipo do arquivo: ".HDR" para cabeçalho (HeaDeR), ".CFG" para configuração (ConFiGuration) e ".DAT" para dados (DATa), isto é: 
Arquivos de Cabeçalho: Contém informações criadas pelo originador dos dados. Este arquivo deve ser lido ou impresso pelo usuário. Não existe qualquer formato específico, apesar de se aconselhar que tipo de informações deva ser escrito. O único cuidado ao gerá-lo é forçar o editor utilizado a salvar o texto em formato ASCII, sem usar os caracteres especiais de formatação específicos de cada editor.

Arquivos de Configuracão: Devem ser lidos por um programa de computador e seu formato, conforme definido na norma, deve ser fielmente obedecido. Possui informações que permitirão interpretar corretamente os dados do transitório. Estas informações incluem itens como: taxas de amostragem, número de canais, frequência da linha, informação dos canais, etc.

Arquivos de Dados: Contém o valor de cada amostra de cada canal medido. O número guardado no arquivo será em formato inteiro, normalmente correspondente ao formato do equipamento digitalizador. No arquivo de configuração são especificados meios de traduzir estes valores adequadamente para grandezas reais, tais como Volts, Ampéres etc. $\mathrm{O}$ arquivo de dados pode estar em formato binário desde que se forneça juntamente um programa que o traduza para formato ASCII.

O COMTRADE define um formato comum para arquivos de dados digitais e mídias, necessários para troca de vários tipos de dados de perturbações, ensaios e simulação. Não há imposição sobre taxa de amostragem e resolução. Há a necessidade, entretanto, de enquadrar em grupos de taxa de amostragem que variam dentro de faixas predefinidas.

Para possibilitar o envio das informações de faltas ao COD, foi necessário o desenvolvimento de um código computacional para conversão dos dados dos 
arquivos ".DAQ", provenientes da placa de aquisição de dados instalada nas subestações, para COMTRADE.

Nas Figuras 4.29 e 4.30 é possível conferir um exemplo dos arquivos de configuração ".CFG" e dados ".DAT" de uma oscilografia gerada por uma falta simulada em uma das subestações em estudo. Tal simulação consistiu de se desconectar temporariamente uma das garras de corrente e conectá-la novamente.

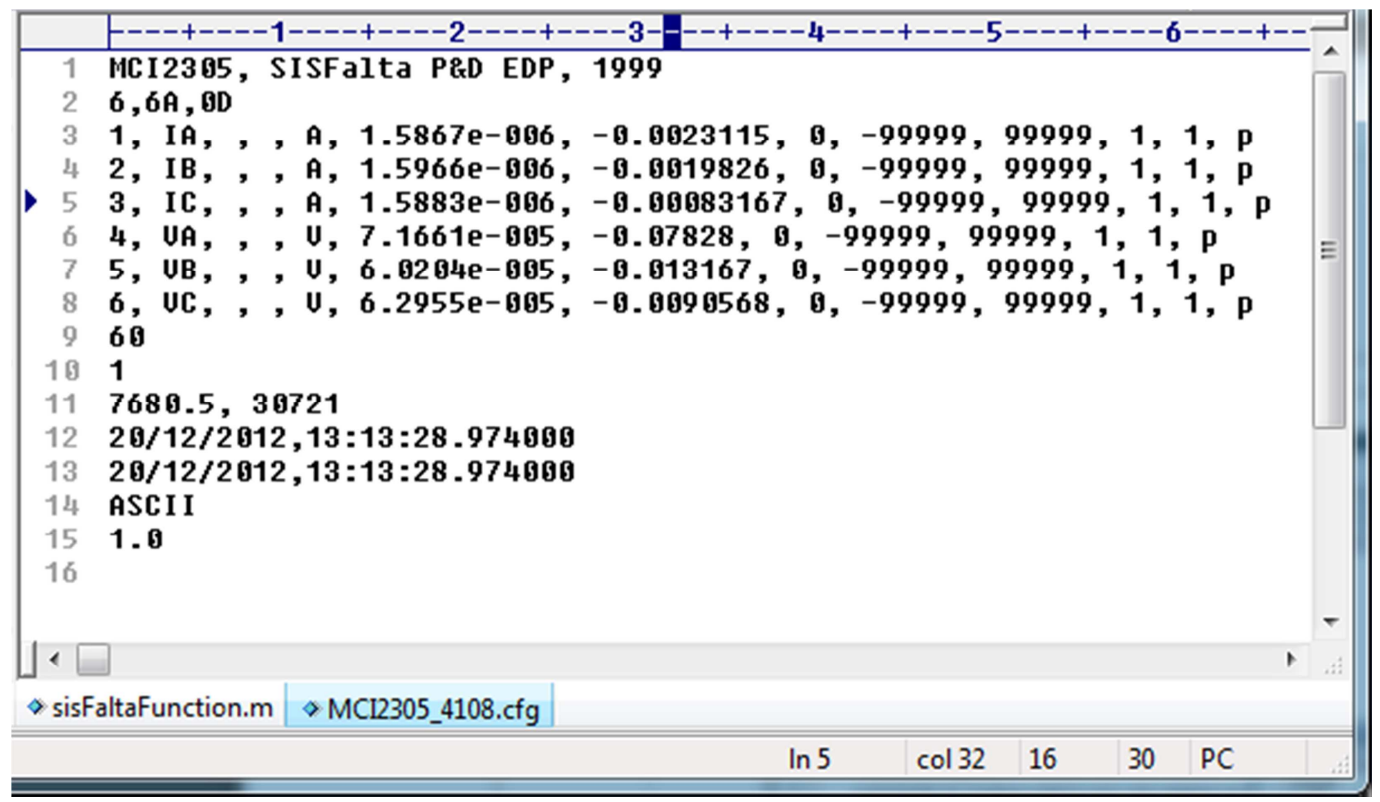

Figura 4.29 - Exemplo de arquivo ".CFG" gerado pelo sistema instalado na SE.

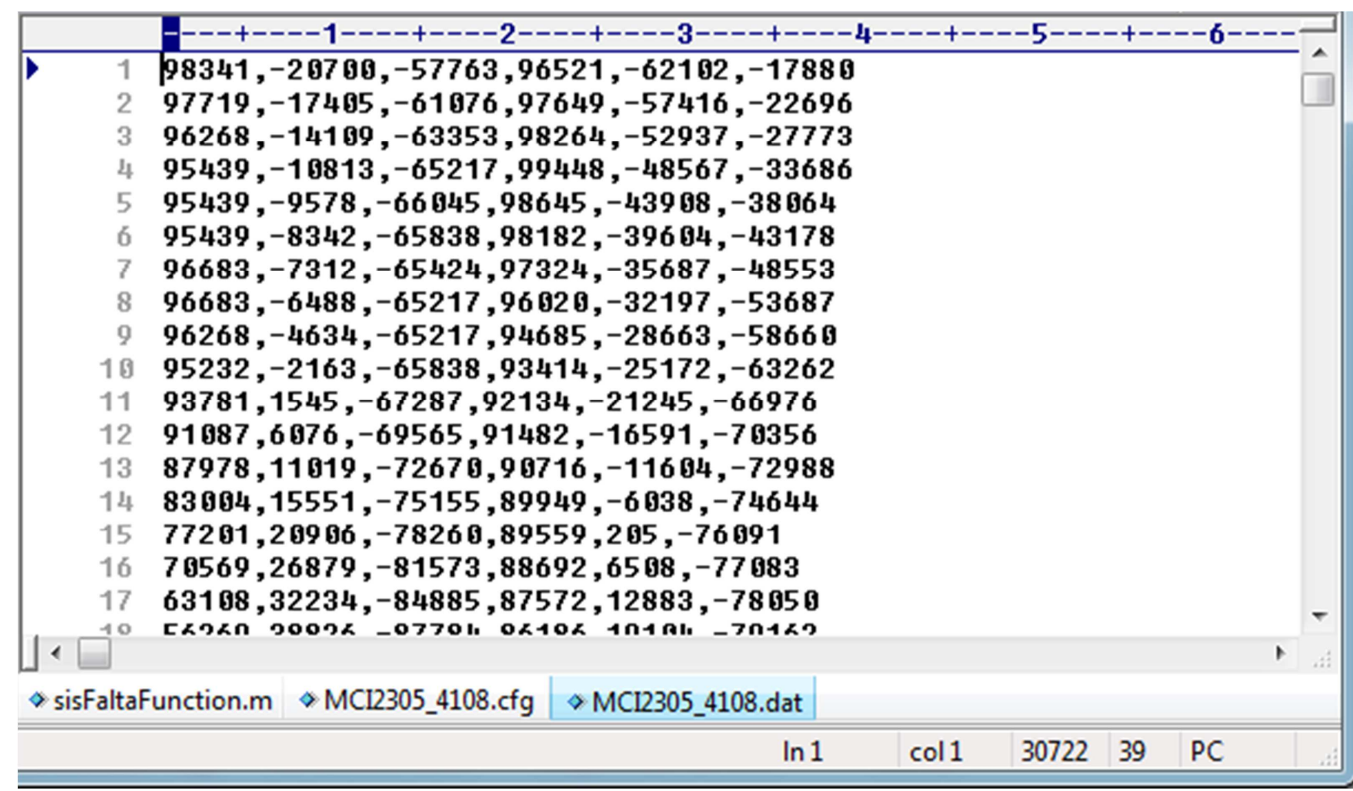

Figura 4.30 -. Exemplo de arquivo ".DAT" gerado pelo sistema instalado no alimentador MCl1305. 
Em se tratando de um estudo inovador, e pela necessidade de duplicidade de informações nas bases do centro de operação, a nomenclatura do alimentador recebeu novo nome para os propósitos desse trabalho.

No Apêndice $D$, se encontra registrado o código que realiza a conversão dos arquivos “.DAQ”, para COMTRADE.

Um enfoque especial deve ser dado aos processos envolvendo a adequação dos padrões de sincronismo de arquivos necessários ao envio das informações de faltas pela central remota instalada na subestação ao Centro de Operações da Distribuição (COD).

$\mathrm{Na}$ maioria das vezes, tais arquivos são compactados em um único envelope, para facilitar os processos de transmissão e possuem uma nomenclatura específica para que o sistema consiga interpretar os dados.

Para o sincronismo realizado nos estudos pilotos, destacam-se dois arquivos que necessitam ter nomenclatura padronizada e também estar compactados.

O primeiro arquivo, REL_OSC_QMCI2305.ZIP, cuja nomenclatura indica que se trata dos relatórios de oscilografias do alimentador $\mathrm{MCl} 2305$, é o envelope responsável pelos arquivos COMTRADE propriamente ditos, englobando os arquivos ".CFG", ".HDR" e ".DAT". O arquivo ".HDR" apesar de não possuir nenhum formato específico, não será utilizado para os propósitos de envio das informações de localização de faltas.

$\mathrm{Na}$ Figura 4.31 tem-se o exemplo do conteúdo de um arquivo ".ZIP" proveniente de uma simulação de falta realizada em uma das subestações em estudo. 


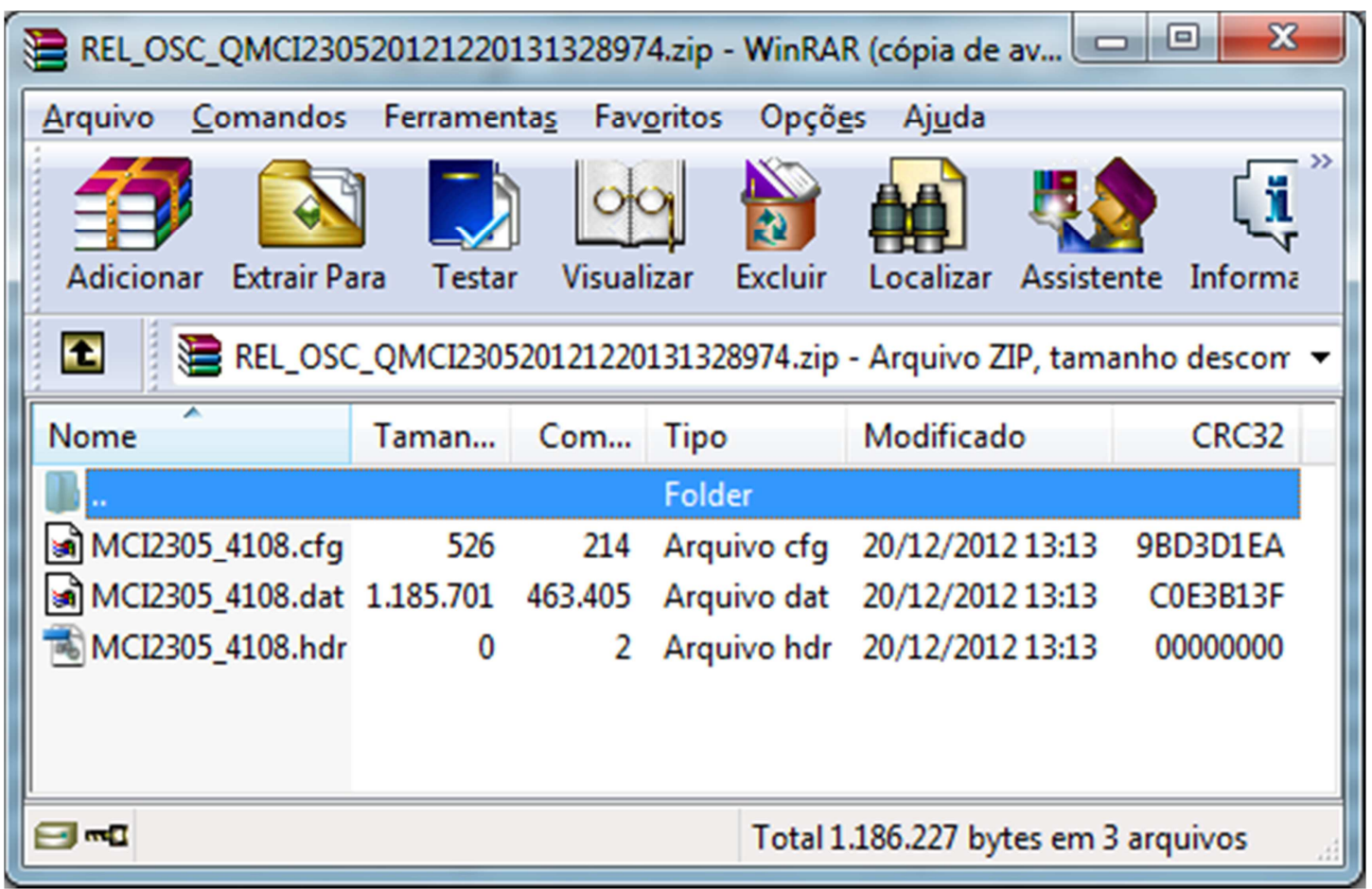

Figura 4.31 - Conteúdo do arquivo ".ZIP" gerado pelo sistema instalado na SE.

O segundo arquivo a ser sincronizado possui extensão ".GZ" e se trata do relatório de eventos, em formato ".CSV”, compactado. A nomenclatura inicial deste arquivo segue o padrão REL_EVE_QMCI2305 identificando que se trata do relatório de eventos das faltas identificadas pelo sistema em estudo.

Na Figura 4.32 tem-se um exemplo do conteúdo do arquivo ".CSV” advindo do mesmo evento simulado e apresentado nas figuras anteriores.

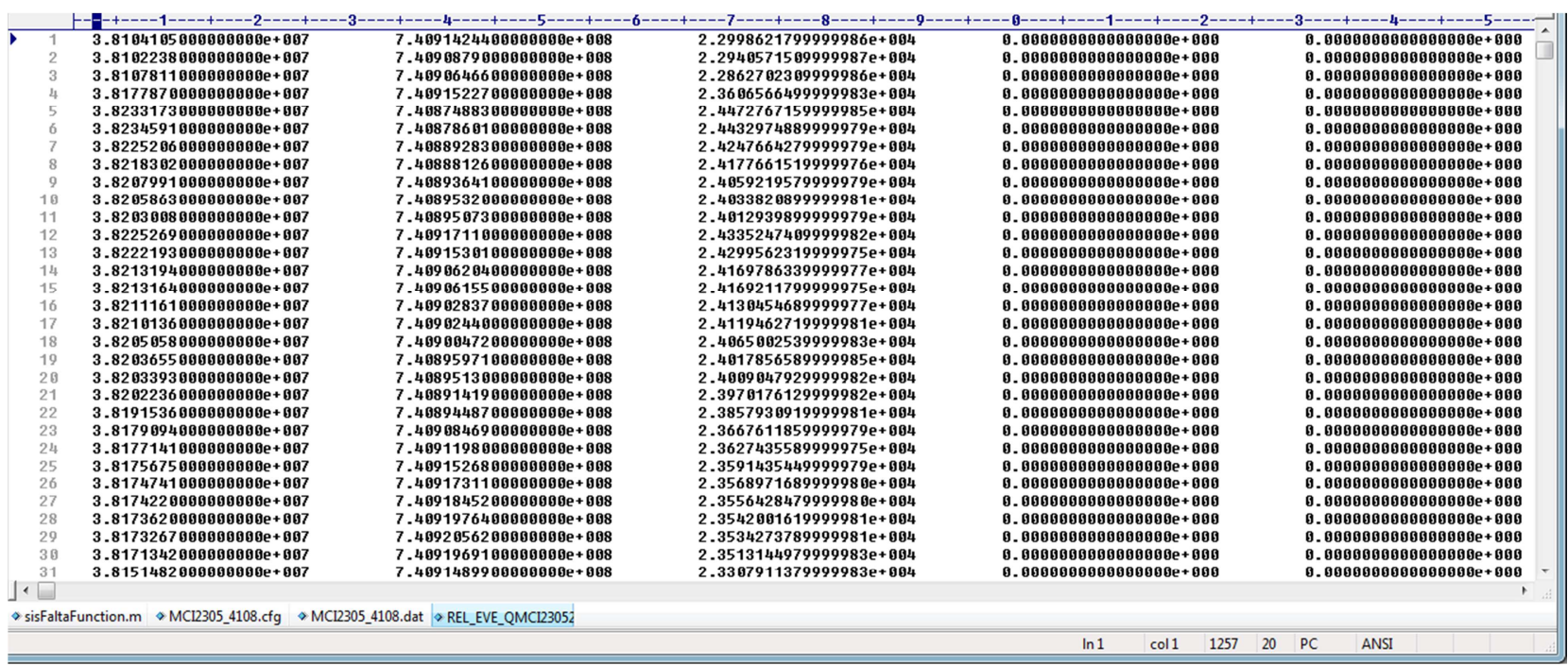

Figura 4.32 - Exemplo de arquivo “.GZ” gerado pelo sistema instalado no alimentador MCl1305. 
Após uma bem sucedida identificação de faltas, os arquivos ".GZ" e ".ZIP” são gerados e salvos numa pasta previamente definida no software. A varredura desta pasta fica por função da Remota H5-SE, que periodicamente a inspeciona em busca de novos arquivos.

Norma COMTRADE permite até 999999 canais entre digitais e analógicos. As informações para os propósitos de localização podem ser inseridas no processo de conversão, dentro do arquivo COMTRADE caso desejável. O formato normatizado do COMTRADE reduz consideravelmente o tamanho do arquivo, favorecendo a comunicação.

\subsection{Implementação de sistema de comunicação em tempo real}

As ferramentas instaladas nos alimentadores tratam os distúrbios em tempo real, resultando em informações processadas das faltas, adequadas aos padrões de sincronismo de arquivos necessários para envio dessas informações do campo ao Centro de Operações da Distribuição.

O sistema de localização de faltas desenvolvido encontra-se em funcionamento em computadores do tipo PC. Após a ocorrência de um transitório, as informações locais são processadas neste computador para a determinação das características de falta.

Caso seja constatada uma falta, todos os mecanismos responsáveis por determinar o local da falta são realizados e os resultados para o auxílio à tomada de decisões são armazenados em um banco de dados neste computador local.

As informações sobre as faltas identificadas que serão armazenadas nesse banco de dados são aquelas apresentadas na Tabela 4.2. 
Tabela 4.2 - Banco de Dados (armazenamento das informações de faltas).

\begin{tabular}{|c|c|c|}
\hline Campo & Tipo & Descrição \\
\hline id & Inteiro (10 posições) & $\begin{array}{l}\text { Campo de identificação, único, incrementado } \\
\text { automaticamente. }\end{array}$ \\
\hline est_tempo & $\begin{array}{l}\text { Tempo } \\
\text { (aaaa/mm/dd HH:MM:SS) }\end{array}$ & Estampa de tempo da primeira oscilografia processada. \\
\hline tipo_falta & $\begin{array}{l}\text { Caractere } \\
\text { (6 posições) }\end{array}$ & $\begin{array}{l}\text { Classificação da Falta: FFF, DLFAB, DLFBC, DLFCA, } \\
\text { FFTAB, FFTBC, FFTCA, FFP_A, FFP_B, FFP_C, FFS_A, } \\
\text { FFS_B e FFS_C. }\end{array}$ \\
\hline distancia_falta & $\begin{array}{l}\text { Real } \\
\text { ( } 9 \text { posições, } 6 \text { casas decimais) }\end{array}$ & Distância da falta à subestação \\
\hline resistencia_falta & $\begin{array}{l}\text { Real } \\
\text { ( } 9 \text { posições, } 6 \text { casas decimais) }\end{array}$ & Resistência da falta calculada pelo sistema \\
\hline tot_err_contabil & Inteiro & Quantidade de respostas possíveis \\
\hline indice_confiabil & Inteiro & Ordem da resposta \\
\hline cod_confi_inf & Inteiro & Código da confiabilidade associada ao local da falta \\
\hline grau_acerto_confiabil & $\begin{array}{l}\text { Real } \\
\text { ( } 9 \text { posições, } 6 \text { casas decimais) }\end{array}$ & Qualidade da resposta em termos de percentual \\
\hline
\end{tabular}

\section{Um exemplo desse banco de dados pode ser visto na Figura 4.33.}

\begin{tabular}{|c|c|c|c|c|c|c|c|c|c|c|c|c|}
\hline \multicolumn{5}{|c|}{ 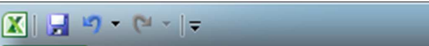 } & \multicolumn{7}{|c|}{ sisfaltas_inp1306.xls [Modo de Compatibilidade] - Microsoft Excel } & \begin{tabular}{|l|l|l|}
0 & 口 & $x$ \\
\end{tabular} \\
\hline \multicolumn{2}{|c|}{ Arquivo } & \multirow{2}{*}{\begin{tabular}{|c|} 
Menu \\
I186 \\
\end{tabular}} & \multirow{2}{*}{$\frac{\text { Menu }}{r}$} & Página Inicial & Inserir & ayout da Página $\quad F$ & Fórmulas & \multirow[t]{2}{*}{ Dados } & \multirow[t]{2}{*}{ Revisão } & \multirow[t]{2}{*}{ Exibição } & Acrobat & $\vee ?-$ 过 $x$ \\
\hline & & & & $f_{x}$ & 0.099656 & & & & & & & 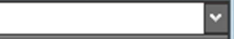 \\
\hline 4 & A & \multirow{2}{*}{\multicolumn{2}{|c|}{$\begin{array}{c}\text { B } \\
\text { Data/Hora }\end{array}$}} & c & D & E & & $\mathrm{F}$ & G & \multicolumn{2}{|r|}{$\mathrm{H}$} & 1 \\
\hline 1 & id & & & \multicolumn{2}{|c|}{ Tipo de Falta Distância da Falta } & Resistência da Falta & \multicolumn{2}{|c|}{ Possibilidades } & Possibilidade & Código da & la confiabilidade & Acerto Confiabilidade \\
\hline 186 & 1316 & $17 / 10 / 2 C$ & 11 19:57:50 & DLFBC & 3.508109 & 1.025415 & & 8 & 8 & & 95460 & 0.099656 \\
\hline 187 & 1315 & $17 / 10 / 2 C$ & 11 19:57:50 & DLFBC & 3.508109 & 1.025415 & & 8 & 7 & & 95424 & 0.175258 \\
\hline 188 & 1314 & $17 / 10 / 2 C$ & 11 19:57:50 & DLFBC & 3.508109 & 1.025415 & & 8 & 6 & & 61922 & 0.16323 \\
\hline 189 & 1313 & $17 / 10 / 2 C$ & 11 19:57:50 & DLFBC & 3.508109 & 1.025415 & & 8 & 5 & & 27366 & 0.109966 \\
\hline 190 & 1312 & $17 / 10 / 2 C$ & 11 19:57:50 & DLFBC & 3.508109 & 1.025415 & & 8 & 4 & & 20740 & 0.109966 \\
\hline 191 & 1311 & $17 / 10 / 2 C$ & 011 19:57:50 & DLFBC & 3.508109 & 1.025415 & & 8 & 3 & & 16850 & 0.142612 \\
\hline 192 & 1310 & $17 / 10 / 2 C$ & D11 19:57:50 & DLFBC & 3.508109 & 1.025415 & & 8 & 2 & & 2464 & 0.092784 \\
\hline 193 & 1309 & $17 / 10 / 2 C$ & D11 19:57:50 & DLFBC & 3.508109 & 1.025415 & & 8 & 1 & & 1873 & 0.106529 \\
\hline 194 & 1308 & $25 / 09 / 2 C$ & 11 10:47:05 & DLFAB & 12.212295 & 8.903498 & & 6 & 6 & & 97443 & 0.170732 \\
\hline 195 & 1307 & $25 / 09 / 2 C$ & 11 10:47:05 & DLFAB & 12.212295 & 8.903498 & & 6 & 5 & & 91576 & 0.134146 \\
\hline 196 & 1306 & $25 / 09 / 2 C$ & 11 10:47:05 & DLFAB & 12.212295 & 8.903498 & & 6 & 4 & & 64047 & 0.14745 \\
\hline 197 & 1305 & $25 / 09 / 2 C$ & 011 10:47:05 & DLFAB & 12.212295 & 8.903498 & & 6 & 3 & & 33467 & 0.260532 \\
\hline 198 & 1304 & $25 / 09 / 2 C$ & 011 10:47:05 & DLFAB & 12.212295 & 8.903498 & & 6 & 2 & & 26062 & 0.149667 \\
\hline 199 & 1303 & $25 / 09 / 2 C$ & 011 10:47:05 & DLFAB & 12.212295 & 8.903498 & & 6 & 1 & & 18905 & 0.137472 \\
\hline 144 & +1 & Plani & Plan2 $\angle \mathrm{Pl}$ & 28 & & & & & & & IIII & D回 \\
\hline Pron & & & & & & Média: 0.125000 & 0125 & Contagem: & Soma: 1.0 & 00001 & 田回 페 $90 \%$ & $\oplus$ \\
\hline
\end{tabular}

Figura 4.33 - Banco de dados de faltas.

Para que o operador possa interpretar as informações dos prováveis locais 
real o Código de Confiabilidade com no máximo quatro prováveis locais para uma falta em sequência, a Distância da Falta e Tipo de Falta.

Para o envio das oscilografias, e alarmes, tais informações precisam, através de um mecanismo de comunicação eficiente, serem rapidamente arquivadas em uma base de acessível aos operadores do COD.

Os protocolos padrões de comunicação utilizados e disponíveis nas quatro ETDs objetos do estudo piloto são o DNP3 serial, DNP3 encapsulado, MODBUS e TCP.

O envio das informações é feito com a utilização de uma remota que faz o envio dos arquivos COMTRADE. A remota cria uma rede virtual entre a ETD piloto e o PC para estudos no COD, conforme ilustrado na Figura 4.34.

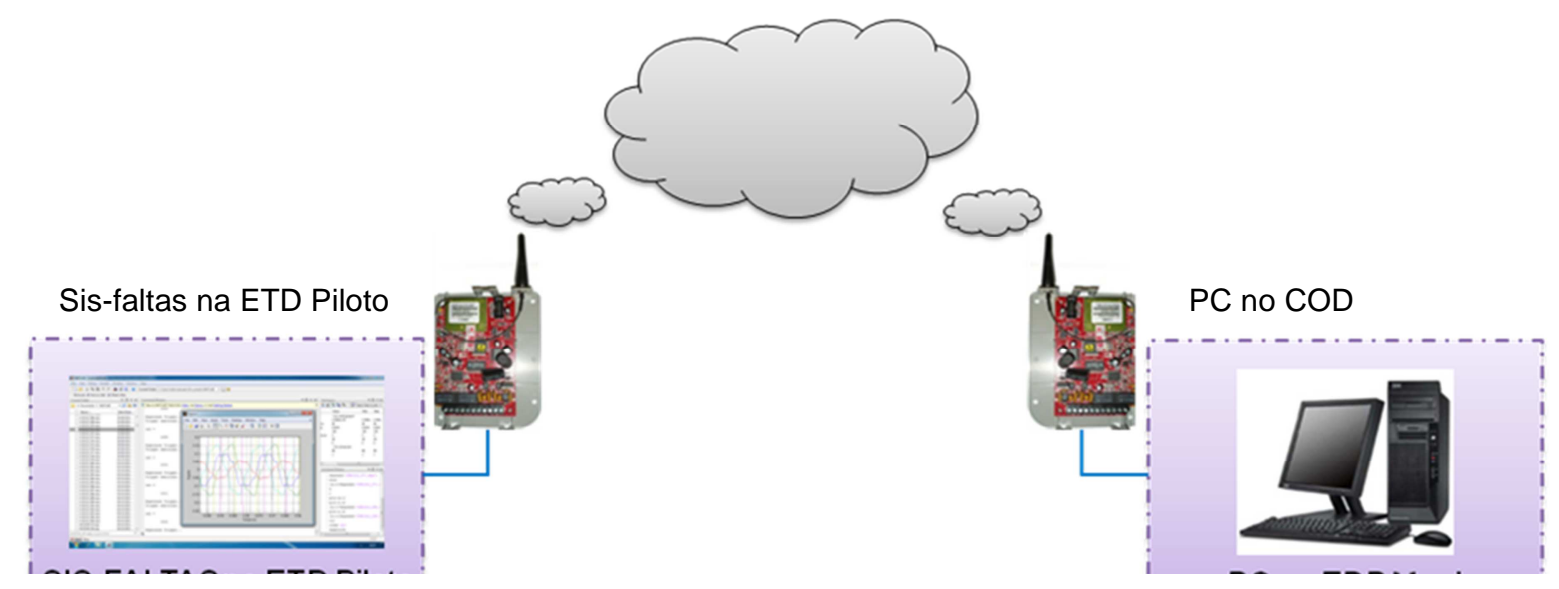

Figura 4.34 - Rede virtual entre a ETD piloto e COD.

Assim que novos arquivos são identificados na ETD desde o último ciclo de varredura, estes são então transmitidos da subestação para o COD.

\subsection{Considerações parciais}

As compilações dos resultados preliminares obtidos a partir da aplicação do sistema automatizado apresentado na Seção 4.2 demonstram que as técnicas 
desenvolvidas fornecem resultados precisos, identificando e localizando de forma automática as diversas ocorrências de faltas observadas no sistema de distribuição.

O método inovador desenvolvido para fins de modelagem de alimentadores agrega maior confiabilidade ao sistema como um todo.

Os aspectos de método inovador para o propósito de localização de faltas, agregado aos mapas de impedância de faltas, ajudam a contornar o problema da multi-estimação de regiões faltosas.

A conversão dos arquivos em COMTRADE e a utilização de um meio rápido e confiável de comunicação, com alarmes e informações bem definidas sobre os prováveis locais de uma falta, contribuem com as atividades dos operadores do COD. 


\section{Resultados Experimentais}

\subsection{Introdução}

A importância e relevância do tema deste trabalho permitiu levantar os principais aspectos relacionados com a implementação eficiente de processos envolvidos com a identificação, localização e comunicação de faltas, cujos resultados podem beneficiar os tempos de restabelecimento do sistema.

Um dos objetivos principais desse trabalho foi estudar como disponibilizar uma ferramenta em forma de um sistema integrado que auxilie os operadores do sistema de distribuição a tomarem decisões acertadas, contribuindo assim para o aumento dos índices de qualidade e, consequentemente, aumento do nível de satisfação de seus clientes.

Por meio da constituição de um banco de dados de ocorrências de faltas, tornar-se-á viável a elaboração de estratégias ou metodologias que auxiliem não apenas a operação do sistema, mas também a área de engenharia e de planejamento da manutenção da concessionária como um todo. 


\subsection{Análise comparativa entre registros oscilográficos e eventos}

A fim de validar o sistema desenvolvido, o processo de cruzamento das oscilografias apresentou grandes desafios, tendo-se em vista o número de registros envolvidos com as análises. Três análises distintas foram realizadas.

A primeira análise, com o objetivo de identificar faltas permanentes, consistiu em buscar o cruzamento de datas obtidas nas oscilografias com as tabelas de desligamentos dos circuitos em estudo.

A segunda análise, com o objetivo de identificar faltas transitórias, consistiu em buscar o cruzamento de datas obtidas nas oscilografias com os registros dos dispositivos de proteção (disjuntores e religadoras).

As Figuras 5.1 e 5.2 representam graficamente como foram os procedimentos realizados nas duas primeiras análises.

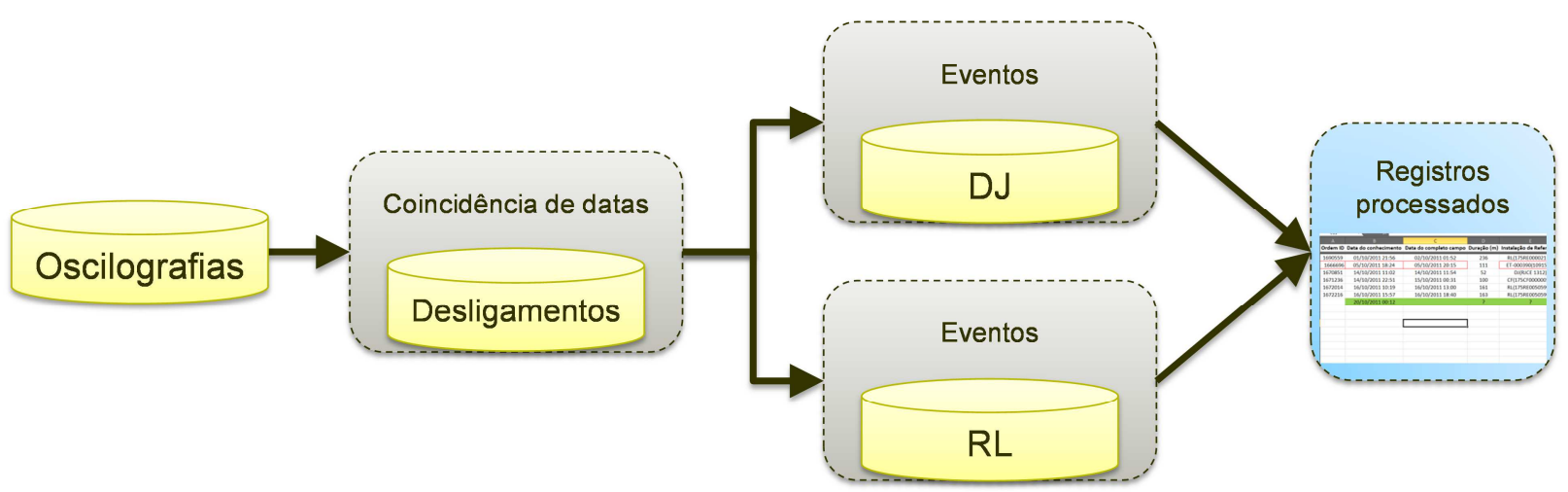

Figura 5.1 - Cruzamento (fase 1).

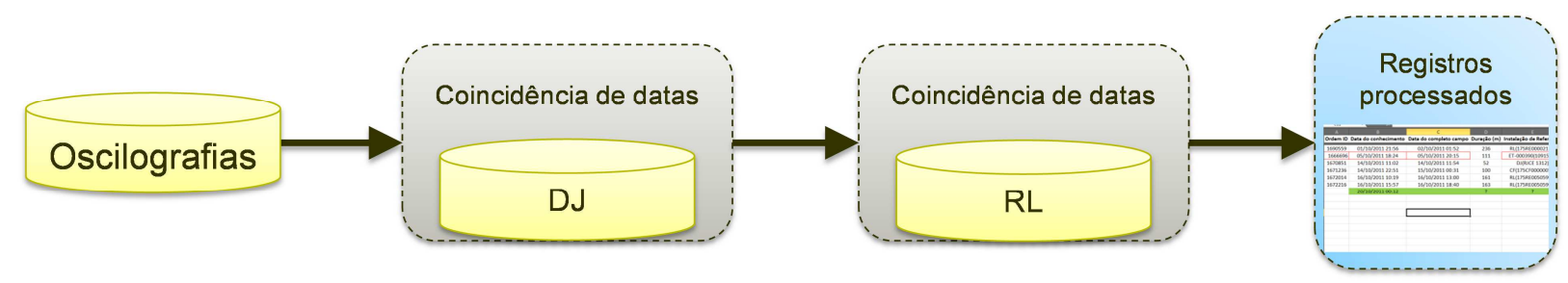

Figura 5.2 - Cruzamento (fase 2).

Após estas duas primeiras, uma terceira etapa procurou identificar distúrbios de faltas registrados pelo sistema de aquisição instalado nos alimentadores pilotos, 
mas que não foram capazes de sensibilizar os dispositivos de proteção. A terceira fase de análises consistiu basicamente de abrir e analisar as oscilografias registradas.

Como resultado, uma tabela auxiliar fora confeccionada, com os seguintes campos de interesse:

- Ordem ID

- Data do conhecimento

- Data do completo campo

- Duração $(m)$

- Instalação de Referência

- Consumidores Afetados

- Classe

- Causa

- Proteção

- Oscilografias

As duas últimas colunas desta tabela referem-se aos dispositivos de proteção envolvidos na falta, responsáveis por removê-la e também aos códigos de oscilografias associados com os eventos.

O objetivo principal de se colher oscilografias foi aquele de identificar situações tais, de modo que pudessem representar importantes fenômenos transitórios e que, devidamente caracterizados, permitam ajustes nos modelos computacionais dos alimentadores pilotos. Este é o caso que será apresentado como exemplo neste capítulo, tomando-se para análise uma ocorrência cuja Ordem ID foi a 1671236. 
Esta Ordem ID está relacionada a uma interrupção com duração de 100 minutos, afetando 7908 clientes. A classe desta ocorrência foi registrada como sendo "201-Ocor.c/ desl.de equip.Prim." cuja causa foi "491-Deterioração Equipamento". A instalação de referência obtida nos primeiros processos de cruzamento de informação apontam para o elemento CF(175CF00000054), sendo que a proteção responsável por remover a falta foi o religador RL-505992. A primeira oscilografia de um total de quatro fora registrada no dia 14/10/2011 (às 22h46), sendo que a hora do conhecimento desta ordem está registrada como sendo em 14/10/2011(às 22h51). Na Figura 5.3 tem-se uma visualização geral desta oscilografia, sendo que na Figura 5.4 tem-se em detalhes o momento do distúrbio.
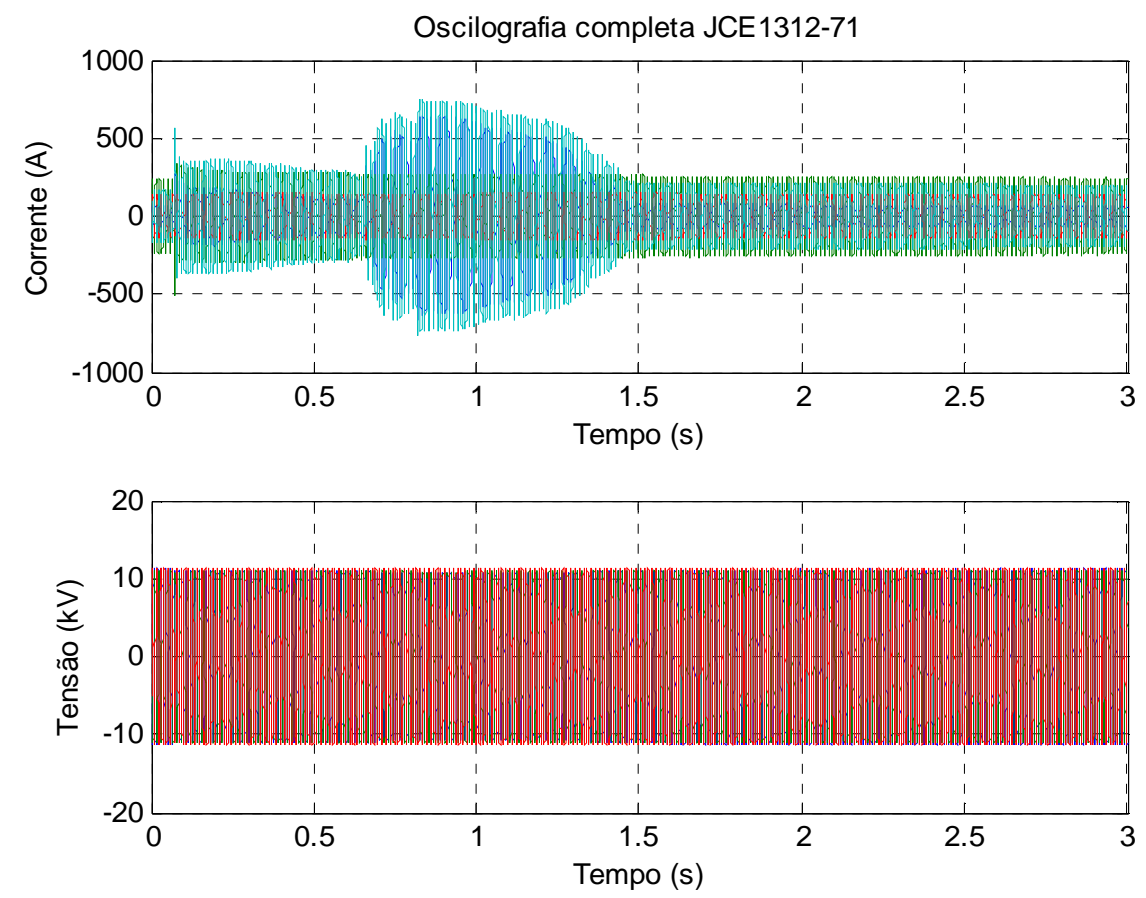

Figura 5.3 - Oscilografia JCE1312-71 completa. 

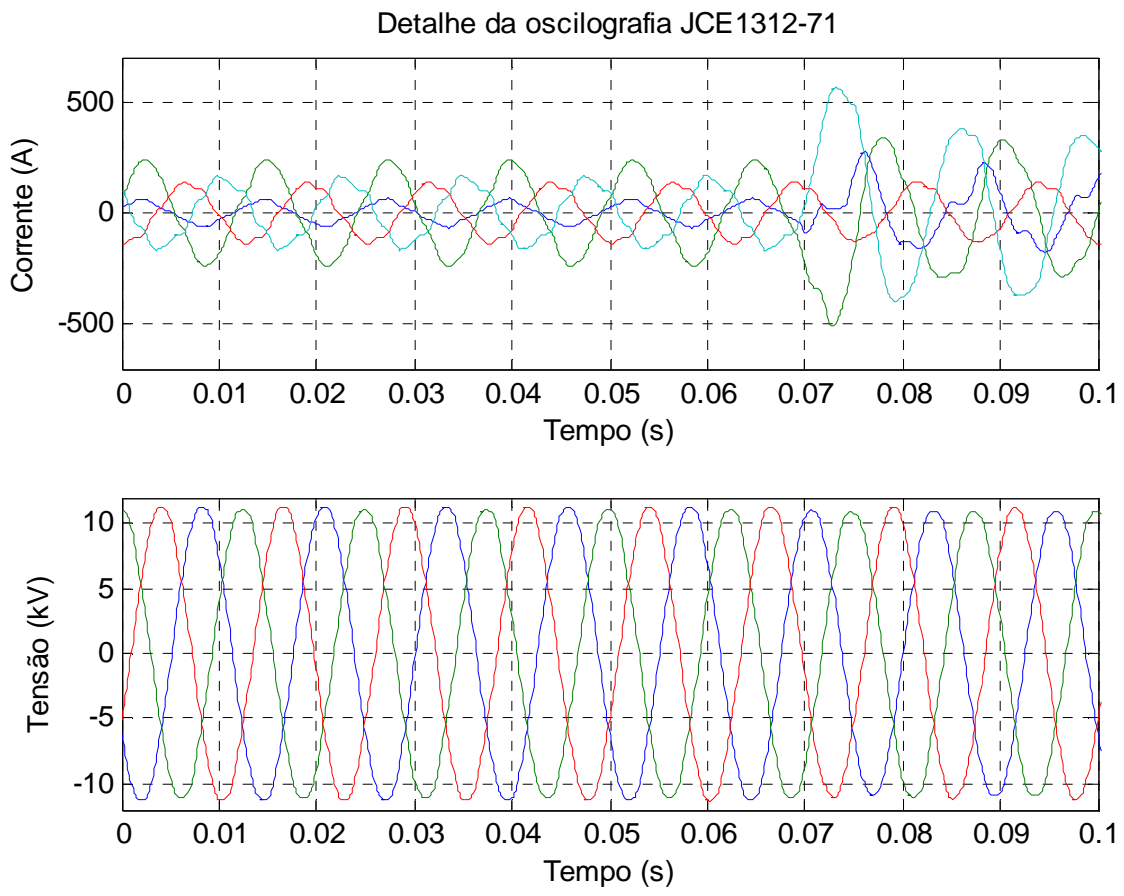

Figura 5.4 - Detalhe da oscilografia JCE1312-71.

É possível observar, a partir da Figura 5.4, duas fases participantes da falta, pois se tem a elevação das correntes e também o afundamento de tensão. A evolução desta falta, apresentadas nas Figuras 5.5, 5.6 e 5.7, mostra algo bem interessante.
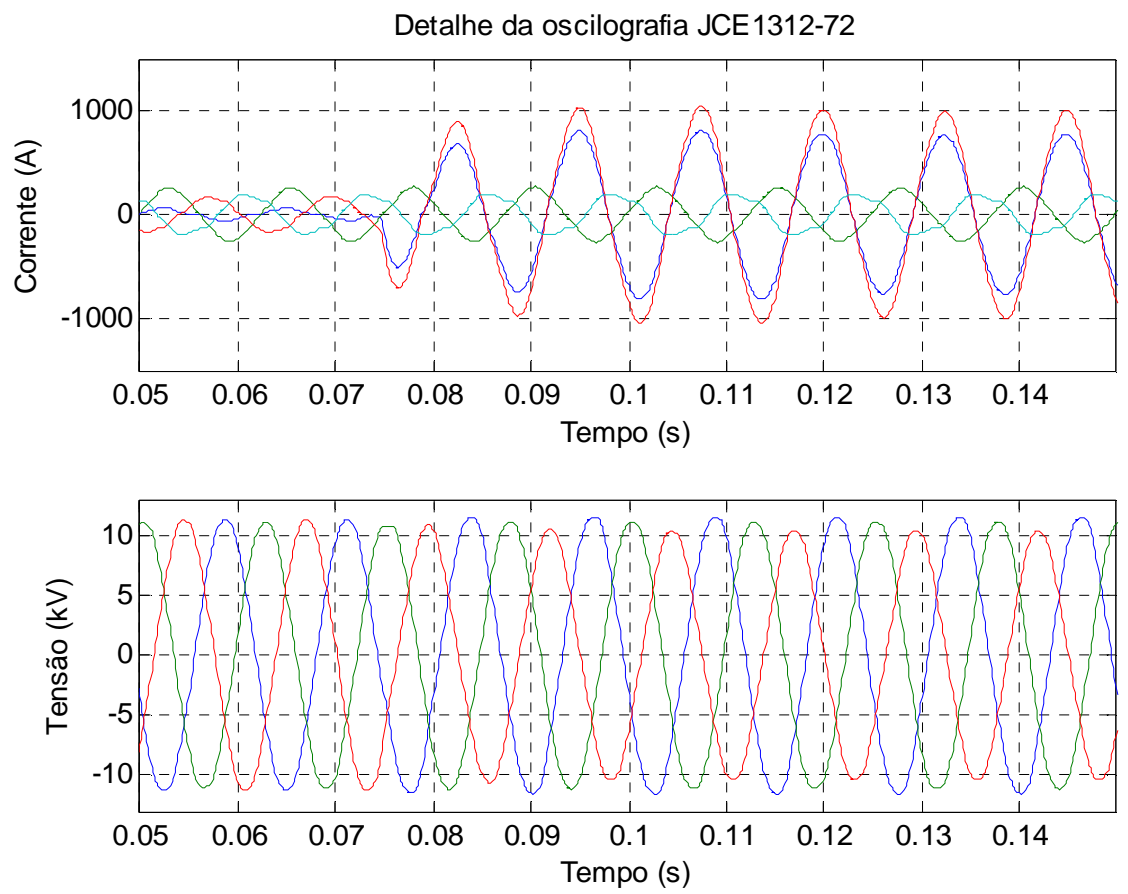

Figura 5.5 - Detalhe da oscilografia JCE1312-72. 

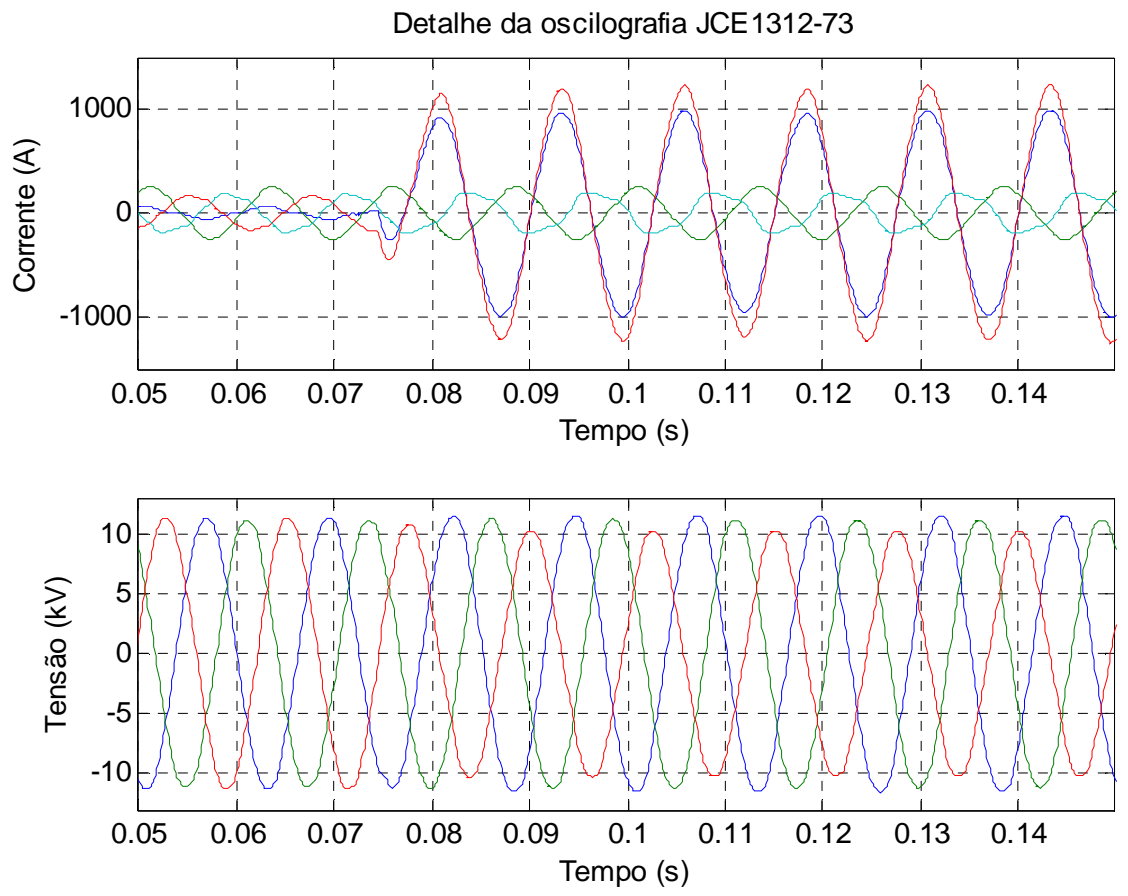

Figura 5.6 - Detalhe da oscilografia JCE1312-73.
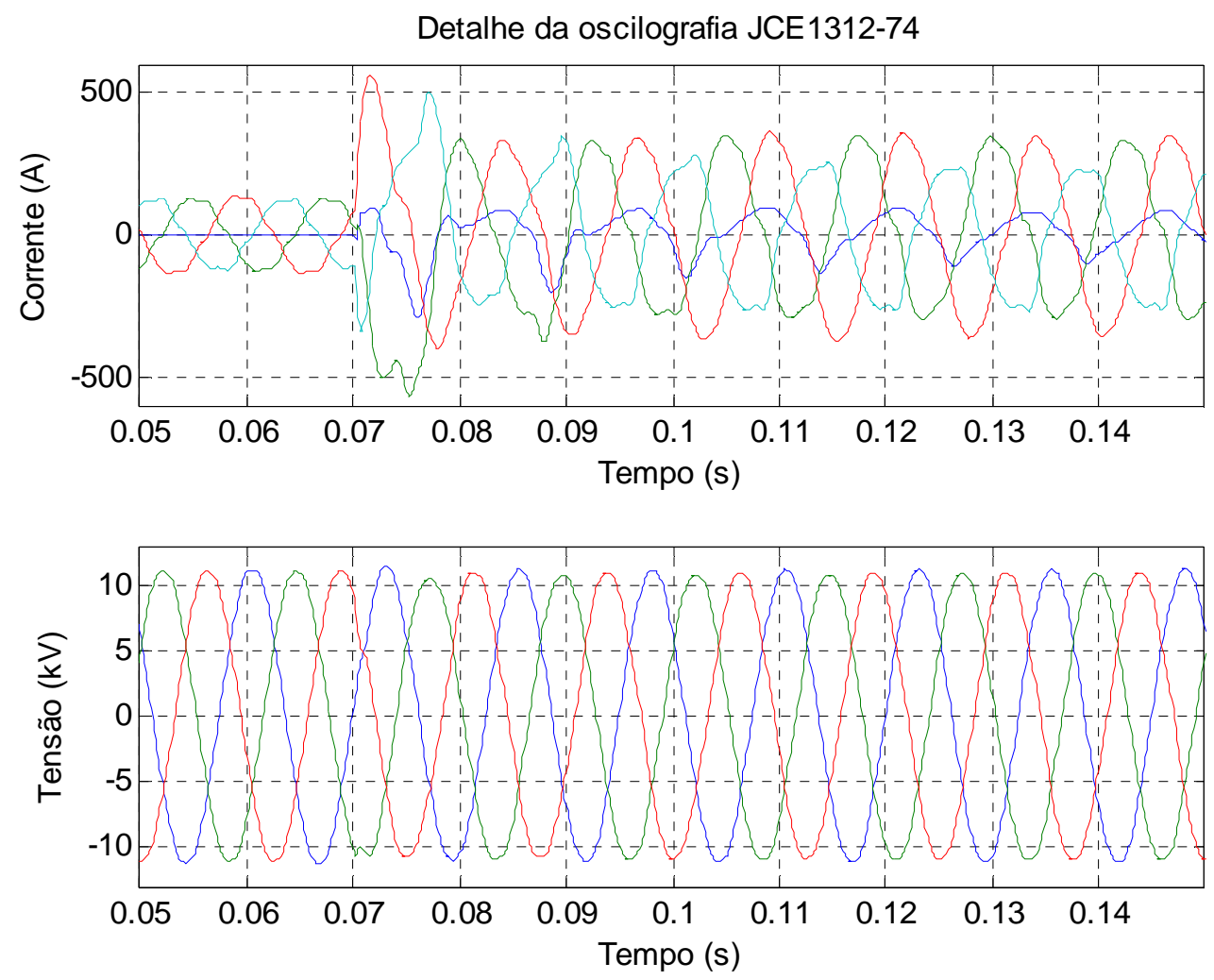

Figura 5.7-Detalhe da oscilografia JCE1312-74. 
A corrente de falta, inicialmente próxima dos $500 \mathrm{~A}$, envolvia duas fases. Em seguida, esta falta evoluiu para uma falta com corrente próxima dos 1000 A. A última oscilografia registrada aponta as três fases participantes da falta.

Sem nenhum conhecimento, além daqueles apresentados pelas oscilografias, torna-se bastante complexo relacionar a falta com o fenômeno responsável pela sua ocorrência. Mas, analisando-se os registros das ações executadas no alimentador JCE1312 naquele período, fica-se então evidente que o sistema conseguiu oscilografar uma falta muito interessante.

São três os registros relacionados a esta Ordem ID, os quais se distinguem entre si no campo "Categoria", sendo estes: "CLIMA", "CONDIÇÃO FIO PROTEÇÃO" e "03 - CABOS (FIOS)". O clima era considerado instável a ponto de se ter provocado o rompimento dos cabos, sendo que a proteção não atuou (segundo o relatório). Não há detalhamento no relatório de quais fases participaram da falta, mas fica evidente que todas participaram, tendo-se em vista as oscilografias registradas no último momento.

O arquivo complementar, com um comentário a respeito da interrupção, aponta as seguintes informações: "CKT NAO DESLIGOU TRECHO FOI MANOBRADO E SOCORRIDO /CAUSA DO CABO PARTIDO FOI CONEXAO MAL FEITA".

Este comentário comprova que realmente fora uma falta diferenciada que acometeu o circuito JCE1312, tendo-se em vista que o cabo se partiu e o transitório resultante apresentou níveis elevadíssimos de corrente, o qual não condiz com situações de alta impedância. No entanto, a proteção não atuou, sendo que será assim possível caracterizar esta situação como sendo de especial interesse para propósitos de modelagem computacional. 


\subsection{Análise de oscilografias referentes às faltas dos}

\section{alimentadores piloto}

Neste capitulo apresentar-se-ão os resultados obtidos com algumas análises de oscilografias registradas pelos sistemas instalados nos quatro alimentadores piloto. Para essas análises foi aplicada a metodologia exemplificada na Seção 5.3.

Para a ETD JCE1312, foram avaliadas 95 oscilografias entre 20/09/2011 e 20/12/2011. Em termos de relatórios de desligamentos, foram avaliados 558 registros entre 31/08/2011 e 29/02/2012. Para os dispositivos de proteção, foram 384 registros para o DJ-22 entre 22/10/2011 e 23/02/2012 e para todos os $R L$ foram 31203 registros entre 31/08/2011 e 29/02/2012. O resultado destas investigações pode ser conferido na Tabela 5.1.

Tabela 5.1 - Cruzamento de oscilografias para JCE1312.

\begin{tabular}{|c|c|c|c|c|c|c|c|c|c|}
\hline Ordem ID & Data do conhecimento & Data do completo campo & Duração $(\mathrm{m})$ & Instalação de Referência & Consumidores Afetados & Classe & Causa & Proteção & Oscilografias \\
\hline 1690559 & 01/10/2011 21:56 & 02/10/2011 01:52 & 236 & RL(175RE00002178) & 1151 & 201 & 180 & RL-002178 & 51-55 \\
\hline 1666696 & 05/10/2011 18:24 & 05/10/2011 20:15 & 111 & ET-000390(1091533) & 19 & 201 & 180 & RL-505992 & 58 \\
\hline 1670851 & 14/10/2011 11:02 & 14/10/2011 11:54 & 52 & DJ(RJCE 1312) & 11582 & 201 & 180 & DJ-22 & $66-70$ \\
\hline 1671236 & 14/10/2011 22:51 & 15/10/2011 00:31 & 100 & CF(175CF00000054) & 7908 & 201 & 491 & RL-505992 & 71-74 \\
\hline 1672014 & 16/10/2011 10:19 & 16/10/2011 13:00 & 161 & RL(175RE00505996) & 105 & 201 & 491 & RL-509996 & $80-81$ \\
\hline \multirow[t]{2}{*}{1672216} & 16/10/2011 15:57 & 16/10/2011 18:40 & 163 & RL(175RE00505996) & 185 & 201 & 491 & RL-509996 & $83-85$ \\
\hline & 20/10/2011 00:12 & & & & & & & RL-509996 & 87 \\
\hline 1676583 & 25/10/2011 21:07 & 25/10/2011 22:35 & 88 & RL(175RE00505990) & 70 & 201 & 11 & RL-505990, RL-505994, RL-2178 & $90-94$ \\
\hline 1679479 & 30/10/2011 09:29 & 30/10/2011 13:35 & 246 & RL(175RE00001942) & 1510 & 201 & 180 & RL-1942, RL-518572, RL-2178 & $101-105$ \\
\hline 1679640 & 30/10/2011 12:40 & 30/10/2011 14:15 & 95 & RL(175RL00518572) & 2205 & 201 & 20 & RL-1942, RL-518572, RL-2178 & 101-105 \\
\hline 1679784 & 30/10/2011 14:40 & 30/10/2011 17:13 & 153 & RL(175RE00002178) & 1151 & 201 & 890 & RL-1942, RL-518572, RL-2178 & 101-105 \\
\hline 1679864 & 30/10/2011 19:34 & 31/10/2011 11:15 & 941 & RL(175RE00001942) & 359 & 201 & 180 & RL-1942 & 106-107 \\
\hline 1674410 & 04/11/2011 12:12 & 04/11/2011 17:14 & 302 & ET005155839 & 260 & 244 & 970 & RL-505992 & 110-111 \\
\hline \multirow[t]{2}{*}{1680954} & 04/11/2011 16:50 & 04/11/2011 17:14 & 24 & ЕТ005155839 & 260 & 244 & 970 & RL-505992 & $110-111$ \\
\hline & 11/11/2011 15:43 & & & & & & & DJ-22, RL-505992 & 112 \\
\hline 1686050 & 13/11/2011 19:05 & 14/11/2011 00:45 & 340 & BF00000711 & 4 & 201 & 11 & RL-2178 & 113 \\
\hline 1687367 & 15/11/2011 10:07 & 15/11/2011 11:50 & 103 & ET-00525579(341280) & 10 & 201 & 180 & RL-2178 & $114-115$ \\
\hline 1687295 & 15/11/2011 08:25 & 15/11/2011 16:13 & 468 & BF00504981) & 5 & 201 & 20 & RL-2178 & 114-115 \\
\hline 1687610 & 15/11/2011 15:25 & 15/11/2011 18:20 & 175 & ET-001921(00318269) & 3 & 201 & 181 & RL-505992 & $116-117$ \\
\hline 1687660 & 15/11/2011 16:39 & 15/11/2011 20:55 & 256 & BF00000157 & 24 & 201 & 180 & RL-50992 & $118-119$ \\
\hline 1687708 & 15/11/2011 17:32 & 15/11/2011 23:15 & 343 & BF00001846 & 12 & 201 & 180 & - & $120-123$ \\
\hline 1689563 & 19/11/2011 10:28 & 19/11/2011 11:45 & 77 & BF00000849 & 172 & 201 & 180 & RL-2178 & $124-130$ \\
\hline 1689568 & 19/11/2011 10:36 & 19/11/2011 14:45 & 249 & ET-005017(1092231) & 1 & 201 & 180 & RL-2178 & $124-130$ \\
\hline 1690363 & 21/11/2011 10:37 & 21/11/2011 13:25 & 168 & BF00000995 & 9 & 201 & 181 & RL-505994 & 131 \\
\hline 1690559 & 21/11/2011 14:57 & 21/11/2011 14:59 & 2 & RL(175RE00505992) & 359 & 201 & 890 & RL-505992 & $132-133$ \\
\hline 1690918 & 22/11/2011 11:39 & 22/11/2011 12:48 & 69 & RL(175RL00518572) & 3360 & 201 & 20 & RL-2178, RL-505996, RL-505990, RL-518572 & 134 \\
\hline 1692166 & 24/11/2011 08:09 & 24/11/2011 10:46 & 157 & BF00000939 & 3 & 201 & 11 & RL-505994 & 135 \\
\hline
\end{tabular}

Como é possível observar da Tabela 5.1, existem registros com e sem Ordem ID. Aqueles que possuem este campo foram as oscilografias referentes à faltas permanentes. Já os que não possuem estão relacionados às faltas transitórias.

Para a ETD BIR1305, foram avaliadas 310 oscilografias entre 04/10/2011 e 20/12/2011. Em termos de relatórios de desligamentos, foram avaliados 303 
registros entre 31/08/2011 e 27/02/2012. Para os dispositivos de proteção, os seguintes registros foram avaliados:

- DJ-19: 459 registros entre 31/08/2011 e 25/02/2012.

- RL-071532: 2093 registros entre 31/08/2011 e 29/02/2012.

- RL-071618: 2751 registros entre 31/08/2011 e 29/02/2012.

- RL-071619: 1496 registros entre 31/08/2011 e 29/02/2012.

- RL-529204: 4560 registros entre 31/08/2011 e 29/02/2012.

O resultado destas investigações pode ser conferido na Tabela 5.2.

Tabela 5.2 - Cruzamento de oscilografias para BIR1305.

\begin{tabular}{|c|c|c|c|c|c|c|c|c|c|}
\hline Ordem ID & Data do conhecimento & Data do completo campo & Duração $(\mathrm{m})$ & Instalação de Referência & Consumidores Afetados & Classe & Causa & Proteção & Oscilografias \\
\hline \multirow[t]{3}{*}{1669771} & 12/10/2011 00:23:00 & 12/10/2011 01:50 & 87 & RL(130RE00071618) & 459 & 201 & 491 & DJ 19, RL-071532, RL-071618 e RL-071619 & $23-25$ \\
\hline & 12/10/2011 01:50:00 & & & & & & & RL-071618 & 27 \\
\hline & 16/10/2011 18:33:00 & & & & & & & RL-529204 & $52-55$ \\
\hline \multirow[t]{4}{*}{1672672} & 17/10/2011 15:41:00 & 17/10/2011 18:00 & 139 & RL(130RL00529204) & 376 & 201 & 890 & RL-529204 & 59 \\
\hline & 17/10/2011 18:31:00 & & & & & & & RL-529204 & 61 \\
\hline & 19/10/2011 14:34:00 & & & & & & & RL-529204 & 68 \\
\hline & 19/10/2011 16:14:00 & & & & & & & RL-529204 & 70 \\
\hline 1674138 & 19/10/2011 21:28:00 & 20/10/2011 12:30 & 902 & ET-005972(1092123) & 24 & 201 & 182 & RL-529204 & 80 \\
\hline \multirow[t]{2}{*}{1676750} & 25/10/2011 22:33:00 & 25/10/2011 23:31 & 58 & DJ(RBIR 1305) & 2049 & 201 & 890 & RL-071618 e RL-529204 & 89-91 \\
\hline & 25/10/2011 23:23:00 & & & & & & & RL-071618 & 92 \\
\hline 1677143 & 26/10/2011 11:08:00 & 26/10/2011 17:12 & 364 & BF(130BF00001379) & 42 & 201 & 180 & RL-071532 & $96-97$ \\
\hline \multirow[t]{3}{*}{1677325} & 26/10/2011 17:20:00 & 26/10/2011 19:44 & 144 & DJ(RBIR 1305) & 3587 & 201 & 491 & RL-071532, RL-071618 e RL-529204 & 99-103 \\
\hline & 29/10/2011 07:55:00 & & & & & & & RL-071532 & 113 \\
\hline & 29/10/2011 17:15:00 & & & & & & & RL-071532 & $115-116$ \\
\hline 1683504 & 08/11/2011 15:41:00 & 08/11/2011 17:10 & 89 & BF(130BF00000981) & 42 & 201 & 180 & DJ 19, RL-071532 e RL-071618 & $128-129$ \\
\hline 1684616 & 11/11/2011 08:29:00 & 11/11/2011 10:21 & 112 & $\mathrm{BF}(130 \mathrm{BF} 00000292)$ & 21 & 102 & 181 & RL-071532 & 135 \\
\hline 1685361 & 12/11/2011 16:11:00 & 12/11/2011 21:50 & 339 & $\mathrm{BF}(130 \mathrm{BF} 00000289)$ & 113 & 201 & 491 & RL-071532 & $136-137$ \\
\hline 1687280 & 15/11/2011 07:46:00 & 15/11/2011 10:00 & 134 & $\mathrm{BF}(130 \mathrm{BF} 00000284)$ & 55 & 201 & 180 & RL-071532 & 140 \\
\hline 1687413 & 15/11/2011 10:55:00 & 15/11/2011 14:10 & 195 & $\mathrm{BF}(130 \mathrm{BF} 00000981)$ & 42 & 201 & 181 & RL-071618 & 141 \\
\hline 1688341 & 16/11/2011 18:11:00 & 16/11/2011 20:36 & 145 & $\mathrm{BF}(130 \mathrm{BF} 00000288)$ & 129 & 201 & 180 & RL-071532 & 149 \\
\hline \multirow[t]{2}{*}{1689838} & 20/11/2011 07:03:00 & 20/11/2011 08:20 & 77 & ET-001769(00297183) & 4 & 201 & 491 & RL-071532 & 158 \\
\hline & 22/11/2011 17:10:00 & & & & & & & DJ 19 e RL-071618 & 201 \\
\hline \multirow[t]{2}{*}{1691911} & 23/11/2011 14:38:00 & 23/11/2011 17:28 & 170 & BF(130BF00001035) & 35 & 201 & 180 & RL-071532 & 203 \\
\hline & 24/11/2011 22:00:00 & & & & & & & RL-071532 & 206 \\
\hline \multirow[t]{2}{*}{1693501} & 27/11/2011 09:00:00 & 27/11/2011 10:31 & 91 & BF(130BF00001193) & 31 & 201 & 200 & RL-071618 & 209 \\
\hline & 01/12/2011 09:08:00 & & & & & & & DJ 19 e RL-071618 & 222 \\
\hline 1696416 & 01/12/2011 16:38:00 & 01/12/2011 19:01 & 143 & ET-002610(00200413) & 11 & 201 & 130 & RL-071532 & $225-226$ \\
\hline \multirow[t]{2}{*}{1696488} & 01/12/2011 17:16:00 & 01/12/2011 20:08 & 172 & ET-006599(1090787) & 48 & 201 & 20 & RL-071618 & 234 \\
\hline & 07/12/2011 19:24:00 & & & & & & & RL-071618 & 238 \\
\hline 1700756 & 08/12/2011 05:06:00 & 08/12/2011 07:52 & 166 & BF(130BF00000981) & 42 & 201 & 180 & RL-071618 & 241 \\
\hline 1702714 & 10/12/2011 00:57:00 & 10/12/2011 09:30 & 513 & $\mathrm{BF}(130 \mathrm{BF} 00000379)$ & 29 & 201 & 180 & RL-071619 & 249 \\
\hline 1705676 & 15/12/2011 02:42:00 & 15/12/2011 06:05 & 203 & $\mathrm{BF}(130 \mathrm{BF} 00000401)$ & 100 & 201 & 180 & RL-071619 & 268 \\
\hline 1706912 & 16/12/2011 17:55:00 & 16/12/2011 19:08 & 73 & $\mathrm{ET}-012715(0)$ & 0 & 199 & 816 & RL-071532 & 280 \\
\hline 1709272 & 19/12/2011 22:28:00 & 20/12/2011 01:38 & 190 & $\mathrm{BF}(130 \mathrm{~B} F 00000288)$ & 131 & 201 & 300 & RL-071532 & 303-304 \\
\hline
\end{tabular}

Para a ETD MCl1305, foram avaliadas 1384 oscilografias entre 14/09/2011 e 20/12/2011. Em termos de relatórios de desligamentos, foram avaliados 364 registros entre 31/08/2011 e 29/02/2011. Para os dispositivos de proteção, os seguintes registros foram avaliados:

- DJ-25: 519 registros entre 03/09/2011 e 29/02/2012.

- RL-071354: 3356 registros entre 04/09/2011 e 29/02/2012.

- RL-503100: 5124 registros entre 31/08/2011 e 29/02/2012. 
- RL-509427: 4748 registros entre 31/08/2011 e 17/01/2012.

- RL-513579: 2086 registros entre 31/08/2011 e 29/02/2012.

O resultado destas investigações pode ser conferido na Tabela 5.3. É possível observar nesta tabela que existem registros onde apenas constam a data do conhecimento e o código correspondente da oscilografia. Tais registros referemse a distúrbios que não foram sensibilizados pelos dispositivos de proteção, mas que pelas características elétricas podem ser caracterizados como faltas.

Tabela 5.3 - Cruzamento de oscilografias para MCl1305.

\begin{tabular}{|c|c|c|c|c|c|c|c|c|c|}
\hline Ordem ID & Data do conhecimento & Data do completo campo & Duração (m) & Instalação de Referência & Consumidores Afetados & Classe & Causa & Proteção & Oscilografias \\
\hline & 22/09/2012 09:01:00 & & & & & & & RL-503100 e RL-509427 & 53 \\
\hline & 22/09/2012 14:49:00 & & & & & & & RL-503100 & 58 \\
\hline 1659773 & 23/09/2011 16:05:00 & 23/09/2011 18:01:00 & 116 & $\mathrm{BF}(130 \mathrm{BF} 00000906)$ & 27 & 201 & 180 & RL-071354 e RL-509427 & 65 \\
\hline 1659761 & 23/09/2011 16:12:00 & 24/09/2011 02:27:00 & 615 & BF(130BF00001114) & 30 & 201 & 180 & RL-509427 & 66 \\
\hline 1659105 & 25/09/2011 16:09:00 & 25/09/2011 16:18:00 & 9 & 130RE000713549 & 513 & 244 & 970 & RL-071354 & 72 \\
\hline 1663575 & 30/09/2011 13:26:00 & 30/09/2011 15:20:00 & 114 & BF(130BF00000159) & 26 & 201 & 20 & RL-503100 & 77 \\
\hline \multirow[t]{2}{*}{1664720} & 02/10/2011 20:19:00 & 02/10/2011 22:51:00 & 152 & BF(130BF00001580) & 146 & 201 & 11 & RL-071354 e RL-503100 & 81 \\
\hline & 03/10/2012 03:46:00 & & & & & & & RL-071354 & 83 \\
\hline 1665534 & 03/10/2011 17:21:00 & 03/10/2011 18:40:00 & 79 & ET-011896(1083631) & 2 & 201 & 20 & RL-071354 e RL-503100 & 87 \\
\hline 1665848 & 04/10/2011 13:00:00 & 04/10/2011 18:25:00 & 325 & RL(130RE00513579) & 124 & 201 & 181 & DJ-25, RL-071354, RL-503100 e RL-509427 & $89-93$ \\
\hline 1667240 & 07/10/2011 08:57:00 & 07/10/2011 09:58:00 & 61 & BF(130BF00000906) & 27 & 201 & 180 & RL-071354 e RL-503100 & 104 \\
\hline 1668296 & 09/10/2011 02:02:33 & 09/10/2011 02:02:33 & 0 & 130DJMCI025 & 0 & 500 & 890 & RL-071354 e RL-503100 & 112 \\
\hline 1670528 & 13/10/2011 21:34:00 & 13/10/2011 22:54:00 & 80 & $\mathrm{BF}(130 \mathrm{BF} 00002202)$ & 24 & 201 & 180 & RL-071354 e RL-503100 & 122 \\
\hline 1672484 & 17/10/2011 07:54:00 & 17/10/2011 15:40:00 & 466 & BF(130BF00001119) & 8 & 201 & 181 & RL-071354 e RL-503100 & 191-193 \\
\hline 1674168 & 20/10/2011 01:11:00 & 20/10/2011 04:42:00 & 211 & BF(130BF00001091) & 64 & 201 & 181 & RL-071354, RL-503100 e RL-509427 & $240-241$ \\
\hline 1676627 & 25/10/2011 21:28:00 & 26/10/2011 13:43:00 & 975 & RL(130RE00503100) & 748 & 201 & 180 & DJ-25, RL-071354 e RL-503100 & $435-539$ \\
\hline 1676627 & 25/10/2011 21:28:00 & 26/10/2011 13:43:00 & 975 & RL(130RE00503100) & 748 & 201 & 180 & DJ-25, RL-071354, RL-503100 e RL-513579 & $540-542$ \\
\hline 1676627 & 25/10/2011 21:28:00 & 26/10/2011 13:43:00 & 975 & RL(130RE00503100) & 748 & 201 & 180 & DJ-25, RL-071354 e RL-503100 & $543-558$ \\
\hline 1676835 & 26/10/2011 00:29:14 & 26/10/2011 00:29:14 & 0 & 130DJMCI025 & 0 & 500 & 890 & DJ-25, RL-071354, RL-503100 e RL-513579 & 561-562 \\
\hline 1680301 & 31/10/2011 15:52:00 & 31/10/2011 17:31:00 & 99 & DJ(RMCI 1305) & 4530 & 201 & 321 & DJ-25, RL-071354, RL-503100 e RL-513579 & $576-579$ \\
\hline \multirow[t]{2}{*}{1673141} & 02/11/2011 09:59:00 & 02/11/2011 10:54:00 & 55 & 130ET000093929 & 4 & 244 & 970 & DJ-25 & 593 \\
\hline & 02/11/2011 13:13:00 & & & & & & & DJ-25 & 595-596 \\
\hline \multirow[t]{5}{*}{1682928} & 06/11/2011 20:38:00 & 07/11/2011 00:36:00 & 238 & RL(130RE00513579) & 124 & 201 & 180 & DJ-25, RL-503100, RL-513579 & 599 \\
\hline & 11/11/2011 04:22:00 & & & & & & & RL-071354 & $620-622$ \\
\hline & 10/11/2011 08:03:00 & & & & & & & RL-513579 & $612-616$ \\
\hline & 12/11/2011 07:11:00 & & & & & & & DJ-25, RL-071354, RL-503100, RL-509427 & $623-630$ \\
\hline & 18/11/2011 00:47:00 & & & & & & & RL-071354, RL-503100 & 658 \\
\hline 1690046 & 20/11/2011 15:35:00 & 20/11/2011 15:50:00 & 15 & BF00001575 & 128 & 201 & 492 & RL-509427 & $663-665$ \\
\hline 1700548 & 07/12/2011 18:11:00 & 07/12/2011 21:35:00 & 204 & BF00000159 & 26 & 201 & 11 & RL-071354, RL-503100 & $743-753$ \\
\hline 1700992 & 08/12/2011 14:18:00 & 08/12/2011 15:43:00 & 85 & RL(130RE00071354) & 515 & 201 & 181 & RL-071354, RL-503100 & $770-780$ \\
\hline 1701019 & 08/12/2011 14:52:00 & 08/12/2011 18:40:00 & 228 & PEE(B000377798) & 1 & 350 & 492 & RL-071354, RL-503100 & $770-780$ \\
\hline \multirow[t]{2}{*}{1701053} & 08/12/2011 15:23:00 & 08/12/2011 17:12:00 & 109 & BF00001060 & 18 & 201 & 180 & RL-071354, RL-503100 & $770-780$ \\
\hline & 09/12/2011 00:58:00 & & & & & & & DJ-25, RL-513579 & 801 \\
\hline \multirow[t]{2}{*}{1702321} & 09/12/2011 13:40:00 & 09/12/2011 15:12:00 & 92 & BF00000159 & 26 & 201 & 20 & RL-503100 & 840 \\
\hline & 10/12/2011 17:33:00 & & & & & & & RL-503100 & 909 \\
\hline 1704266 & 12/12/2011 22:28:00 & 13/12/2011 02:03:00 & 215 & BF00001060 & 26 & 201 & 300 & & $938-940$ \\
\hline 1705687 & 15/12/2011 04:18:00 & 15/12/2011 08:50:00 & 272 & BF00001060 & 18 & 201 & 180 & & 1014-1019 \\
\hline 1705993 & 15/12/2011 13:22:00 & 15/12/2011 15:45:00 & 143 & BF00508422 & 2 & 201 & 180 & todos os RL & 1066 \\
\hline 1706384 & 15/12/2011 21:21:00 & 15/12/2011 23:30:00 & 129 & BF00001091 & 65 & 201 & 180 & RL-071354, RL-503100, RL-509427 & 1068-1069 \\
\hline \multirow[t]{2}{*}{1708342} & 18/12/2011 19:17:00 & 18/12/2011 22:35:00 & 198 & BF00001119 & 8 & 201 & 491 & & 1340-1347 \\
\hline & 19/12/2011 13:49:00 & & & & & & & & 1369 \\
\hline
\end{tabular}

Para a ETD INP1306, foram avaliadas 17971 oscilografias entre 13/09/2011 e 20/12/2011. Os relatórios de desligamentos para esta ETD estavam indisponíveis. Assim, procedeu-se com as fases dois e três das análises apenas. Para os dispositivos de proteção foram avaliados 175 registros entre 13/09/2011 e 23/02/2012. Cabe ressaltar que nenhum cruzamento foi encontrado para esta ETD. 
Com base nos arquivos das ações envolvendo as ocorrências tratadas fora possível traçar um perfil com diversos casos de situações reais de faltas e que serviram para aperfeiçoar os modelos computacionais dos alimentadores pilotos.

Dentre tais atividades destaca-se a identificação das distâncias envolvendo as ocorrências, pois estas permitiram validar os procedimentos de localização de faltas fundamentados na determinação da confiabilidade mais próxima do local de ocorrência de uma falta.

A validação dos resultados torna-se complexa em circuitos reais de distribuição, devido a não linearidade das variáveis envolvidas nas faltas e também a falta do registro do local exato da ocorrência de uma falta, registrado muitas vezes como sendo o local do equipamento de proteção atuado, sua confiabilidade mais próxima, principalmente em faltas transitórias.

Assim, para os quatro alimentadores pilotos, foram realizadas diversas etapas de cruzamento de informações, nos mais diversos tipos de arquivos, sendo que um resumo do que fora encontrado para cada alimentador pode ser conferido nas Tabelas 5.4 a 5.7 a seguir: 
Tabela 5.4 - Cruzamento de informações oscilográficas - JCE1312.

\begin{tabular}{|lc|}
\hline \multicolumn{1}{|c|}{ Parâmetro } & Valor \\
\hline Registros de desligamentos processados & 557 \\
\hline Registros de proteção (DJ e RL) processados & 15833 \\
\hline Registros de ações processados & 637 \\
\hline Registros de comentários processados & 557 \\
\hline Número de oscilografias processadas & 94 \\
\hline Número de oscilografias úteis para modelagem & 80 \\
\hline Número de casos distintos encontrados & 27 \\
\hline Número de casos envolvendo DJ & 2 \\
\hline Número de casos envolvendo RL & 25 \\
\hline Número de casos com referência direta de distância & 4 \\
\hline Número de casos não relatados em base de dados & 2 \\
\hline Percentual de faltas trifásicas (\%) & 25.92 \\
\hline Percentual de faltas monofásicas (\%) & 29.63 \\
\hline Percentual de faltas fase-fase (\%) & 7.40 \\
\hline Percentual de faltas de outro tipo ou não identificadas (\%) & 37.05 \\
\hline $\begin{array}{l}\text { Percentual de ocorrência com maior incidência } \\
\text { Causa 180 - Galho de Arvores (\%) }\end{array}$ & 37.03 \\
\hline $\begin{array}{l}\text { Percentual de ocorrência (\%) } \\
\text { Causas 011 (Descarga Atmosférica) + 020 (Vento Forte) }\end{array}$ & 22.22 \\
\hline $\begin{array}{l}\text { Percentual de ocorrência com menor incidência (\%) } \\
\text { Causa 890 - Causas não determinadas }\end{array}$ & $\mathbf{7 . 4 0}$ \\
\hline $\begin{array}{l}\text { Percentual de categoria com maior incidência (\%) } \\
\text { Categoria Clima chuvoso }\end{array}$ & 29.62 \\
\hline $\begin{array}{l}\text { Percentual de ocorrência (\%) } \\
\text { Categoria Cabo rompido }\end{array}$ & $\mathbf{1 1 . 1 1}$ \\
\hline $\begin{array}{l}\text { Percentual de categoria com menor incidência (\%) } \\
\text { Categoria Ventania / Religador colocado em operação }\end{array}$ & 3.70 \\
\hline
\end{tabular}


Tabela 5.5 - Cruzamento de informações oscilográficas - INP1306.

\begin{tabular}{|lc|}
\hline \multicolumn{1}{|c|}{ Parâmetro } & Valor \\
\hline Registros de desligamentos processados & 426 \\
\hline Registros de proteção (DJ e RL) processados & 175 \\
\hline Registros de ações processados & 2025 \\
\hline Registros de comentários processados & 426 \\
\hline Número de oscilografias processadas & 273 \\
\hline Número de oscilografias úteis para modelagem & 15 \\
\hline Número de casos distintos encontrados & 5 \\
\hline Número de casos envolvendo DJ & - \\
\hline Número de casos envolvendo RL & - \\
\hline Número de casos com referência direta de distância & 1 \\
\hline Número de casos não relatados em base de dados & - \\
\hline Percentual de faltas trifásicas (\%) & 20.0 \\
\hline Percentual de faltas monofásicas (\%) & 0.0 \\
\hline Percentual de faltas fase-fase (\%) & 20.0 \\
\hline Percentual de faltas de outro tipo ou não identificadas (\%) & 60.0 \\
\hline $\begin{array}{l}\text { Percentual de ocorrência com maior incidência } \\
\text { Causa 180 - Galho de Arvores (\%) }\end{array}$ & 80.0 \\
\hline $\begin{array}{l}\text { Percentual de ocorrência (\%) } \\
\text { Causas 011 (Descarga Atmosférica) + 020 (Vento Forte) }\end{array}$ & 0.0 \\
\hline $\begin{array}{l}\text { Percentual de ocorrência com menor incidência (\%) } \\
\text { Causa 814 - Verificações }\end{array}$ & 20.0 \\
\hline $\begin{array}{l}\text { Percentual de categoria com maior incidência (\%) } \\
\text { Categoria Clima bom }\end{array}$ & 60.0 \\
\hline $\begin{array}{l}\text { Percentual de ocorrência (\%) } \\
\text { Categoria Cabo rompido }\end{array}$ & 20.0 \\
\hline $\begin{array}{l}\text { Percentual de categoria com menor incidência (\%) } \\
\text { Categoria Objeto estranho }\end{array}$ & 20.0 \\
\hline
\end{tabular}

Tabela 5.6 - Cruzamento de informações oscilográficas - BIR1305.

\begin{tabular}{|lc|}
\hline \multicolumn{1}{|c|}{ Parâmetro } & Valor \\
\hline Registros de desligamentos processados & 302 \\
\hline Registros de proteção (DJ e RL) processados & 11359 \\
\hline Registros de ações processados & 681 \\
\hline Registros de comentários processados & 302 \\
\hline Número de oscilografias processadas & 310 \\
\hline Número de oscilografias úteis para modelagem & 51 \\
\hline Número de casos distintos encontrados & 34 \\
\hline Número de casos envolvendo DJ & 4 \\
\hline Número de casos envolvendo RL & 30 \\
\hline Número de casos com referência direta de distância & 8 \\
\hline Número de casos não relatados em base de dados & 12 \\
\hline Percentual de faltas trifásicas (\%) & 17.64 \\
\hline Percentual de faltas monofásicas (\%) & 17.64 \\
\hline Percentual de faltas fase-fase (\%) & 23.52 \\
\hline Percentual de faltas de outro tipo ou não identificadas (\%) & 41.20 \\
\hline $\begin{array}{l}\text { Percentual de ocorrência com maior incidência } \\
\text { Causa 180 - Galho de Arvores (\%) }\end{array}$ & 17.64 \\
\hline $\begin{array}{l}\text { Percentual de ocorrência (\%) } \\
\text { Causas 011 (Descarga Atmosférica) + 020 (Vento Forte) }\end{array}$ & 2.94 \\
\hline $\begin{array}{l}\text { Percentual de ocorrência com menor incidência (\%) } \\
\text { Causa 890 - Causas não determinadas }\end{array}$ & 2.94 \\
\hline $\begin{array}{l}\text { Percentual de categoria com maior incidência (\%) } \\
\text { Categoria Clima bom }\end{array}$ & 32.35 \\
\hline $\begin{array}{l}\text { Percentual de ocorrência (\%) } \\
\text { Categoria Cabo rompido }\end{array}$ & 5.88 \\
\hline $\begin{array}{l}\text { Percentual de categoria com menor incidência (\%) } \\
\text { Categoria Poste podre }\end{array}$ & 2.94 \\
\hline
\end{tabular}


Tabela 5.7 - Cruzamento de informações oscilográficas - MCl1305.

\begin{tabular}{|lc|}
\hline \multicolumn{1}{|c|}{ Parâmetro } & Valor \\
\hline Registros de desligamentos processados & 363 \\
\hline Registros de proteção (DJ e RL) processados & 15833 \\
\hline Registros de ações processados & 351 \\
\hline Registros de comentários processados & 364 \\
\hline Número de oscilografias processadas & 1384 \\
\hline Número de oscilografias úteis para modelagem & 244 \\
\hline Número de casos distintos encontrados & 41 \\
\hline Número de casos envolvendo DJ & 11 \\
\hline Número de casos envolvendo RL & 30 \\
\hline Número de casos com referência direta de distância & 5 \\
\hline Número de casos não relatados em base de dados & 11 \\
\hline Percentual de faltas trifásicas (\%) & 26.82 \\
\hline Percentual de faltas monofásicas (\%) & 7.31 \\
\hline Percentual de faltas fase-fase (\%) & 14.63 \\
\hline Percentual de faltas de outro tipo ou não identificadas (\%) & 51.24 \\
\hline $\begin{array}{l}\text { Percentual de ocorrência com maior incidência } \\
\text { Causa 180 - Galho de Arvores (\%) }\end{array}$ & 29.26 \\
\hline $\begin{array}{l}\text { Percentual de ocorrência (\%) } \\
\text { Causas 011 (Descarga Atmosférica) + 020 (Vento Forte) }\end{array}$ & 9.75 \\
\hline $\begin{array}{l}\text { Percentual de ocorrência com menor incidência (\%) } \\
\text { Causa 321 - Abalroamento }\end{array}$ & 2.43 \\
\hline $\begin{array}{l}\text { Percentual de categoria com maior incidência (\%) } \\
\text { Categoria Clima bom }\end{array}$ & 24.39 \\
\hline $\begin{array}{l}\text { Percentual de ocorrência (\%) } \\
\text { Categoria Cabo rompido }\end{array}$ & 17.07 \\
\hline $\begin{array}{l}\text { Percentual de categoria com menor incidência (\%) } \\
\text { Categoria Isolador quebrado }\end{array}$ & 2.43 \\
\hline
\end{tabular}

Foi possível constatar das tabelas apresentadas que a maior causa relatada em base de dados como responsável pelos desligamentos está associada com o contato de vegetação com a rede, sob ambiente de clima bom, sem presença de descargas atmosféricas ou ventos.

Cabe-se salientar também a grande diferença entre os alimentadores pilotos selecionados, principalmente à classificação de faltas, pois MCI1305 apresenta mais faltas trifásicas, já BIR1305 apresenta mais faltas fase-fase, ao passo que o JCE1312 apresenta mais faltas monofásicas. Finalmente, INP1306 apresenta um equilíbrio entre faltas trifásicas e fase-fase. 


\section{Considerações Finais e Continuidade do Trabalho}

\subsection{Conclusões gerais}

Atualmente tem sido verificada junto ao setor elétrico brasileiro uma constante busca pela melhoria da qualidade dos serviços prestados. Para se atingir os índices de qualidade esperados, a detecção, classificação e localização de faltas em sistemas de energia elétrica constituíram-se em metas almejadas por diversos setores do sistema elétrico de potência.

A pesquisa bibliográfica realizada em bases técnico-científicas em busca de trabalhos que contemplem metodologias de detecção, classificação e localização de faltas em sistemas de distribuição mostra o empenho de pesquisadores de vários países, com proposições de trabalhos que fazem uso das mais distintas ferramentas, nas mais variadas conjunções.

O problema se mostra complexo e apresenta inúmeros desafios, principalmente quanto à generalidade da ferramenta a ser desenvolvida, frente às mais variadas situações de carga e faltas inerentes aos sistemas de distribuição.

As ferramentas inteligentes se destacam devido ao seu comprovado potencial de aplicação, complementando limitações de técnicas convencionais. 
Fica evidente na pesquisa correlata que apenas a utilização de uma ferramenta inteligente não é capaz de suprir as necessidades de fenômenos faltosos nos sistemas de distribuição de energia elétrica. Observa-se que abordagens empregando conjuntamente técnicas inteligentes e técnicas convencionais para tratamento de faltas têm obtido resultados expressivos aos processos envolvidos com a detecção de faltas.

A metodologia abordada neste trabalho utiliza ferramentas inteligentes e numéricas, integradas e sintonizadas entre si por um sistema automatizado, visando reunir as potencialidades individuais de cada uma delas num único sistema.

A arquitetura utilizada foi elaborada de maneira modular a fim de conferir um maior índice de redundância aos processos de identificação, classificação e localização de faltas, permitindo agregar novas tarefas em qualquer etapa do processo. Assim, a tecnologia proposta, com encadeamento das tarefas de identificação, classificação e localização da falta, confere uma maior robustez ao sistema como um todo e visa uma eficiência superior às demais técnicas.

Além de uma arquitetura modular e robusta sob o ponto de vista da ocorrência de falhas, o sistema inteligente para identificação de faltas foi implementado fazendo-se uso de ferramentas comprovadamente eficientes, dedicadas à realização do pré-processamento dos sinais de tensão e de corrente amostrados na subestação. Essas ferramentas operam somente sobre os referidos sinais de maneira a lhes extrair características que particularizem e diferenciem condições de faltas das demais condições normais de operação.

Assim, a eficiência dessas ferramentas de pré-processamento conferem ao sistema uma robustez e precisão tanto no que se refere à identificação de faltas, bem como para a determinação da fase participante da mesma e contribuindo com 
informações para implementação de novas metodologias para a localização e setorização de faltas.

O processo de setorização de faltas, em virtude do número e da não linearidade das variáveis envolvidas, mostra ser complexo. A dinâmica não linear de um sistema elétrico, as simples e constantes variações de carga, de temperatura, de terreno e de tipo de falta, são capazes de influenciar na eficiência da abordagem desenvolvida. Uma forma de contornar tais limitações é incorporar ao sistema redundâncias de informações.

A principal contribuição desse trabalho foi focada na elaboração de uma nova metodologia destinada aos propósitos de localização e setorização de faltas em sistemas de distribuição.

A nova técnica para localização e setorização, baseada na análise espectral dos sinais e informações reais da rede, permite obter várias estimativas de local de falta por meio de múltiplas frequências, utilizando informações estatísticas como métricas para se quantificar a probabilidade da falta ter acontecido em um determinado local.

Uma vez desenvolvida essa nova técnica e integrada às técnicas inteligentes que já têm sido desenvolvidas, o sistema foi testado e validado em laboratório e em campo, contemplando quatro circuitos de distribuição.

Os resultados apresentados no Capitulo 5 mostram que o sistema desenvolvido tem a capacidade de identificar mais defeitos do que os observados pelos atuais sistemas de proteção instalados na concessionária, propondo sua provável localização.

Esta arquitetura modular e integrada para identificação, classificação, localização e setorização de faltas poderá auxiliar os operadores do sistema de 
distribuição a tomarem decisões acertadas, contribuindo-se assim para a elevação dos índices de qualidade e, consequentemente, para o aumento do nível de satisfação de seus clientes.

\subsection{Continuidades do trabalho}

Como continuidade desse trabalho, seria interessante avaliar com maior profundidade os benefícios da indicação do provável lugar da falta nos indicadores da empresa, qual o reflexo dessa nova ferramenta nas atividades do COD e quais são seus impactos nos indicadores de qualidade.

Como foi verificada uma grande diferença entre os alimentadores piloto selecionados, outra proposta de continuidade seria estudar a confiabilidade dos resultados alcançados nesse trabalho com maior abrangência, em um estudo semelhante a um lote pioneiro, permitindo avaliar com maior profundidade seus benefícios para a qualidade do serviço em toda a cadeia.

Pelo aspecto modular do sistema desenvolvido, trabalhos futuros podem surgir para aprimorar a ferramenta, utilizando o conhecimento obtido em estudos anteriores e pela inserção de novas técnicas que possam surgir com o propósito de identificação e localização de faltas, e comunicação da mesma ao COD, o que também pode vir da implementação do sistema como um todo em relés de proteção, supervisão ou controle ou até em religadores que têm sido aplicados com maior frequência nas novas subestações em substituição aos tradicionais disjuntores e relés. 


\section{Referências Bibliográficas}

AKAIKE, H., "Fitting autoregressive models for prediction". Annals Inst. Statist. Math., vol. 21, pp. 243-247, 1969.

ANEEL, PRODIST Módulo 8 (Estabelece os procedimentos relativos à qualidade da energia elétrica - QEE, abordando a qualidade do produto e a qualidade do serviço prestado), 62 p., http://www.aneel.gov.br, 2009.

BORGHETTI, A.; BOSETTI, M.; NUCCI, C.A.; PAOLONE, M., ABUR, A., "Integrated use of time-frequency wavelet decompositions for fault location in distribution networks: theory and experimental validation". IEEE Transactions on Power Delivery, vol. PP, n. 99, pp. 1-8, 2010.

BRETAS, A.S.; MORETO, M.; SALIM, R.H., PIRES, L.O., "A novel high impedance fault location for distribution systems considering distributed generation". IEEE/PES Transmission \& Distribution Conference and Exposition: Latin America, pp. 1-6, 2006.

BUTLER, K. L., MOMOH, J. A., "Robust features selection scheme for fault diagnosis in as electric power distribution system". CCECE/CCGEl'93, pp. 209-213, 1993.

BUTLER, K.L., MOMOH, J.A., "A neural net based approach for fault diagnosis in distribution networks". IEEE Power Eng. Society, vol. 2, pp. 1275-1278, 2000. 
BUTLER, K.L., MOMOH, J.A., SOBAJIC, D.J., "Field studies using a neural-netbased approach for fault diagnosis in distribution networks". IEE Proceedings Generation, Transmission and Distribution, vol. 144, no. 5, pp. 429-436, 1997.

CHAN, D.; WAI, T. and YIBIN, X., "A novel technique for high impedance fault identification". IEEE Transactions on Power Delivery, vol. 13, no. 3, pp. 738$744,1998$.

CHEN, W.H.; LIU, C.W., TSAI, M.S., "On-line fault diagnosis of distribution substations using hybrid cause-effect network and fuzzy rule-based method". IEEE Transactions on Power Delivery, vol. 15, no. 2, pp. 710-717, 2000.

$\mathrm{CHO}, \mathrm{N}$., HÁ, B., "The results of the field test in distribution automation system for the Korea Utility". Proceedings of Power System Technology - POWERCON '98, vol.1, pp. 48-52, 1998.

CHOI, M.S., LEE, S.J., LEE, D.S., "A new fault location algorithm using direct circuit analysis for distribution systems", IEEE Transactions on Power Delivery, vol. 19, no. 1, pp. 35-41, 2004.

CHOI, T.; KOH, I.S; KIM, B.H.; SONG, W.S., JANG, W.S., "PC-based remote control and fault location system for distribution line". IEEE Power Engineering Society Winter Meeting, vol. 2, pp. 1085-1090, 1999.

CHUNJU, F., HUARONG, C., WEIYONG, Y., "Application of six-sequence fault components in fault location for joint parallel transmission line". Tsinghu Science and Technology, vol. 10, no. 2, pp. 247-253, 2005.

CONG, D.P.; RAISON, B.; ROGNON, J.P.; BONNOIT, S., MANJAL, B., "Optimization of fault indicators placement with dispersed generation insertion". IEEE Power Engineering Society General Meeting, pp. 1530-1537, 2005. 
DAS, B., "Fuzzy Logic-Based Fault-Type Identification in Unbalanced Radial Power Distribution System" ", IEEE Transactions on Power Delivery, vol. 21, no. 1, pp. 278-285, 2006.

DEPEW, A.C., PARSICK, J.M., DEMPSEY, R.W., BENNER, C.L., RUSSELL, B.D., ADAMIAK, M.G., "Field experience with high-impedance fault detection relays". 59th Annual Conference for Protective Relay Engineers, vol. 1, pp. 1-6, 2006.

DUGAN, R.C., MCGRANAGHAN, M.F., SANTOSO, S., BEATY H. W., "Electrical Power Systems Quality". Second Edition, New York: McGraw Hill, 2003. 528 p. EBRON, S., LUBKEMAN, D.L., WHITE, M., "A neural network approach to the detection of incipient faults on power distribution feeders". IEEE Transactions on Power Delivery, vol. 5, no. 2, pp. 905914, 1990.

FARIA, J.A.B., "Application of Clarke's Transformation to the modal analysis of asymmetrical single-circuit three-fase line configuration". ETEP European Transaction on Electrical Power, vol. 10, pp. 225-231, 2000.

FLAUZINO, R.A., Identificação e Localização de Faltas de Alta Impedância em Sistemas de Distribuição Baseadas em Decomposição por Componentes Ortogonais e Inferência Fuzzy, Tese de Doutorado, Universidade de São (USP), Escola de Engenharia de São Carlos, 2007.

FLAUZINO, R.A., Silva, I.N., "Uma abordagem baseada na técnica de decomposição em componentes ortogonais e sistemas de inferência fuzzy para localização de faltas de alta-impedância em sistemas de distribuição de energia elétrica", Anais do VIII Simpósio Brasileiro de Automação Inteligente, pp. 1-6, 2007.

GAOUDA, A.M.; KANOUN, S.H.; SALAMA, M.M.A., CHIKHANI, A.Y., "Waveletbased signal processing for disturbance classification and measurement". IEE 
Proceedings on Generation, Transmission and Distribution, vol. 149, no. 3, pp. 310-318, 2002.

GIRIGIS, A. A., FALLON, C. M., LUBKEMAN, D. L., "A fault location technique for rural distribution feeders", IEEE Transactions on Industry Application, vol. 29, no. 6, pp. 1170-1175, 1993.

IEEE C37.111. "IEEE Standard common format for transient data exchange (COMTRADE) for power systems." The Institute of Electrical and Electronics Engineers (IEEE), 1999.

JARVENTAUStA, P., VERHO, P., PARTANEN, J., "Using fuzzy sets to model the uncertainty in the fault location process of distribution networks". IEEE Transactions on Power Delivery, vol. 9, no. 2, pp. 954-960, 1994.

JOTA, F.G., JOTA, P.R.S., "High-impedance fault identification using a Fuzzy reasoning system". IEE Proceedings - Generation, Transmission and Distribution, vol. 145, no. 6, pp. 656-661, 1998.

KARIMI, M.; MOKHTARI, H., IRAVANI, M.R., "Wavelet based on-line disturbance detection for power quality applications". IEEE Transactions on Power Delivery, vol. 15, no. 4, pp. 1212-1220, 2000.

KO, J.H., "Detection of high impedance faults using neural nets and chaotic degree". Proc. of Energy Management and Power Delivery, vol. 2, pp. 399-404, 1998.

KO, J.H., SHIM, J.C., WAN RYU, C., PARK, G. and YIM, W.Y., "Detection of high impedance faults using neural nets and chaotic degree". Proceedings of Energy Management and Power Delivery, vol. 2, pp. 399-404, 1998.

LEE, S-J., CHOI, M-S., KANG, S-H., JIN, B-G., LEE, D-S., AHN, B-S., YOON, N-S., KIM, H-Y., WEE, S-B., "An intelligent and efficient fault location and diagnosis 
scheme for radial distribution systems". ", IEEE Transactions on Power Delivery, vol. 19, no. 2, pp. 524-532, 2004.

LEHTONEN, M.; MATSINEN, A.; ANTILA.; KURU, J., "An advanced model for automatic fault management in distribution networks". IEEE Power Engineering Society Winter Meeting, vol. 3, pp. 1900-1904, 2000.

LIU, W.H.E., ZHONG, W., "A Fuzzy set method for fault location identification in power distribution systems". Proc. of 35th IEEE Conf. on Decision and Control, vol. 2, pp. 2208-2212, 1996.

LUO, S., KEZUNOVIC, M.,. SEVICK, D.R, "Locating faults in the transmission network using field measurements, simulation data and genetic algorithm". Electric Power Systems Research, vol. 71, pp. 169-177, 2004.

MAGNAGO, F.H., ABUR, A., "A new fault location technique for radial distribution systems based on high frequency signals". IEEE Power Engineering Society Summer Meeting, vol. 1, pp. 426-431, 1999.

MAHANTY, R.N., GUPTA, P.B.D., "Application of RBF neural network to fault classification and location in transmission lines". IEE Proc. on Generation, Transmission and Distribution, vol. 151, no. 2, pp. 201-212, 2004.

MAHMOOD, W.N, MUKERJEE, R.N., RAMACHANDARAMURTHY, V.K, "Fault point identification in a power network using single-point measurement". IEEE TENCON Conference, pp. 381-384, 2004.

MARTINS, L.S., MARTINS, J.F., PIRES, F.V., ALEGRIA, C.M., "A neural space vector fault location for parallel doublé-circuit distribution lines". Electrical Power \& Energy Systems, vol. 27, 225-231, 2005.

MARTINS, L.S.; MARTINS, J.F.; PIRES, V.F., ALEGRIA, C.M., "The application of neural networks and Clarke-Concordia transformation in fault location on 
distribution power systems". IEEE Transactions on Power Delivery, vol. 4, no. 2, pp. 2091-2095, 2002.

MARUSIC, A., GRUHONJIC-FERHATBEGOVIC, S., "A computerized fault location process for overhead radial distribution feeders". 2006 IEEE Mediterranean Electrotechnical Conference - MELECON 2006, pp. 1114-1117, 2006.

MIRZAI, M.A., AFZALIAN, A.A., "A novel fault-locator system; algorithm, principle and practical implementation". IEEE Transactions on Power Delivery, vol. 25, n. 1, pp. 35-46, 2010.

MORA, J.J.; CARRILLO, G., PEREZ, L., "Fault location in power distribution systems using ANFIS nets and current patterns". IEEE/PES Transmission \& Distribution Conference and Exposition: Latin America, pp. 1-6, 2006.

MORA-FLOREZ, J.; ESTRADA-CARDONA, N., MORALES-ESPANA, G., "Single phase fault location in power distribution systems using statistical analysis". IEEE/PES Transmission and Distribution Conference and Exposition: Latin America, pp. 1-5, 2008.

MOSHTAGH, J., AGGARWAL, R.K., "A new approach to fault location in a single core underground cable system using combined Fuzzy logic and wavelet analysis". Eighth IEE International Conference on Developments in Power System Protection, vol. 1 pp. 228-231, 2004.

ROBERTS, J. GUZMAN, A. SCHWEITZER, E.O., "Z=V/I does not make a distance relay". 20th annual western protective relay conference, 1993.

TAKAGI, T., YAMAKOSHI, Y., BABA, J., UEMURA, K., SAKAGUSHI, T., "A new algorithm of an accurate fault location for EHV/UHV transmission lines: part I fourier transformation method". IEEE Transactions on Power Apparatus and Systems, Vol. PAS-100, No. 3, 1316-1323, 1981. 
TAKAGI, T., YAMAKOSHI, Y., YAMAMURA, M., KONDOW, R., MATSUSHIMA, T., "Development of a new type fault locator using the one-terminal voltage and current data". IEEE Transactions on Power Apparatus and Systems, Vol. PAS101, No. 8, pp. 2892-2898, 1982.

TANG, Y., WANG, H.F., AGGARWAL, R.K., JOHNS, A.T, "Fault indicators in transmission and distribution systems", Proceedings of Electric Utility Deregulation and Restructuring and Power Technologies, pp. 238-243, 2000.

TANNLUND, P., BJORKMAN, G., "An advanced distribution automation system experience from application development and project implementation". Proceedings of Power System Technology - PowerCon 2000, vol.1, pp. 127132, 2000.

TOMSOVIC, K., BAKKEN, D.E., VENKATASUBRAMANIAN, V., BOSE, A., "Designing the next generation of real-time control, communication, and computations for large power systems", Proc. IEEE, vol. 93, no. 5, pp. 965-979, 2005.

ULRYCH, T., BISHOP, T., "Maximum entropy spectral analysis and autoregressive". Rev. Geophysics and Space Physic, vol. 13, pp. 183-200, 1975.

YAOZHONG, G., "New types of protective relaying and fault location - Theory and technique", Xi'an Jiao Tong University Press, 1996.

YOUSSEF, O.A.S., "Applications of fuzzy-logic-wavelet-based techniques for transformers inrush currents identification and power system faults classification". IEEE PES Power Systems Conf. and Exposition, pp. 553-559, 2004. 
YOUSSEF, O.A.S., "Combined fuzzy-logic wavelet-based fault classification technique for power system relaying". IEEE Transactions on Power Delivery, vol. 19, no. 2, pp. 582-589, 2004.

ZABORZSKY, J., WHANG, K., PRASAD, K., "Fast contingency evaluation using concentric relaxation", IEEE Transactions on Power Apparatus and Systems, vol. PAS-99, no. 1, pp. 28-36, 1980.

ZAHRA, F., JEYASURYA, B., QUAICOE, J.E., "High-speed transmission line relaying using artificial neural networks". Electric Power Systems Research, no. 53, pp. 173-179, 2000.

ZHU ET AL. "Automated fault location and diagnosis on electric power distribution feeders". IEEE Transactions on Power Delivery, vol. 12, no. 2, pp. 801-809, 1997. 


\section{Apêndices}

\section{Apêndice A - Código da função para Identificação dos}

\section{segmentos de falta}

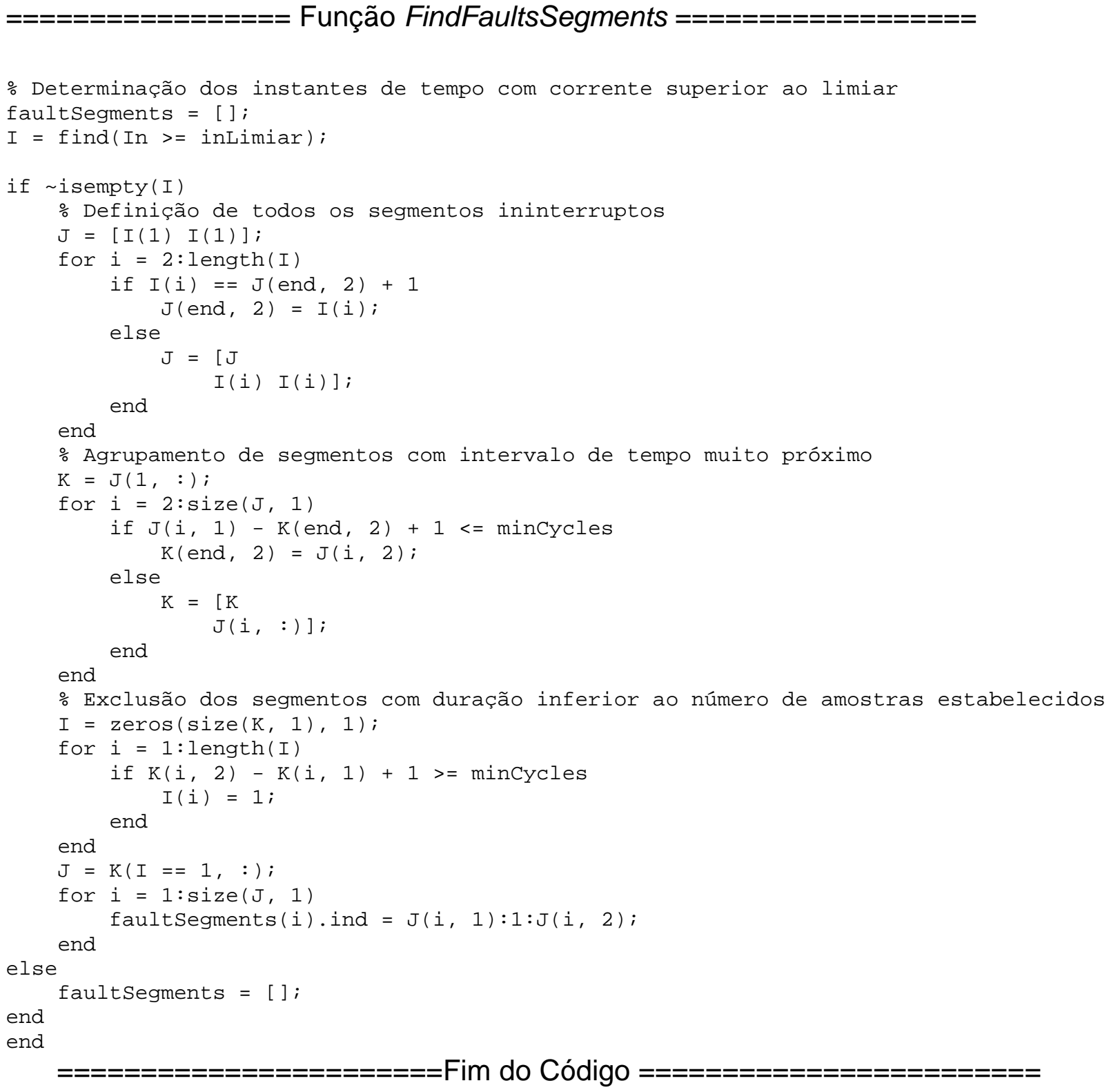




\section{Apêndice B - Código da função para determinação da fase participante da falta}

$===============+$ Função FindFaultedPhase $=================$

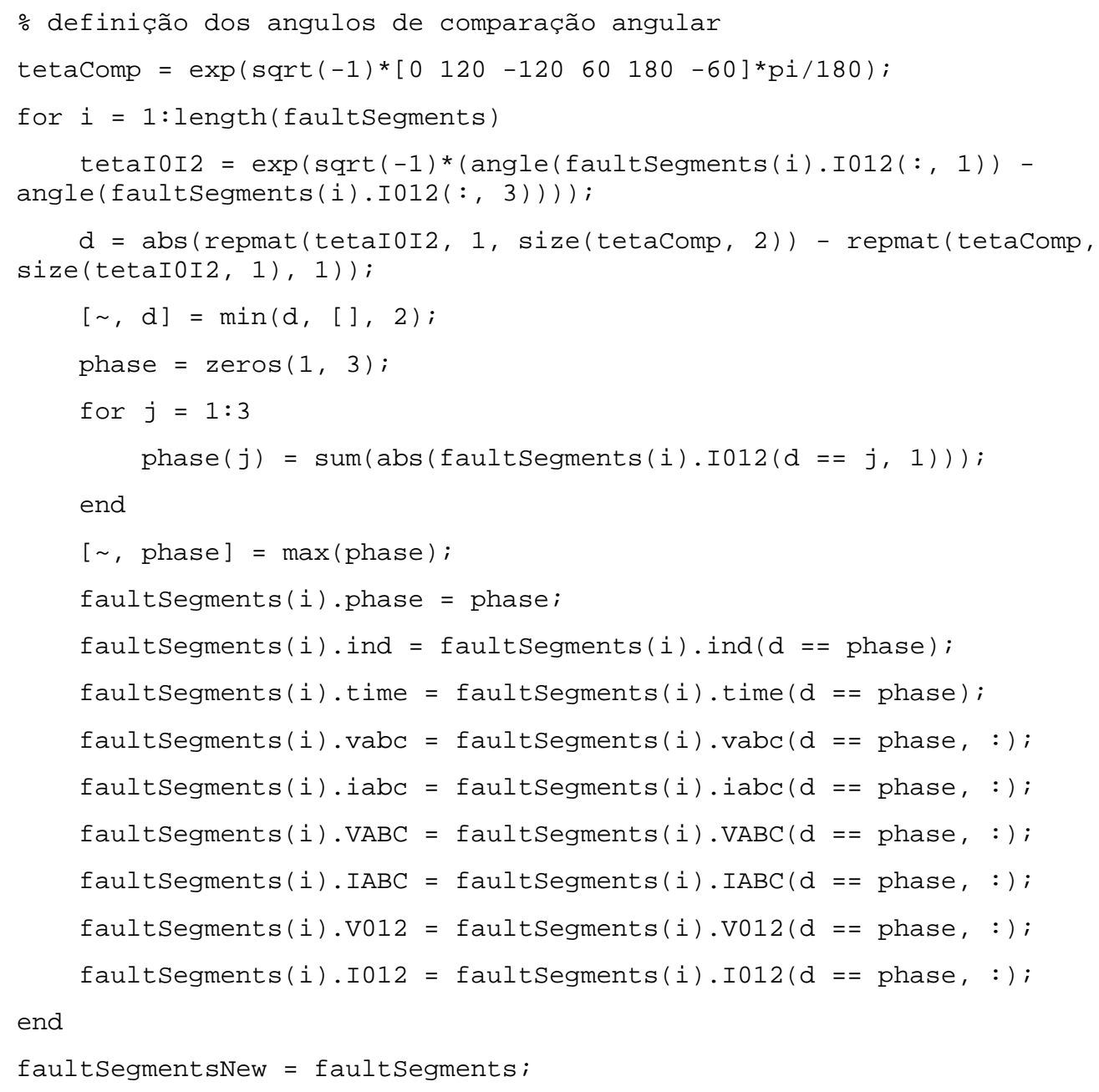




\section{Apêndice C - Código da função para análise de reatância e resistência de falta para cada segmento}

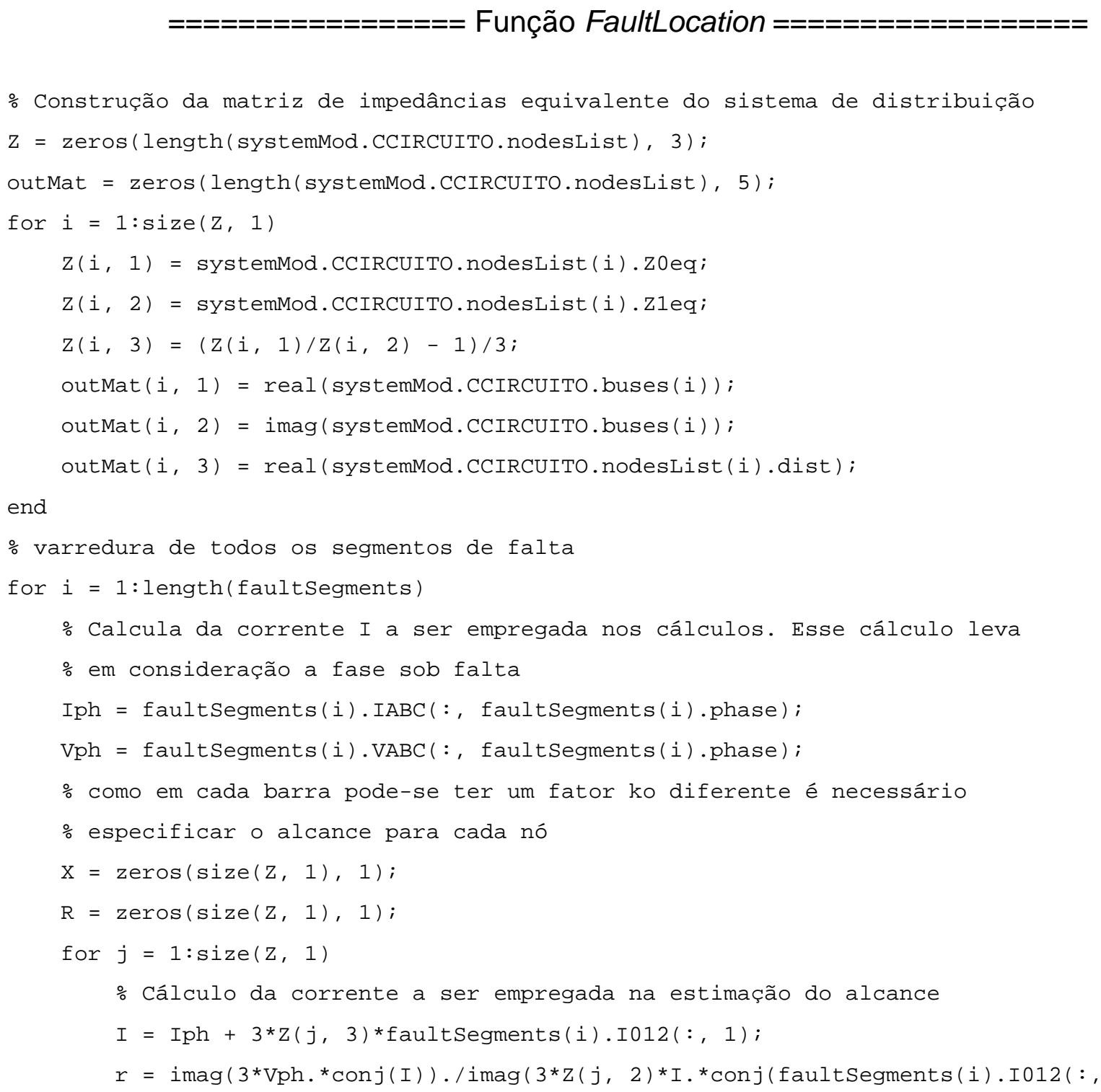




\section{Apêndice D - Código de conversão dos arquivos “.DAQ” para COMTRADE}

A seguir encontra-se registrado o código que realiza a conversão dos arquivos “.DAQ”, provenientes da placa de aquisição de dados, para COMTRADE.

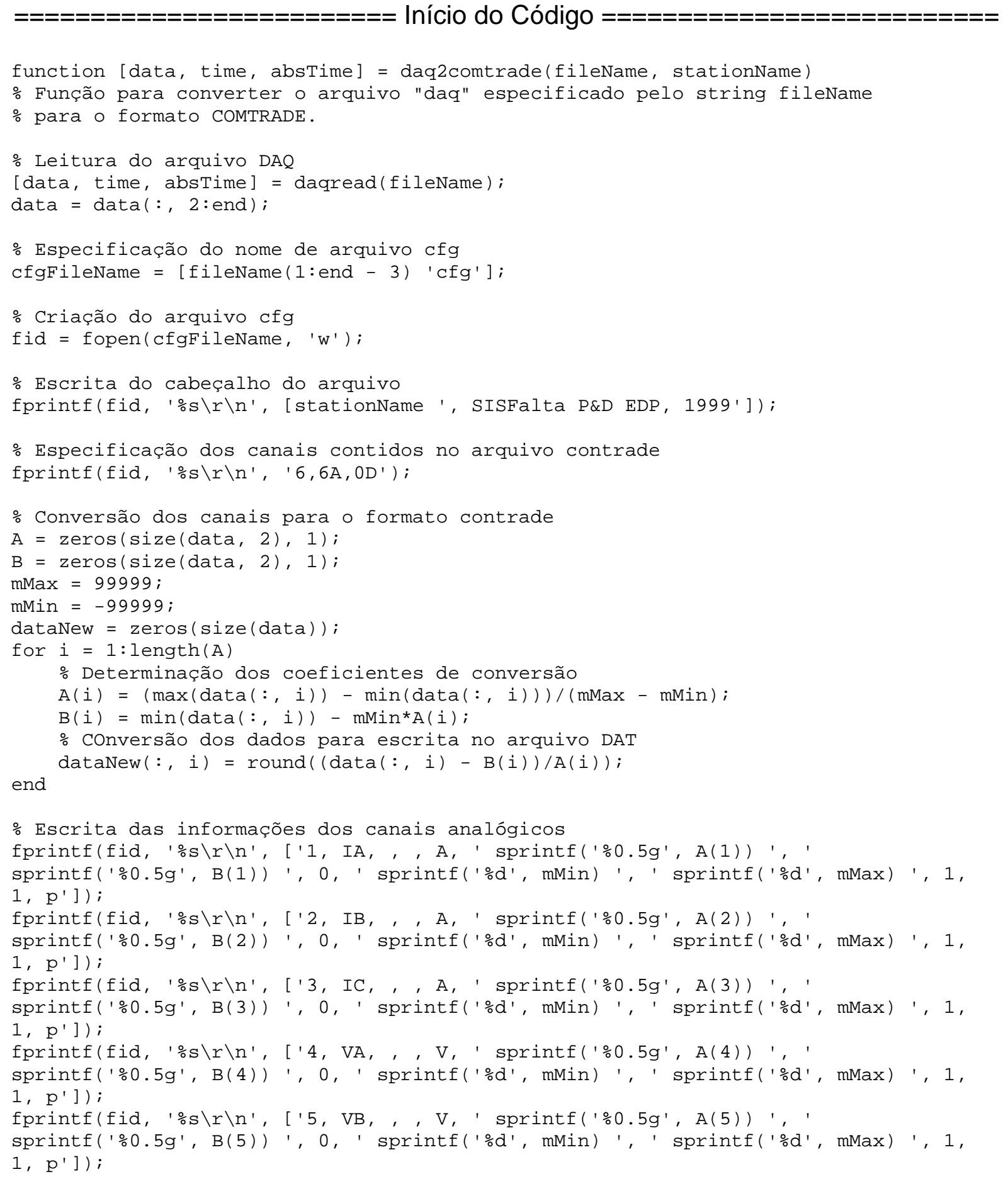




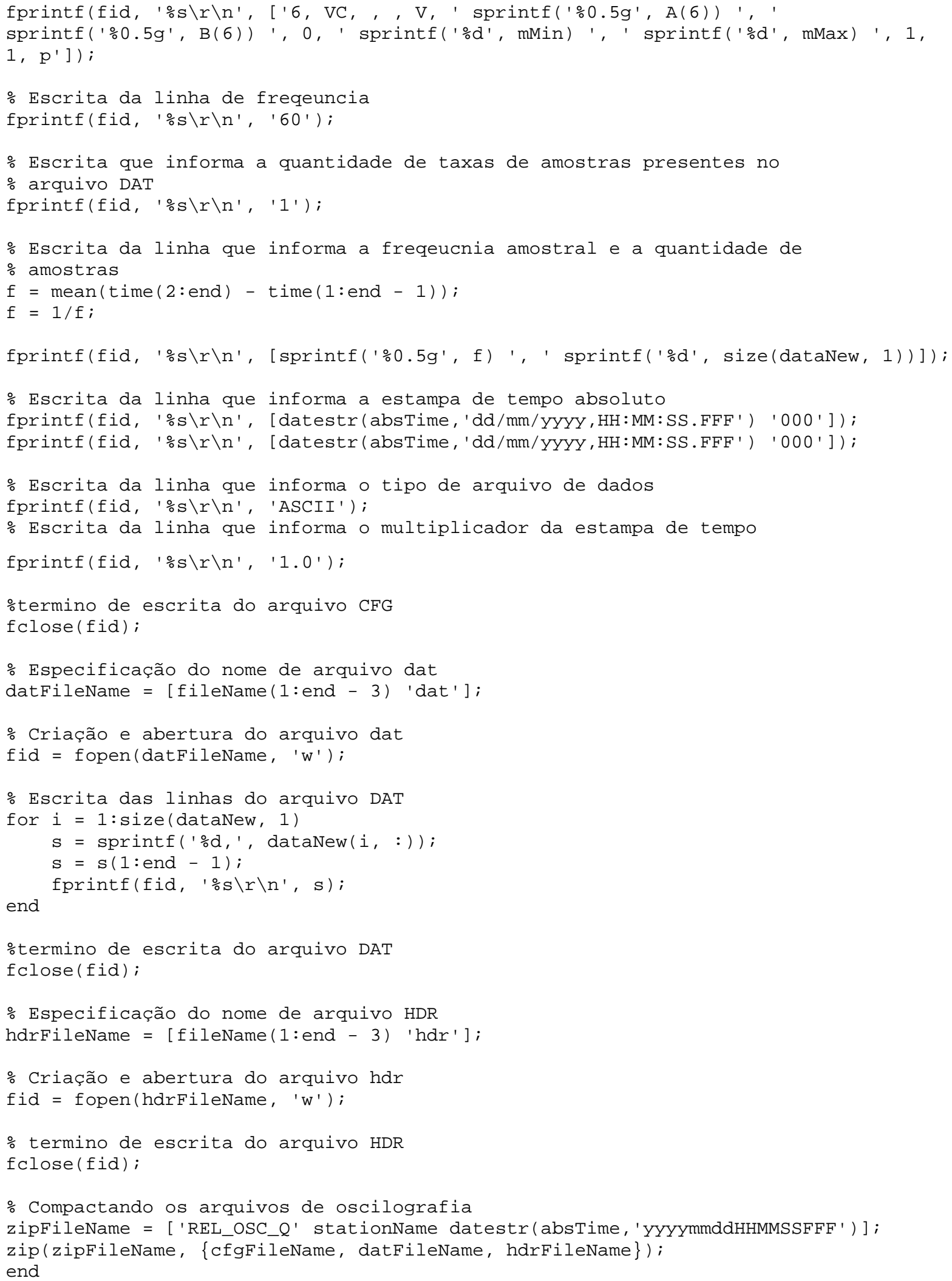




\section{Apêndice E - Sistema de Oscilografia}

Para atender os requisitos do projeto piloto foi desenvolvido um sistema de aquisição de dados de baixo custo, conforme ilustrado na figura a seguir:

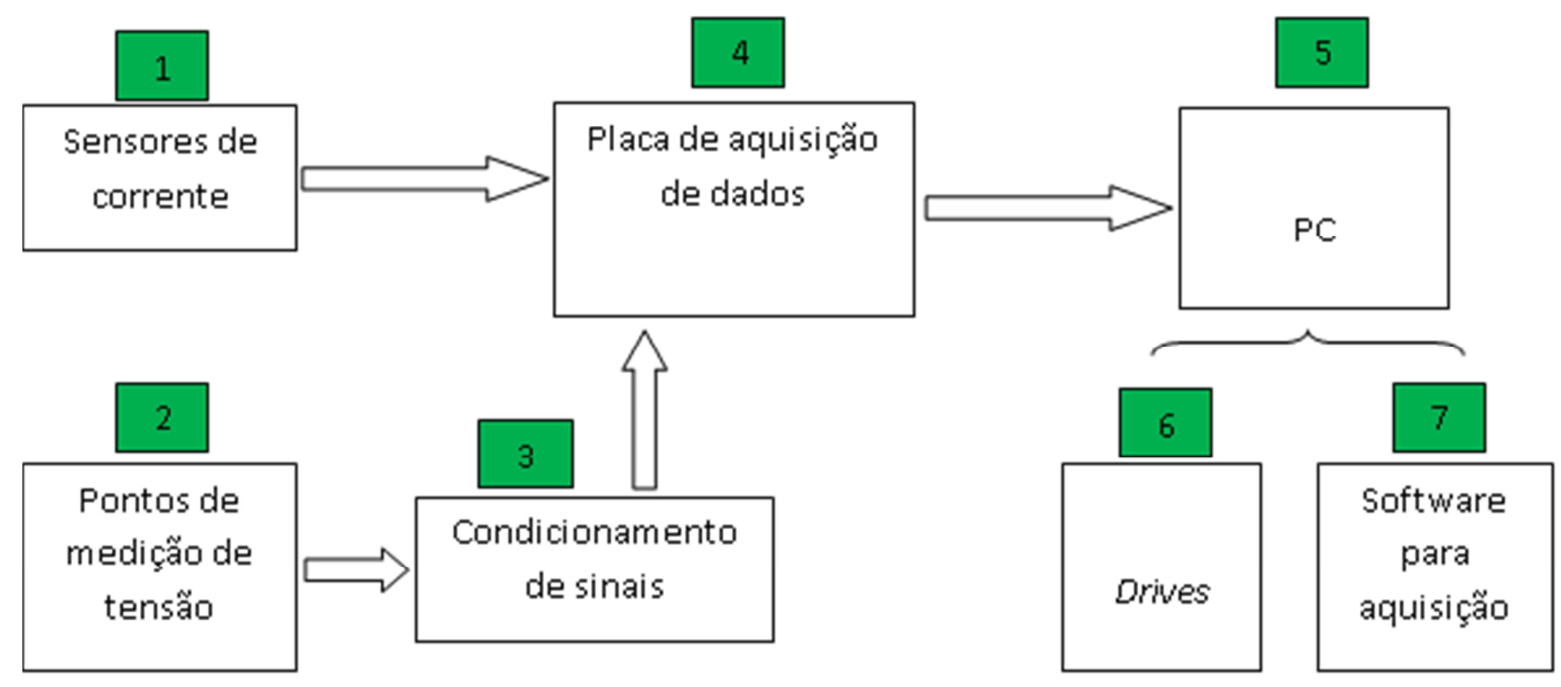

Figura: Sistema de aquisição de dados

1. Clamps de corrente $10 \mathrm{~A}$ (medição de corrente)

- Garras de corrente: EB10/100 Embrasul

- Sensibilidade: $100 \mathrm{mV} / \mathrm{A}$

- Secundário de TC - $5 \mathrm{~A}$

2. Pontos de medição de tensão

- Secundário de TP $115 \mathrm{~V}$

- Proteção: fusíveis

3. Condicionamento de sinais:

- $115 \mathrm{~V} \rightarrow \sim 5 \mathrm{~V}$

4. Placa de aquisição de dados:

- National Instruments modelo USB 6211 (16 bits, 256 kS/s)

- Trigger: Software (Imediato) - Falta FT

- Entrada 0 : corrente de neutro 
- Entrada 1, 2, 3: correntes de fase

- Entrada 4, 5, 6: tensões fase-neutro

5. PC:

- Software para registro dos eventos

- Software identificação de falta

- Software para localização da falta

6. Drivers

7. Software para controle da aquisição: Matlab

- Interface de controle: linha de comando

- Formato dos arquivos: .daq

- Visualização dos eventos: gráfica 